\title{
From Callas To Netrebko: diva power, vocality, and the mediatisation of the operatic voice
}

\author{
Jenny Wollerman
}

\begin{abstract}
A thesis
submitted to Victoria University of Wellington in fulfilment of the requirements for the degree of

Doctor of Philosophy
\end{abstract}

Victoria University of Wellington

2019 


\section{CONTENTS}

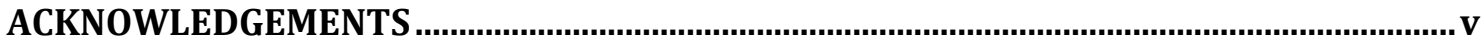

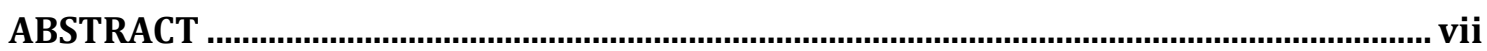

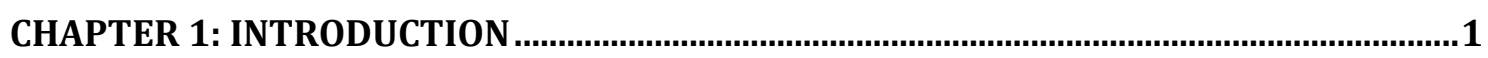

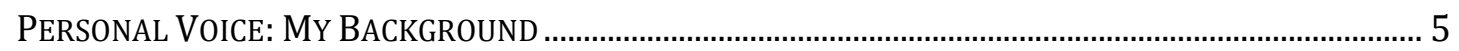

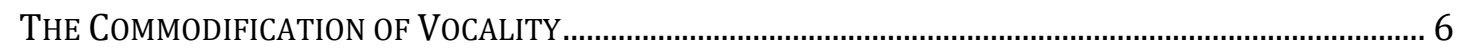

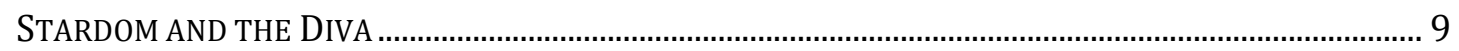

CONTROL AND AGENCY ...........................................................................................................14

THE TECHNOLOGY OF LIVE OPERA ………………………........................................................18

THE INFLUENCE OF RECORDED OPERA ……………….................................................................

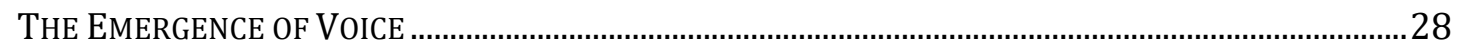

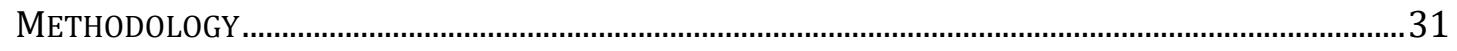

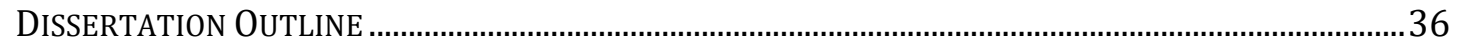

CHAPTER 2: BEWITCHING: THE DRAMATIC VOCALITY OF MARIA CALLAS.....................39

THE GHOST OF MARIA CALLAS ......................................................................................................... 43

Diva RIVALRY: AN AESTHETIC DICHOTOMY................................................................................49

CALLAS AND AUTHENTICITY.......................................................................................................5

A DISCONCERTING VoCALITY: INTERNATIONAL RECEPTION …….......................................................54

'WITCHCRAFT': THE POWER OF VOCAL FAILURE......................................................................................6

L'Ultima Voce: CALLAS AND THE BEAUTIFUL VoICE..........................................................................67

La Divina AS MEDIUM: AURAL ImmortalitY......................................................................................77

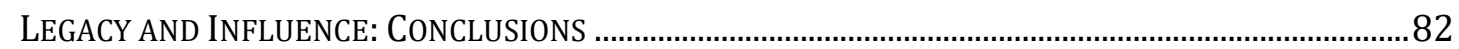

CHAPTER 3: MAKING BEAUTY: KIRI TE KANAWA AND THE FEMININE IDEAL ..............89

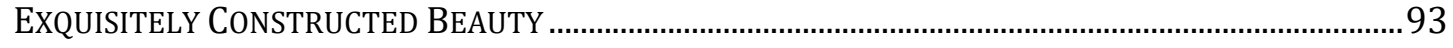

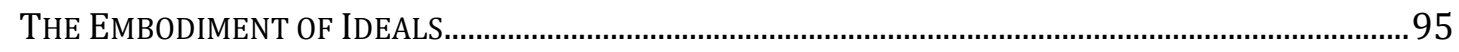

CALLAS OR TEBALDI: INFLUENCES ..............................................................................................98

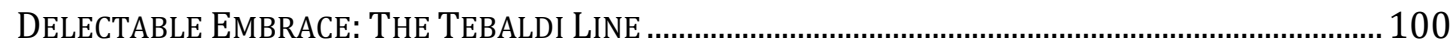

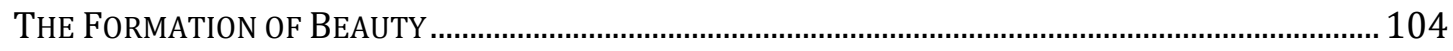

CONCEPTS OF AGENCY IN BEAUTIFUL SINGING ……………....................................................... 111

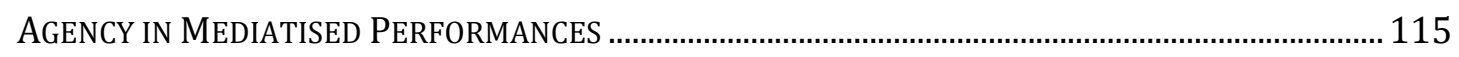

VOCAL FASHION: THE MARKETABLE SOUND .............................................................................. 119

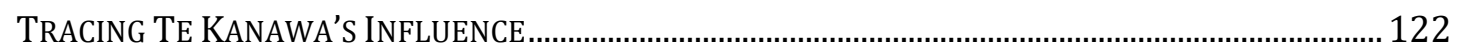

The Authorial Voice OF THE 'NATURAL' SingER: ConCluSiOnS.................................................... 126

CHAPTER 4: GLOBALISATION AND THE 'UN-PRIMA DONNA': ANNA NETREBKO .....131

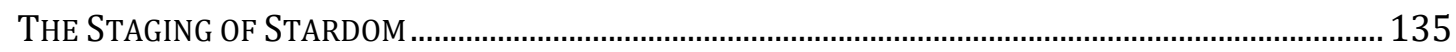

FASHION MODELS AND FANTASIES: THE CURATED IMAGE ................................................................ 141 


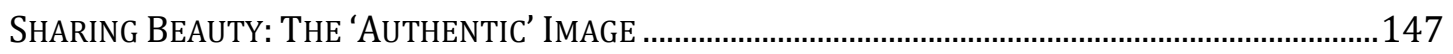

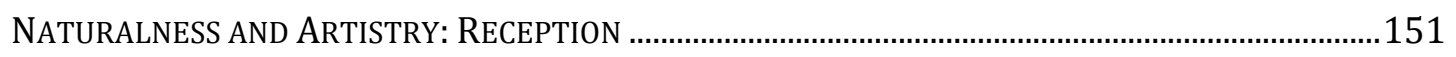

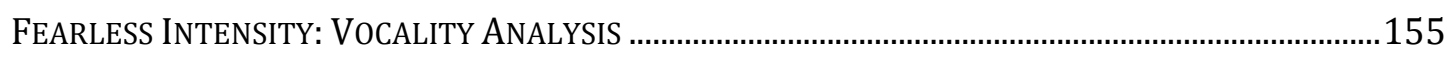

LIVE OR MEDIATISED? NETREBKo's PERFORMANCES....................................................................166

AuthoRIAL VoICES IN MEDIATISED PRODUCTION ......................................................................171

THE NEW TYPE OF DIVA: CoNCLUSIONS .....................................................................................176

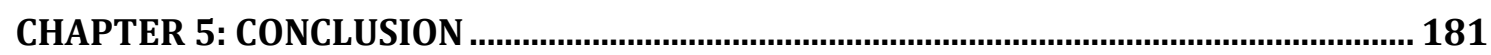

BIBLIOGRAPHY

\section{MUSICAL EXAMPLES}

MUSICAL EXAMPLE 1: 'UN BEL DÌ VEDREMO' - MARIA CALLAS ............................................................. 71

MuSiCAL EXAMPLE 2: 'S'ALTRO CHE LAGRIME' - KIRI TE KANAWA ....................................................108

MuSICAL EXAMPLE 3: 'NON MI DIR' - ANNA NETREBKO_...................................................................162 


\section{ACKNOWLEDGEMENTS}

My immense thanks are due in the first instance to my wonderful supervisors: Inge van Rij and Kimberly Cannady who guided me with invaluable and insightful feedback through the last half of the doctoral journey; Elizabeth Hudson, who inspired and challenged me, and helped me focus my ideas through to the proposal stage; and Robert Legg who introduced me to constructivism, ontology and all of that, then supported me with thoughtful and stimulating ideas and feedback for the first half of my study.

There are many other people to thank who have been there for me through this process.

Thank you firstly my exceptionally intelligent and empathetic parents, Margaret and Bill Wollerman; my beloved partner, supporter, intellectual sounding board, and in the end, cuisinier, Tony Rabbit; and other family members and friends, especially Diana, Annie, Peter, Karlene, and Ian.

I would like to thank also all my colleagues at New Zealand School of Music - Te Kōkī, in particular Margaret Medlyn, Richard Greager, Mark Dorrell, in the Classical Voice department; New Zealand School of Music Directors Sally Jane Norman, Euan Murdoch and Elizabeth Hudson; and Donald Maurice as mentor and guide.

Beyond this, thanks are due to Lynne Wenden for her superb work producing the musical examples; Graduate Women Wellington for the completion grant that made such a difference, and Victoria University of Wellington for study leave, overseas conference leave and associated grants and all the FGR research workshops and seminars. My fellow writers at 'Shut Up and Write' sessions over the past years have been a great support network, including in particular Micky, Ha, Corrina, Miranda and Lehyla; and thank you, Lizzie and Sara, for organising and running these, and being mentors and supporters to us all.

Last but by no means least: thank you to all those who have inspired and supported me in my long musical journey as my teachers, coaches and collaborators, including: Mary White, Greer Garden, Mikael Eliasen, Marlena Malas, Audrey Langford, Eduardo Asqueth, Paul Farrington, Michael Houstoun and Bruce Greenfield. 


\section{ABSTRACT}

Maria Callas's fame as an opera star in the 1950s is still recognised today, and, for many, her name is synonymous with the modern concept of the opera 'diva'. The increasing diversity of mediatised forms of operatic performances since her time has altered the way audiences engage with the art form. This has implications for singers in terms of values around vocality, authorship and power, and, in particular, the agency of singers in creating the meaningful, affective, and distinctively personal vocal tone that opera calls for. I suggest that for "divas" as defined by twentieth- and twenty-first century global stardom, power is amassed at least in part through particular ways in which they make use of their vocality or vocal timbre, and the way they manage their voices' presentation in the mediatised versions of their performances.

The recent turn towards a performative focus in musicology encourages the investigation of such aspects of performance. While authorship remains central in the consideration of performance, the contribution of the singer to the authorial and creative process has tended to be ignored, and at times the singer's work has been regarded as servile to the point of nullification. A critical examination of scholarly writings around operatic performance, with reference to those of diva, voice, and stardom studies, forms the foundation of my study. In case studies of Callas and two later divas, Kiri Te Kanawa and Anna Netrebko, I examine the individual vocality of each singer, their interaction with the forms of mediatisation of their time, their position in the continuum of vocal fashion and influence, and the function of all of these factors in relation to perceptions of creative agency.

My study investigates these issues from the standpoint of a singer, and it provides insights into the singer's processes around the creation of vocality. It offers a new perspective through a fine-tuned analysis of vocal production, which reconnects perceptions of specific timbres with explicitly defined techniques for their production. Through this dissertation I show how signature vocality works: how it is created and managed by these divas, and how the mediatisation of vocality affects perceptions of their power as performers. 


\section{CHAPTER 1: INTRODUCTION}

The name Maria Callas is synonymous with the modern concept of the opera 'diva'. But what do we really mean by this term? In the imagination of the general public the diva is wilful, demanding and grandiose - she has a big voice, and an over-the-top personality, and in popular usage the term has developed pejorative meanings. Scholars, however, have proposed much more favourable perspectives: they position the diva first and foremost as an artist, one who can be defined variously by her musical ability, her 'creation' of various roles, her business acumen, her histrionic ability or style; indeed, historically, this more empowered diva has been shown to have established some level of standing within otherwise repressive constraints on the female in western society. In this dissertation I will go beyond both the pejorative associations that have built up around the term and the more nuanced critical understanding to posit that the diva is defined by her vocality. Far from being irrelevant, the mediatisation that contributed to Callas's diva status in the public perception is actually central to this more favourable critical perspective. This knowledge helps shape our understanding not only of Callas, but of the divas who followed her: this study will thus explore the vocality of Maria Callas, Kiri Te Kanawa and Anna Netrebko through a series of case studies that situate their careers and reception as divas in relation to key aspects of their signature vocality, the creative agency and power associated with that vocality, and the role played by mediatisation in shaping their distinctive forms of divahood. The dissertation focuses on the values around vocality and seeks to tease out some of the effects of increasing mediatisation on the form of operatic vocality and the career of the modern diva.

Historically, the diva has been conceptualised in line with a range of meanings by various scholars, including Susan Rutherford, Mary Ann Smart, Rachel Cowgill and Hilary Poriss. ${ }^{1}$ While the term 'diva' may be utilised in opera studies alongside that of 'prima donna', both of these descriptors have been variously applied to other genres. ${ }^{2}$ In The Angel's Cry, Michel Poizat suggests that 'the divine voice of the female singer makes her a diva, a goddess [...] it is the female singer and she alone who is accorded divine status, as though

\footnotetext{
${ }^{1}$ Susan Rutherford, The Prima Donna and Opera, 1815-1930 (Cambridge University Press, 2006); Susan Rutherford, "'La Cantante Delle Passioni": Giuditta Pasta and the Idea of Operatic Performance', Cambridge Opera Journal 19, no. 2 (2007): 107-38; Mary Ann Smart, 'The Lost Voice of Rosine Stoltz', Cambridge Opera Journal 6, no. 01 (March 1994): 31-50; Rachel Cowgill and Hilary Poriss, eds., The Arts of the Prima Donna in the Long Nineteenth Century (New York: Oxford University Press, 2012).

2 Tracy C. Davis, 'From Diva to Drama Queen', in The Arts of the Prima Donna in the Long Nineteenth Century, ed. Rachel Cowgill and Hilary Poriss (New York: Oxford University Press, 2012), 252-71.
} 
it were her power to transform herself into pure voice'. ${ }^{3}$ Poizat's Lacanian viewpoint raises questions about the significance and meaning of voice itself and how, or indeed whether, voice can or should be thought of as separate from the singer and their body.

When considering twentieth-century opera singers our notion of the diva must encompass the increasingly mediatised context within which their stardom plays out. Further, any consideration of a diva's effect is inevitably bound up with larger issues of the affective power of music, the fantasy of opera and emotive drama involved, the effects of the listener's attitudes and values, and consideration of the voice itself. While Callas may be understood to have launched a new version of the mediatised operatic star, over the succeeding fifty years a number of other singers have reached a level of global stardom that confers diva status, despite exhibiting vastly differing performative styles and approaches that reflect the changing emphasis on voice as the central feature of operatic performance. The nature of these singers' successful negotiation of the new mediatised forms thus opens up the possibility of an investigation into their techniques and approaches. An examination of the vocality of such singers as able to be heard on their legacy of recordings reveals significant agency exerted by the diva in these mediatised contexts.

I suggest that for divas as defined by twentieth- and twenty-first century global stardom, while the overall nature of divadom may be a complex combination of many different aspects, power is amassed at least in part through particular ways in which they make use of their vocality or vocal timbre, and the way they manage the presentation of their voices in the mediatised versions of their performances. The recording of voice has moved through various modes since Callas's day (and indeed since the dawn of the recording age, with which opera singers were extensively involved). While recordings of singers may have initially been seen as providing an adjunct to live performance, such mediatised forms have increasingly provided the main or indeed the only impression of the artist many will ever experience. As Philip Auslander has shown, so influential and ubiquitous has the mediatised performance become, that live performance is increasingly a mirage, in that it is only perceived through the lens of mediatised performances. ${ }^{4}$ The response of the listener to these artists is therefore contingent on the sound heard in these mediatised

\footnotetext{
${ }^{3}$ Michel Poizat, The Angel's Cry: Beyond the Pleasure Principle in Opera, trans. Arthur Denner (Cornell University Press, 1992), 178-79. (original emphasis).

${ }^{4}$ Philip Auslander, Liveness: Performance in a Mediatized Culture (Psychology Press, 1999). I am using the term 'mediatisation' here in the form that Auslander used in this book: although he may have 'borrowed [it] from Jean Baudrillard', he uses it in a more straightforward way, simply referring to it as 'performance that is circulated on television, as audio or video recordings, and in other forms based in technologies of reproduction' (page 5).
} 
versions. Authors such as Wayne Koestenbaum have considered the influence of the recorded voice from the perspective of the fan. ${ }^{5}$ But what is the implication for our understanding of the diva's processes in the development of her signature sound and the form of vocality that is chosen to be promoted through these media? An understanding of these aspects of the opera singer's art seems crucial, both to our critical readings of operatic performance, as well as for the development of effective forms of vocal pedagogy for this mediatised age.

In the current context, readily available recordings (be they audio or audio-visual) take the place of live performance, as a means to experience the modern diva's voice. Moreover, recordings can also indirectly influence the response of listeners to a singer when they have been used within other media. For example, recordings of Kiri Te Kanawa performing Puccini arias were used extensively within the soundtrack of the 1985 film $A$ Room with a View. ${ }^{6}$ While Te Kanawa never appears in the movie, and we only hear the music as a background to the action, anyone who has seen this film may later 'recognise' her vocality when they hear it, and is likely to have subconscious associations linked to it, without even realising they had ever heard her. This is one way liveness and mediatisation may interact with each other, and the borders between them can become blurred. ${ }^{7}$

Having an individual signature sound that identifies the singer is an essential part of these processes of affect and influence, and this reinforces the importance of the individual vocality of the star singer. As John Steane notes, the greatest singers are 'instantly recognisable' solely from their recorded sound. ${ }^{8}$ Their distinctive vocal sound, and their approach to the creation of sung sound, sets the form of a career, maintains it and determines the artist's long-term influence. Yet opera singers must ensure that they utilise tone that lies within a limited range of colour and a perception of beauty deemed stylistically appropriate for the genre. Like Leslie Dunn and Nancy Jones in Embodied Voices, in this dissertation I use the term 'vocality' to indicate a broader spectrum of

\footnotetext{
${ }^{5}$ Wayne Koestenbaum, The Queen's Throat: Opera, Homosexuality and the Mystery of Desire (Da Capo Press, 2001).

${ }^{6}$ These were recordings of her singing the Puccini arias 'Canzone di Doretta' and ' 0 mio babbino'. The two arias were thematically revisited during the film although they played as 'background' music.

${ }^{7}$ I am using the term 'liveness' in this context with the connotation of the quality or state of a performance in which the performer is present in the same event space as the audience, as used by Auslander, although there are many different possibilities for the use of the term 'live', some of which will be discussed later in this chapter. The influence of this mediatised 'background' music heard in a film, on a listener experiencing later 'live' or mediatised performances in this regard is simply an example of the ubiquitous and often hidden nature of our experience with mediatisation. 8 J. B. Steane, Singers of the Century (Volume 2) (Amadeus Press, 1998), 259.
} 
vocalisation than simply vocal tone..$^{9}$ In this form, the singer's distinctive vocal timbre and singing style are grouped together as their 'signature vocality'. It is important to note that this individuality of vocal tone is not simply a matter of a singer's 'natural' sound, however that might be defined. ${ }^{10}$ All singers are capable of making or 'imitating' a wide variety of vocal sounds and styles, but the development and maintenance of their individual vocality is a key part of the creative agency of a singer.

Opera, and its power, traceable through various qualities including affect, influence, inspiration and so forth, is fundamentally a creation based on voice and singing. Many different factors feed into the audience's interest in it as an art form, but the diva holds a powerful place within its structure, and the power of the female voice has been acknowledged alongside that of the male. ${ }^{11}$ It is important to note also that for opera professionals the terms 'diva' and 'prima donna' do not necessarily carry negative connotations and they continue to be used to indicate rank and standing within the artistic hierarchy of opera.

When it comes to the relationship between the power of the singer's voice and creative agency, the connection has not always been clearly made, in particular when it comes to female agency and wider concepts surrounding the feminine, such as conformity and the rights of self-assertion. Over the past three decades feminist scholarship has challenged these social attitudes, in works such as Susan Bordo's Unbearable Weight. Within opera studies also, feminist critical discourse has developed, including that around Catherine Clément's review of the implications of opera plots with respect to values and attitudes towards women, and the work of Susan McClary to do with operatic excess and the idea of madness and the female voice both needing to be contained - framed and viewed, yet controlled. ${ }^{12}$ In 'Opera; or, the Envoicing of Women', Carolyn Abbate responded to Clément's claims, suggesting instead that the music of opera can and often does imply different alignments of power between male and female characters than is set up by the

\footnotetext{
${ }^{9}$ Leslie C. Dunn and Nancy A. Jones, eds., Embodied Voices: Representing Female Vocality in Western Culture (Cambridge University Press, 1994).

10 The concept or trope of 'natural' voice is prevalent in the popular discourse, and identified as an essential quality of the each person - their 'natural' voice being thought of as an existing ability and/or the unchanging quality of their 'personal' sound.

11 Terry Castle, 'Breath's End: Opera and Mortality', in The Arts of the Prima Donna in the Long Nineteenth Century, ed. Rachel Cowgill and Hilary Poriss, 1 edition (New York: Oxford University Press, 2012), 211.

12 Susan Bordo, Unbearable Weight (University of California Press, 2003); Catherine Clément, Opera, or, The Undoing of Women, trans. Betsy Wing (London: Virago, 1989); Susan McClary, 'Excess and Frame: The Musical Representation of Madwomen', in Feminine Endings: Music, Gender, and Sexuality (University of Minnesota Press, 1991), 80-111.
} 
plot, and in this essay she started also to tease out different possibilities for the authorial voice of the performer and the nature of that authorship. ${ }^{13}$

Recent scholarship in the emerging area of voice studies is giving rise to new approaches and topics of study such as the work of Nina Sun Eidsheim around voice and identity. ${ }^{14}$ However, despite the acknowledgement of the power of female vocality in more critical and conceptual terms, the nature of the agency of the singer in controlling that power is generally less well understood and not fully covered in existing literature. In this study vocality is looked at in an in-depth way in order to connect the singer's choices around the production of sound with the aural impressions they create, on the basis that signature vocality is effectively an aural 'image' which is analogous to the star 'image' that is cultivated to empower all forms of stardom. I consider the framework within which the diva produces her power, and the question of further sites of authorial voice within opera performance to include the singer's production of both meaningful vocal sound and their own personal vocality. ${ }^{15}$

Through the examination of the careers of these divas, we can gain insight into the questions of who, within such performances, is in control of operatic meaning, how the power of the diva is expressed through vocality, and what forms their power of influence may take. This study explores the location of authorship and the nature of the power of the diva in relation to the values around voice and the female singer through the lens of the singer's vocality. Basing my research on a detailed analysis of this vocality, traced within the cultural context of the careers of the three sopranos - Maria Callas, Kiri Te Kanawa, and the twenty-first century star Anna Netrebko - I show how signature vocality works: how it is created and managed by these divas, and how the mediatisation of vocality affects perceptions of their power as performers.

\section{Personal Voice: My Background}

My perspective of the various areas of research covered by this dissertation is informed by and shaped by my own background as a professional singer and singing teacher. This experience encompasses my training as a singer firstly in New Zealand and then at the

\footnotetext{
${ }^{13}$ Carolyn Abbate, 'Opera; or, the Envoicing of Women', in Musicology and Difference: Gender and Sexuality in Music Scholarship, ed. Ruth A. Solie (University of California Press, 1995), 225-58.

${ }^{14}$ Nina Sun Eidsheim, The Race of Sound: Listening, Timbre, and Vocality in African American Music (Duke University Press, 2019).

${ }^{15}$ Abbate, 'Opera, or, The Envoicing of Women'. Abbate refers to this possibility in her 1995 essay where she dares to suggest that 'the performer in some sense usurps the authorial voice' from the composer (page 234).
} 
Curtis Institute of Music in Philadelphia, PA, in the United States of America; more than two decades of freelance professional contracts as a soprano soloist with the major arts organisations throughout New Zealand and Australia; engagements as a recording artist for Radio New Zealand; and seven CD recordings, one of which, Stations, of a work by New Zealand composer Anthony Ritchie, was nominated for MusicWeb International's recording of the year. 16 This experience with training institutions and professional organisations internationally, along with my understanding of recording processes, has provided me with a foundation for the investigation of the various aspects of the diva singer's successful negotiation of the international operatic industry. Additionally, with an overlap of time period, my teaching experience covers nearly two decades of teaching singing at tertiary level, for most of which I have been based at Victoria University of Wellington, New Zealand.

Other opportunities that have special relevance to this dissertation, and in particular the case study on Kiri Te Kanawa, include my engagement as understudy for Donna Elvira in Don Giovanni in 1995 and Mimì in La Bohème in 1991, in Auckland, New Zealand, where both of these roles were played by Te Kanawa. I was also commissioned by the Kiri Te Kanawa Foundation in 2007 to undertake a research project in which I investigated the options for study and the experiences of young New Zealand singers in the United Kingdom in terms of their training and preparation for careers, and my report on this was published by the Foundation in 2008. While working on that project I was fortunate to be offered a series of individual singing coaching sessions by Dame Kiri on repertoire I was preparing for upcoming performances, as well as consultation lessons with various London singing teachers and coaches. ${ }^{17}$

\section{The Commodification of Vocality}

As a recorded singer, I understand how the finished sound of any musical recording is shaped and modified by the various processes which allow the 'live' sound to be converted into a lasting 'product', whether it is to be held within an electronic file or a physical object such as a compact disc. Indeed, by choosing three sopranos whose careers span the period since the mid-twentieth century I have intentionally placed this study within the temporal context of a new and influential aspect of the diva's career: the commodification of sound, recordings, and indeed, the commodification of singers themselves. This development has

\footnotetext{
16 'Recording of the Year 2015', MusicWeb International (blog), 2015, http://www.musicwebinternational.com/classrev/2015/ROTY/ROTY_2015_AL.htm.

17 Jenny Wollerman, New Zealand Singers Taking Flight (Kiri Te Kanawa Foundation, 2008), http://www.kiritekanawa.org/assets/Article-attachments/NZ-SINGERS-TAKE-FLIGHT-MARCH2008.pdf.
} 
had a material effect on the nature of the relationship between the diva and her audience, and has offered new opportunities as well as placing new limitations on the authorial voice and agency of the singer.

Apart from the acoustics of the particular recording venue, the effect of different types of microphones and any change to the positioning of them can vary the sound to a great extent. This means that the taste of the recording producer and engineer, the 'fashion', or the type of sound that the recording company desires, will inevitably affect the output, and this could be far removed from the sound quality the singer was attempting to cultivate. It may also mean that a singer is encouraged to develop a particular aspect of their vocal sound which, over time, becomes part of their signature vocality, and is seen as desirable for both their recorded sound and their live performances. While the mode of transmission (and the playback equipment used) has changed over the decades since recording began, the use of recordings as a mass communication means of building the diva's status soon reached the point where voices were treated as something separate from their originator, the singer. Singers' voices effectively started to be treated as a commodity, a saleable item, embodied in the recording as artefact.

In terms of the singing industry, mass consumerism already existed before recordings became possible; Jenny Lind's hugely successful promotion by P. T. Barnum for her tour of America in the 1850s may be seen as an example of the early commodification of the singer. As David Cavicchi points out in his examination of reactions of music lovers to this new form of cultural consumption, this was part of the rise of mass consumerism in America, when musical experience (and urban leisure) started to become 'a tangible product'.18 If the media technology and recordings effect a separation between the saleable commodity and the singer, the sound that the fans of such singers are attracted to and form an attachment to, which may be supposed by them to be an accurate representation of the 'real' sound of the singer, given the 'high fidelity' of the modern recording processes, may also be quite different from the vocal sound that they would experience in hearing that singer in a live performance.

While the mediatisation of vocal artists had been underway since the time of the first recordings, with opera singers Enrico Caruso, Nellie Melba and Amelita Galli-Curci all having been successfully promoted via phonograph recordings, the limitations of early

\footnotetext{
18 Daniel Cavicchi, 'Loving Music: Listeners, Entertainments, and the Origins of Music Fandom in Nineteenth Century America', in Fandom: Identities and Communities in a Mediated World, ed. Jonathan Gray, Cornel Sandvoss, and C. Lee Harrington (New York: New York University Press, 2007), 248.
} 
recording equipment meant that only certain singers had voices that recorded well. As Mark Katz points out, this had the effect of promoting a particular type of sound, such as that of Caruso, as being 'better', which influenced a change in the 'fashion' for desirable vocal sound at that point. ${ }^{19}$ In fact, Caruso's recording company, Victor, specifically chose to reinforce the higher frequency harmonics in one of his 1906 recordings to create a brighter tone, then advertised it as 'so natural that it seems to be Caruso himself singing instead of the machine'. ${ }^{20}$ This is only one instance of many that exemplify the layers of authorial voice that are intrinsic to the mediatisation of the singer, and raises questions about the effects that the different media formats arising during the period since Callas have had on the fashion for vocal sound.

Daniel Leech-Wilkinson's study of recorded singing style over the twentieth century provides valuable insights into the trends in audio recordings over this period. His findings suggest that recording artists during the post-Second World War period were particularly focused on accuracy in their approach to the music, and used fewer expressive effects that would disrupt the line and/or the beauty of the tone than tended to be used before the war. From his close comparison of the corpus of classical recordings he noticed that in the early period of recording (early in the twentieth century) there were pronounced differences between the performance styles of musicians from different countries. With the growth of available recordings, however, all the styles tended to merge and homogenise, and he interprets this to be due to the influence of the recording industry, in that the artists' own musical styles were being influenced by the recordings of other artists they had heard. ${ }^{21}$

Recognising this effect of the recording industry, he also found a noticeable change in this relatively 'homogenised' stylistic fashion after the Second World War. 'One thing that recording has undoubtedly caused [...] is a trend towards the literal performance of scores. [...] For singers and string players that means less portamento, less rubato, less ornamentation [...] removing, in other words, all the things that musicians used to do as a matter of course [before the war] in order to intensify the expressivity of a performance.'22

\footnotetext{
${ }^{19}$ Alexandra Wilson, 'Galli-Curci Comes to Town: The Prima Donna's Presence in the Age of Mechanical Reproduction', in The Arts of the Prima Donna in the Long Nineteenth Century, ed. Rachel Cowgill and Hilary Poriss (New York: Oxford University Press, 2012), 328; Mark Katz, Capturing Sound: How Technology Has Changed Music (Berkeley: University of California Press, 2004).

${ }^{20}$ Anna Fishzon, Fandom, Authenticity, and Opera: Mad Acts and Letter Scenes in Fin-de-Siècle Russia (Palgrave Macmillan, 2013), 144.

${ }^{21}$ Daniel Leech-Wilkinson, 'The Changing Sound of Music: Approaches to Studying Recorded Musical Performance', London: CHARM, 2009, para. 44, www.charm.kcl.ac.uk/studies/chapter/chap4.html.

${ }^{22}$ Leech-Wilkinson, para. 44.

Page 8
} 
He links this less overtly expressive style of performance with the much earlier recordings made when the industry first started. By the time the Second World War started, he reports, the initially relatively plain readings of scores had developed into a more free and expressive style. He attributes the post-war reversion to the less expressive style to the psychological effect of the war on those who lived through it. In general he noted a dampening of expressivity in these later recordings, with fewer expressive effects above and beyond those notated in the score.

These observations are of necessity generalised, and are focused in the main on expressivity, omitting the wider issues of vocal fashion and the popularity of particular types of vocal sound and vocality. ${ }^{23}$ Furthermore, alongside the growth of mediatisation via sound recording, the rise of opera films from the 1970s on, and the availability of streaming and downloadable audio and video media through the internet, have changed the landscape of mediatisation substantially since Callas's career was established in the 1950s.

\section{Stardom and the Diva}

This changing landscape has provided fans with more and more opportunities to 'connect' with the singer in different ways through an increasing diversity of mediatised modes. If Caruso, and his particular form of tenor vocality, were promoted largely through his audio recordings, later singers have had to contend with a wide variety of public interfaces, from television interviews and performances, to filmed opera, and, more recently, through 'live' video broadcasts, online video platforms and social media. ${ }^{24}$ How might this affect our perception of the diva, her approach to performance and engagement with her audience, and the qualities that denote her divahood?

The star singers who came after Callas have often exhibited vastly differing personal and performative styles, both histrionically and vocally. If we consider the sopranos Kiri Te Kanawa, Joan Sutherland, Montserrat Caballé, Leontyne Price and Anna Netrebko, all of whom have been variously acknowledged as divas, it seems that despite Callas's iconic reputation the definition of modern divahood is not fully captured by any definition based on her. ${ }^{25}$ Even leaving aside questions of differences in the approaches of the various

\footnotetext{
${ }^{23}$ Leech-Wilkinson, 'The Changing Sound of Music: Approaches to Studying Recorded Musical Performance'.

24 Susan Rutherford, 'Voices and Singers', in The Cambridge Companion to Opera Studies, ed. Nicholas Till (Cambridge University Press, 2012), 126.

25 Davis, 'From Diva to Drama Queen', 263-65. Davis identifies several twentieth century operatic divas: Maria Callas, Montserrat Caballé, and Dame Kiri Te Kanawa and writes that in terms of the
} 
singers to on-stage movement or off-stage behaviour, in terms of their vocal sound and approach they seem far removed from each other.

In fact, the individuality of voice can be seen as one of the most important qualities of a diva. In her 2004 autobiography, soprano Renée Fleming gives her view of the requisite 'package' for a successful singer: she lists image, stage presence, charisma, but emphasises that 'there has to be a distinctive sound - not just a good voice, but a distinctive and unique one - and, most important, an ability to communicate meaning and emotion to the audience'. ${ }^{26}$ Of all these important characteristics that Fleming puts forward, only the quality of the voice is something that is 'distinctive'. For her this is the main individual quality of a singer.

There are of course no unequivocal definitions of the term 'diva'. Despite numerous studies and articles written on the topic, even a seemingly straightforward term such as 'a great singer' can be problematic. In 2007, BBC Music Magazine published an article entitled 'The 20 Greatest Sopranos of All Time', that provided readers with a list based on the opinions of twenty-two eminent music critics from the United Kingdom. ${ }^{27}$ The list provides an intriguing snapshot of the general attitudes and tastes of music critics in relation to operatic sopranos at that time. The 'jury' each contributed the names of their chosen 'top ten' sopranos, which resulted in an initial set of no fewer than ninety names, a much wider spread than the twenty that were included in the final article. No criteria were given for the choices, leaving one to wonder to what degree various attributes might have been taken into account, such as the possession of an outstanding or distinctive voice, whether some form of vocal or expressive 'presence' survived in the recorded performances considered (since most of the singers chosen were no longer performing), their degree of international fame, or their success in terms of albums recorded or sold. We did not learn whether, for these critics, the 'greatest singer' was the most memorable, the most affecting, the one who was able to perform the greatest variety of music, or who was at the top of their field in a specific genre. All of these aspects were pointed to at some

\footnotetext{
'drama queen' concept of the diva, Anna Netrebko is the exception to the rule, quoting Anne Midgette in the New York Times who suggests she is "blissfully unaware of the rules of the diva handbook".

${ }^{26}$ Renée Fleming, The Inner Voice: The Making of a Singer (Viking Penguin, 2004), 161. See also pages 87-88, where she comments further on this need for an 'instantly recognizable sound', and page 72, where she outlines Leontyne Price's advice to her early on in her career about the importance of the voice: 'You're experiencing the noise.... the hype, the demands that are being made on you from all corners... You have to learn to tune out all of the noise and focus on one thing... [The voice] is all that matters. Because the minute this goes, they'll disappear so fast you won't even know what happened.'

27 Anna Picard et al., 'The 20 Greatest Sopranos of All Time', BBC Music Magazine 15, no. 8 (2007): 27-37.
} 
point in the descriptions given for each of the individual singers profiled in the article, but few of them were said to have all of these attributes. 'The most mythologised beings in opera, sopranos are alluring,' commented John Allison, one of the contributors, 'but I wouldn't have found the challenge of listing my favourite sopranos so fascinating if it weren't for the fact that they are great artists first and divas (whatever that means) second.'28 Allison separates the divas from their artistic ability or achievement in this comment, and also points to an unknowable mythology surrounding them. Judging by the descriptions in the article, however, this 'mystique' of the star soprano, to which he refers, is bound up with their vocality, even if other aspects of each singer's 'image' and their artistry may be part of the 'allure' that Allison senses.

The sopranos selected for this dissertation have not only been recognised as 'great singers' but have been labelled 'divas' by various authors including experts and critics. ${ }^{29}$ Despite the precariousness of attributions in this field, basing a study such as this around acknowledged 'great singers', who, at least theoretically, epitomise the qualities that singers aspire to, and have had major success in their careers within the opera industry, allows for the sense of them as representative of their generation and type of singer.

To study the diva in a modern context also allows for a consideration of the significance of the female opera singer during this period and how her experience might compare with that of the male singer. In his review of Catherine Clément's Opera, or the Undoing of Women, Paul Robinson argues that the 'female victims' which Clément identifies in so many operas are not usually experienced as victims, since they are in fact able, and are usually given the opportunity, to sing 'with an authority equal to that of their male oppressors' in these operatic works. Robinson suggests, for example, that Cio-cio-san's 'musical phrases of extraordinary grandeur, carrying the voice repeatedly to the top of its range' are a form of 'vocal assertiveness' and the fact that Desdemona's vocal line 'soars splendidly over the Act Three ensemble' makes her 'a more powerful figure' than Shakespeare's character. ${ }^{30}$ The fact remains, however, that these female characters do die, and in terms of the social interaction that leads to their deaths they are ultimately

\footnotetext{
${ }^{28}$ John Allison, 'Soprano Sensations: Contributor Comments', BBC Music Magazine 15, no. 8 (2007): 5; John Allison et al., Sopranos in Opera: Profiles of Fifteen Great Sopranos (Opera Magazine Ltd, 2001), 2.

29 Davis, 'From Diva to Drama Queen'; Castle, 'Breath's End: Opera and Mortality'; Susan J. Leonardi and Rebecca A. Pope, The Diva's Mouth: Body, Voice, Prima Donna Politics (Rutgers University Press, 1996); Rutherford, 'Voices and Singers'; Rupert Christiansen, Prima Donna: A History (Pimlico, 1995); Jürgen Kesting, Die grossen Sänger, 4 vols (Hamburg: Hoffmann und Campe, 2008). 30 Paul Robinson, 'Book Review: It's Not Over Till the Soprano Dies: OPERA, OR THE UNDOING OF WOMEN By Catherine Clement', New York Times, 1 January 1989.
} 
disempowered. But there is more to uncover in terms of the assertive-sounding feminine voice, and I aim to shed light on this here by examining the power that the singer herself injects into the vocality she creates and the manner in which she chooses to wield that power. These are aspects that cannot be predetermined, or at least not fully defined, by the composer, director or conductor, but instead form part of the agency and authorship of the singer.

The particular pressures that female opera singers have been subject to in terms of gendered attitudes and social and cultural values in the context of opera performance in the period since the mid-twentieth century have shaped both this vocality and the behaviour of the diva. For example, Nina Sun Eidsheim points out in her study of the way Maria Callas's remodelling of her body and image has been interpreted, that commentators tended to base their assessments of her vocal abilities on factors of control. After her substantial weight loss they often blamed any vocal issues on its effects, as if the self-control required to transform her own body had ironically created a lack of control of voice. Attitudes towards women and female singers, and their ability to control their bodies and behaviour, inform many aspects of the rhetoric around divas in this period. I argue that Callas's vocal 'failures' should be viewed in light of her evident ability to choose what tone she made, rather than necessarily as a lack of control, and I explore these cultural effects further in my case studies of Te Kanawa and Netrebko, who dealt with these gendered attitudes and pressures in other ways. ${ }^{31}$

Given the focus on vocal aspects in operatic performance, the concepts of 'presence' and 'charisma', which are often pointed to as requirements for such levels of recognition in opera, must surely have some connection with the singer's use of an individual vocality in their affective connection with the audience. While to an extent fame may be self-fuelling (success breeding success), to achieve an enduring status of 'divahood', a singer must first rise to the upper levels of the operatic hierarchy, and be recognised as a performer, before fame, stardom and divahood may be achieved. Audiences' excitement at simply hearing and seeing a 'famous name' artist may affect their response to a performance, but this is not enough to explain the rise of such artists to the stratosphere of stardom.

Richard Dyer places the features of star quality in a cultural context, identifying a key quality for fans as the desire for the star to be able to be perceived as 'real' and 'authentic', and to be seen to exist outside the realm of their performances. Dyer shows that,

\footnotetext{
31 Castle, 'Breath's End: Opera and Mortality', 211; Nina Sun Eidsheim, 'Maria Callas's Waistline and the Organology of Voice', The Opera Quarterly 33, no. 3-4 (2017): 249-68.
} 
ironically, the media holds the power to both unsettle and reaffirm the sense of authenticity of a star, in that media narratives drive our understanding of these aspects of the star's personality. ${ }^{32}$ Edward Shils suggested in the American Sociological Review in 1965 that 'The charismatic quality of an individual as perceived by others, or himself [sic] lies in what is thought to be his connection with (including possession by or embedment in) some very central feature of man's existence and the cosmos in which he lives. The centrality, coupled with intensity, makes it extraordinary'.33 This 'very central feature' is a generic description that leaves the door wide open for interpretation of its nature, and opera's preoccupation with such very human issues and emotions in fact would tend to suggest that every singer might display such a connection in their performances, something which negates the very concept of this as an exceptional characteristic or ability.

Poizat interprets this 'very central feature' for opera as 'the angel's cry', the desire for jouissance, and a Lacanian desire for a return to the parent-child relationship. ${ }^{34}$ As a performer, I focus on the expression of deep emotions through the music I perform and through my vocality, and as an opera fan, my desire in attending the opera is to be moved, and ideally, transfixed by the intensity of the performer's unworldly yet thoroughly human and emotive connection. For me there is no sense of having returned to the motheredchild state when such a connection has been made, nor when experiencing the frisson of excitement that a glorious voice inspires, rather, this aural experience is much more likely to be invigorating and inspiring. Such connections are all the more desirable for their rarity and I do not expect to come across them in every performance, even of my favourite star. The effects of such singing on audience members must surely be individual to each listener, as the experiences of the Parisian opera lovers Poizat interviews in his book imply. Claude, for example, states 'you never experience exactly the same sensation, you have a different reaction [to opera performances] every time', so perhaps Poizat's sense of a return to the powerlessness of childhood may be a personal response rather than one that is generally felt by the opera audience. ${ }^{35}$

\footnotetext{
32 Richard Dyer, 'A Star Is Born and the Construction of Authenticity', in Stardom: Industry of Desire, ed. Christine Gledhill (London ; New York: Routledge, 1991).

${ }^{33}$ Edward Shils, 'Charisma, Order and Status', American Sociological Review 30, no. 2 (April 1965). (original emphasis)

${ }^{34}$ Poizat, The Angel's Cry, xiii, 4-6; Michel Poizat, "'The Blue Note" and "The Objectified Voice and the Vocal Object"', Cambridge Opera Journal 3, no. 3 (November 1991): 208; Raymond Monelle, 'Review: The Angel's Cry: Beyond the Pleasure Principle in Opera by Michel Poizat and Arthur Denner', Cambridge Opera Journal 74, no. 3 (August 1993): 453-55.

35 Poizat, The Angel's Cry, 17-18.
} 
Poizat also contends that 'what drives the [...] opera devotee is the desire for vocal and musical moments, never visual ones' ${ }^{36}$ The nature of this desire will surely vary depending on the actual audience member concerned, but this assertion also ignores the fetishistic aspect of some fans' attachment to the star, for example as revealed by Koestenbaum, for whom the object (in this case the vinyl LP record) on the cover of which the star appears, or out of which their invisible voice emanates, also holds the power of deep and even erotic fascination. ${ }^{37}$

According to Poizat, "The mission of the [singing] artist on the [opera] stage is, in a sense, to approach self-annihilation as a subject in order to offer himself or herself as pure voice'. This is in order to achieve 'the dissolution of incongruity between singer and role'. 38 While Poizat puts forward the notion of the power of the vocal experience cogently, the terms in which he positions the performative act seem here to ensnare the singer in a conundrum: one in which she must nullify her own person at the same time as build a vital personal connection with the audience. Poizat's discourse is viewed wholly from the side of the spectator, and the spectator's theoretical stance as performance receptor. For a singer, there is no possibility of transporting an audience without being 'present', that is, personally connected and invested in the scene or musical work. Moreover, I would suggest, based on my own experience in singing and teaching, that this sense of connection is not effectively communicated if the singer does not find a way to contribute something of herself in the performance process. This study focuses on vocality within the cultural context of the international arena in which western classical opera performances typically occur. This contextual consideration allows for the examination of the specific implications of this connection between singer and audience, the nature of attitudes surrounding the singer and their work, and aims to provide a greater understanding of how vocality itself is used and created in this setting.

\section{Control and Agency}

A key concept for cultural studies of operatic singing is the singer's agency. Existing studies have taken a number of approaches. For example, Nina Sun Eidsheim has examined this topic through the lens of racialised concepts of timbre, showing that the singer has agency in the construction of her timbre; while Freya Jarman-Ivens has examined aspects of timbre in terms of gender binaries of the composer versus the singer,

\footnotetext{
36 Poizat, 35.

37 Koestenbaum, The Queen's Throat, 59; Linda Hutcheon and Michael Hutcheon, Bodily Charm: Living Opera (University of Nebraska Press, 2000), 15.

38 Poizat, The Angel's Cry, 35.
} 
suggesting that some singing 'failures' could also be seen as a form of resistance. ${ }^{39}$ What is missing from all these studies is how the singer's control and agency in the process of the formation of their vocality connects with the power that they wield through it.

While the singer's body has been the subject of scholarly work for some time, overall there has been less scholarship that focuses on the timbre or individual sound of the singer. ${ }^{40}$ In practice, the lack of recognition of singing as the playing of a musical instrument, or as a high-level skill that is developed by the singer, is still encountered on a frequent basis by singers. This study aims to provide substantive evidence towards dispelling such myths. As part of this, I consider underlying attitudes within the journalistic media towards vocal agency and the authorship that agency implies, which can in turn impact on the way an individual singer's vocality is received.

The literature that best represents the singer's perspective is in the field of voice science the science of the physiological and acoustic properties of the vocal mechanism - and this is the area of research with which both singers and singing teachers most commonly engage. The motivation for this generally lies in the desire for aid in achieving technical singing goals, since opera singers must have superb singing technique to achieve the vocal feats demanded by the written work, to cope with the endurance required and to communicate expressively through sung tone. It must be remembered that vocalisation constitutes an alternative use for the larynx, which is fundamentally a primal, lifesaving, valve that is able to open for breathing and close up to protect the airways from obstruction by food. There is no 'instrument' that continuously exists; rather the instrument is created from moment to moment by the singer's active modification of the shape and position of the different parts of the vocal tract, larynx and articulators.

Jo Estill, whose scholarly work in voice science led to the development of the Estill Voice Training System, recognised this achievement as agency realised through expressivity. She identified the purpose and objective of acquiring vocal skills in these terms, and separated what she called 'Craft' and 'Artistry', from 'Metaphysics'. She described the latter as 'that

\footnotetext{
${ }^{39}$ Nina Eidsheim, 'Voice as Action: Towards a Model for Analyzing the Dynamic Construction of Racialized Voice', Current Musicology, no. 93 (2012): 8; Nina Sun Eidsheim, 'Marian Anderson and "Sonic Blackness" in American Opera', American Quarterly 63, no. 3 (2011): 641-71, https://doi.org/10.1353/aq.2011.0045; Freya Jarman-Ivens, Queer Voices - Technologies, Vocalities, and the Musical Flaw (Palgrave Macmillan, 2011).

${ }^{40}$ Recent studies that do focus on vocal timbre include: Eidsheim, 'Voice as Action'; Eidsheim, The Race of Sound; Kate Heidemann, 'Hearing Women's Voices in Popular Song: Analyzing Sound and Identity in Country and Soul - ProQuest Dissertations \& Theses Global - ProQuest' (Dissertation, Columbia, 2014).
} 
realm of mastery in which performers create "magic", entering a state similar to "the zone" in athletics'. For Estill, craft denoted the gaining of fundamental vocal skills through practice, and artistry meant 'acquiring the skill to perform a piece in accordance with the style rules of its genre'. ${ }^{41}$ Whether or not a singer ever achieves the special metaphysical 'magic' outlined by Estill, her term 'artistry' would seem to denote the ability for expression and communication of personal meaning.

As Eidsheim notes, 'an opera singer's art is the epitome of self-control in areas from practice and lifestyle to actual vocal execution'.42 One of the cultural pressures around this control, in the form of an aim passed on to students from teachers, and reinforced by critics in their reviews, is that the final output, the musically sung phrases or the highpitched notes of great beauty, should be perceived by listeners and viewers as easy to achieve. The opera singer's training focuses a great deal on not only achieving control but also making that control invisible and inaudible. High notes, for example, should be exciting and thrilling for the observer-auditor, yet must not communicate too much of a sense of risk, and the singer must therefore strike a delicate balance between the potential for failure and the need to show some, but not all, of the sense of the risk of that failure, in achieving the particular phrase or note. For sopranos (and of course, tenors, who also specialise in high pitches) this is the currency of their art, since the so-called 'money notes' for these voice types are their high notes. So we struggle with a paradox, one of many in the singers' art, in attempting to achieve something well enough for it to be lauded, generating a sense of excitement and achievement, while making it seem facile. So that the audience is not disturbed or worried by the risk undertaken, we must communicate a certain frisson of danger without stumbling or making evident the possibility of technical or performative incompetence that would lead to failure. ${ }^{43}$

This sense of the need for control perhaps drives the singer's tendency to talk about 'the voice', that is, the singer's own voice, as some sort of entity outside of herself or himself.

\footnotetext{
${ }^{41}$ Kimberly Steinhauer, Mary McDonald Klimek, and Jo Estill, The Estill Voice Model: Theory and Translation (Estill Voice International, 2017), 26-29; Mary McDonald Klimek et al., Estill Voice Training System Workbook Level Two (Pittsburgh, PA: Estill Voice Training Systems International, 2005), 3. In The Estill Voice Model related terms are used: 'Craft' (Physiology), 'Artistry' (Aesthetics), 'Performance Magic' (Metaphysics).

${ }^{42}$ Eidsheim, 'Maria Callas's Waistline and the Organology of Voice', 255.

${ }^{43}$ Christopher Morris, 'Digital Diva: Opera on Video', The Opera Quarterly 26, no. 1 (1 January 2010): 100-101. Morris comments: "The singer's failure to "pull it off" may tellingly reveal the labor involved, may elicit sympathy. It also, however, generates displeasure that will be eagerly, even ruthlessly, flagged in audience reaction and in the critic's pen [...] Perhaps, in some ways, poor performances throw the successful ones into greater relief, but I doubt that performers willingly test this hypothesis from the negative side, or that audiences actually welcome the cracked high note' (page 100).
} 
Rather than referring to their instrument as their own, a singer will often use a phrase such as 'The voice is a bit rough today', to constitute this other. To speak of their own voice as if it were something other, has resonance with the self-regulation of patients dealing with eating disorders, as described by Hilde Bruch, in which a 'basic delusion, of not owning the body and its sensations' occurs. Bordo points to the division of the body and the self, and 'the triumph of the will over the body' as echoes that 'run deep in our culture'. ${ }^{44}$ It seems clear that for the opera singer the governing of self and willpower over the errant body is a key feature of their agency.

Moreover, for the female singer, these abstractions occur within a context of society's expectations of women alongside the historical social setting of most of the operas she performs. These expectations include, as Bordo describes it, 'the rules governing the construction of contemporary femininity' within which woman is cast as 'chief emotional and physical nurturer'. Discussing the 'female hunger for public power, for independence, for sexual gratification' she points to expectations that in order to achieve such aspects of personal power women must take on 'the "masculine" language and values of that arena self-control, determination, cool, emotional discipline, [sic] mastery, and so on'.45 Such attributes are familiar for singers, since they are in fact attributes they cultivate in order to perform adequately on stage. Callas encountered conflicting pressures related to her weight loss, in which she was both publicly praised for her compliance with the feminine ideal while at the same time her 'loss of voice' was attributed to its effects. ${ }^{46}$ This dissertation applies Bordo's concepts to an examination of the individual vocality of the three singers to pinpoint aspects of their sound and approach that align or resist such conceptualisations of the feminine.

These pressures are reflected in the reception of Te Kanawa as a 'package' of personal physical beauty and vocal beauty, and the focus by reviewers and journalists on Anna Netrebko's physical attractiveness as a slim young emerging star whose model-like looks fit the image of the 'famous for being famous' generation. As we shall see, Netrebko's voice was also held to be beautiful by many at the time of her rise to international stardom, even though her vocality did not necessarily match the ideals of the opera profession. Perhaps this was a conflation of vocal beauty with physical beauty, in other words, the tendency to hear what we see.

${ }^{44}$ Bordo, Unbearable Weight, 147.

45 Bordo, 171.

${ }^{46}$ Eidsheim, 'Maria Callas's Waistline and the Organology of Voice'. 
Effective use of a star's 'image', defined by Dyer as a 'complex configuration of visual, verbal, and aural signs', is integral to the building and maintenance of the diva's star status, and in the case studies, particularly that of Netrebko in Chapter 4, I will consider this complex in the context of the changing forms of mediatisation in the period since Callas. ${ }^{47}$ Over this period the modes of transmission of both the performances of opera and also the mediatised star 'image' of the individual divas have diversified. Overall the trends have been towards greater ease of distribution and higher quality of both the audio and visual elements of performances, and with the rise of the internet, greater ease of connection between the diva and her fans. The complexity of the types and functions of these mediatised distribution platforms has also increased over this period, as has the diversification of the types of technology used within opera, which may also affect our sense of the nature of the performance and of the performer herself.

\section{The Technology of Live Opera}

Any consideration of mediatisation of performance must also examine the question of what constitutes live performance. For some scholars, such as Erika Fischer-Lichte and Peggy Phelan, liveness, which usually entails the bodily co-presence of performers and spectators, is inextricably linked with the performative qualities of an event. ${ }^{48}$ Such views valorise live performance at the expense of the mediatised forms that increasingly form the mainstay of public consumption of classical music and opera. ${ }^{49}$ Phelan and Philip Auslander set up the discourse on liveness in the 1990s through their opposing stances on the intrinsic qualities of live performances versus those consumed or experienced via recorded media.50 For Phelan, once a performance is saved or recorded it 'becomes something other than performance'.51 While she made the case for the audience having a

\footnotetext{
47 Richard Dyer and Paul McDonald, Stars (BFI Publishing, 1998), 32.

48 Erika Fischer-Lichte, The Transformative Power of Performance: A New Aesthetics, trans. Saskya Iris Jain (Routledge, 2008), 38, 50; Peggy Phelan, Unmarked: The Politics of Performance (Routledge, 1993), 146.

49 It is perhaps worth recalling here some of the different ways the term 'live' is used with respect to performances. We commonly use the term 'live broadcast', when the performance is broadcast or aired/livestreamed, at the same time it is being performed to an audience. This can then be extended to the case of a 'live recording' where the video or audio recording was made when the performers were playing to a 'live audience', as opposed to one made through a 'studio recording'. A third form is the 'live' performance which Phelan and Fischer-Lichte valorise, which we experience in person as a member of the audience sharing some portion of a physical space with the performers.

${ }^{50}$ Auslander, Liveness. Live performance is also contrasted in these contexts with any performance that mixes the two forms, such as performance events incorporating recorded media or other technology that modifies the immediate physical presence of the performers involved. Both Phelan and Auslander counted such 'mixed media' events as mediatised.

51 Phelan, Unmarked, 146. Phelan's concept does seem negating: in order to exist as a performance it must be capable of ceasing to exist. This is because, in Phelan's view, any attempt to record, video or otherwise document a performance turns it into 'something other than performance.
} 
sense of liveness and 'authenticity' in such performances, Auslander argued in 1999 that our senses had already been infected and altered by the influence of mediatised performances, and that live performances themselves had been similarly affected, to the extent that the dichotomy pointed to by Phelan had effectively ceased to exist. ${ }^{52}$

Experiencing an opera performance live, as an audience member present within the space with the performers, is certainly different from experiencing a mediatised one, such as an opera viewed on video, or as one of the Met Live in HD broadcasts. I contend, however, that the simple binary of liveness versus mediatised misses important aspects of the performative connection that remain affective for the viewer in a mediatised performance.

Several technological aspects have altered the experience of live opera for modern audiences. The use of surtitles to display the libretto text, or translation, has reduced the live audience's level of reliance on performers' actions to discern meaning. ${ }^{53}$ David Levin, in Unsettling Opera, points to the use of surtitles as revolutionising the staging of operas in the United States, as well as potentially changing the demographics of the audience, providing 'a forced redistribution of aesthetic wealth', in that, through surtitles, all members of the audience now have access to a full understanding of the text. He also suggests that because everyone in the audience now understands the details of the story, the performers have had to adjust their dramatic approach and that 'histrionics front and center, empty posturing, and formulaic gestures no longer suffice' ${ }^{54}$

The increase in understanding afforded by the surtitles can indeed allow for a more 'naturalistic' and less demonstrative style of acting and movement on the stage, since the singers do not need to rely on strong physical gestures to reinforce the meaning of the text being sung. But in a large auditorium, strong gestures and an intense physical stance also draw attention to the soloist, providing for a 'stage presence', which may be of the utmost

\footnotetext{
52 Auslander, Liveness; Fischer-Lichte, The Transformative Power of Performance, 68-69. This discourse is outlined here particularly well by Erika Fischer-Lichte.

53 Marcia Adair, 'Supertitles, Once Denounced, Loom Large in Modern-Day Opera', Los Angeles Times, 19 May 2013, http://articles.latimes.com/2013/may/19/entertainment/la-ca-cmsupertitles-opera-20130519/2. This is in contrast to some earlier historical practices such as the audience's reading of librettos during the opera performance. The standard practice in major opera houses in late twentieth-century prior to the use of surtitles was for audiences who did not understand the language the opera was being sung in to absorb the details of the plot by reading (effectively 'learning') the synopsis prior to the curtain's rising. There was not usually enough light provided in the auditorium during the performance for a programme or libretto to be read. During individual scenes the audience members were reliant therefore on the performers' actions and the affect of their singing to deduce the progression of the plot.

54 David J. Levin, Unsettling Opera: Staging Mozart, Verdi, Wagner, and Zemlinsky (University of Chicago Press, 2008), 51-52. Levin reports that 'Almost every major house in North America has had to adjust its dramatic standards... Given the newfound and ready accessibility of textual meaning, the text is finally being staged; histrionics front and center, empty posturing, and formulaic gestures no longer suffice.'
} 
importance on a stage filled with other performers - the singer may not be identified by the audience as the person currently singing, otherwise. Without the need to make such a strong physical impression, the singers have more freedom to move naturally as performers but may lose this element of 'presence'. Conversely, the director can also take advantage of this increased level of understanding by requiring more stylised movements from the singers that do not relate directly to the text's meaning. In any of these cases this understanding still works to free the performers from the greatly derided 'park and bark' stillness or stock gestures of the 'non-actor' singer, or the energised styles of acting that were needed prior to the arrival of surtitles in order to maintain focus.

Since the time of Levin's writing, the advent of in-cinema 'live transmission' opera performances could be seen to have further democratised the consumption of opera globally. Perhaps the most successful of these ventures has been the Met Live in HD series which can be seen to have caused the dramatic performance of singers to move even further towards a naturalistic style, and has also aimed to increase the audience for the operatic art form. Whether the dissemination of this new mediatised form of the Metropolitan Opera performances has actually been effective in terms of bringing a new audience to opera is still debated, but it seems clear that the Met Live in HD series has been a success financially for the company. 55

Video projection is often used now in opera as an adjunct to extend the existing scenography by projecting images over the physical set. 56 The enlargement of the audience's view of the on-stage action through projection of live-action video, as in many sports games, has not become a regular feature of opera productions. This is not to say that video projection is never used in this way, but such video footage is often prerecorded, rather than being 'live' video that magnifies the current actions of the performers on the stage. ${ }^{57}$

\footnotetext{
55 James Steichen, 'HD Opera: A Love/Hate Story', The Opera Quarterly 27, no. 4 (1 December 2011): 449.

56 Scenographer Joseph Svoboda was already using video as part of his scenography for opera productions as early as the 1970s, but some recent examples of this usage include the 2014 productions of Don Giovanni at Royal Opera Covent Garden and The Turn of the Screw at Glyndebourne Opera. from the same year. Jarka Burian, The Scenography of Josef Svoboda (Connecticut: Wesleyan University Press, 1974); Glyndebourne, Insight into The Turn of The Screw, accessed 24 June 2018, https://www.youtube.com/watch?v=2LiA8G5F15k; Royal Opera House, Don Giovanni Trailer (The Royal Opera), accessed 24 June 2018, https://www.youtube.com/watch?v=09CaqCLG8tc.

${ }^{57}$ One example of this type of usage in opera is in the Robert Lepage production of La damnation de Faust at the Metropolitan Opera in 2008, at the beginning of the aria 'D'amour, l'ardente flamme' Marguerite is alone centre stage. Fast Company, Robert Lepage's 'La Damnation de Faust': Opera in the Age of Windows [PART 2], accessed 1 August 2018, https://www.youtube.com/watch?v=lAyqWwk52w8.
} 
The audience's aural experience of the live performance is enhanced in many major opera venues, however, often without their knowledge. This technology is usually termed 'sound enhancement', or 'acoustic enhancement'. A vehement resistance to the use of any form of sound amplification within the opera house is frequently voiced by opera critics who hold it to be an anathema to the fundamental concept of opera. 58 This opposition to its use leads opera companies to maintain a level of secrecy about it that seems to be rarely penetrated by the public media, but in fact such technology is used in a number of notable opera houses. ${ }^{59}$ Its usage in the opera house usually involves a low-level amplification of the existing 'live' sound that goes out to the audience seated within the venue. Because of the value placed on singers' acoustic projection of their own sound in opera, and the personal quality of their timbre and tone produced by them, the technology tends to be used only to ameliorate poor acoustics, rather than being a replacement for the singers' own projection. ${ }^{60}$ The idea is to bring the sound level and clarity up to that of the best auditoria, for all the seats in the house, but it is done by adding to the existing acoustic sound the singer and orchestra produce, rather than replacing it with the sound emanating from the speaker system. Its effect is intended to aid both the clarity of the words, and the audience's ability to clearly perceive the timbre of the singer's vocality, but it may also at times affect the quality of the vocal timbre heard by the listener.

\section{The Influence of Recorded Opera}

The influence of audio recordings on audience expectations for live performances of classical singing, while difficult to trace empirically, would seem to have had an effect over the past decades since the introduction of high-quality recordings in the 1950s. Such recordings were able to provide listeners with a level of audibility and clarity that until the arrival of acoustic enhancement technology was not always available in live performance, due to factors such as the size and acoustic qualities of the venue, the singer's projection or their quality of vocal tone. Moreover, the accuracy and virtuosic achievement of singers

\footnotetext{
${ }^{58}$ Fred Plotkin, 'In Opera, There Is No Such Thing as a Magic Mike', WQXR, 16 July 2013, http://www.wqxr.org/story/306794-opera-there-no-such-thing-magic-mike/; Anthony Tommasini, 'Wearing a Wire at the Opera, Secretly, of Course', The New York Times, 28 June 2013, sec. Music, https://www.nytimes.com/2013/06/30/arts/music/wearing-a-wire-at-the-operasecretly-of-course.html.

${ }^{59}$ Opera houses and companies which use or have used 'sound enhancement' technology include Aotea Centre in Auckland, New Zealand; The Festival Theatre in the Adelaide Festival Centre, Adelaide, Australia; The New York City Opera, New York State Theatre (as noted by Fred Plotkin); Staatsoper, Berlin (mentioned on the E-Coustic Systems website) Plotkin, 'In Opera, There Is No Such Thing as a Magic Mike'; 'E-Coustic Systems - Opera \& Ballet', accessed 25 January 2018, http://www.ecousticsystems.com/applications.

60 'E-Coustic Systems - Opera \& Ballet'.
} 
in features such as runs and high notes are not variable in these recordings in the way they can be in live performances, and a recorded performance can be listened to multiple times. Some listeners who are used to experiencing opera via recordings may miss this enhanced sense of intimacy, which the closeness of the singer to the microphone transmits. The lack of control over the repetition of the performance may also be felt by some listeners as a disadvantage when they attend a live performance. This is perhaps what the opera lover Renaud is referring to in his interview with Poizat when he says he still prefers recordings to live performances and is 'yet to see a performance I really like', since Renaud's experience of opera at that stage had consisted mostly of listening to records. ${ }^{61}$

The qualities of intimacy and immediacy provided by audio recordings were also attributed to television and identified as the qualities that 'enabled it to displace live performance'.62 Television broadcasts of operas began to be produced in Italy from the early days of television, and other countries followed this trend. By the 1980s full opera productions were regular features on the small screen in Britain and elsewhere, and had an important effect on the spread of opera to a wider audience. The more ubiquitous, and arguably more successful mode for opera's dissemination for private home consumption through most of the twentieth century, however, was via audio recordings. ${ }^{63}$ The different level of intimacy provided by audio recordings and the spread of opera to new audiences who became used to viewing opera on television with subtitles, combined with the rise of the use of surtitle projections in live opera, can be seen to have influenced both audience behaviour and audience expectations. The use of technology such as video projections, the rise of audiovisual recordings and the 'live transmission' of opera performances since that time constitutes a blurring of the boundary between 'live' and 'mediatised' performance, as pointed to by Auslander.

Another way that the boundary between the live and the mediatised is blurred in opera is to do with Auslander's proposition that live performances now tend to emulate the styles

\footnotetext{
61 Poizat, The Angel's Cry, 14.

62 Auslander, Liveness, 32.

${ }^{63}$ Emanuele Senici, 'Opera on Italian Television', in Opera and Video: Technology and Spectatorship, ed. Héctor Pérez (Bern; New York: Peter Lang AG, Internationaler Verlag der Wissenschaften, 2012). Senici's informative chapter explains how opera was broadcast on television in Italy in the 1950s using a pre-recorded audio track to which the same singers lip synched in a staging of the performance done within a television studio. Later in the twentieth century the television productions were much better developed, not only in Italy, but in the United Kingdom and other countries, as well as the operas filmed 'on location' which were successful at the box office, including Joseph Losey's film of Don Giovanni, and Franco Zeffirelli's La Traviata.
} 
of mediatised ones. ${ }^{64}$ When considering the performance styles of the 'made for broadcast' Met Live in HD operas and comparing these with similar productions from other houses or those seen prior to the introduction of this series, it does seem that the performers have modified their onstage behaviour to fit with expectations of fully 'naturalistic' acting as is the norm for television drama and film. As noted earlier, the introduction of surtitles had already allowed for more naturalism in operatic acting. However, there has been a further development in the operatic acting style which has been linked to the 'live transmission' series and its production values, as well as the intimacy of the 'close up' shots employed for these broadcasts to large cinema screens. ${ }^{65}$

The performance styles used for opera in visual mediatisation today can also be seen to have evolved from the seminal developments in films of operas made in the 1970s. Jaume Radigales points to Joseph Losey's very popular 1979 film of Don Giovanni as one of the most successful in terms of the development of cinematic style at the time, with what Radigales calls a 'narrative conception of editing'.66 The cast was a group of renowned singers, but it was perhaps Kiri Te Kanawa, who played the role of Donna Elvira, who made the biggest impression on the public. The film had a significant impact on both her fame and in terms of connecting the general public with opera as an art form, since it was so successful at the box-office. For this film Losey moved away from showing the performance confined within the internal spaces of a theatre, instead placing the performers 'on location' both out of doors and within other realistic settings. Radigales suggests that, as well as combining the different modes of cinematic and operatic visual presentation, employing shooting techniques such as camera zoom and pan, this film was one of the first to successfully negotiate the difficulties of the cinematic expectations of verisimilitude with respect to both acting styles and the performers' lip-synching. ${ }^{67}$ This question of the successful negotiation of 'naturalness', as can be seen to have been achieved within this film, despite the constraints set up by the lip-synch process itself, is

\footnotetext{
${ }^{64}$ Auslander, Liveness, 91.

${ }^{65}$ Lincoln Center, Matthew Polenzani: Beyond 'Park and Bark', 2014, https://www.youtube.com/watch?v=ezJUCYBaQtE. Metropolitan Opera star Matthew Polenzani comments on the experience of the 'new generation of singers' in terms of acting and physicalisation of the drama 'with our bodies as well as our voices'. A discussion and analysis of the effect of cinematic style on the singers in the Met Live in HD movies and 'reworkings of film grammar and technological evocations of affect and sensation' can also be found in Kay Armatage, 'Cinematic Operatics: Barbara Willis Sweete Directs Metropolitan Opera HD Transmissions', University of Toronto Quarterly 81, no. 4 (21 November 2012): 909-27.

${ }^{66}$ Jaume Radigales, 'Playback Problems When Filming Opera for the Screen: Two Case Studies', in Opera and Video: Technology and Spectatorship, ed. Héctor Pérez (Bern; New York: Peter Lang, 2012), 120-23, 126. Another important opera film from the time, Ponnelle's Le nozze di Figaro, also with Te Kanawa in a leading role, is also considered by Radigales (page 118).

${ }^{67}$ Radigales, 117.
} 
key to my consideration of the values and expectations around the presentation of operatic singing throughout the period from Callas to Netrebko. I will return to this question of naturalness in later chapters, including within the context of my personal experiences of the Met Live in HD movie broadcast versions and 'live' performances at the Metropolitan Opera in the Netrebko chapter.

The potential influence of audio recordings and online videos on live performances is also significant. This aspect of mediatisation is likely to have an impact through the imitation of vocal tone and vocality by singers, either intentionally or unconsciously. Humans are one of the few species with the ability to imitate vocal sounds made by others and this is foundational to our socially learned linguistic communication. ${ }^{68}$ The imitation of timbre under the influence of audio recordings is one application of this innate human ability and an important one for vocal pedagogy and the development of vocal arts in the operatic community as a whole. The individual vocal tone (signature vocality) developed by each singer and the expressive changes made by singers to communicate emotion and meaning are affected by the influence of other singers as well as the training received from singing teachers and vocal coaches. This means that each singer's individual tone is not a given, but is crafted and developed in response to cultural and aesthetic expectations to which they are exposed. Vocality, therefore, must be considered within a cultural context, even if this is the internationally distributed culture of western classical opera. The potential of such aural influence on the vocal fashion and the aesthetics of operatic sound over the past half century is something I consider more fully within the case studies of each of the three singers.

Along with videos, audio recordings of music also need some reconsideration in terms of their categorisation as performances. Fischer-Lichte's concept of the performative as necessarily involving the bodily co-presence of performers and audience, with its inherent 'relationship of influence' does not fit easily with my own experience as a recording artist, nor as a listener when it comes to recordings. Fischer-Lichte identifies the special relationship she is referring to as an 'autopoietic feedback loop', an exchange of affect and influence between the audience and performers which gives rise to the special quality of a 'live' performance. ${ }^{69} \mathrm{Her}$ placement of the 'live performance' in opposition to recorded performances disregards the circumstances under which studio recordings of classical music actually take place, and I suggest a more nuanced perspective on recorded

\footnotetext{
68 José Z. Abramson et al., 'Imitation of Novel Conspecific and Human Speech Sounds in the Killer Whale (Orcinus Orca)', Proc. R. Soc. B 285, no. 1871 (31 January 2018): 20172171.

${ }^{69}$ Fischer-Lichte, The Transformative Power of Performance, 38.
} 
performances of opera is needed. Bodily co-presence is important in opera and concerts in a similar way as it is for theatre and other performing arts, since, as performers we 'feed off' the energy provided by the audience's responses. In a studio recording artists do have a real audience, in the form of the producers who are present with them in the studio, and the artist interacts with them as they perform for the recording, creating what is in effect a 'live performance' even though it is being recorded at the time. If tested by Fischer-Lichte's definitions, such a studio performance of classical music therefore involves 'production' and 'reception' and a self-referential feedback loop. ${ }^{70}$ There may be a difference for the person listening to the final version of a recording, who may expect that it to be a perfect performance, where nothing will 'go wrong', since all mistakes will have been edited out or replaced with a better take. But in the studio, while each 'take' of the recording may later be replaced by another, the nature of the recording process means that the performers must strive for each take to be the best of the session. Each take is therefore being experienced 'live' within the studio. There is intense focus on it being done well, and an autopoietic feedback loop is in place.

Fischer-Lichte's concept of liveness involving a relationship of influence is also problematic when it comes to the experience of the listener and/or viewer of a mediatised performance. From my own experiences viewing YouTube videos of opera, and the experiences pointed to by the online comments of others, such as those noted by Clemens Risi in 'The Diva's Fans', it is clear that these forms of mediatised performances can be very affecting. ${ }^{71}$ For example, while researching opera items on the YouTube platform for this research project, I soon found I became engrossed in the experience of viewing the videos themselves. Even though the sound quality of my laptop was not very good, I still responded intensely, at least in a comparative way, to the tone quality and colour of the vocal production of each of the different artists, and I found myself engaged emotionally, musically and intellectually. Perhaps it may be significant that all the performances I watched in that sitting were 'recorded live' as performances in front of a paying audience. The events in this case (which included concerts given by the singers Kristen Chenoweth and Jessica Pratt) were all ones where the audience and performers were sharing the same venue, giving the 'bodily co-presence' that Fischer-Lichte gives as a pre-requisite for the transformative power of performance. She suggests that such power comes from the feedback loop between and within performers and spectators, which makes the transformation it can provide 'a fundamental category of an aesthetics of the

\footnotetext{
70 Fischer-Lichte, 38.

71 Clemens Risi, 'The Diva's Fans: Opera and Bodily Participation', Performance Research 16, no. 3 (1 September 2011): 49-54.
} 
performative'. ${ }^{72}$ While the experience of recorded media may not be the same as hearing it live in a venue where one shares the space and acoustic with the performers, I do not see how we can summarily discount mediatised versions and treat them as something other than performance, as Phelan has proposed. ${ }^{73}$

If a mediatised performance provides for the same sort of affective impact on viewers as a live audience experiences, even if not at the same level of intensity, then the mediatised version of the performance must still be 'performative' and should be acknowledged as such. My use of the term 'performative' in this sense is related to John Austin's original application of the term. When the words and/or actions of the performer are intended to have an effect on the audience members, and are successful in doing so, surely the performative effect is occurring, whether it is happening within a reciprocal relationship or not. ${ }^{74}$

Opera as a genre has traditionally included such autopoietic or interactive performative elements. Indeed, in the case of 'number' operas, where the music comes to a complete stop at the end of each aria or ensemble, before the next number starts, audiences expect to be involved in many moments of applause or ovation during the performance and this constitutes their main form of feedback to the performers during the course of the work. This sets up a structured feedback loop that is perhaps more tangible in a large opera house than the more subdued audience responses that might be able to be transferred to the stage within a smaller venue. Fischer-Lichte also identifies what she calls 'moments of enchantment' as key performative effects, and these are plentiful in operatic performances, as are Jill Dolan's related 'utopian performatives', both of which are said to provide 'a sudden deeper insight into the shared process of being in the world.'75 Although opera may have held to the traditions of semiotic performance styles much longer than other forms of theatre, the specifics of the on-stage behaviour of opera's singer-actors and

\footnotetext{
72 Fischer-Lichte, The Transformative Power of Performance, 38, 50.

${ }^{73}$ Phelan, Unmarked, 146. Phelan asserts here that once a performance is documented or recorded it 'becomes something other than performance'.

${ }^{74}$ Paul Allain and Jen Harvie, The Routledge Companion to Theatre and Performance, 2nd edition (London; New York: Routledge, 2014), 222.

75 Fischer-Lichte, The Transformative Power of Performance, 9; Jill Dolan, Utopia in Performance: Finding Hope at the Theater (University of Michigan Press, 2005), 5. The term 'utopian performatives' is used by Dolan in her book Utopia in Performance to describe those 'small but profound moments in which performance calls the attention of the audience in a way that lifts everyone slightly above the present, into a hopeful feeling of what the world might be like if every moment of our lives were as emotionally voluminous, generous, aesthetically striking, and intersubjectively intense.' Clemens Risi also writes about his experience of such moments in Neuenfel's production of Verdi's Nabucco in his article Clemens Risi, 'Swinging Signs, Representation and Presence in Operatic Performances: Remarks on Hans Neuenfels, Jossi Wieler, and a New Analytical Approach', Arcadia 36, no. 2 (2001): 363-73.
} 
their 'in-the-moment' evolution of expressive tone and vocality continue to be affected by audience responses, generating and perpetuating the performative autopoietic feedback loop. In the Western countries where I have attended opera performances, formal or informal codes of conduct dictate much more muted audience responses than might be expected in other types of events such as comic plays, or in a circus act or a performance art work that is based around some specific type of audience participation. ${ }^{76}$ Even though audiences attending classical music events are not expected to vocalise their responses or make them otherwise audible except within designated time periods such as at the end of a section, aria, or work, Fischer-Lichte's autopoietic feedback loop certainly exists in live opera performances.

If we can also experience Dolan's 'utopian performatives' when viewing video recordings or listening to audio recordings, as I have, then surely it must be granted that these performances are having a performative effect. The fundamental difference when these are compared to a live event is that the feedback loop which exists as an unbroken circle in live performances is not able to be completed in recorded or broadcast performances. The 'break' in the loop is only in the return of feedback from viewers/auditors to the performers. I contend that this feedback loop is still functioning in such situations, even if it does not form a completed circle. I think of this as an incomplete autopoietic feedback loop. An appropriate metaphor for this effect would be the horseshoe-shaped magnet: while there is physical connection between all points within the magnet itself, the 'ethereal' connection between its end points is still operating even though it may be invisible. This incomplete loop or horseshoe may include feedback interactions within the recording studio, or within the auditorium for a live recording, and can include interactions between audience members if the viewing is shared or it is a broadcast or presentation in a cinema. Interactions between audience members can also occur via online comments on a platform such as YouTube, as noted by Risi, a situation dubbed 'online liveness' by Nick Couldry. ${ }^{77}$ I argue that if the audience experience is that of a

\footnotetext{
76 This expectation of silence applies also to orchestral concerts and various other performance genres, such as ballet. Of course such silence remains in complete contrast to earlier audience behaviour at such performances prior to the Romantic era, and the change from rowdy socialisation to hushed expectation has been documented by authors such as James Johnson: James H. Johnson, Listening in Paris: A Cultural History, vol. 21, Studies on the History of Society and Culture (University of California Press, 1995). Also of relevance are Benjamin Lumley's reminiscences as director of Her Majesty's Theatre, London, in particular his descriptions of audience behaviour such as that on page 63 re the so-called 'Fop's Alley' whereby the fashionable male patrons of the opera would move to the aisles of the stalls and 'lounge, chatter, eye the boxes from convenient vantage points, and likewise criticise and applaud in common.' Benjamin Lumley, Reminiscences of the Opera (Hurst and Blackett, 1864), 63.

77 Risi, 'The Diva's Fans'; Nick Couldry, 'Liveness, "Reality," and the Mediated Habitus from Television to the Mobile Phone', The Communication Review 7, no. 4 (1 October 2004): 353-61.
} 
performance, such viewing instances must also be regarded as performances. Phelan's implication that a recording of a performance necessarily 'becomes something other than performance' serves to undermine our regard for mediatised performance and its importance. ${ }^{78}$ I therefore classify the viewing of mediatised performances as instances of performance within this dissertation.

\section{The Emergence of Voice}

The turn in musicology in the late twentieth century to more detailed considerations of performance in general and opera performance specifically, encourages the posing of fundamental questions about the opera singer's art. ${ }^{79}$ While on the surface the performative focus challenges the traditional emphasis on the situating of the work's meaning primarily with the composer and his or her score, authorship remains central to the consideration of performance, and its location has been extended from composer to director or conductor. The perspective of the spectator and the opera fan is increasingly taken into account in scholarly work around opera, with studies by authors such as Claudio Benzecry and Clemens Risi as well as Poizat's influential text. ${ }^{80}$ The contribution of the singer, on the other hand, is less likely to be acknowledged as part of the authorial and creative process: indeed, as discussed by authors such as Abbate, the singer's work has been regarded as servile to the point of nullification, with the aim of the singer suggested by Poizat to be 'the dissolution of incongruity between singer and role'. ${ }^{81}$

The implication is problematic to me as a singer, to imagine that in every aspect of my performance I am necessarily only 'following orders' or even attempting annihilation of my self and, moreover, that what I contribute to the performance in terms of imagination and sheer physical creation of sound does not 'count' as creative agency. I do regard my

Couldry's example involved members of support groups chatting or leaving messages online for each other, creating a sense of social co-presence. This refers therefore to a decentralised liveness, as opposed to a centralised 'live' broadcast experienced by many people online at the same time. Couldry was writing in 2004 before the rise of YouTube from 2006 on, but this term is certainly applicable here.

78 Phelan, Unmarked, 146.

79 This performative turn and other changes in musicology over this period are outlined by Nicholas Cook in, for example: Nicholas Cook, 'We Are All (Ethno)Musicologists Now', in The New (Ethno)Musicologies, ed. Henry Stobart (Rowman \& Littlefield, 2008); Nicholas Cook, 'Music as Performance', in The Cultural Study of Music: A Critical Introduction / Edited by Martin Clayton, Trevor Herbert, Richard Middleton. (New York: Routledge, 2002), 204-14.

80 Poizat, The Angel's Cry; Claudio E. Benzecry, The Opera Fanatic: Ethnography of an Obsession (Chicago: University of Chicago Press, 2011); Risi, 'Swinging Signs'; Clemens Risi, 'Opera in Performance-In Search of New Analytical Approaches', The Opera Quarterly 27, no. 2 (2011): 28395; Risi, 'The Diva's Fans'.

81 Carolyn Abbate, In Search of Opera (Princeton University Press, 2001), 50-53; Poizat, The Angel's Cry, 35. Poizat asserts that 'The mission of the [singing] artist on the [opera] stage is, in a sense, to approach self-annihilation as a subject in order to offer himself or herself as pure voice'. 
work as a singer as creative, perhaps because as a practitioner I am able to recognise the amount of thought and decision-making that goes into the production of every note, as well as the imaginative choices and decisions made by the singer about the physicalisation and embodiment of a character for on-stage performances. It is clear to me that this is a creative process that is used to realise an expressive goal, even if part of the process may be 'intuitive' or habitual, since not all of the details of vocal production will always be directed fully consciously by the singer. This is where a consideration of the choices available in terms of vocality, and the agency of singers in the production of vocal sound, may be able to contribute to the performative study of the discipline. To investigate these issues from the standpoint of a (female) singer thus offers a new perspective.

My study lines up with what Heather Hadlock has described as the 'move away from studying representations of "the feminine" and toward studying women as performers both in history and in the contemporary opera world', and therefore is a part of a subfield 'diva studies' which she proposes as a site 'where feminist theory and women's history intersect'.82 A large part of the period that my study covers retains the predominantly male-authored discourse she describes as providing methodological challenges for such studies, as the music critics whose reviews are included in the study are almost exclusively male, as are the composers of the majority of works still presented in major opera houses. ${ }^{83}$ However, I am treating this research project as an opportunity to consider how assessments of the female performer from the point of view of the male gaze provide a window to underlying attitudes about female singers and their vocality and agency. My study will reconfigure the binarism pointed to by Hadlock in showing how 'masculine' values of coolness of emotion and self-control figure in the agency of the female singer. ${ }^{84}$

Alternative approaches to the study of the performative in opera which make use of the personal experience of the individual spectator or fan point out that attraction, and fan attachment to singers and divas in particular, is not necessarily about voices as such, but rather about the way this is integrated into what we perceive as their persona. ${ }^{85}$ Wayne

\footnotetext{
${ }^{82}$ Heather Hadlock, 'Opera and Gender Studies', in The Cambridge Companion to Opera Studies, ed. Nicholas Till (Cambridge University Press, 2012), 269.

${ }^{83}$ Hadlock, 270. It is not true that all opera composers are male, of course: there have been many female composers writing opera from the twentieth century on, and some, such as Louise Bertin who had works performed in the nineteenth century. Likewise, the male critics also review male singers, but my interest for this study is in the female singer specifically.

${ }^{84}$ Bordo, Unbearable Weight, 171.

${ }^{85}$ Cavicchi, 'Loving Music: Listeners, Entertainments, and the Origins of Music Fandom in Nineteenth Century America', 238; Poizat, The Angel's Cry, 8-28.
} 
Koestenbaum describes the concept of the diva, stating it is 'a specific female role (a woman opera singer of great fame and brilliance), but it is also a pliant social institution, a framework for emotion, a kind of conduct, expectation, or desire, that can move through a body that has nothing to do with opera, that can flush the cheeks of a nonsinging, nonperforming body, a body called "private" because it does not depend on being seen or heard.'86 Koestenbaum's in-depth consideration of how the object of his fancy, and his fantasy, the diva, affects him, gives many insights into the relationship of fan to singer and has been considered by a number of other authors. While such works provide us with important insights, and are helpful in countering the privileging of the authorial perspective, we might also gain new understanding as singers and as fans or scholars, if we consider this relationship from the singer's point of view.

The complexity of the area which is my interest is not only about the viewpoint of the spectator: it is also about producing the sound, and the singer's activity in making for the success of the event, that is, in creating performances. The making of good connections with fans and audience may be the test of the success of a performance; however, the fundamental aspect I wish to explore is found within the singer's approach, and provides an opportunity to think about what the singer's perspective in relation to this new discourse might offer in terms of methodological perspective.

Given the importance placed on a distinctive timbre and vocality by singers, it is perhaps surprising that to date this has been so little studied in the academic realm. The increasing interest in voice as a focus for study calls for an expansion of the methodological toolset that can explore this type of detail in a more meaningful way than existing tools such as spectrographic analysis provide for. Discussion of these aspects and some possible new approaches are covered by Martha Feldman and others in articles such as 'Why Voice Now', including Steven Rings' article in which he identifies the analysis of vocal individuality and timbre as 'one of the central challenges' in the study of the singing voice. 87 The conversation around the processes of vocal production and vocal performance within the context of the operatic diva and the mediatised effects on her vocality is one that I am able to contribute to from my viewpoint as an experienced singer and singing teacher. This understanding of vocal technique and the approach of singers to vocality in

\footnotetext{
${ }^{86}$ Koestenbaum, The Queen's Throat, 111.

87 Martha Feldman et al., 'Why Voice Now? The Interstitial Voice: An Opening; Demo's Stutter, Subjectivity, and the Virtuosity of Vocal Failure; Analyzing the Popular Singing Voice: Sense and Surplus; The Model Voice; Voice Belongs', Journal of the American Musicological Society 68, no. 3 (1 December 2015): 653-85; Steven Rings, 'Analyzing the Popular Singing Voice: Sense and Surplus' in 'Why Voice Now', Journal of the American Musicological Society 68, no. 3 (1 December 2015): 66371.
} 
performance opens up new possibilities for research, which fall under the newly emerging discipline of 'voice studies'. This dissertation explores and develops a new avenue of approach to this issue, and in the following section I outline the theoretical basis for my analysis of the vocality of each of the singers in my case studies, which forms a foundation for my research.

\section{Methodology}

[W] know, when we think about it, that voices are culturally constructed. Voices are always performances of a relationship negotiated between the individual vocalizer and the vocalizer's culture. (Suzanne Cusick) 88

For the modern diva, the relationship Cusick refers to, between the singer and the culture that surrounds her, includes a globally situated audience that may experience her vocality through different media, and respond to it in different ways. In the case of the three divas in my study, the effectiveness of their performances when carried by a variety of media forms is widely recognised. I consider how these singers have made use of vocal tone and vocality in the building and sustaining of their 'divadom', and analyse their choices in their interaction with the development of new media technology since the 1950s. While the finding of intention is always difficult to prove or define, by focusing on the process of performative vocal production, the question of managing vocal tone and vocality in a variety of contexts inevitably focuses on specific technique (i.e., that always must be learned and managed consciously), in the process throwing new light on aspects of vocal pedagogy and diva studies.

Existing theoretical foundations in the musicology of opera, diva and fandom studies allow for the singer and their effectiveness, or the nature of their affect, to be studied from the outside. My approach combines this with a viewpoint from the inside (as a singer), to incorporate an understanding of praxis with the study of external effects and attitudes. By this integration of existing approaches with singing teaching theory and practice (vocal pedagogy and voice science) it is possible to investigate aspects of the nature of performativity in opera, specifically in terms of a detailed analysis of the performative actions made use of by opera singers. The examination of the singers' careers, training and background, and their personal statements about the performative aspects of opera singing within my three case studies also allows me to consider the influence of the

${ }^{88}$ Suzanne G Cusick, 'On Musical Performances of Gender and Sex', in Audible Traces: Gender, Identity, and Music, ed. Elaine Barkin and Lydia Hamessley (Zurich ; Los Angeles: Carciofoli, 1999), 29. 
increasing mediatisation of opera and the values around operatic voice on the ways such performative actions have been constructed over this period.

Promoting the understanding of signature vocality as a key element of vocal performance, and of vocal 'presence', which encompasses a meaningful degree of power, is a fundamental part of my motivation in undertaking this study. An understanding of such aspects is of particular importance to classical singers and their teachers, who endeavour to find or enhance the elusive sonic quality that will satisfy both the desire for individual expressivity and the need to conform to accepted traditions of vocal operatic sound and tonal effects. Outside of singing practitioners, the creative processes underlying the production of vocal sound are in general poorly understood or appreciated and even downplayed. Therefore, part of my research aim is to raise awareness of these attitudes through a critical approach to the reception of the opera performer's art.

Drawing on methods used in vocal pedagogy I offer here an investigative model based on the analysis of each singer's vocal tone in relation to the method of its production, to build up a definitive description of her vocality. This analytical method utilises an existing model of vocal processes to reconnect perceptions of specific timbres with explicitly defined techniques for their production. The underlying foundation of my analysis of the vocality of each of the case study singers in this dissertation lies in accepted bel canto concepts, but the theoretical framework I have used for processing the aural information is derived from voice science research. The terminology and the analytical processes I have used derive from the diagnostic use of the Estill Voice Training System and Estill Voice Model. ${ }^{89}$ This approach also has similarities to other analytical processes for determining the nature of vocal sounds and qualities in a diagnostic sense, such as the Vocal Profile Analysis protocol developed by John Laver for use by speech therapists. ${ }^{90}$

${ }^{89}$ Steinhauer, Klimek, and Estill, The Estill Voice Model; Mary McDonald Klimek et al., Estill Voice Training System Workbooks (Level One \& Two) (Pittsburgh, PA: Estill Voice Training Systems International, 2005). The Estill Voice Model is based on the long term research into the vocal mechanism conducted by Johan Sundberg, William Vennard, Ingo Titze, and other voice science luminaries, as well as Jo Estill and her associates.

90 John Laver, a phoniatrician, developed the VPA diagnostic protocol, which has been used extensively within the United Kingdom by speech therapists (speech-language pathologists). This protocol identifies voice qualities by relating perceived sound to the physical positioning of the voice apparatus in habitual 'settings' of the vocal tract, which in Estill terminology would be termed 'attractor states', and also for perceptual analysis of vocal problems. For more details see: John Laver, 'Phonetic Evaluation of Voice Quality', in Voice Quality Measurement, ed. R. D. Kent and M. J. Ball (San Diego: Singular, 2000), 37-48; Paul Carding et al., 'Formal Perceptual Evaluation of Voice Quality in the United Kingdom', Logopedics Phoniatrics Vocology 25, no. 3 (1 January 2000): 13338; Brad H. Story, 'Modification of Emotional Speech and Voice Quality Based on Changes to the Vocal Tract Structure', in Emotions in the Human Voice (Vol 1), ed. Krzysztof Izdebski (San Diego: Plural Publishing, 2008). 
The Estill voice training model links specific vocal qualities (timbres or other sound qualities) with their underlying physiological or 'technical' actions. While this can be used by singing teachers for training singers in the production of specific vocal qualities which will enhance their range of vocal colours (tonal palette), it is also possible to use it in the reverse direction, in order to identify the physical production from the sound heard. ${ }^{91}$ This is possible because of the mainly one-to-one correspondence of each quality with the physical actions needed for its production. The person making that link needs to be cognisant of the characteristics of the particular sound of each vocal quality as identified by the Estill Model in order to accurately connect this sound quality with the physiological process used for its production. This makes it possible to identify how particular vocal sounds have been made solely through the perception of the sound produced. In practical usage, an embodied cognition, in which the perceiver is familiar with the method by which the sound qualities are able be produced, and able to create the same sounds accurately, enhances the perceiver's ability to correctly identify both the sound made and the method used to produce it.92 This process, it is important to note, does not require the perceiver to be able to see the person as they produce the sound, nor to be co-present with them in the same space, so such analyses can therefore be done using audio recordings only. In cases where more than one possible production method could produce a particular vocal quality, the ability to physically reproduce or attempt to reproduce the particular sound being heard enhances the analyst's ability to pinpoint the probable physiological process being used.

Using this method it is possible for a voice teacher, or other voice professional who has been trained in the process, to identify or 'diagnose' the qualities of sound being made with a high degree of accuracy. It also provides descriptions of individual elements of vocal sound, which are able to be reproduced by singers by generating the physiological actions associated with more than one of the qualities at the same time. Using my experience as a university voice lecturer who utilises these concepts in singing teaching on a daily basis, and my own understanding of these technical aspects from my training through the Estill system, I analyse qualitatively the specific aspects of vocality that are

\footnotetext{
${ }^{91}$ It is also useful in singing teaching to be able to diagnose vocal production issues from the sound quality heard, and so this is also an important use of the Estill Voice Model in practice.

${ }^{92}$ In this case, the perceiver (listener) would most likely use 'mirror neurons' to silently, or audibly, reproduce the same actions as the person who is vocalising. Mirror neurons remain a controversial area of research, but one that has sustained interest, and application to many areas, of which this is one.
} 
evident in particular vocal recordings of the singers within this study. ${ }^{93}$ I am using the Estill concepts as a methodological tool here in the same way as I use them when teaching singing to voice students. There is no conflict of 'method', since the Estill concepts are not part of a singing method in the vein of earlier pedagogical approaches, but are merely tools, which can be used analytically by any teacher or singer as part of the process for achieving particular sound qualities. My approach involves the recognition of voice as an intrinsic part of the make up of the singer's body, which is therefore subject to a host of power politics and dynamics, and to complex cultural and historical values and attitudes. So the body-voice-person is considered within all these contexts as intrinsic to the study of voice, or, more properly, of singing. ${ }^{94}$

For the case study of each singer I have made an in-depth analysis of their signature vocality through repeated listening to a set of recordings, chosen as representative of their prime, using recordings made by them soon after their rise to international stardom. The specific recordings used are outlined within each chapter, and in each case I used studio recordings, as released on compact disc, that were associated with their success within that period of their career. I played these on the highest quality audio equipment available to me, and I listened to all of them using the same equipment to ensure the best possibilities for comparison of the vocal qualities involved. Where possible I compared various remastered versions of the same recordings to check for changes in the quality that might affect my judgement of the sound.

Alongside this analysis of each singer's vocality I consider their critical reception around the time of their early international success. To do this I examine reviews written by the recognised music critics writing for the established media relevant to that place and time. Journalistic reviews are one of the few lasting ways in which views about performances have been openly expressed both in this period and historically. While many performers dislike having to deal with these publicly distributed critical responses, the reviews provide a valuable resource of written assessments, and since they were typically written

\footnotetext{
93 I have completed two Level One \& Level Two courses and one Level Three course in the Estill Voice Training System within New Zealand over the period 2009-2015, with Vanguard Practitioner Paul Farrington as the lead Course Instructor, as well as a one-day 'Estill for Singing Teachers' course at the Royal Academy of Music in London, England in 2007.

${ }^{94}$ Recent research that utilises some aspects of my approach, but used for different applications and aims, include that of Kate Heidemann and Nina Sun Eidsheim, who describes her approach in one study as 'critical vocal organology'. Zachary Wallmark's research on the appraisal of timbre also has relevance. Heidemann, 'Hearing Women's Voices in Popular Song'; Eidsheim, 'Maria Callas's Waistline and the Organology of Voice'; Zachary Wallmark, 'Appraising Timbre: Embodiment and Affect at the Threshold of Music and Noise' (Dissertation, University of California, 2014).
} 
within days of the performance itself, they provide a platform for sharing the individual impressions of the writers while those impressions were still newly formed. While reviewers' opinions are necessarily subjective, written evaluations of this kind can provide useful insights into particular performances and performers, and the culturally constructed attitudes that influence the critics' evaluations, which in turn may influence their readers. ${ }^{95}$

My approach for this aspect of the study is based on the principles of critical discourse analysis. Discourse analysis has been described as an approach that examines 'patterns of language across texts as well as the social and cultural contexts in which the texts occur', and which allows us to consider ways 'the use of language presents different views of the world and different understandings' and how these are constructed through the discourse. ${ }^{96}$ The way a writer frames the presentation of the information, or the type of language they use, not only affects our impression and understanding of the topics discussed and can have such influence that a particular social 'reality' can begin to exist that did not exist before. This reflects a social constructivist view of discourse in that the language that is used is seen as shaping our concepts of the information given and effectively constructing a particular reality. ${ }^{97}$

For this study I focus on the London and New York reviews of the three singers in order to retain a sense of parity in terms of the expectations around styles of writing and the cultural and social background that may impact the content of the reviews. Each of the case study singers made important debuts at the Royal Opera Covent Garden in London, either as their first international success or close to the time that that international success began, and each of them also had significant success at the Metropolitan Opera in New York. This makes the focus on reviews from London and New York particularly relevant in terms of these singers. The descriptions of the singer's vocality made by each of the music critics in these reviews provide additional information for comparison to my own analyses of the vocality of each singer. I have included excerpts from the set of

\footnotetext{
${ }^{95}$ Because of these issues, and their own personal experiences of them, some singers choose not to follow the published reviews of their own performances. This choice is understandable given the fact that singers provide their own body as their instrument and any criticism of the playing of that instrument is therefore likely to be difficult to disassociate from criticism of one's own self. In other cases the criticism, whether valid or not, may be simply unhelpful for a performing artist to have to cope with in the light of upcoming performances.

96 Brian Paltridge, Discourse Analysis: An Introduction (Continuum, 2012), 2.

${ }^{97}$ Paltridge, 8.
} 
reviews of each singer that are representative of the larger corpus I collected and analysed for the project. 98

As Deborah Cameron and Don Kulick have pointed out: 'We cannot understand the significance of any word unless we attend closely to its relationship to other words and to the discourse (indeed, the competing discourses) in which words are always embedded'. 99 A close, critically alert reading, therefore, can reveal underlying attitudes about the agency of singers in creating their sound or creating characters, but any such assumptions must be made with an awareness of the cultural context and the changing discourse of the time. The actual words used by the reviewer to describe the singer's sound can be 'loaded' and gain meaning through the context of the written review, so I have considered the implications of attitudes and meanings with care and with a sense of the context in mind.

Overall, an inductive methodology has been used as the foundation for the research which forms this dissertation, to seek out wider implications and meanings relevant to the overall period spanned by the three singers' careers. Through the discourse analysis I reveal the differing attitudes that appear to have influenced the critical responses of the reviewers to the three different singers. The responses of these critics align in different ways with the common conceptualisations of the diva singer and her image and are bound up with cultural connotations of the time and expectations around female singers, and aesthetic traditions applied to the operatic soprano. I explore these from the viewpoint of an inherent understanding of the singer's control and agency in terms of shaping and developing their signature vocality, and I shed light on the way this power is constituted through their sound, and how this power is conveyed in their live and mediatised performances and is effective in terms of their influence and legacy.

\section{Dissertation Outline}

In the chapters that follow, for each of the three divas, I examine the individual vocality, their interaction with the forms of mediatisation of their time, their position in the continuum of vocal fashion and influence, and the function of all of these in relation to perceptions of creative agency. The first singer is Maria Callas, whose main period of

\footnotetext{
${ }^{98}$ For each of the three case study singers, I collected and analysed between 22-25 reviews relevant to their debuts and their period of early international success. I analysed those which were of their performances at the Royal Opera Covent Garden in London and Metropolitan Opera in New York and in a few cases (as specified individually in the chapters) I referred to reviews from other performances during the same period.

${ }^{99}$ Deborah Cameron and Don Kulick, Language and Sexuality (Cambridge University Press, 2003), 29.
} 
success was during the 1950s, in which she made her career first within Italy, and expanded this internationally from the time of her debut in London as Norma in 1952. In this chapter I explore the relationship between attitudes to her as a diva and her disruptive effect on the vocal paradigm of the time, seeking to show how her signature vocality imparts a sense of her power and agency that contributed to that effect.

The second diva is Kiri Te Kanawa, who came to international notice from the time of her debut in London in 1971 and whose career extended through the 2000s, with her final appearance in opera in 2010.100 Kiri Te Kanawa, whose success can be seen as based around perceptions of beauty, and of a beautiful voice within a beautiful body, was subject to the effects of various tropes surrounding singers and in particular the female singer. I show how her control of her vocality was treated differently due to these attitudes and how her agency and power was effectively masked by this perception, despite her vocal beauty actually being produced and maintained through that control, as is revealed by my original analysis of her vocality.

The third singer is Anna Netrebko, who started her career in Russia, but for whom international success came in the 2000s, in particular with her performances as Donna Anna in Don Giovanni for the Salzburg Festival in 2002 and 2003, followed by her London debut and ongoing success at the Metropolitan Opera in New York. Anna Netrebko encountered new forms of mediatisation as well as an increase in its use as she rose to stardom and this led to different pressures. Her successful negotiation of the possibilities for a career based on the opportunities such mediatisation affords is both impressive and informative. In my study I show how the formation of her vocality and her own control of her star image have worked together in the development and maintenance of her divahood, despite the effective decrease in authorial voice of the singer within such new forms of mediatised performance.

This research has implications for the study of musical timbre, critical organology, and opera fandom, as well as for the musicological critical study of opera performance and for singers who wish to enhance their communicative effectiveness in opera, especially in relation to the building of new audiences that modern careers in our mediatised age increasingly require. Each of the case studies provides a snapshot of the way the vocality of a diva was treated in a specific era and time and place. For all three singers the stages of London and New York were especially significant and these locations provide a continuity

100 'Dame Kiri Te Kanawa: Biography', The Arts Foundation, 26 September 2015, https://www.thearts.co.nz/artists/dame-kiri-te-kanawa. 
of backdrop for my examination of their vocality and their careers. Each singer was treated differently within this social context in terms of the expectations around their vocality and their diva image. For each also, a differentiated form of vocality yielded power: for Callas this was a disruptive power associated with dramatic affect that remains hugely influential; Te Kanawa's influence on vocal fashion involved extending the ideals of beauty; and the undercurrent of power in Netrebko's vocality contributes to her image as a 'new type' of diva. In the following chapters I trace these forms of power through the careers of these influential divas of the twentieth and twenty-first centuries, revealing how for each of these divas there are foundations of exceptional levels of control. 


\section{CHAPTER 2: BEWITCHING: THE DRAMATIC VOCALITY OF MARIA CALLAS}

The voices of the dead - on the gramophone, on records, on the radio - are opera's glorious past, a decaying voice, which in its very decay is a thrill to fans [...] opera lives in a fantasy of reliving and re-creating its past, [...] and, if it could, it would do so with the exact same voices

(Michal Grover-Friedlander, Vocal Apparitions) ${ }^{1}$

When a California-based events company announced in 2017 that Maria Callas would soon be performing again - as a hologram - the New York Times critic Anthony Tommasini was invited to the preview. In a subsequent article he raised the question of what a hologram such as this might mean for opera. ${ }^{2}$ If, as Michal Grover-Friedlander suggests, opera continually seeks to revive the past, and to do so with past voices, we might expect this representation of the diva, reincarnated for a twenty-first century hologram 'event', to satisfy such desires. But to what extent can it in fact achieve this aim, and how might it do so? How satisfying might it be as a show, whether it is intended for opera lovers, Callas fans, or opera initiates? The very existence of the show in itself serves to highlight issues for opera as an art form at this particular point in the age of mediatisation, but it also raises questions about the fundamental basis of Callas's divahood, and how it is that her remarkable impact on opera, made through a career based in the 1950s, continues to have resonance today.

The general perception of Callas as a diva has focused on her behaviour, the impression of which is backed up by the iconography around her as a performer and celebrity, and her dramatic power in the roles she performed. Authors such as Jürgen Kesting, John Ardoin, and Michael Scott have nuanced this perception by pointing to evidence which shows her intensive focus as an artist committed to the music, and the optimal performance of it, and have pointed to her powerful legacy of influence and affect as being contained within the audio recordings she made. ${ }^{3}$ However, no one has fully accounted for how it is that the

\footnotetext{
${ }^{1}$ Michal Grover-Friedlander, Vocal Apparitions: The Attraction of Cinema to Opera (Princeton University Press, 2014), 136-37.

2 Anthony Tommasini, 'What a Hologram of Maria Callas Can Teach Us About Opera', The New York Times, 16 January 2018, sec. Arts, https://www.nytimes.com/2018/01/15/arts/music/mariacallas-hologram-opera.html.

3 Jürgen Kesting, Maria Callas, trans. John Hunt, First Edition edition (Boston: Northeastern, 1993); John Ardoin, The Callas Legacy: The Complete Guide to Her Recordings on Compact Discs, Fourth (Gerald Duckworth \& Co, 1995); Michael Scott, Maria Meneghini Callas (London: Simon \& Schuster, 1991).
} 
audio recordings carry this power given the lack of the visual elements that would normally be associated with stage presence and dramatic power.

In this chapter I argue that Callas's power lies in her use of her vocality, and that, at least in her main period of success, many of her so-called vocal flaws were deliberate choices made for dramatic purposes. As such she was actively disrupting the paradigm of vocal beauty that was in place within opera at that time. In so doing she was allowing her agency in the creative process to become audible and perceivable through her vocality, and her signature vocality imparts this same power and agency - which makes it captivating or, for some, distressing. This disruption, which was made apparent through the vocality she created and used, also transgressed gender-based ideals associated with operatic singing, making her an assertive force in the operatic world and attracting obsessive desire as well as wonder at the creative and ultimately authorial power she wielded.

Various scholars have addressed the nature of the power of Callas. Freya Jarman-Ivens points to Callas's 'moments of vocal failure' as showing the body in the sound, and relates this to Barthes' 'grain'.4 She identifies this as the significant factor providing the source of power within her performances, suggesting that these moments of failure 'intersect with the powers of composition and bodily discipline to bring about moments of resistance at which identification and desire emerge in response to the forbidden pleasures of her vocal flaws'. ${ }^{5}$ Moreover, she argues that the vocal 'failure' moments were 'a refusal to conform to the composer's text [as] a technology of power in which gendered work is being done' where the operatic composer's voice and the composition itself are seen as a masculine power. ${ }^{6}$ However, this does not seem entirely convincing, given that, as Seletsky points out, Callas was stylistically cautious, particularly in terms of what he calls the 'creative collaboration of the performer' through ornamentation. He states that 'Callas was convinced that everything she needed was in the score and in the relationship of the music to the text'. 7 Since as an artist she actively sought to serve the music and the composer by adhering to the score, Jarman-Ivens' suggestion of Callas's so-called vocal 'failures' as 'a refusal to be contained and disciplined by the composition' does not ring true.

\footnotetext{
${ }^{4}$ Jarman-Ivens, Queer Voices - Technologies, Vocalities, and the Musical Flaw, 121, 105.

5 Jarman-Ivens, 23.

6 Jarman-Ivens, 121.

7 Robert E. Seletsky, 'The Performance Practice of Maria Callas: Interpretation and Instinct', The Opera Quarterly 20, no. 4 (1 January 2004): 591-93. Daniel Leech-Wilkinson's observations of the stylistic changes in the post-Second World War period also show a trend towards this type of cautious interpretation of the music based on the written score. Leech-Wilkinson, 'The Changing Sound of Music: Approaches to Studying Recorded Musical Performance'.
} 
Nina Sun Eidsheim, in her essay 'Maria Callas's Waistline and the Organology of Voice', picks up some of the threads laid down by Jarman-Ivens as well as by Linda and Michael Hutcheon in Bodily Charm. ${ }^{8}$ Eidsheim interprets assertions about Callas's significant weight loss in 1953-54 with reference to narratives around voice, control of self, and the female body. For this study, Eidsheim uses an approach she terms 'critical organology'. Her approach and subject matter relate in some ways to my own in that I also consider the artist's vocal production and associations of power and agency along with implications of attitudes both to singers and women. Eidsheim states that through her study she aims to inspire others to 'change the discourse about Callas's and others' voices', and to 'reboot the language, concepts and analytical framework through which we understand voice'. 9 This ultimate goal aligns with my own aims in opening up the view of vocal processes and increasing the general understanding of the use of the singer's body in creating vocal sound.

A great deal has been written about the topic of what was 'wrong' with Callas's voice; how she had 'three voices' (as if all sopranos do not); and in terms of speculation on why she 'lost' her voice and ended up withdrawing from performing in the mid-1960s. ${ }^{10}$ Various causes for Callas's retreat from performing have been asserted, firstly by the media at the time, and then by other singers, and some of these have been taken up and considered by scholars. These assertions include that her technique was not actually as good as it initially seemed, that her dramatic weight loss affected her ability to sing, that she 'forced' her voice and thereby 'ruined' it, that she tried to sing too wide a repertoire, or that she pushed her voice into the wrong types of roles for her vocal abilities.

For the purposes of this dissertation, however, I focus on the characteristics of Callas's vocality in the main period of her international success, and the techniques that underlie her vocal tone production. Rather than trying to identify the causes of this so-called vocal 'ruin', my aim is to draw out the qualities of her singing that meant she was able to utilise her voice so well for the incredibly successful years of her initial career during the 1950s.

\footnotetext{
${ }^{8}$ Eidsheim, 'Maria Callas's Waistline and the Organology of Voice'; Hutcheon and Hutcheon, Bodily Charm, 120-22, 137-43.

9 Eidsheim, 'Maria Callas's Waistline and the Organology of Voice', 264.

10 The 'three voices' of all sopranos are the different registers or ranges of the voice, which each tend to have distinctive quality that separates them from each other due to the different way they must be produced physically. These are often identified as the 'chest', 'middle' and 'head' registers. Some high-voiced sopranos would also count their highest range as a fourth register. While singers tend to work to smooth over the 'breaks' between these registers (the passaggio or bridge between each range) they may also at times choose to emphasise the difference between the vocal qualities, for example, by dropping down to a low note that is strongly 'chesty' in quality to stress it or give it strength alongside the higher notes.
} 
My focus is on the creative agency wielded by her and the attitudes to this that surrounded her at the time. I also consider some of the more unusual features of her singing which some have described as vocal flaws or 'failures', to look at the underlying technical processes which she was working with, and the aspects of the sound produced which gave those features a particular assertiveness and magnetism.

Despite there being so many ways she used her voice expressively, like many others, I believe there is a signature sound, a signature vocality, that is recognisable as Callas in all her singing. ${ }^{11}$ Before moving on to an analysis of her vocality I start with a fuller consideration of the implications of the hologram show as representative of attempts to continue her active influence, to examine how her power may be transmitted by mediatised forms. I then discuss the way her vocality was cemented as a specific type in the public discourse through the so-called rivalry between her and Renata Tebaldi in the 1950s and the comparisons made between them. I then examine the critical response to some of Callas's performances including her debut in London in 1952 and what this reception tells us about attitudes to voice, singers and singing that were common at this crucial period of her international career. Her vocality was confronting and controversial even as she won over her audience, and less evenly, the music critics. Through a deep reading of these reviews using the framework of discourse analysis I consider the way she was regarded in this period of her international success in terms of her vocality, and tease out underlying attitudes which give an indication of the way female singers at that time were thought about in terms of their agency in controlling voice and creating vocal sound.

This in-depth reading also provides a sense of some of the wider issues to do with attitudes towards women and I consider this in relation to the binary construction of the female as submissive and weak, associated with beauty and purity, in contrast to the 'masculine' qualities of assertiveness and powerful bodily strength. While all binary constructions tend to be problematic, in considering these I build on Jarman-Ivens' concepts with respect to performative constructs around gender presentation in singing. ${ }^{12}$ Aspects of this gender binary have prompted a great deal of discourse around opera. One particular example is Abbate's reading of Richard Strauss's Salome, which has implications for my own exploration of these ideas as they apply to attitudes toward female singers and their creative agency around vocality. With Salome placed as a transgressor of gender

\footnotetext{
${ }^{11}$ Examples of others who state this include John Ardoin, Walter Legge (Kesting), and Guy Coutance (Lowe). Ardoin, The Callas Legacy, 205; Kesting, Maria Callas, 41; David A. Lowe, ed., Callas: As They Saw Her, First Edition edition (New York: Ungar Pub Co, 1986), 170.

12 Jarman-Ivens, Queer Voices - Technologies, Vocalities, and the Musical Flaw, 20.
} 
roles, Abbate identifies Jochanaan as taking the 'feminine' part of passive, weak acceptance when confronted with Salome's so-called monstrousness of 'disobedient, unbridled female sexuality'.13 This mantle, which Salome desires, and in part manages to take on, is shown by Abbate to centre on the desire to take the role of the active, masculine, observer-speaker-author who wields both physical and authorial power. ${ }^{14}$ Callas can be seen as taking on such a mantle and this has proved to have ultimately provided her influential power.

I discuss the nature of this lasting influence and legacy, along with the degree of agency she had in creating and maintaining this through her stardom image and the mediatisation of her performances, thinking about how her relationship with these have connected her artistry with her audience but also have been significant in affecting values and attitudes towards voice in opera through to the twenty-first century.

\section{The Ghost of Maria Callas}

While the question of what a hologram of Callas might mean for opera was only lightly glossed over in Tommasini's article, it seems a particularly pertinent one at this point in time given the increasing influence of mediatisation within society. It is timely to consider the implications of a technological reincarnation of a past star for the current and future audiences for opera, and how the nature of such a representation might afford new opportunities for forms of performance and/or fall short of transmitting and perpetuating the power of an iconic diva such as Callas.

The hologram show features 'Callas' performing famous arias she recorded during her career. Clearly the hologram company believed that presenting such a show would yield a good return on the not-inconsiderable financial investment involved in mounting it. Perhaps, given the paucity of film footage of the artist, and the increasing trend towards video as a medium, this is understandable, since Callas was a global star in her time, and continues to hold such an iconic place in the public's imagination. The illusion used for the show is not three-dimensional like a true hologram, but it is said to have a 'ghostly' appearance that adds to its sense of reality. Might such a ghostly re-animation be more or less successful than Franco Zeffirelli's attempts to recreate Callas in his films? He admits he was effectively 'cloning' her in the form of Teresa Stratas in his 1982 film of $L a$

\footnotetext{
${ }^{13}$ Abbate, 'Opera, or, The Envoicing of Women', 236-37. Elliot Gilbert's description of Salome in terms of a 'patriarchal culture' in conflict with 'disobedient, unbridled female sexuality' is quoted by Abbate on page 236.

${ }^{14}$ Abbate, 236-39.
} 
Traviata, and his movie Callas Forever (2002) puts forward various views of possible Callas reimaginings which Michal Grover-Friedlander has interpreted as complex and insightful, but not necessarily satisfying as incarnations of the diva. ${ }^{15}$

The video projected to create the hologram illusion does not consist of extant film of Callas, but has been created especially for the show using an actress. The video image of the actress has then had Callas's facial features morphed onto it. The sound track of Callas singing that is used in the show is taken from one of Callas's recordings but it has had the orchestral sound removed via a high-level technological process, leaving behind only her vocal line. So Callas is 'singing' in the show, since it is her voice on the recording, even though her voice emanates from an illusory body - an avatar that is intended to manifest the deity - 'La Divina' - Callas. Rather oddly, everything else about the performance is real and 'live', since a live orchestra and conductor perform on the stage behind the projected image to accompany the audio recording of Callas's voice and the hologram projection of her pseudo-body. Is this addition of liveness, in the form of the musicians and conductor, done in order to make the un-live projection seem more real? It is nonsensical in some ways, since there is no live interaction possible between the 'Callas' singer and the orchestra: a denial of what can be seen as one of the basic foundations of the classical music idiom, that is, the spontaneous interaction between performers that affects the performances of them all, as noted here in the Introduction. ${ }^{16}$

Carolyn Abbate's discussion of the image of the dead Orpheus as a severed head 'its mouth still open in song' seems relevant when considering this supposed revival of the singing body of Callas in its illusory form, as does her discussion of René Leibowitz's various 'paradoxical inversions' about the role of the performer. ${ }^{17}$ Particularly germane is Leibowitz's suggestion that the performer is on the one hand effectively annihilated as a

\footnotetext{
15 Michal Grover-Friedlander, 'The Afterlife of Maria Callas's Voice', The Musical Quarterly 88, no. 1 (1 March 2005): 38. Grover-Friedlander quotes Zeffirelli's statement from page 324 of The Autobiography of Franco Zeffirelli where he states: 'Almost everyone on the film had at one time or another worked with Callas. To us she was Violetta and in making the film we were somehow giving ourselves a second chance to make the film with Maria. I was as much to blame as anyone: every gesture I had asked of Teresa and every detail of interpretation, no matter how I tried to disguise it, had been inspired by the work I had done with Callas so many years before.'

${ }^{16}$ Fischer-Lichte, The Transformative Power of Performance. See my discussion of Fischer-Lichte's concept of the auto-poietic feedback loop in the Introduction to this dissertation. In this case I am thinking specifically in terms of the nuances of timing and other expressive musical features, which would normally be a matter for moment by moment negotiation through the interaction between the various performers. Despite its score-based nature, classical music 'lives' in this way: through this constant shifting and changing of expressive details.
}

${ }^{17}$ Abbate, In Search of Opera, 1, 41-43. 
living being (let alone a creative one), and yet is brought to life by the composer's musical work itself:

[I]n the end, it is the composer and the musical work that have created the performance and the performer. [...] [The performer] seizes and realizes [the musical structures of the work] at the moment when, delivered up to his score, he is as if possessed by it, at the very moment he possesses it. [...] The performer has no life except through the score that he brings alive 18

Abbate comments that Leibowitz has proposed 'a strange reversal of terms in which human beings are dead material, forced into motion by something operating from behind or beyond their bodies'.19 In a similar way, the hologram, for some, may seem to have brought Callas back to life, but it is in fact a 'zombie' life, a version which is in some ways 'uncanny' and yet seems to denigrate the musical form involved, in that it ignores the musical 'liveness' which is so fundamental to that form, let alone the degree of high-level musical negotiation that Callas engaged in in such performances. One of the advertisements used for the show includes a video clip of the hologram version of the 'Habanera' from Carmen, a role Callas never played on stage, although she did record it as a complete opera (for EMI in 1964). ${ }^{20}$ She sang this aria numerous times in concert, however, and videos of her performing it in Hamburg and at Covent Garden in London, both from 1962, remain popular online. ${ }^{21}$ These seem to have been the models used for the video but in fact even when only viewed on a computer screen the original film clips are so much more engaging than the hologram version.

The actress used for the hologram video is unsatisfying as Callas because she seems too tiny (a strange observation given that the projection could be any size desired - so perhaps it is a matter of proportion, and her head is too large). The mimed movements she makes do not communicate in the way Callas does in the videos of her singing this aria in recitals; in fact there is no real communication on a human level in evidence. There are gestures but not communicative ones. Maybe this problem is due to the morphing process or perhaps it is the actress herself - it is impossible to tell. Though the 'actions' of the

\footnotetext{
18 Abbate, 42.

${ }^{19}$ Abbate, 42.

20 Callas En Concert, the Hologram Tour - Habanera (Carmen), 2018, https://www.youtube.com/watch?v=BCclI5sUoRg.

21 Warner Classics, 'Maria Callas Live: Bizet's Carmen Habanera, Hamburg 1962', accessed 13 December 2018, https://www.youtube.com/watch?v=EseMHr6VEM0; Maria Callas (1962) At Covent Garden - Georges Bizet - Habanera (Carmen), 1962, https://www.youtube.com/watch?v=RbX8WDAXUmg.
} 
Callas-avatar are theoretically 'correct' there is no sense of any proper acting going on. A comparison of this with the Hamburg video online, where Callas is totally involved and engaging, shows the hologram to be more suggestive of Offenbach's Olympia 'Doll' from Les Contes d'Hoffmann than of Callas herself. This 'performance' as a hologram gives a completely underwhelming sense of the artistry of the singer, even though it uses her own audio recording, which is itself intense and powerful.

The nature of the performance and the lack of affect arising from this hologram raise many questions. Where does it leave our twenty-first century hologram audience, who have perhaps never seen or heard a recording of Callas? What happens to the sense of the affective power of her voice, identified by so many authors as the key to her artistry, in this realisation? Are we distracted so much by the visuals that it is not possible to focus on the audio, and if that is the case, what does that mean for broadcast, televised or filmed performances of opera today?

Such issues are integral to all forms of mediatisation of opera and classical singing performances, be they high definition 'live broadcasts' of opera, YouTube videos, or any other form. Callas's continuing influence has been based on audio-only recordings, yet this hologram seems to disrupt this form of her legacy, and its meaning for the future. Where previously listeners inevitably focused on the aural experience of her recorded work and imagined the 'face in the voice' and 'gestures' that supposedly constituted the greatness of her recorded art, now, by providing a distracting realisation of her physicality, this development perhaps leads us further away from the source of her artistry. 'Her voice was her face,' reminisces John Ardoin, 'and I came to know and love almost every feature of it through her many recordings. It is still the best way to know Callas. And now it is the only way.'22 Ardoin later came to know Callas personally, but at the time he is referring to, he had not met yet her - he was only fifteen years old and was living in South Texas, a long way from anywhere she was performing at that time. He had only experienced her performances through her audio recordings. It is not totally clear whether he means that the vocal sound replaces the face for him, or whether he imagines Callas's face when hearing her sing. Since the recordings at that time (1953) were LP albums, there would usually have been images of her face on the album covers for him to reference, so he would have had a sense of what she looked like. However, this 'face-voice' effect worked for him, and this points to the importance of her vocality in so far as it constituted her as

\footnotetext{
22 John Ardoin, Terrence McNally: A Casebook, ed. Toby Silverman Zinman (CRC Press, 2016), 15758.
} 
body/face and voice. This gives some sense of how essential our experience of the singer's vocality is to our understanding of the singer as a diva.

Callas attracted intense obsession from her fans, and her fan base has, if anything, gained in momentum over the years. She is unmatched in this by any other soprano or diva of the twentieth or twenty-first centuries. Callas never seems to die. She is probably still the most well known opera singer of our times and she is reincarnated 'in effigy'. This again recalls Abbate's iconised Orpheus, particularly in the Moreau painting she describes, in which 'an unworried nymph [is] gazing at Orpheus's extraordinarily peaceful head, which she has collected on his lyre. [...] The closed mouth looks as if it never sang at all. But mouth and eyes are eloquent nonetheless, since, devoid of trauma, they lull the observer into a delusion'. ${ }^{23}$ As Abbate notes, the once-singing head is silent, revered, yet dismembered, body-less, the dreamed-of dead.

Moreau's painting encapsulates the longing for the body, and for the song, of the beloved singer, showing us the aural imagination of his sound evident in the gaze of the Nymph who holds him, contemplating him like a fan may gaze at a record or its cover, and imagine the body from contemplating the object, through the dreamed-of singing. The Moreau painting itself recalls Koestenbaum's 'Yes, I fetishize records' image, and one could readily imagine the painting as an image of a Callas fan holding their favourite record with the 'head shot' image of the singer on its cover, gazing at the object of their desire, about to place it on the turntable to restart the electrically-reinstated singing voice of the diva..24 Indeed, through the continued production of documentaries and films such as Tom Volf's Maria by Callas (2017) and Zeffirelli's Callas Forever, Callas as a figure is truly kept alive.

The hologram show, and all the films, documentaries and plays which have been created about her, matter because they show the degree to which Callas's public still tries to recreate her and hold onto her, because these media versions reinforce and perpetuate her status as an icon and an artist. The visual aspects of the discourse around her as a diva, including memorabilia such as the album covers, books full of dramatic photos of her performing, and the still shots that accompany YouTube videos, are extensive and significant in that they involve tangible objects that may be collected and retained by her fans. There has always been a discourse as well that centred on her physicality - in particular, her weight loss, her constructed beauty and physical transformation, and whether this affected her voice. A myth was built up about her live performances being

23 Abbate, In Search of Opera, 3-4.

${ }^{24}$ Koestenbaum, The Queen's Throat, 59. 
more effective than her recordings, yet many who did not have the opportunity to experience her live, including myself, find her recordings spellbinding. Arguably, this implies that her diva power and influence is actually present in her voice and her singing, and later in this chapter I explore the elements of her vocality to uncover the source of that power.

Callas forms an iconic diva model and remains strongly influential in the twenty-first century. Her influence is variously associated with her 'successors', those who copied her, not necessarily successfully, her influence on repertoire (the 'revival of bel canto') and her dramatic focus, as Steane puts it, 'the need for an operatic artist to combine the skills of musician and actor'. ${ }^{25}$ This interest in her dramatic artistry persists, despite the fact that people who did see her perform on stage in operas tend to state that she moved very little. But while much of the literature emphasises Callas's stage presence, I argue that ultimately her signature vocality and what is revealed through that vocality, is primarily responsible for her status and impact as a diva.

As an artist, Callas was renowned for presenting a vast variety of tone colours, which she used extremely expressively. She was also acknowledged as having a distinctive and 'instantly recognisable' voice. ${ }^{26}$ For a singer to have both a distinctive tone colour, and also a wide range of constantly changing tone colours, may seem contradictory. This is one of the central issues in identifying a 'signature vocality': how to determine what is similar about the singer's different tones that ultimately identifies her. This comes down to a determination of which tones are the most predominantly used, as these form a recognisable basis for her sound alongside the elements of her habitual singing style that can be said to form her individual vocality. In the case of Callas, despite her variety of tonal colouration this is possible to determine, as I will outline in my analysis of her vocality.

The many high-quality audio recordings made by her in the studio provide a rich resource for such study. The recordings of her performing live in operas, which were either made by audience members during the performance using their own portable equipment or

\footnotetext{
25 Peter G. Davis, 'The Diva Standard. Still.', Opera News 80, no. 4 (November 2015): 34; Ira Siff, 'Angela Gheorghiu: "Homage to Maria Callas - Favourite Opera Arias"', Opera News 76, no. 6 (December 2011); Steane, Singers of the Century (Volume 2), 253-54.

26 Steane, Singers of the Century (Volume 2), 259; John Ardoin, Callas at Juilliard: The Master Classes (New York: Knopf, 1987), xii. In the Foreword to Ardoin's book, conductor Nicola Rescigno describes Callas as even choosing a different 'special voice' for each role, and then varying that timbre expressively. He states: 'Callas has very often been accused of having three voices. Nonsense! She had three hundred. Every role she portrayed had a special voice and within that particular timbre she would constantly change colors to convey the message of the composer.'
} 
dubbed off live broadcasts from the radio by listeners at home, are usually of much poorer audio quality than the professionally recorded studio versions due to the lower quality recording equipment used, but these are able to provide some sense of aspects of her live performances in opera roles on stage. ${ }^{27}$ Since my interest is in the detail of the tonal quality that marks her voice as distinctive (and expressive) I have chosen to use only the studio recordings for my analysis and have selected remastered versions that have had the highest recommendations wherever possible. ${ }^{28}$ Before considering these recordings and her international reception in terms of the particular qualities of her vocality, in the following section I outline salient features of her so-called 'rivalry' with soprano Renata Tebaldi, which has had an ongoing impact on the way the vocality and divahood of later singers have been received. Fuelled by the press and rival fans of the two divas, this divergence of vocal style grew to represent an aesthetic dichotomy, which split the opera audiences into two bodies of opinion and set up a lasting influence on vocal fashion.

\section{Diva Rivalry: An Aesthetic Dichotomy}

[T]he soprano's power - her economic, creative and sexual independence - seems to demand containment, and much of the rhetoric that surrounds her, whether in 'primary' sources, journalistic writings or biographies, attempts to control or limit her potential supremacy. ${ }^{29}$

While Mary Ann Smart was referring here to the nineteenth-century diva Rosine Stolz, the question of the containment of the diva's agency is one that appears in multiple forms and resonates through the centuries, and the description above seems to apply equally well to the situation Callas encountered. Throughout her expanding global reach, as her career and fame grew, Callas continued to reign as a major star at La Scala, appearing there regularly until 1958, when she broke with the house, blaming what she described as 'constant intrigues and unpleasantness' ${ }^{30}$ The issues she was referring to at La Scala revolved largely around what came to be known as her 'rivalry' with her colleague Renata Tebaldi, which, fuelled by the press, ultimately set up the two sopranos and their vocal

\footnotetext{
${ }^{27}$ At the time broadcast performances did not tend to be recorded, just relayed directly on the airwaves from where some listeners with the right equipment recorded them onto acetate. The 'live' recordings have been released by various record companies, but their actual provenance (who they were recorded by, and the equipment used) is not usually indicated. For example, Callas In Her Own Words by John Ardoin includes many such excerpts, but, apart from the location and year of the performance, they are all just called 'live recordings' or 'live material'.

${ }^{28}$ Robert E. Seletsky, 'Callas at EMI: Remastering and Perception', The Opera Quarterly; Oxford 16, no. 2 (Spring 2000): 240-55; Robert E. Seletsky, 'A Callas Recording Update', The Opera Quarterly 21, no. 2 (7 July 2005): 387-91.

${ }^{29}$ Smart, 'The Lost Voice of Rosine Stoltz', 33.

${ }^{30}$ Kesting, Maria Callas, 195.
} 
styles and aesthetics of vocality in a form of binary opposition that remains in effect today. While historically this type of dichotomy was not new, the fact that it occurred during the mid-twentieth century and that both singers were recording artists means that the influence of this aesthetic split is retained over time, unlike those between the 'lost' voices of historical divas. ${ }^{31}$

The supposed rivalry between Callas and Tebaldi has been covered in detail in many biographies but in terms of the relationship between the two singers, its fundamental basis is refuted by researchers examining the actual evidence. This evidence shows there was little real animosity or even competitiveness between the two singers, who were in fact rarely in competition for the same roles. ${ }^{32}$ Callas was also suffering from the bad press associated with supposed 'scandals' such as the 1958 performance in Rome that she abandoned part way through, despite the fact that this was verifiably due to vocal illness and exhaustion. ${ }^{33}$ In her regular appearances prior to 1958 she had had huge success in Milan, but she also aroused huge controversy and vitriolic press, with fans of Renata Tebaldi heckling and disturbing most of her performances. An example of this was the first performance of Giordano's Andrea Chénier at La Scala in January 1955:

[Callas's] high B-flat was not quite under control, with the result that an inferno broke out after the big aria in the third act, 'La mamma morta'. The Tebaldi fans, and the claque which Callas had always refused to pay, voiced a devilish demonstration [...] If one listens to the live recording today, the signs of disapproval after 'La mamma morta' seem to be simply evidence of hostile fanaticism. ${ }^{34}$

These sorts of disturbances by the 'claques', the perhaps loosely organised but very powerful groups of bribed 'supporters', were rife in the Italian theatre system, but disruptions of shows in which Callas performed were often attributed to the rival sets of fans. Since the aesthetics and attributes of the two singers were almost polar opposites there was never likely to be any peaceful resolution to the arguments between their fans. Tebaldi left La Scala soon after the 1954-55 season and began to perform more regularly at the Metropolitan Opera in New York. This affected the way the press prepared the

\footnotetext{
${ }^{31}$ One of the most famous of these earlier 'rivalries' was between Faustina Bordoni and Francesca Cuzzoni in the eighteenth century.

${ }^{32}$ Sarah Pozderac-Chenevey, 'Diva Rivalry for Fun and Profit: An Examination of Diva [Mis-

]Conceptions via the Rivalry of Maria Callas and Renata Tebaldi' (University of Cincinnati, 2013).

33 Kesting, Maria Callas, 192.

${ }^{34}$ Kesting, 152.
}

Page 50 
public for Callas's own debut there in 1956. For example, Time magazine printed a long feature on Callas that appeared just before her debut as Norma, which made a host of allegations including the statement that 'Maria Callas clawed her way to her present preeminence with a ruthless ferocity infecting fear into her enemies and leaving her with few professional friends'. The same article characterised Tebaldi as 'the owner of a voice of creamy softness and delicate and sensitive musicality - and a temperament to match.'35 Christiansen suggests that 'to anyone accustomed to Tebaldi's smoothness and steadiness, Callas would have sounded shockingly self-assertive' and this difference of vocality and vocal approach was clearly played upon by the press. ${ }^{36}$

In this way the two 'sides' were set against one another, with opera lovers' allegiances for Callas and Tebaldi effectively set up as an aesthetic choice. The concept of a rivalry was kindled more and more by the international and local press, which fostered an everincreasing division between opera audiences. The aesthetic dichotomy was constructed as a competition over the power of attraction. Ultimately Callas would seem to have won this contest, given the longevity of her fame and notoriety alongside that of Tebaldi. However, at the time, these pressures had a real effect on Callas's nerves, and her ability to perform adequately seems to have been quite seriously affected.

In the year prior to her New York debut, during an acclaimed set of appearances as Madame Butterfly in Chicago, two 'process servers' employed to deliver a summons relating to a legal wrangle with a former agent unexpectedly confronted her in her dressing room. Callas inadvertently presented the press with an iconic image that they naturally leapt to include in their publications. As Kesting describes, this became her 'most famous and notorious' photographic image' and shows her 'as a raging fury, abusing two officials through her grotesque, stage made-up lips.'37 This played perfectly into the image of Callas as a temperamental, difficult, ambitious, nasty and even demonic diva, which had already been built up around her, however erroneously, by the press. This was a form of power, but it was the type that demanded, and resisted, containment even though at the same time it provided a legendary diva-image for her as a performer. Arguably this image is symbolic of both the envoicing and the suppression of the diva, as it continues to speak (or scream) at the viewer through the reproduced photographic image today. An image of aggression or self-assertion, power or powerlessness depending on one's viewpoint, as in

\footnotetext{
35 Kesting, 153, 175.

36 Christiansen, Prima Donna, 282.

${ }^{37}$ Kesting, Maria Callas, 9.
} 
Abbate's Salome demanding and commanding the 'masculine' power of speech as she gazes (or glares) out at the viewer. ${ }^{38}$

During her period of retreat from the stage between 1965 and the early 1970s, Callas became the very model of mystique, as a personality star who was idolised and still had recordings in the public sphere yet had retired or at least retreated from the stage. Her international success, her acclaim and veneration, were combined with the images of misbehaviour, her romantic misfortune and her lonely final years prior to her death in Paris, to develop the public's concept of her as a diva that has continued to influence public perception of the prima donna. As Smart shows and Catherine Clément implies, the diva's tragic operatic roles are easily subsumed into their biographies, and Callas's life was narrated thereafter through the darkened lens of operatic tragedy. ${ }^{39}$ Her 'star image' had been largely created, inflated and controlled by the media, yet it was the image of notoriety, scandal and outrageously demanding behaviour that lit up the popular imagination to the point where it has become the defining form of both the 'diva' and the 'prima donna' for the general public. For opera enthusiasts and artists, Callas remains influential in terms of her artistry, but, for many members of the general public, the lasting impression of her is based around this largely negative 'prima donna' image. As I will discuss in my analysis of her vocality, this disruptive and resistant image continues to resonate within her signature vocality, which communicates through its sound a sense of underlying assertiveness as well as her resistance to operatic norms.

\section{Callas and Authenticity}

Christine Gledhill summarises Richard Dyer's concept of the star in the following terms:

The star promises what mass society and the human sciences - sociology, Marxism, psychoanalysis - throw into question: intimate access to the authentic self. In this respect, stars offer their audiences not only consumable images or ideological values but personal relationships. ${ }^{40}$

\footnotetext{
38 Abbate, 'Opera, or, The Envoicing of Women', 238.

39 Smart, 'The Lost Voice of Rosine Stoltz', 33; Clément, Opera, or, The Undoing of Women, 31.

40 Christine Gledhill, ed., Stardom: Industry of Desire (London ; New York: Routledge, 1991), xvii. This is Gledhill's summary of Dyer's chapter in the book. In his essay about Judy Garland, Dyer interprets how the star is both 'created' and authenticated by the media. The first way he suggests this happens is by the fact of our knowledge of the existence of the film star as a real person who continues to exist when they are not seen on the screen. The second aspect of this is what he refers to as 'authentication', through the uncovering of characteristics that are unlike the movie star's image on screen, found in such photos or scandal stories or such like, which serve to show us their 'real' selves and to reinforce our sense of having found a 'real' person, thus we feel we have connected with an authentic persona.
} 
According to Dyer's notion, the press reports such as those in Time and in other media during the period of her international debuts, which focused on her supposedly ferocious personality and built up scandalous stories about her in contrast to those about Tebaldi, can actually be seen as part of the mechanism that allows for a star to be both 'created' and authenticated by the media. ${ }^{41}$ He suggests that a star's attraction involves an association with values important to the audience, and a perception of genuineness that makes that association meaningful and potent. An intrinsic factor for this is the perception of the star as a real person who continues to exist even when they are not on the screen or on stage. The photographs and stories, including scandals, that show the star's life outside the theatre reveal to an audience their 'real' selves and serve to reinforce our sense of having connected with an authentic person. While the authentic Callas is truly difficult to discern, due in part to her own performative approach to the interface with the press, and in fact the world in general, these stories sufficed to cement the public perception of her as a star.

This perception of the diva, while built up by the media, is intensified by the fans who follow her career and who, long after Callas's death, still continue to collect and listen to her recordings, as in Koestenbaum's fetishising fan whose image reflects that of Moreau's Orpheus. ${ }^{42}$ While Koestenbaum writes in The Queen's Throat about his own experience as an opera fan, in The Angel's Cry Poizat takes as his starting point a set of conversations he had with opera devotees waiting for tickets in Paris. Some of these fans explicitly express their physical responses to Callas's recordings. 43 Once Poizat moves on from the specifics of these particular comments, however, his interpretation is much more personal (and is based on Lacanian ideas) and he expands his concepts to bring in the psychological responses which he relates to a physical response on the part of the listener. When singing 'deliberately presents itself as singing, as pure music free of all ties to speech; [...] a purely musical melody that develops little by little until it verges on the cry', he asserts, 'an emotion arises which can be expressed only by the eruption of the sob that signals absolute loss; [...] where the listener himself is stripped of all possibility of speech'.44 For Poizat, the listener is usually male, or the 'generic' "he", and the singer is referred to as being of either gender, but here is specified as female. In the same way as the male listener has an emotional physical reaction of affect to the cry of the female so may he (or indeed

\footnotetext{
${ }^{41}$ Dyer, 'A Star Is Born and the Construction of Authenticity', 135-36.

${ }^{42}$ Koestenbaum, The Queen's Throat, 59.

43 Poizat, The Angel's Cry, 26-27. In this case it is Anne and Étienne who describe a 'physical sensation' as a response to listening to Callas, including 'shivers down my spine' (Anne).

${ }^{44}$ Poizat, 37.
} 
she) have a perception of the physicality of power through the vocal sound, as well as the communication of emotion.

Not all responses to such a perception are necessarily positive, however. In the next section I examine the reception of Callas's performances during the 1950s as she moved from a career based almost exclusively in Italy, to one that included Britain, the United States, and eventually other parts of Europe. The reactions of music critics point to entrenched attitudes about what constitutes 'good' compositions and 'good' singing, as well as the specific vocality she presented at the time of her rise to global stardom, and the agency that she was seen to have in creating these performances.

\section{A Disconcerting Vocality: International Reception}

Her fioriture were fabulous. The chromatic glissandi held no terrors for her in the cadenza at the end of Casta diva and in the duet [...]. Nor, in the second-act trio Oh non tremare, did the superhuman leap from middle $\mathrm{F}$ to a forte high $\mathrm{C}$. One of her most stunning moments came at the end of [...] this trio, when she held for twelve beats a stupendous, free high D. [...] From this point onward, Callas held her audience in abject slavery. She rewarded them by never letting them down, and by reaching a peak of eloquence in the infinitely moving closing scene of the opera. (Cecil Smith, Opera) ${ }^{45}$

This was Callas's debut performance in London in 1952, in Bellini's Norma. While she was treated as a great new star after this performance, and Henry Wisneski describes it as the first of 'virtually an unbroken series of triumphs' for her at Covent Garden, each of the reviews of her performance contained both strongly positive and strongly negative comments. ${ }^{46}$

45 Cecil Smith, 'Opera Diary: Covent Garden “Norma”', Opera, January 1953, 40.

${ }^{46}$ Henry Wisneski, Maria Callas: The Art Behind the Legend (London: Robert Hale, 1976), 44. 
She turned out to be a brilliant, though not a perfect, artist. We had to wait until the second act to discover how good she could be. This means that she did not pass the great test, namely, the cavatina "Casta Diva", one of the loveliest of soprano songs and perhaps the most difficult of all. This was a disappointment. The flaws were a broken, aspirated performance of the gruppetti at the beginning of the melody, and later on an occasional loss of roundness-not to say a shrillness-on high notes. (Richard Capell, The Daily Telegraph) ${ }^{47}$

Some things, such as the gliding runs in the first scene and the attacked high notes in the second, were dazzling and amazed the audience. There were some beautiful soft phrases. But the voice did not ride the big final ensemble as it should. Much of the proper resonance was "boxed in" and uncomfortable and though the performance she gave was impressive I myself cannot feel that she is more than a plausible Norma. (Philip Hope-Wallace, The Manchester Guardian) ${ }^{48}$

Maria Callas as Norma I found a trifle inadequate for much of the time: her voice was magnificently lustrous and flexible above the stave but somewhat colourless and ineffective within it; and of course it is within this lower range that dramatic psychology must look for its full expression. All in all, while grateful to her for much very beautiful singing, I could not quite accept her as the Norma of my dreams. (Ernest Newman, The Sunday Times) ${ }^{49}$

This critical response shows the controversial nature of Callas's sound and approach to the emotional expression. The London critics, many of whom were very excited by her performance, grumbled about the 'flaws' in her singing. At the time a 'dramatic' vocal approach was not usually heard in this type of repertoire, and Callas's tendency to sacrifice beauty of tone for expressive colouration was not what was expected, even though it may have been acceptable if it had been used in a verismo work. ${ }^{50}$ Aside from the

\footnotetext{
${ }^{47}$ Richard Capell, “'Norma” Sung With Spirit: Brilliant Soprano At Covent Garden', The Daily Telegraph, 10 November 1952.

${ }^{48}$ Philip Hope-Wallace, “'Norma” at Covent Garden: After 20 Years', The Manchester Guardian, 10 November 1952.

${ }^{49}$ Ernest Newman, 'The World of Music: “Norma”', The Sunday Times, 16 November 1952.

${ }^{50}$ Various authors have pointed to Callas as having a similar vocal approach and voice type to Giuditta Pasta, for whom Bellini wrote the role originally, and have characterised Callas as being in the same 'soprano sfogato' vocal category as Pasta. It is worth noting that this demanding role was one she had by then performed many times in Italy, as well as in Mexico and South America. She must have felt confident about it, since she specified it for her London debut, and also used it for her debut in the United States at Chicago Lyric Opera in 1954, and her debuts at the Metropolitan Opera in New York in 1956, and for Paris in 1964. Over her career she appeared as Norma no fewer than ninety times in eight different countries, so this was one of her favourite roles, which she had
} 
critics' overt responses to these issues of tonal beauty and perfection, from the language and tone of their writing it is possible to gain a sense of their attitudes towards singing and the agency of the singer, as well as other underlying values in play at this crucial moment in Callas's rise to fame. Expressions that I identify as containing an implication of the agency of the singer in creating the sound include when the author uses an active description to do with singing, or causing the sound to be produced, such as 'She enunciates with dramatic power', or 'at the end [...] she held for twelve beats a stupendous, free high D'.51 This is contrasted with the tendency to 'instrumentalise' the singing, and treat the action as being a part of the singer's voice, or done by their voice without their own agency or control, such as 'her voice was magnificently lustrous and flexible above the stave' or 'She possesses uncommon beauty of tone'.52

There was a strong focus in the reviews of Callas's London debut on singing and vocality. Although she already had a reputation for her dramatic acting this was either not deemed important by the reviewers, or it was felt not to be particularly impressive. Perhaps it was Callas's vocal expressivity, her acting through the sung tone, that was not yet fully appreciated. John Steane wrote later about the 1952 debut that he remembered her singing, but apart from sensing a strong stage presence, 'of her acting, I gained no very favourable impression'.53 It may be that Callas's acting had not developed fully at this point, but it seems that her gestures were minimalised in a similar way to her later work on stage.

In these reviews the authors tend to use language that implies agency in the creation of sung sound even though not all their comments are positive, and in some cases the implication of agency was present only for the negative comments about her singing. In Smith's review in Opera he tends to discuss Callas's singing and her attainments, and the confidence she displayed, rather than her voice. Only when he discusses the actual characteristics of her vocality, does he use the term 'voice':

tackled successfully many times. Wisneski, Maria Callas: The Art Behind the Legend, 41-46; Norman Lebrecht, Covent Garden: The Untold Story-Dispatches from the English Culture War, 1945-2000 (London: Pocket Books, 2001), 153; Kesting, Maria Callas, 148.

${ }^{51}$ Hope-Wallace, "'Norma” at Covent Garden: After 20 Years'; Smith, 'Opera Diary: Covent Garden "Norma"'.

52 Newman, 'The World of Music: "Norma"'; Lowe, Callas, 37.

53 Steane, Singers of the Century (Volume 2), 258. 
Essentially, Miss Callas sings with two voices. Her chest voice and her upper voice are open and clean, with a splendid cutting edge that makes for exactness of pitch. In the middle register her tone is heavily covered. ${ }^{54}$

Smith's use of language generally acknowledges the singer's agency in the process of vocal production, assigning the voice its place as a tool to be used for singing, rather than a 'gift' or an instrument that exists outside of the singer herself. The only exception is when he states he 'did not always feel that her voice completely bore out her intentions in the moments of most imperious dramatic accent'. ${ }^{55}$ By this wording he directly acknowledges the singer's will and her decision-making in the act of the creation of sound.

Andrew Porter lists the qualities of Callas's voice, or rather describes her 'virtues'. He begins by noting her 'Great range and power, prime necessities', and her variety of vocal colour, including affecting and thrilling tone. As well as power, the tone of his review in The Musical Times is clearly granting her agency in the creation of this affecting vocality: she has 'the ability to invest coloratura with dramatic and expressive qualities...' (an act undertaken at will) and her 'great range of vocal colour' is 'allied to an exceptional dramatic understanding'. Porter stresses her 'imposing presence', physical expression and gesture, and her 'command of the stage', all acknowledging her power as a stage performer through her acting as well as her voice. ${ }^{56}$

Capell calls her 'a brilliant, though not a perfect, artist' and later states she is 'extraordinarily gifted, both vocally and temperamentally'. In terms of the vesting of agency, this seems almost a contradiction. The statement that she is a brilliant artist carries an implication of agency, yet Capell suggests that her vocal ability comes from the fact that she is extraordinarily 'gifted' which undermines this. Her agency is granted by him, however, when he mentions how she acts: 'no one will forget this offended Druidess's fury when she rounded on the faithless Pro-consul'.57

The reviews for her New York debut in 1956 were similarly mixed and the reviewers often seemed disconcerted. Again, there had been much publicity prior to the event, including some strong invective about her personality and behaviour. The audience and critics had

\footnotetext{
${ }^{54}$ Smith, 'Opera Diary: Covent Garden “Norma”', 40.

55 Smith, 40.

56 Andrew Porter, 'Opera in London: "Norma” in Italian', The Musical Times 94, no. 1319 (January 1953): 34.

57 Capell, “'Norma” Sung With Spirit: Brilliant Soprano At Covent Garden'.
} 
been led to expect an outstanding performance, and she does not seem to have lived up to these exceptionally high expectations.

Peter G. Davis comments:

When she brought her Norma to the Met in 1956, [...] the critics were puzzled by a soprano who "gives the impression of having been formed out of sheer willpower rather than natural endowment" (Howard Taubman in The New York Times). Even so, compared to most people's previous experiences with Norma, this interpretation suggested a range of emotions that few suspected the role embodied. ${ }^{58}$

Taubman's comment is revealing, but so is Davis's response to it. Both these authors clearly do not recognise the willpower that is required by all singers in order to continue to create vocal sound while under the pressure of performing. The slightest thought of failure can be enough to bring about a momentary lapse in the stabilisation of the singer's vocal apparatus (the larynx, vocal tract and so on) which, if it occurs prior to a demanding passage or a high note with particularly difficult approach, can cause complete collapse of the mechanism (throat closure and the lack of false fold retraction) resulting in the note or passage not being achievable. This is where the psychology required to be developed by singers, particularly those performing in the type of situation that Callas experienced, becomes crucial to understand. In her case a tremendous amount of willpower was inevitably required to achieve both the specifics of the score and her dramatic and expressive aims in this live performance. Callas clearly had that willpower even though her nerves seem to have become increasingly difficult to control as her career went on. In this repertoire, under these circumstances, willpower seems a necessity.

However, in commenting in this way on her willpower, Taubman may instead be responding to the sound of her vocality. A description like this perhaps implies his concern about the lack of smooth and silky tone that most coloratura sopranos would have utilised for such repertoire at the time, and a recognition of her replacement of this beauty of tone, for example, by the much stronger 'metal' or 'blade' colour in her high range tone. ${ }^{99}$ In conflating his impression of Callas's dramatically expressive approach with this aural signifier of power, and describing it in terms of near failure or risk, Taubman presents us

\footnotetext{
58 Davis, 'The Diva Standard. Still.'

59 The terms 'metal' and 'blade', are used to describe tone which emphasises the high harmonics in the spectrum of vocal sound. Another term related to 'blade' is the term 'cut' which usually refers to the projection of the singer's sound, and again would be expected usually to refer to a tone that has strong upper harmonics.
}

Page 58 
with a concern that ultimately implies desire for control of the dangerously powerful female voice.

Callas's artistic influence and the legacy of her career are bound up with nineteenthcentury Italian repertoire and she is recognised as influential in the 'bel canto revival'. Kesting suggests that this was because she indicated a new direction, caused the resurrection of the Romantic coloratura soprano with dramatic possibilities of expression - and with this the musico-dramatic oeuvre of Rossini, Cherubini, Bellini, Donizetti and the young Verdi.' 60 Her legacy does not only apply to the singing of coloratura repertoire, however, and she 'revolutionise[d] singing technique [by] turning musical style into theatrical expression'.61

This seems an over-simplification, in that the stylistic elements that Callas utilised were already in existence and were in fact usually marked in the musical score by the composers. One can say, however, that Callas developed a much wider palette of tone colouring than other singers had utilised, and she applied these with intense commitment to the characterisation of the roles she was playing, often taking the changes of colour and dynamic to extremes that would not have been normally attempted by other singers at that time. She was always scrupulously attentive to the musical accuracy, however, and her changes were made strictly within the limitations implied by the written score.

London Green, in the essay 'Callas and Lucia' discusses how Callas 'transformed our understanding of bel canto opera' and the role of Lucia in particular', in that she revealed it as 'profoundly expressive of the densities of human feeling'. He points to nineteenthcentury performances of Lucia as gradually becoming more 'decorative' than expressive, and shows how this affected judgements of the work in general, to the point where even an 'astute' critic, perceived it in 1860 as musically banal, and its libretto as 'insipid nothingness'.62 The perception that Callas may have returned to the work some of the emotional weight that it was assumed to have lost, or made it possible for audiences to perceive it, is another of the possible creative effects that may be enacted on a composer's work through the performer's vocalism. Earlier performers caused the work to be perceived as lightweight, while Callas's performance of the role opened up new understanding of it. Acknowledging that Callas also created her realisation of the role of Lucia, through the manner in which she used her vocal technique, Green relates how:

60 Kesting, Maria Callas, 27.

61 Kesting, 26.

${ }^{62}$ London Green, 'Callas and Lucia', The Opera Quarterly; Cary 14, no. 3 (Spring 1998): 65. 
Callas shocked the operatic world into a reevaluation of the work. She offered a voice filled with colors and shadow, unequaled musical and dramatic sensitivity, and the energy and conviction to search out the greatness in the bel canto repertory. ${ }^{63}$

While maintaining in this excerpt that Callas 'offered' her voice for this purpose, rather than creating it, Green nevertheless recognises the fundamentally creative activity of the singer in bringing the music to life, and performing her own interpretation of its meaning through the vocal tone she chooses to produce.

\section{'Witchcraft': The Power of Vocal Failure}

The critical response reveals the degree to which Callas's singing in her lifetime inspired outrage and acclaim, denigration and adoration: at times within the same review. A binary division seemed to occur in response to her performances: there where those who were thrilled and inspired and those who were appalled and felt, to put it bluntly, that she had desecrated the high art of opera. Her crime was to sing expressively without regard for the beauty of her tone. In a review of Callas's later appearance as Norma in 1957 at the Royal Opera in London, Philip Hope-Wallace gives the following description:

Mme Callas never fails to hypnotise her audience. She takes the stage as Rachel must have taken it. Visually she is magnificent. Musically she exerts so much willpower and bends art to her fashioning in such an imperious manner that one guesses that even if she were to whistle the music or play it on a violin instead of vocalising it, she would still make us hang upon her every phrase. [...] [Yet] her tutta forza was invariably sour and [...] her climatic [sic] high notes often developed a zagging beat like the sound of a plank being sawn. Moreover, the actual timbre of the voice often sounded nasal and "blocked". [...] But such is Mme Callas's witchcraft that one was utterly resigned to including her second scene of act 2 among the supreme experiences of opera. [...] She gave proof that whatever one may think of her as a singer or as a voice she is a mighty performer. ${ }^{64}$

Good singing is not really about the instrument's fundamental structure, since all voices are fundamentally the same. It is about what the singer does with her instrument as she

\footnotetext{
63 Green, 66.

64 Philip Hope-Wallace, 'A Controversial Prima Donna: Mme Callas in “Norma”', The Manchester Guardian, 4 February 1957.
} 
brings it into being and plays it. Callas's connection to emotion is identified over and again as being contained within the aural expression, and is found within the development of particular sounds in particular phrases. Here she is acclaimed for her 'imperious' willpower that showed her to be musically 'mighty', despite the shortcomings of her vocalism on the night. The degree of 'vocal failure' as some might term it, was, from HopeWallace's point of view, major, and the slow 'wobble' in the high notes and the 'blocked' tone which he describes seem unlikely to be chosen by her for expressive reasons. However, more often than not, in listening to recordings of her performances the listener is struck not by the imperfections and 'failures', but the expressive effects of her vocal creations. Indeed, Hope-Wallace admits that in the end he found himself ignoring these negative aspects and acknowledges her expressive power.

Jarman-Ivens' suggestion that 'moments of vocal "failure" on Callas's part can themselves be read as part of a resistance to the gender-policing work that the aria is attempting to undertake' is in contrast to the way Callas herself performed femininity. ${ }^{65}$ She did so very conservatively, both in the star image she portrayed and in her assumption of her operatic roles, and she was very focused on conforming to the written score, so it seems unlikely that her intention was to work against the 'masculine' power structure. I argue that these 'failures' can be seen as a resistance to the concept of vocal beauty as a necessity for good singing. This 'failure' can also be seen as contributing to the reason why she was seen as creative and having agency in that form.

Willpower - the determination to make the singing happen no matter what - is fundamental to successful vocalisation. Callas was often recognised for her willpower in her vocal production, and this is bound up with the granting of agency to her as a singer. The action of vocal production was made obvious to the listener in part by these vocal 'failures' (obvious breaks between registers, unsteady high notes, imperfect tone) even at the same time as her overall performance was recognised as mesmerising and powerful.

This creativity and its associated authorship are recognisable here because of failure and vocality that represents less than perfection. The implied corollary is that the 'perfect' singer must not actually do the creation of singing, or sung sound, herself. If action is associated with agency, and with imperfection, it must lie in opposition to perfection. Perfection in vocality is associated therefore with passivity and its connotations of

\footnotetext{
65 Jarman-Ivens, Queer Voices - Technologies, Vocalities, and the Musical Flaw, 121. In this paradigm, the composer's text is considered as a gendered instrument of power 'where the excess of woman is often framed in some way'.
} 
feminine 'weakness'.66 Here we arrive again at a gender-powered interpretation: that the imperfect female singer shows agency while the perfect one has been 'gifted' her voice rather than developing it herself. The perfect singer must not actively create her sung tone or her singing voice, as no woman could?

In this gendered paradigm the voice-object, as Abbate calls it in Unsung Voices, the sound of the 'perfect' singing voice, does have power, however. In the example she gives, Lakmé's 'Bell Song' draws Gerald in to imbibe her aural and visual beauty, and the male gaze therefore becomes male delectation, brought on by the power of her singing. Yet she retains agency only in so far as this action or power eventually leads to and effectively 'causes' her own death (in the form of self-sacrifice, which effectively stands as punishment for her seductive vocalisation). Abbate suggests that Nilakantha 'seems to realize that [...] [Lakmé] must be a sheer source of sound, to attract - fatally - the attention of that single listener'. ${ }^{67}$ The sound of the singing voice here is identified by Abbate as being treated as an 'object' which draws the listener's attention away from 'words, plot, character, and even from music as it resides in the orchestra, or music as formal gestures'. She describes this as 'a radical autonomization of the human voice that occurs, in varying degrees, in all vocal music'.68 Yet autonomy surely involves agency, and in such a plot as Lakmé, the singer, (that is Lakmé, the singer in the story) seems to hold little agency in real terms as a female within society. As a singer she is definitely powerful, and her power is encouraged (by Nilakantha), but it is then used against her (despite the 'happy ending' of her ascent to paradise after her death).

By contrast, Koestenbaum muses on Callas's vocal agency:

Commentators describe Callas as a reincarnation of a kind of singer that flourished in opera's golden age - a singer who could span all ranges and styles. We admire Callas for exceeding and giving the lie to modern measurements. No note she sings remains the same; she changes voice inside the note, as if to say: "Try to catch me, to name me, to confine me in your brutalizing classifications!"69

\footnotetext{
${ }^{66}$ Linda and Michael Hutcheon illustrate this concept through their discussion of Salome's power. She demanded power in the form of the gaze through her dance, and it actively gave her control and therefore agency. Hutcheon and Hutcheon, Bodily Charm, 106-9.

${ }^{67}$ Carolyn Abbate, Unsung Voices: Opera and Musical Narrative in the Nineteenth Century (Princeton University Press, 1991), 6.

68 Abbate, 9-10.

${ }^{69}$ Koestenbaum, The Queen's Throat, 146.
} 
Even singers themselves sometimes need to be reminded that we can change the characteristics of a note while performing it - that the note is never set in stone. This is because we do create all our notes one by one, and keep doing so for every millisecond that we sustain them. The voice, as Eidsheim stresses, is an action: the singer sings - it is an active behaviour that creates the sound. ${ }^{70}$ The singer is not someone who 'has a voice'. As we know, the human singing voice is not an instrument in the sense that it exists all the time as such, it is an instrument that becomes one in the moment that it is used for the production of sound. The quality of the singing instrument is much more about the actions and decisions of the singer than many commentators assume. Koestenbaum, for example, assumes Callas's register breaks are out of her control:

Most singers of Callas's caliber hide the register break. Callas couldn't. The naked break shows her to be, though a genius, a bit of a freak - delightfully selfembarrassing, unable to control herself in this tiny matter on which bel canto art depends. The break between registers is the moment when the voice proves itself to be of two minds. Compare her 1953 Lucia and her 1959 Lucia: although her tone is darker in the 1959 version, her register break is tranquilized, and so she travels up and down without disgrace - a subdued Callas, a Callas about to quit. ${ }^{71}$

It is remarkable how much can be (and how much tends to be) read into the singing voice and/or the singer's sound. According to Koestenbaum, the smoothing over of the register break by Callas in her 1959 recording of Lucia is a tranquilising of herself, her own bodyvoice, rather than simply an example of good singing. Instead of Callas now achieving something that, according to Koestenbaum, she could not achieve previously, he sets this achievement up to be something negative that she has done to herself, as she supposedly sinks into a depression that leads inevitably to her giving up singing. ${ }^{72}$ So a moment that could be read in terms of empowerment and as a sign of agency is here read as the diva actively subduing herself, quietening down an otherwise disruptive action or an attribute that is supposedly outside her control.

Jarman-Ivens discusses these register breaks in different terms: 'In allowing the breaks between her registers to be heard so clearly, what Callas's voice does - even more than crossing a discursively-produced masculine/feminine divide audibly - is to reveal the

\footnotetext{
70 Eidsheim, 'Maria Callas's Waistline and the Organology of Voice', 250; Eidsheim, 'Voice as Action', 23-24.

71 Koestenbaum, The Queen's Throat, 146.

72 While we may know that in fact her career wound down from 1960, this seems a tenuous reading of what could easily be seen as a gain in power and vocal control.
} 
technologies of vocal production'. ${ }^{73}$ Making reference to Roland Barthes' 'The grain of the voice' she suggests that 'at these moments, we hear "the body in the voice as it sings"; the internal technologies of the voice become audible'. ${ }^{74}$ Whether Barthes, who found operatic expression to have little significance, would have approved of this particular way of making the 'body' audible is questionable. He stated that 'opera is a genre in which the voice has gone over in its entirety to dramatic expressivity, a voice with a grain which little signifies'. ${ }^{75}$ This gives some inkling of where he is leading us with his concept of 'grain': for Barthes, grain has to be in a 'dual production' (en double production) of language and music together in order to become significant as grain. He states that he dislikes Dietrich Fischer-Dieskau's 'inordinately expressive' art, which is made by way of the soul (which is identified by Barthes as the breath or pneuma) accompanying the song instead of the body doing so. ${ }^{76}$

Barthes elucidates his viewpoint further in the lecture 'Music, voice, language', when he discusses his 'lover's relation to Panzéra's voice: not to his raw, physical voice, but to his voice as it passes over language, over our French language, like a desire'. ${ }^{77}$ He goes on to describe what specifically attracts him to the singing of Charles Panzéra, including the pureness of his vowels, the 'distinct and fragile beauty' of the $a$ vowels, 'the grain of the nasals, a little harsh, as though spiced', his pure brief rolled $r$ of which the 'symbolic role is to virilize gentleness without abandoning it', and the 'patina of certain consonants', and describes this as pronunciation as opposed to articulation. ${ }^{78}$ It seems that Barthes' 'body in the voice' is intimately bound up with the sensation of diction, particularly French language diction, where the body carries eloquence rather than the breath, which, according to Barthes, can only impart emotion. Callas's dramatic emotional (breath-based) vocal production is therefore unlikely to provide this particular sense of the body in the voice to which Barthes is drawing attention, however, the sense of a body creating the sound, and the sense of the agency that that involves, is definitely able to be brought out by a vocal production such as Callas's.

\footnotetext{
73 Jarman-Ivens, Queer Voices - Technologies, Vocalities, and the Musical Flaw, 105.

74 Jarman-Ivens, 105.

75 Barthes states: 'pour l'opéra, c'est un genre où la voix tout entière est passée du côté de l'expressivité dramatique : une voix au grain peu signifiant'. Roland Barthes, 'The Grain of the Voice', in Image, Music, Text - Essays Selected and Translated by Stephen Heath (Fontana/Collins, 1977), 181; Roland Barthes, 'Le grain de la voix', Musique en jeu, no. No. 9 (November 1972): 58. ${ }^{76}$ Barthes, 'The Grain of the Voice', 181-83.

77 Roland Barthes, 'Music, Voice, Language', in Music, Words and Voice: A Reader, ed. Martin Clayton (Manchester University Press, 2008), 80.

78 Barthes, 82.
} 
Referring to Susan Bordo's work around the 'construction of the body as something apart from the true self (whether conceived as soul, mind, will, creativity, freedom. . .)', Eidsheim suggests that ' $[t]$ he questioning of Callas's voice is arguably ignited because in her voice we hear the body'. ${ }^{79}$ This concept of the body in the sound is again not being used in the sense of the 'grain' that Barthes delights in, but rather the weight or loss of body weight which supposedly affected Callas's sound. Eidsheim refutes the supposed connection between Callas's vocal ability and her weight loss on the basis of the specific vocal techniques required for control of those aspects of her singing that were criticised. She identifies these censured vocal qualities as 'range, pitch, vibrato, timbre, vocal support, and register'. ${ }^{80}$ These aspects are discussed in terms of the 'loss' of Callas's upper range, the supposed increase in her 'wobble' (an uncontrolled or too-wide vibrato), supposed lack of beauty of vocal tone and ability to manage the outflow of breath, and the lack of smoothing of the changes between different 'registers' of the voice. All of these were cited as issues affected by her weight loss, but most, if not indeed all, of these issues existed prior to this, even if they may have increased later on in her career. They could be attributed to a lack of technical control, but this concept is also problematic when one considers Callas's astonishing control in so many performances (the 1955 Berlin Lucia, conducted by Herbert von Karajan, for example).

There are indications that the music critics were affected by Callas's presentation of a more slender body in their assessments of her singing. While she was described as 'tall and splendid, like one of Millais's pictures of mid-Victorian divas' by Philip Hope-Wallace in 1952, her debut in New York as a slimmed down Norma in 1956 elicited references to her body as 'rangy' (tall and thin) and 'the possessor of a somewhat small voice that she uses to great effect'. ${ }^{81}$ The reviewers described her vocal sound as fuller and stronger when she looked heavier: were these critics affected by the phenomenon of hearing what you see? Since she was now thinner they therefore heard a 'thinner' voice? Listeners often project what they expect to hear onto the actual sound, and the listener's own values and beliefs may contribute to what they hear. ${ }^{82}$

\footnotetext{
${ }^{79}$ Bordo, Unbearable Weight, 5; Eidsheim, 'Maria Callas's Waistline and the Organology of Voice', 253.

${ }^{80}$ Eidsheim, 'Maria Callas's Waistline and the Organology of Voice', 249, 260.

${ }^{81}$ Hope-Wallace, "'Norma” at Covent Garden: After 20 Years'; Douglas Watt, 'Callas a Success in Met Debut', Daily News, 30 October 1956. It is unclear which paintings Hope-Wallace was referring to, but possibly John Everett Millais' 'Portrait of Mrs Charles Wertheimer'.

${ }^{82}$ Eidsheim, 'Voice as Action', 20, 24-25.
} 
The weight loss as such would have been unlikely to affect Callas's vocal capabilities significantly. ${ }^{83}$ The suggestion made by soprano Renée Fleming that Callas may previously have relied on the body fat as part of her support mechanism also does not seem plausible given her rigorous training and the degree of self-control shown in her vocality. ${ }^{84}$ The weight could have helped her to relax the abdominal muscles however, which do need to remain flexible (not the diaphragm, as asserted by Giulietta Simionato) and this could have contributed to a decreasing ability to control her vibrato. ${ }^{85}$

Callas often took risks with her approach to vocal performance. I do not intend to imply that what she did vocally was necessarily dangerous to her vocal health, but rather that she showed immense courage and determination in the face of challenging vocal writing. One example is in the way she insistently applied herself to the creation of strong dynamic contrasts and attempted particularly acute pianissimi on sustained high notes, despite the fact that soft sustained high notes clearly presented technical issues for her and she was often unsuccessful in producing them without losing stability of the pitch and the control of her vibrato.

The ability to continue to achieve high notes under increasing stress in public performances requires a coolness that perhaps was starting to elude Callas, as well as the physical need to maintain an 'open throat' (identified as 'false vocal fold retraction' in the Estill model), something which becomes ever more difficult under such psychological pressure. ${ }^{86}$ The register changes were never something Callas actively sought to cover up, rather she emphasised them by choosing to use a high degree of 'raw' chest in the low range of the dramatic arias she sang, which gave her great expressive power and projection. Perhaps, having never attempted to match the colours of the different registers (ranges) in her earlier career, it was impossible for her to find the way to correct this later on. When she returned to singing in 1973-74 the low passaggio register change (between

\footnotetext{
${ }^{83}$ Abdul-Latif Hamdan et al., 'Effect of Weight Loss on Voice After Bariatric Surgery', Journal of Voice 28, no. 5 (1 September 2014): 618-23.There have been very few studies testing of the relationship between weight loss and vocal quality. This study from 2014 concluded that 'weight loss does not have a perceptual or acoustic effect on voice', although some subjects did notice a change in their fundamental pitch which they perceived as being higher. The researchers point out that such weight loss by an obese singer would be more likely to improve their health and impact positively on their vocal power and stamina, unless their restricted diet provided poor nutrition. One possibility, for which there is no convincing evidence, is that Callas may have been suffering from an eating disorder such as bulimia. If so, the side-effects of the associated vomiting could certainly be detrimental to the condition of her voice in terms of timbre and hoarseness, but would be unlikely to affect the support and stabilisation required for the control of vibrato which is one of the main aspects identified as part of her supposed vocal 'ruin' brought on by the loss of weight. 84 James C Whitson, 'The Callas Legacy', Opera News 70, no. 4 (2005): 18-22, 24.

85 Eidsheim, 'Maria Callas's Waistline and the Organology of Voice', 256-57.

${ }^{86}$ Steinhauer, Klimek, and Estill, The Estill Voice Model, 61, 65.
} 
'chest' and 'middle voice') had become much worse and very obvious. But this, as Eidsheim shows, cannot be attributed in any causal way to the slimming process she undertook twenty years earlier. ${ }^{87}$ In fact, it seems much more likely that Callas decided to emphasise these differences for effect, perhaps initially under her complete control. Even later, at least in the early 1960s, as Koestenbaum has noticed, she was able to 'fix' this 'issue'. 88

These questions aside, what many of the assertions by music critics, and other readings of Callas's singing body, show overall, is how poorly singing is generally understood in terms of how it is achieved, how it is enacted and created physically. The 'magic' created by Callas was recognised by reviewers despite the shortcomings of her singing when judged in terms of the paradigm of vocal beauty and consistency. As a disruptive influence against this paradigm, Callas's agency was alternately acknowledged and disparaged: she was lauded for her great variety of vocal colouration, that was seen as created by her, yet criticised for vocal 'flaws' which were interpreted as a lack of control. In the following section I analyse recordings from the main period of her success to consider this control and her creation of her distinctive vocality by describing the means of its production.

\section{L'Ultima Voce: Callas and the Beautiful Voice}

Maria Callas: It is not enough to have a beautiful voice. What does that mean? When one is interpreting a role, one must have a thousand colours in order to express happiness, joy, sorrow and fear. How can you do that simply with a beautiful voice? Even if at times you sound harsh, as I often have, that is a necessity of expression. One must do it, even if people do not understand! 89

Callas's statement above, in which she implies that the beautiful voice is inexpressive, clearly outlines her ideology to do with vocal beauty, and suggests that her vocal flaws, or 'harsh' sounds, were very often intentional, and created for expressive purposes. My own first memories of the experience of hearing Callas centre around a particular LP vinyl disc I obtained while a student of singing on which, among various other arias, was Ponchielli's 'Suicidio' from La Gioconda. ${ }^{90}$ I remember being wholly taken over by this performance. I

\footnotetext{
${ }^{87}$ Eidsheim, 'Maria Callas's Waistline and the Organology of Voice', 262.

88 Koestenbaum, The Queen's Throat, 146.

${ }^{89}$ Kesting, Maria Callas, 53; John Ardoin, 'The Art and the Life', in Callas: The Art and the Life - The Great Years, 1st edition (New York: Holt, Rinehart and Winston, 1974), 11.

90 This was the 1952 recording made at RAI Auditorium by Cetra, with Antonino Votto conducting. A version of the same recording can currently be found online at: Maria Callas - Suicido! - La Gioconda 1952 Studio with Sound Externalisation GREAT SOUND!, accessed 19 September 2019, https://www.youtube.com/watch?v=7Xws7wKuc4w.
} 
could hardly fathom that such strength of tone, such charged powerfulness of voice, that I experienced through her performance on the recording, could arise from the female voice. More than anything, I realise now, this recording was inspiring to me in terms of this power of the voice, and most importantly, the female voice. Where did such tone and commanding authority come from? It conjured up a sense of female power, in a fully embodied form, that transferred itself to me, allowing me to imitate and enjoy the tremendous feeling of creating such dominant and imposing authority through my own voice.

I realised that in 'Suicidio', La Gioconda, the character in the opera, was contemplating suicide, yet the impression I gained of it from the recording was the fuming rage of a decisive woman, and it sounded to me more like someone about to commit revengeful murder than contemplating taking her own life. The sense of agency that came through the sound however was very strong, and created a very compelling sensory construction (or 'image') for me. The La Gioconda-Callas sang of suicide as actively tempting her and described it as the 'Ultima voce del mio destino' - 'the last voice of my destiny'.

Of course I copied Callas in this recording, trying to emulate the dark rich torrent of sound she made, and satisfied myself that I managed it quite well. In reality while it probably made me connect more deeply to my core muscles and my breath support, I worked out soon after that while listening to such dramatic singing was tremendously exciting, as a young lyric soprano, actually copying it was probably not doing much for my vocal development. The ultima voce was in fact Callas's dramatic voice: it tempted me, and it tempted her, though not in a suicidal way, at least on the edge of danger, as in Abbate's 'uncanny qualities' and the wildness she identifies as inherent in the drastic actions encountered in opera. ${ }^{91}$

John Ardoin compares Callas's performance approach to an aerial circus act without a net, in which the audience sensed the 'danger' inherent in her way of tackling the musical demands in the same way that the audience experiences a trapeze act differently when the safety net is removed. He quotes Henri Beyle Stendhal, who in 1824 commented with regard to Giuditta Pasta, the nineteenth-century diva for whom Amina in La sonnambula and Norma were written:

\footnotetext{
91 Carolyn Abbate, 'Music-Drastic or Gnostic?', Critical Inquiry 30, no. 3 (Spring 2004) (2004): 508-9.
} 
A large number of other outstanding singers of the old school long ago

demonstrated how easily an apparent defect might be transformed into a source of infinite beauty, and how it might be used to bring about a most fascinating touch of originality. In fact, the history of the art might tend to suggest that it is not the perfectly pure, silvery voice, impeccably accurate in tone throughout every note of its compass, which lends itself to the greatest achievements of impassioned singing. No voice whose timbre is completely incapable of variation can ever produce that kind of opaque, or as it were, suffocated tone, which is at once so moving and so natural in the portrayal of certain instants of violent emotion or passionate anguish. ${ }^{92}$

Ardoin comments that this description can fully apply to Callas, continuing that 'it was a voice that was better than beautiful, for it was a voice that once heard could not be easily forgotten. It haunted and disturbed as many as it thrilled and inspired, and it was the very personal colors of her voice, combined with its deficiencies, that made her sound so strikingly individual.'93 Therefore, according to Stendhal and Ardoin, a great singer's voice must have individuality and distinctiveness, and they redirect their faults to become 'sources of infinite beauty'. I would agree that such faults in Callas's voice or singing made her performances unforgettable, thrillingly expressive, and fascinating, but I am not thoroughly convinced that 'beautiful' is the most useful word to employ here. Indeed, I am not sure that beauty should be an ideal for a singer. What does this imply about society's need to define female voices as beautiful, when such a voice could be lauded instead as expressive, commanding and powerful? If these 'faults' are qualities that are so useful in singing, then they should not be called faults. Rather than faults we should instead describe them as expressive tools and choices: this is the nature of Callas's use of such sounds.

Ardoin avoids this issue by saying her voice is something 'better than beautiful' whereas Stendhal expects the great artist to transform a defect into beauty. What seems more applicable to Callas is the term attrice cantante, or 'singing actress' a term in use from the early 1800s. As Susan Rutherford describes, these were singers 'who regarded dramatic performance as an integral part of operatic practice'. ${ }^{44}$ To assert that Callas used her vocal faults as tools and sources of dramatic expression is reasonably straightforward, and many examples of this could be pointed to in her recordings of dramatic roles such as

92 Ardoin, The Callas Legacy, 203-4.

93 Ardoin, 205.

94 Rutherford, The Prima Donna and Opera, 1815-1930, 207. 
Gioconda, Tosca and Norma. She also used the faults as sources of emotional expression, heightening the differences between her registers and colouring the voice with a wide palette of tonal hues. But rarely does she use a tone that I would describe as truly beautiful, even though she is capable of doing so - the fact that she does at times use a beautiful tone shows this. It seems instead that her use of her voice in this way deliberately goes against the standard expectation of beauty of voice and beauty of vocal tone.

One exception is in the section of Puccini's 'Un bel dì' in the 1955 recording of Madama Butterfly, where she sings the passage 'Io non gli scendo incontro' through to 'non mi pesa la lunga attesa' (I do not go down to meet him [...] the long wait does not trouble me'). ${ }^{95}$ Callas aligns her vocal tone closely to Puccini's marking of dolcemente (sweetly) right through this section, perhaps the sweetest tone I have heard in any of her recordings.

In the preceding 16 bars however, from the beginning of the aria till this section, Callas moves through a whole catalogue of vocal colours. In just the very first set of phrases, 'Un bel dì' through to 'e poi la nave appare' (One beautiful day [...] and then the ship appears) she begins with a fil di voce - a fine thread of tone, to which she adds a small fast vibrato. As she descends through the middle voice she refrains from darkening the tone and only allows this on the four notes at 'estremo confin del' in bar 23 in the range $f$ ' to $a b$ ', then returns to a clear harmonically-balanced tone for 'mare' on the middle voice $b b$ '. As the line continues down to the low $d b$ ' notes at 'E poi la nave appare' she uses a strong 'chesty mix' (thick-fold, low larynx) tone and retains this quality for the middle voice $g b^{\prime}$ notes, only allowing this to release into head voice at the very end of the second note, as noted in the musical example below.

\footnotetext{
95 The Ultimate Maria Callas Collection (Audio CD) (EMI Classics, 2003). The recording of 'Un bel dì vedremo' is an excerpt from the complete recording of Madama Butterfly made for EMI in Milan at La Scala in August 1955. The recording is conducted by Herbert von Karajan, with the Orchestra del Teatro alla Scala di Milano. According to the CD booklet this mono recording was digitally remastered in 1997 by EMI Records Ltd.
} 


\section{Musical Example 1: 'Un bel dì vedremo' - Maria Callas}

'Un bel dì vedremo' from Madama Butterfly by G. Puccini. The vocality features that are marked in the score relate to the studio recording made by Maria Callas with Herbert von Karajan in 1955. ${ }^{96}$
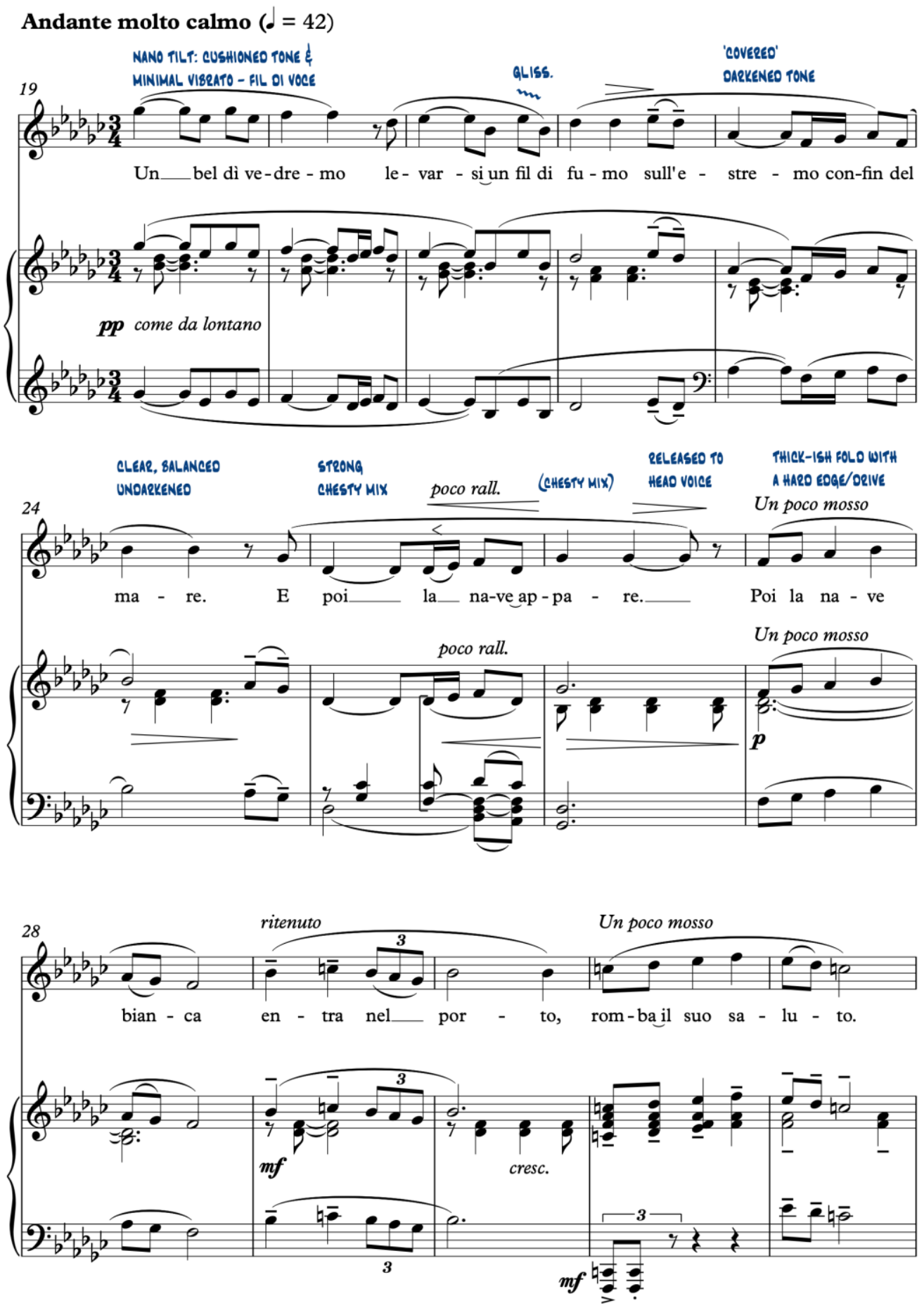

96 The Ultimate Maria Callas Collection (Audio CD). This is currently available online at: Maria Callas - Un Bel Di Vedremo, n.d., https://www.youtube.com/watch?v=c-r2vu4t9-g. 

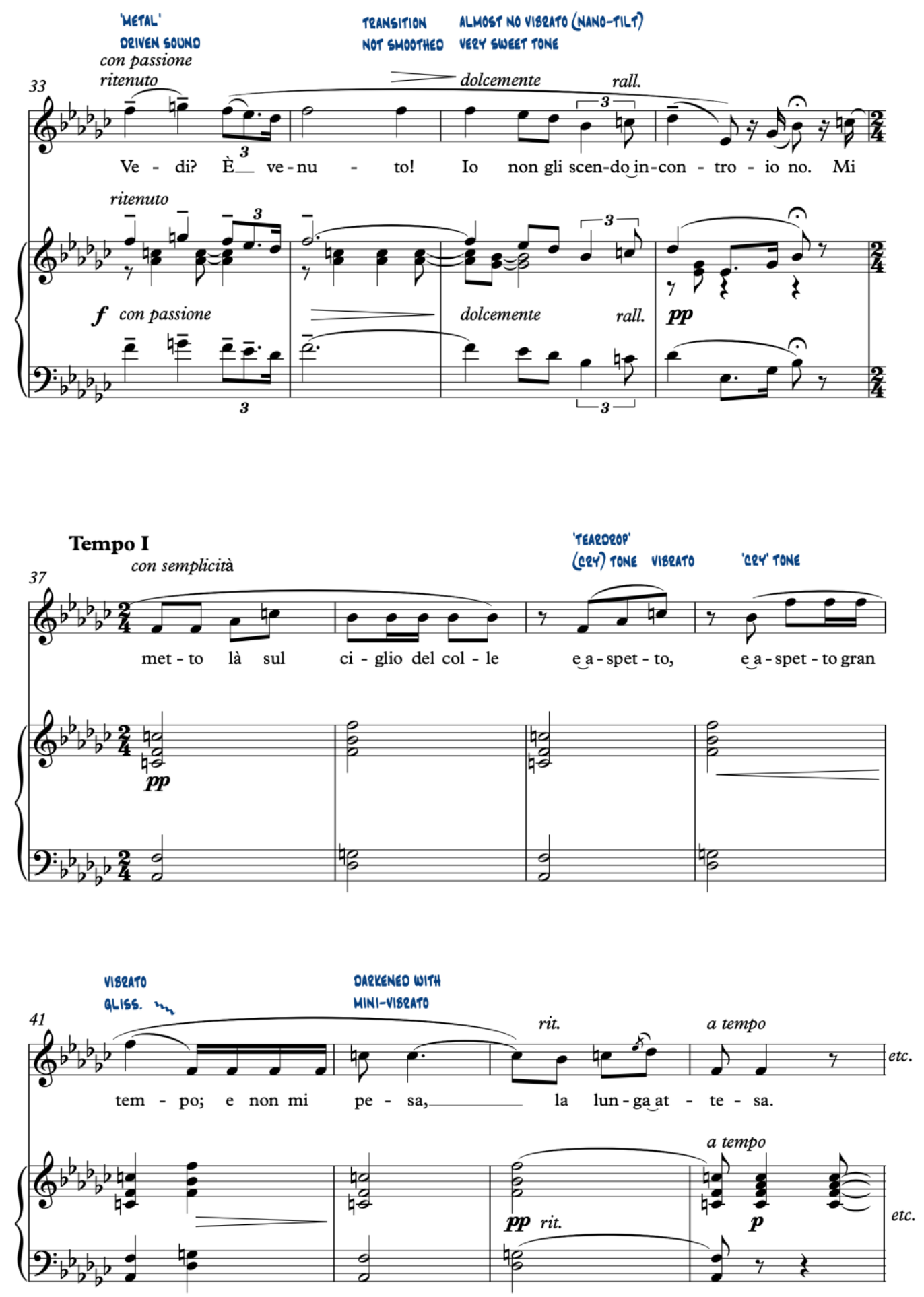

These few phrases serve to illustrate not only her variety of tonal colorations, and the control she has over the tone she is using, but how her choices often deviate from the limits normally adhered to by singers of the bel canto tradition, including those who followed Callas such as Caballé and Sutherland. They did not transgress the traditional 
lore that limited and still limits such usage. For example, the ratio of thick-fold 'chest mix' tone that Callas uses in her middle range ( $g$ b) notes here is unusual, perhaps not for some repertoire, but certainly for this aria. While the work is from the verismo repertoire, most sopranos at the time, and since, would treat it throughout, tonally at least, more like bel canto style, using sweet, cushioned tone, with a great deal of 'cry' (formed in the larynx by crico-thyroid tilt) and 'sob' (formed by crico-thyroid tilt plus a lowered larynx) providing for consistent vibrato and warmth for the more passionate sections. ${ }^{97}$

Callas, however, uses her vibrato as an expressive device that can be taken away and added in, often retaining no vibrato in the sound for some phrases then letting the colour flare for a particular note or notes through the addition of vibrato, for example at bars 20 24 ('levarsi' to 'mare'). At times, such as in the first phrase (Un bel dì vedremo), she is only using part of the crico-thyroid muscle (the pars oblique) to thin the folds and give a cushioned tone without allowing a full vibrato. This type of tone production can be thought of as a minimised tilt of the thyroid cartilage, or a 'nano-tilt'. 98

While Callas uses a darkened tone for the first few notes in bar 23, as mentioned above, this tonal darkening is much less prevalent in this recording than in others she made around that time. In her 'Casta diva', in the full recording for EMI made with Serafin in 1954 , for example, the tone of most of the notes in this middle range, from $f^{\prime}$ up to $d^{\prime \prime}$, a range which is so important for the opening passages of the verses, tended to be very dark. ${ }^{99}$ This darkening has moved all of her vowels towards a more backed position, so that they sound as the next vowel (a has moved to o, o to u, etc., and the i of 'diva' is modified from [i] to [u]). This adversely affects the clarity of the diction as well as creating an extreme colouration that for me crosses over the boundary line of bel canto beauty. This particular sound in the middle range relates to the 'bottled' tone that Walter Legge, who was producer for these recordings, complained about in Callas's singing, as well as the 'boxed in' resonance, and 'heavily covered' tone referred to by Hope-Wallace and Cecil Smith in their reviews of her 1952 London debut. ${ }^{100}$ In her 1960 recording for EMI of the

\footnotetext{
97 The 'cry' tone, as defined in the Estill Voice Model is a sweet tone with vibrato and is formed in the larynx by tilting the thyroid cartilage using the crico-thyroid muscles. The 'sob' tone, which has vibrato and a dark 'cushioned' tone, is formed by using the same crico-thyroid tilt with the addition of a lowered larynx. Steinhauer, Klimek, and Estill, The Estill Voice Model, 91, 95, 216.

${ }^{98}$ This term (nano-tilt) was used by the instructor (Paul Farrington) at the Estill Advanced Course (Level Three) which I attended in 2015 as a component of 'speech-cry' voice quality. Here Callas seems to be using it in as part of an 'opera' or 'cry' voice quality (as defined by the Estill Voice Model).

${ }^{99}$ Maria Callas at Juilliard: The Masterclasses (Audio CD) (EMI Classics, 1987).

100 Hope-Wallace, “'Norma” at Covent Garden: After 20 Years'; Smith, 'Opera Diary: Covent Garden "Norma"'.
} 
same aria, also with Serafin conducting, she has lessened the darkening and the diction is much clearer. ${ }^{101}$

Returning to the aria from Madama Butterfly, in the opening section, right after the few notes of darkened tone, there is a moment where I feel her genuine bel canto voice speaks, with an unaffected clarity. While this is only for a brief moment (the two crotchet notes of 'mare' in bar 24) we hear here a tone that is well balanced in terms of harmonics (upper harmonic brightness along with lower harmonic warmth) and gives what I believe to be a glimpse into the basic foundational instrument with which Callas worked. It is not a glorious sound, but it is a simple and truthful one, which, if she had ever been content to work as other lesser artists did, with just this basic tone, we would have heard often, and might even have identified this as her 'signature' sound.

Some might call this basic, simple tone Callas's 'natural' voice. I prefer to focus on the signature sound that a singer such as Callas chooses to develop as part of their signature vocality since this seems more pertinent to their success. Jarman-Ivens challenges the ideologies of both the 'natural' voice and uniqueness of the individual voice, calling both the 'natural' voice and vocal categorisations 'performative constructs with important gendered operations':102

[T] he naturalness of the voice itself must be called into question, as the voice has a performative function more than it is a direct marker of a stable, fixed, or inherent nature. Certainly, the ideology of the natural voice is a powerful one, and it is intimately bound to two other important ideologies of the voice-that it is a signifier of a very core of the speaker, and that it is individual, a unique sonic fingerprint. 103

I agree that uniqueness in vocal sound is a concept to be wary of, yet as we hear with Callas and the other two singers in this study, individuality, although it is at least in part performative, is a key element of the markers of success for such singers. In point of fact, we hear this particular 'natural' sound from Callas rarely, and yet, many commentators mention her distinctive and instantly recognisable voice. This points not only to the performative aspects of vocality, but also the agency which she wielded, not only as a

101 The Ultimate Maria Callas Collection (Audio CD).

102 Jarman-Ivens, Queer Voices - Technologies, Vocalities, and the Musical Flaw, 20.

103 Jarman-Ivens, 19. 
dramatically founded musical artist, but also as a singer who developed and maintained her own signature vocality.

In describing the 'mad scene' from Lucia, in the live audio-only recording of Callas's performance from Berlin in 1955, London Green describes how she manages to not only call up visions for the listener but also maintain mood while continuously changing her vocal colouration. This explanation of vocality used expressively gives some sense of the way a singer may vary their vocality while maintaining a constant in another aspect:

When Callas next enters, her Lucia is truly mad, driven to illusion by despair. The vocal tone expresses the visionary. What she gives us, even without the visual component, is the gift of only the most complete operatic artists: a moment of genuine privacy in public. Again the legato is superbly expressive. The music seems to be pure projection of feeling. It has all the frail vibrance of the moment before death. Each vision calls forth an altered tone quality, and yet there is absolute continuity of mood. ${ }^{104}$

What then is the true nature of Callas's signature vocality? Steane finds her voice instantly recognisable as it is for all great singers. Many others, however, have commented on her supposedly numerous 'voices': some state she has two, others three, and still others suggest hundreds. ${ }^{105}$ Those who assert two or three 'voices' are clearly referring to the different registers of the soprano voice breaking up her range by the passaggi between them often being not negotiated smoothly. Partly this is to do with the extreme differences of colour that Callas wanted to use in the different ranges, which makes it difficult to smooth the joins between the registers well. She used chest voice in particular for dramatic purposes, allowing the thick-fold sound normally used only for a soprano's lowest range to rise higher than most singers would today (although, according to Lowe, this usage was more common earlier in the century). ${ }^{106}$

Yet apart from this distinctiveness of registration, what is it that we recognise as Callas's distinctive vocality even without hearing a range or a melody? For me it is this foundational tone that we hear on 'mare' in 'Un bel dì' to which we are accustomed to hear

\footnotetext{
104 Green, 'Callas and Lucia', 70.

105 Smith, 'Opera Diary: Covent Garden “Norma”'; Kesting, Maria Callas, 41; Lowe, Callas, 8; Ardoin, The Callas Legacy, 204; Ardoin, Callas at Juilliard, xii. In the Foreword to Ardoin's Callas at Juilliard, conductor Nicola Rescigno states: 'Callas has very often been accused of having three voices. Nonsense! She had three hundred. Every role she portrayed had a special voice and within that particular timbre she would constantly change colors to convey the message of the composer.' 106 Lowe, Callas, 9.
} 
added metal (otherwise known as blade, or simply brightness), vibrato, and a variety of dark and light colouring, all incompletely mixed together. This mixed tone, which is at its best and most consistent in her verismo recordings such as the 1953 'Vissi d'arte' or the 1959 'Suicidio', is a form of the chiaroscuro that is used in the bel canto style of singing, in that it contains light and dark colouring, but these seem not to be fully blended together, as if they continued to exist as separate entities within the tone colour. ${ }^{107}$ It is the extreme 'cut' (or 'blade') of the high notes providing the brightness in the middle range, when she wants it to be there, and the darkness as in the 1954 'Casta diva', transformed by less action from the tongue allowing for more effect to from the laryngeal position (lowered) and clearer diction. Her chest (low range) notes are always stunning, the dramatically attained and sustained clear high notes from her early period are remarkable, but it is her middle voice that we hear the most often and therefore recognise as her signature vocality.

Callas controlled her vocal quality absolutely: she just did not always choose to make her sounds conform with the ideals of bel canto beauty in terms of vocal colour that were current at that time. Instead she chose to impart dramatic and emotional intensity and meaning through her vocal tone, and in doing so amplified the register changes, particularly from 'chest voice' to 'head voice'. This communicative purpose was prioritised over technical issues such as register 'breaks' or a widening vibrato. In fact, in arias such as 'Suicidio' her use of the power of raw chest tone is a form of transgression, one which takes a timbral form. ${ }^{108}$ It is clear that, at least in the decade of her heyday, she was able to control, and did control, other aspects of her vocalisation very precisely. These aspects included the pitch, flexibility and agility displayed in fioriture and cadenzas, and of course her range of colouration of the tone for expressive purposes. ${ }^{109}$

Callas's vocality displays power and agency. This power constitutes its fundamental sound quality through the intensity of the colouration as well as the variety of expression she creates. It is not beautiful, unless one is attracted by its raw unrounded quality, its underlying darkness of colour with its speckles of sparkling gold. As her teacher Elvira de

\footnotetext{
107 The word chiaroscuro, which relates in painting to the light and dark that allows for sculpted rounding of objects within a two-dimensional work of art, is also used to denote the shaping of light and dark tone in singing and one of the key components of the bel canto style involves the blending of chiaro (bright) and oscuro (dark) tone colour. 'Chiaroscuro | Art', Encyclopedia Britannica, accessed 14 June 2017, https://www.britannica.com/art/chiaroscuro; Martha Elliott, Singing in Style: A Guide to Vocal Performance Practices (Yale University Press, 2006), 137.

108 Eidsheim, 'Maria Callas's Waistline and the Organology of Voice', 257.

${ }^{109}$ Eidsheim in fact admits this possibility: 'Given her training and overall command of her voice (a command that is not disputed by her commentators), it is quite possible that the registral changes were intended.)' Eidsheim, 261.
} 
Hidalgo said, she pours out 'cascades of sound', which to me seems like a liquid stream one of fire hose strength, and with the energy of lava rather than champagne. ${ }^{110} \mathrm{Her}$ agency is clearly evident in the power that is recognised in her use of her voice for the expressivity of her singing, as music critics at the time of her debuts and from her legacy of recordings seem to have frequently noted, and even her authorship in terms of the creation of performances is recognised.

\section{La Divina as Medium: Aural Immortality}

What is forever lost, and what is always and repeatedly preserved of the operatic voice after the singer's death? Could a different body seemingly produce the bygone voice, thereby trying to recreate Callas, re-animate her, or would the new body refashion the voice? Or, more uncannily, would the voice affect the image sounding it?

(Michal Grover-Friedlander, re Callas Forever) ${ }^{111}$

Mediatisation in the form of studio-made audio recordings of her roles not only helped establish Callas's career but set up her legacy as a performer. She was one of the first singers to have almost their complete repertoire survive as audio recordings and as such she built and wielded significant power as a diva through these emerging mediatised channels. This was due in part to the fact that her career coincided with the development of audio-recording technology that allowed for high quality vinyl records to be released for home use. The timing of the exclusive contract for EMI which Walter Legge negotiated with her in 1952 was important not only for her career but also for the recording industry. As Ardoin notes:

Legge found Callas at a crucial moment. The record industry, just entering the LP era, was in its infancy in terms of packaging and promotion. Callas not only rode the crest of this new phonographic wave (as did Tebaldi on the Decca/London label), but she greatly contributed to its fortunes and its emergence as a mature artistic medium. ${ }^{112}$

At the time of Callas's career the recording of opera performances using the moving image was in its infancy and the first television broadcasts were made in television studios. There are films of concerts in which she sings arias and duets, but there are only three

110 Ardoin, 'The Art and the Life', 27.

111 Grover-Friedlander, 'The Afterlife of Maria Callas's Voice', 36.

112 Ardoin, 'The Art and the Life', 31. 
filmed excerpts of her in a staged opera production. All of these are of Act II of Tosca, and each of them was made as an excerpt from the opera specifically for television broadcast. None of them were made during a live performance of the full opera. While in Italy many operas were broadcast on television from 1954 onwards, usually these were filmed in a studio setting with the singers lip-synching to their own audio recording. ${ }^{113}$ Callas never consented to do this for any of the opera productions she appeared in in Italy, even though she was asked to do so. This reluctance seems to be due to the influence of Visconti, the esteemed director with whom she collaborated frequently. According to Visconti, the medium was still at the trial stage and the process was rudimentary: the cameras moved 'in such a way as to induce seasickness' and the black and white television produced only 'a flat, soulless, feeble grey'.114

Callas's remodelling of herself in the image of Audrey Hepburn through her 1953-54 weight loss is linked by Grover-Friedlander with a desire on her part to 'look cinematic while sounding operatic'.115 It now seems ironic that by doing this Callas 'projected herself' onto the figure of Audrey Hepburn, and that decades later, in the twenty-first century, her image should be projected, or more correctly, morphed, onto the image of an actress to create the illusory 'hologram' that performs on her behalf.

The lack of audio-visual recordings has certainly frustrated some, including Franco Zeffirelli, whose association with Callas during her lifetime was as a director and designer for some of her roles in opera, and as a friend. Zeffirelli wanted to create a film of Tosca with Callas, which, due to issues with the film rights, was never made, even though the soundtrack of the full opera was completed for this purpose in 1964.116 The first of the two movies based around her that Zeffirelli made after her death, La Traviata, was, he said, 'inspired by the work I had done with Callas so many years before' and he explained that 'To us she was Violetta and in making the film we were somehow giving ourselves a second chance to make the film with Maria'.117

\footnotetext{
113 Senici, 'Opera on Italian Television', 50.

${ }^{114}$ Senici, 50.

115 Michal Grover-Friedlander, 'Fellini's Ashes', in Vocal Apparitions: The Attraction of Cinema to Opera (Princeton University Press, 2014), 143; Kesting, Maria Callas, 156, 133. Kesting states Zeffirelli maintained that while they were rehearsing for II Turco at La Scala in 1955, Callas saw the film Roman Holiday in which Hepburn starred and decided she wanted to look like her. Hepburn is also quoted as stating 'I got to know her in Paris because we both had the same cosmetician... Maria explained that she wanted to lose weight and asked Alberto [the cosmetician] to correct her makeup in the way that he did for me. She took me as her model! That was an immense compliment for me.'

116 Kesting, Maria Callas, 260.

117 Grover-Friedlander, 'The Afterlife of Maria Callas's Voice', 38.
} 
Teresa Stratas played the Callas-role of Violetta for this movie version of the opera, and Zeffirelli wanted her to play Callas for his second film about her, Callas Forever. This time Callas was the main character in a fictional story about making a film version of Bizet's Carmen. Stratas turned the role down on the basis that it required an actor rather than a singer. Grover-Friedlander suggests that 'perhaps for Stratas, it was already too much to play not just one of the diva's roles but to impersonate the dead diva herself, miming to the great diva's voice.'118 Stratas's reluctance to play Callas in the later movie may have stemmed not only from her reverence for Callas, but also from not wanting to be further typecast as a Callas 'clone', and by so doing take on the burden of all the various associations of Callas, her career, the personal issues in her life, and her untimely death. Since she would also have been seen vocalising as Callas, with her own voice erased in favour of Callas's, it is possible she was concerned about this also, but it is unclear whether this had any bearing on her decision.

In the end, the role of Callas was played by actor Fanny Ardant, who not only played her for the dialogue scenes, but also lip-synched to the recording of Carmen that Callas had made in 1964 for EMI. This movie plays with themes and concepts of alive and 'undead' voices within the context of mediatising technology. In the film, Callas, played by Ardant, who has completed the lip-synched version of her own Carmen, in the end rejects this technically produced re-awakening of her own voice and refuses to allow the footage to be used. She wants instead to try to resurrect and record her own voice despite it being past its prime. As Grover-Friedlander describes it, her problem is that 'the film falsifies what it means to have a voice such as she once had. The voice, she implies, should remain "whole" and "in its time." In creating a Callas troubled by this [lip-synched film of] Carmen, Zeffirelli casts suspicion on the very technique on which his film operas are based.'119

In the movie it is the fictional Callas who is lip-synching to her own recording but, for us, it is the actor playing Callas (Fanny Ardant) who produces this doubly 'uncanny' version of the diva. Zeffirelli's question, through this means, of the status of the singer's voice as an object that transcends her lifetime is insightful. The movie-Callas's rejection of this seeming resurrection of her voice in her 'own' body serves instead to designate Callas's voice in sacred terms, to make a 'holy' object of her voice. This aim has of course already been accomplished by her many worshippers, but here Callas herself is in some way laying claim to her own voice, through these filtering layers of reality and pretence, and

118 Grover-Friedlander, 147.

119 Grover-Friedlander, 40. 
enshrining it, or rather, Zeffirelli's movie, through the actions of its characters, serves to do so. In fact it is more correct to say that the movie serves to deify or sanctify Callas's singing and vocality, rather than her voice. A form of posthumous claim to a copyright that has long since been waived, where, through the continued existence of her recordings, she becomes a lost voice that is 'un-lost'.

Along with the audio recordings Callas made for CETRA and EMI as part of her contracts to them, the 'pirate' recordings of many of her live performances in operas have been released on disc over the decades. John Ardoin discusses many of these 'live recordings' in fine detail in The Callas Legacy. ${ }^{120}$ The sources of such 'live recordings' are usually not identified in the release material. The sound quality of this type of recording is understandably variable, but some of her most acclaimed performances have been captured this way, and form part of her legacy. Initially the studio recordings made by EMI, with whom she had an exclusive contract for most of her career, were monophonic, but her later recordings were made in stereo sound. Perhaps a measure of the interest in her recordings is the number of times all of these recordings have been remastered over the ensuing years. It is even possible now to purchase all the known recordings in one boxed set, which have been digitally remastered at a 'state of the art' level in 2013.

Robert Seletsky, in his detailed appraisal of the recording quality of the various versions of Callas's recordings, states that the CDs released between 1985 and 1990 are more successful than the versions of the mono recordings that were remastered in 1997. Seletsky states that they 'preserve and enhance the breadth and richness of Callas's vocal color and musical expressiveness; Callas invariably sounds larger than life, projecting an exciting, palpable presence.'121 Seletsky's investigation of the differences between the released versions reminds us of the largely hidden effect of the authorship of the recording producers at the time the recording was made, as well as those undertaking subsequent remasterings. Such effects are unable to be found out without comparing the different iterations of the recordings yet can have a significant effect on the impression gained by the listener.

The listener's experience of Callas as an artist may also have been affected during her lifetime by the many interviews for television and the printed media she gave, and as noted earlier, these had an important role in connecting her to the public as a 'real' or 'authentic' person. Such media exposure stoked her fame, even though the interviews 
were not necessarily accurately reported in their published form, and many (often spurious) accusations and stories of various 'scandals' were also published. The result made her more than a singing diva - rather an international idol, both in her lifetime and after her death - but the audio recordings provide her true legacy of influence in terms of singing and opera. The audio recordings released during her career also built her career and developed her international fame as a diva singing star.

Those who heard Callas 'live' often maintained that her recordings did not match up to what they heard in the live performances. One example is Lord Harewood, the managing director of the English National Opera Company during the period of Callas's Covent Garden debut and heard her in many performances, who was quoted in The Guardian's obituary for Callas in 1977 as stating 'She was a truly great artist. [...] She was much better in person than on records. The records do not do her justice.' ${ }^{122}$ It seems that anyone who had heard her in person promulgated this idea for a long time; that the performances as experienced live were quite different from what was heard on recordings, however, most commentators debunk this as a myth. John Steane commented:

So much of her genius lay in her perception of a crucial point, which she would then endow with such life that the whole opera would be transformed [...]. This runs through her recordings and is one of the reasons why the sound of her singing is also visual. The recordings are no second-best. When people say of Callas, 'Oh but of course you had to see her!' the answer is 'I can! I do!'123

Steane points to the focused detail of Callas's interpretation as a reason for the sense of the visual element to her audio recordings. Her specificity in making a more general point through emphasising the meaning of a particular line of text or a particular aspect of the character of the role is certainly one of her modes of expression. However, Steane's interpretation of this relies on the listener having an in-depth understanding of the plot and the details of each line and/or scene. So it is Steane who is imagining the action, and although it may be prompted by what he hears, it is by no means certain that all listeners would have the same experience. Grover-Friedlander makes the connection of the voice with the body via the concept of 'presence':

\footnotetext{
122 Paul Webster, 'Callas the Divine Is Dead: From the Archive, 17 September 1977', The Guardian, 17 September 2014, sec. Music, https://www.theguardian.com/music/2014/sep/17/maria-callasdead-opera-1977.

${ }^{123}$ Steane, Singers of the Century (Volume 2), 258.
} 
[A] prominent trope [regarding Callas] invokes the opposite notion of presence by focusing on the roles Callas only recorded in a studio and never appeared in onstage. These studio recordings are referred to as the "theatre of the imagination," the spatial "mise-en-scène conceived in acoustic terms, a virtual space enhanced by stereophonic sound, a music theatre without a stage." Here, as the body is unseen, Callas's presence derives from her voice alone, for it is her voice that calls up the performing body. ${ }^{124}$

In fact, Callas's own sense of the process for studio recording was described by her as follows: 'It takes a little more time to get into the role, but not very much more. In making a record you don't have the sense of projection over a distance as in an opera house. We have this microphone and this magnifies all details of a performance, all exaggerations. In the theater you can get away with a very large, very grand phrase. For the microphone you have to tone it down. It's the same as making a film; your gestures will be seen in close-up, so they cannot be exaggerated as they would be in a theater.' 125 This comment is interesting for the way she conflates gestures as both vocal and physical in trying to describe her experience: she does not seem to be saying that she moves, but rather that she makes vocal gestures.

\section{Legacy and Influence: Conclusions}

Callas, appointed 'La Divina' (the divine one) by her fans, became legendary while she was still alive, and her life story, including her tragic early death, added to the unobtainable mystique surrounding her as a histrionic figure. As Anthony Tommasini has commented, 'Like so many now, I loved her without ever seeing her live'.126 This continued fascination with Callas, and the continued attempts to 'reincarnate' her via documentaries, plays, films (such as the recent film Maria by Callas) are epitomised by the hologram show described earlier in this chapter. The producers of all these seem to be desperately attempting to return to the world some form of a live 'Maria Callas'. However, Steane disagrees with this as a worthwhile aim:

124 Grover-Friedlander, 'The Afterlife of Maria Callas's Voice', 53.

125 Ardoin, The Callas Legacy, 31.

126 Tommasini, 'What a Hologram of Maria Callas Can Teach Us About Opera'. 
The recent play about her [McNally's Master Class] did Callas the great disservice of restoring her to life. That is no longer her element, and she is well out of it. [...] Callas is now beyond these things, and for the time being it would be better that she should remain so. Essentially, just as surely as Rembrandt is his paintings and Shakespeare his plays, Callas is her recordings. ${ }^{127}$

Some years ago I performed as one of the singers in the McNally play myself, and as a theatrical consideration of some of the issues around Callas as a performer, I believe it has a good deal of merit. In the play, Callas appears played by an actress, who does not sing, but interacts with the singers who take part in her masterclass (based on the series of masterclasses she gave at the Juilliard School in New York in 1971). At a number of points in the play, Callas is heard singing, as the on stage actress-Callas remembers her own performances, and an actual recording by Callas of the particular aria is played at each of these points. The focus at this point becomes centred around the sound of the recording, rather than the action on stage, so we do hear Callas, rather than some reincarnated version of a Callas, or a Callas proxy, singing. The play therefore avoids the problems of hearing the Callas voice coming from a different body, as in the case of the hologram show or in the movie Callas Forever. Steane's description of Callas as being restored to life is only true in terms of her speaking voice, and her singing voice is left alone in this play to 'speak' for itself, and introduce the real performer to the audience through her legacy of recordings.

The question of whether it is better to view a hologram of a long dead opera singer played by an actor who is lip-synching to remastered recordings, or to simply go to the opera or a concert to experience the power of the singing voice seems a straightforward choice, assuming they are both available for a reasonable price. However, since the audience for the hologram show are actually hearing Callas singing in one of her audio recordings, and this is still the real artist, in some way this might seem to satisfy Steane's requirement for Callas not to be reincarnated, since Callas the artist is still 'present' through her recording. While a hologram show of Callas with other 'live' performers on stage may be more 'live' than a normal video recording, I feel it is never likely to be a better experience than listening to the audio alone. Yet as Auslander has demonstrated, we are never far away now from some form of the mediatised within the live performance. ${ }^{128}$ Here liveness is constrained by mediatisation, in that the orchestral players most conform to the unchanging and 'unresponsive' recorded version of Callas. It is in fact another, quite

127 Steane, Singers of the Century (Volume 2), 253.

128 Auslander, Liveness. 
complex, version of Peggy Phelan's 'representations of representations', playing out as a 'live' performance:

Performance cannot be saved, recorded, documented, or otherwise participate in the circulation of representations of representations: once it does so, it becomes something other than performance. To the degree that performance attempts to enter the economy of reproduction, it betrays and lessens the promise of its own ontology. 129

Rather than live performance betraying its own ontology, in the case of this hologram 'accompanied' by a live orchestra, it seems that perhaps mediatisation has committed a self-betrayal and created a lesser version of itself.

Callas's legacy of audio recordings has influenced opera and singers in numerous ways, bringing renewed interest in the bel canto repertoire while showing how the dramatic voice type can sing works requiring agility dramatically. ${ }^{130}$ This influence and the taste for her dark-coloured heavier-quality signature vocality can be seen as having been passed on to later singers including Katia Ricciarelli, Elena Souliotis, Angela Gheorghiu, and Anna Netrebko. ${ }^{131}$

Callas showed by example that vocal expression is an influential medium through which to affect vocal fashion, and this aspect of her art has come to be identified with the agency of the singer. Further, the perceived 'rivalry' with Tebaldi, or rather, Callas's challenge to the accepted traditions of the ideal of vocal beauty, resulted in the splitting of the audience for opera into of two distinct factions, a phenomenon particularly evident in the hysteria surrounding her La Scala performances in the 1950s. This effectively set up a binary in terms of 'taste' in vocal fashion, with Tebaldi's 'beauty of tone' style being placed in opposition to Callas's expressivity and dramaticism of tone. Callas's influence continues to promulgate the dramatic vocal approach and listeners hearing her recordings still divide into groups along the lines of this binary opposition. In this way she changed the value placed on voice, in that it came to be acceptable (and in fact encouraged) for singers to follow her premise of 'acting with the voice'. Most have also attempted to satisfy the demands of the traditional concept of 'beauty of voice' as well however.

\footnotetext{
129 Phelan, Unmarked, 146.

130 Lowe, Callas, 13.

131 Kesting, Maria Callas, 26-27; Rutherford, 'Voices and Singers', 121; Siff, 'Angela Gheorghiu:

"Homage to Maria Callas - Favourite Opera Arias"'; Davis, 'The Diva Standard. Still.'
} 
Eidsheim concludes that 'Iconic singers are heightened carriers of culture. As representatives, these singers become idealized versions of the various roles on offer. That is, not only is Callas herself measured and perceived in comparison to the iconized version of herself, but so are female opera singers en masse.'132 This effect is heightened by recordings, visual or audio-visual, and to a degree by photography. Without mediatisation such comparisons are hazy and easy to lose sight of, but with lasting records of the performances and studio recordings the influence of an iconic diva such as Callas is strengthened, and in her case this influence has proved to be vast. Most sopranos since Callas point to her influence on the development of their own artistry, even if, for example in the case of Anna Netrebko, they may reject comparisons of themselves with her.

In an age where high-quality audio recordings were new, and there was little real competition from other mediatised performance forms, Callas demonstrated how this form of mediatisation could capture and transmit affective performance and influence attitudes towards voice in opera. Will this influence be retained as the twenty-first century proceeds? We are still listening to and watching Callas so she still maintains this power posthumously, but the popular focus of the general audience is now increasingly on the visual, which raises questions about whether her power will be able to be sustained through the future, given her legacy resides almost exclusively in the audio realm. There are also further areas yet to investigate in terms of this type of mediatisation, in particular around the phenomenological aspects of connecting with a mediatised voice, and how that actually differs from the perception of a live voice in performance and the values around that in a twenty-first century context. All of these are crucial questions related to the survival of the operatic medium and I will return to these in the context of specific examples in the following case study chapters.

Callas shows us how voice can 'live' through her audio recording legacy and her use of the voice as an instrument of dramatic action within a musical context. The influence of mediatisation, in the form of her recordings, in this way plays on the values around voice and the agency of the diva in constructing and maintaining power through different media forms. From considering the affective power that her recordings can still have on listeners, although they may be distributed in new formats and platforms, we learn that audio alone is enough for an operatic performance to be affective. The hologram video reveals how the visual can intrude and overshadow the effectiveness of aural media: for me the

132 Eidsheim, 'Maria Callas's Waistline and the Organology of Voice', 253. 
unconvincing morphed actor-image drew attention away from the undeniably intense and otherwise satisfying audio track. Perhaps this is merely a matter of the disjunction between image and sound, and if the image had been convincing but the audio was not, I may be just as distracted by that disjunction. This balance of the attraction of the senses to the visual versus the audio becomes acutely relevant for filmed opera, and in the chapter on Anna Netrebko I discuss this within the context of my own experiences of her live and Met Live in HD 'live transmission’ video performances.

It seems in some ways that, as a diva, Callas was a starting point, in that her approach to singing and performance have been so influential that a new era was marked by her career. ${ }^{133}$ However, she is also regarded as the 'one and only' Callas, a legend, mythologised in her own lifetime. While she introduced a new level of intensely focused vocally dramatic performance, for many fans no one can ever match up to her mythical status as a singer and a diva nor to her genius. She is regarded as a divine goddess who, by definition, can never truly have a successor, and these two ideas have been set up as both a beginning and an end point, in that she is a revolutionary influence and yet impossible for any soprano to follow or succeed. ${ }^{134}$

Callas's vocality, while powerfully affecting, was controversial because it was often dramatic at the expense of beauty, and the split in vocal fashion that came out of her agency and determination in showing the dramatic power of expressive vocality is also part of her legacy. As a dramatically-focused singer she seems to have had her agency acknowledged in a way that other singers did not, and she influenced attitudes and values around voice by winning over critics and audience to her dramatically focused vocal style.

Callas traversed the border between opera star and star, diva and public figure. While the 'rivalry' with Tebaldi and this controversy over different vocality styles was divisive, it also heightened the opera audience's understanding or engagement with vocal fashion, and vocality itself, as part of the underlying psychological response to singing pointed to by Poizat in The Angel's Cry. ${ }^{135}$ Although the controversy was disruptive at the time, it set up more clearly the two possibilities of the future path for vocal fashion that allowed for

\footnotetext{
133 Lowe, Callas, 180, 211, 226. The comments here by Jean Lacouture, and Eugenio Gara, music critic, are about the change and even 'revolution' brought about by Callas. Christiansen, Prima Donna, 279. Christiansen states: 'for many people the idea of the prima donna still begins and ends with Callas. This is absurd. Callas was indeed a revolutionary, but not a revolutionary without a tradition to inherit or a band of comrades'.

134 Steane, Singers of the Century (Volume 2), 254; Davis, 'The Diva Standard. Still.'; Christiansen, Prima Donna, 289-90.

135 Poizat, The Angel's Cry.
} 
an intense engagement of the audience for opera with both or either aesthetic style. In the next chapter, we will see how Callas's legacy impacted on Te Kanawa as a diva whose intensely beautiful vocality meant she followed the footsteps of Renata Tebaldi rather than her 'rival' Callas. 


\section{CHAPTER 3: MAKING BEAUTY: KIRI TE KANAWA AND THE FEMININE IDEAL}

I couldn't believe it [...] I hadn't heard such a beautiful voice

for years and years and years.

(Colin Davis, Music Director, Royal Opera Covent Garden) ${ }^{1}$

On the 29th of July 1981, New Zealand soprano Kiri Te Kanawa performed Handel's 'Let the bright seraphim' at the royal wedding of Prince Charles and Lady Diana Spencer. The intense interest in this event meant Te Kanawa's performance during the service in St Paul's Cathedral, London, was watched by an estimated global television audience of at least 600 million people. This was probably the largest audience for any single performance of classical music up until that time, and the audience size also made it the most popular television programme that had ever been broadcast. ${ }^{2}$

With this performance Te Kanawa ascended to the podium of global stardom, taking her place as an internationally famous opera singer. ${ }^{3}$ She went overnight from a star within opera circles, with a voice of divine beauty, to global recognition, and took on the mantle of Michel Poizat's 'celebrated singer' - a divine goddess, a diva. ${ }^{4}$ Yet an arguably more important event for her legacy was her astonishingly successful debut as the Countess in Le nozze di Figaro in December 1971 at the Royal Opera, Covent Garden. The critical and popular acclaim for this debut pointed to her physical beauty, her assured stage manner, and her beauty of voice. Over time this vocal quality and style - her 'signature vocality' can be seen as the enduring feature of her fame. Moreover, the combination of her physical beauty with her beauty of voice fed into the public concepts of stardom, and was emphasised in the mediatisation and promotion which propelled her career to global fame, with the result that both the general public and scholars alike have treated her as a diva.

\footnotetext{
${ }^{1}$ David Fingleton, Kiri Te Kanawa: A Biography (London: Collins, 1983), 181. Colin Davis describes his reaction to hearing Kiri Te Kanawa for the first time, probably in late 1969, in her first audition for the Royal Opera Covent Garden.

${ }^{2}$ Adrienne Simpson and Peter Downes, Southern Voices: International Opera Singers of New Zealand (Auckland: Reed Books, 1992), 227. Other sources give a higher estimate of the number of television viewers. See, for example, the BBC 'On this day' article, which states that the Royal Wedding was viewed by 'an estimated global TV audience of 750 million - making it the most popular programme ever broadcast'. '1981: Charles and Diana Marry', 29 July 1981, http://news.bbc.co.uk/onthisday/hi/dates/stories/july/29/newsid_2494000/2494949.stm. 3 Fingleton, Kiri Te Kanawa, 176-77.

${ }^{4}$ Poizat, The Angel's Cry, 179.
} 
Through her hugely successful Covent Garden debut Te Kanawa established her distinctive signature sound as a new exemplar of professional vocal timbre. Her rise in standing through this level of success at such an important opera house left her in a position to influence the fashion and vocal trends in operatic singing of the final decades of the twentieth century. Yet despite the extent of Te Kanawa's fame and influence, critical examination of her singing has been almost entirely limited to journalistic reviews, and her underlying vocal production is rarely considered. Moreover, while she is mentioned frequently in articles, books and other works that discuss celebrated singers, and is often referred to in these in these as a 'diva', it does not seem a straightforward task to align her with the generally accepted concepts of divahood.

We have seen how Maria Callas's rise to global celebrity in the 1950s set up a popular perception of the modern diva that was in fact based more on her style of behaviour off the stage than her dramatically-focused performance approach. In terms of her standing as a diva within the operatic world Callas's dramatic focus had a huge influence, yet many singers since that time whose global fame would seem to confer divahood have deviated from both the dramatic approach and the off-stage behaviour implied by her model. In the case of Kiri Te Kanawa we cannot easily reconcile her vocal style, with its smoothly lyrical outpouring of sound, with Callas's intensely dramatic vocal characterisations.

According to the generally accepted rules for operatic style that stood before Callas's version of divahood came into play, opera singers must ensure that they utilise tone that lies within a limited range of colour and within a perception of beauty that will be deemed stylistically appropriate for the genre. This is where Callas transgressed the rules. Te Kanawa, by contrast, complies with them, and does so in a way that is individual, and yet epitomises the qualities of beauty of tone and physicality, to provide a continuation of the other type of diva, the Tebaldi type. This is part of the story of 'what happened after Callas'.

As a lyric voice the expectations placed on Te Kanawa were based on beauty, both of voice and of body, and in her case she not only fitted these expectations but took them to new levels. But with this conformity to the 'ideal' for the female lyric singer, she was also subject to attitudes and tropes that undermined the sense of her artistry and agency: being seen as both a supposedly 'natural' singer, and a 'non-intellectual' one, which was further emphasised by the idea of a woman as able to be either attractive or intelligent, but not both. Her promotion emphasised this beauty of voice, treating her as an artist with a great voice rather than as a great singing artist. Moreover, she signifies the beautiful 
woman archetype, which leads to other tropes, and the female/male binaries already discussed with respect to Callas. All of these concepts and attitudes serve to mask the underlying agency that is required to build and maintain the signature vocality of such an artist.

Few scholars have paid attention to Te Kanawa as an artist, at least not in any in-depth way, which in itself can be seen to perpetuate the lack of recognition of her work as a musician and artist. Where she is mentioned in scholarly texts this tends either to be as an example of a particular type of star or singer, where she is usually identified as a 'diva'; or to make a point about the marketing applied to opera along with other musical or artistic forms in the late twentieth century. Scholars such as Rutherford, Eidsheim, Jarman-Ivens and Leonardi and Pope have appraised the various tropes that tend to be applied to singers such as the 'natural' voice or the 'natural' singer, and the singer as nonintellectual. ${ }^{5}$ These are examined from a critical point of view, but little has been done to show the work and agency which does underlie the production of the sort of consistent vocal beauty for which Te Kanawa was renowned, which would work to combat these concepts and attitudes.

The competing pressures for individuality of vocal tone and conformity to 'operatic' sound and style make the stages of training and steps towards a career particularly difficult for singers with lyric voices like Te Kanawa. ${ }^{6}$ The young lyric soprano finds herself numbered among the most populous group of voice types, one that has an expectation of the use of a particularly narrow range of tone that must always be 'beautiful' (while beauty is of course subjective and there are no agreed definitions for this). ${ }^{7}$ At the same time, as an

\footnotetext{
${ }^{5}$ Rutherford, 'Voices and Singers', 133; Eidsheim, The Race of Sound; Jarman-Ivens, Queer Voices Technologies, Vocalities, and the Musical Flaw, 104-7; Leonardi and Pope, The Diva's Mouth, 17. ${ }^{6}$ Te Kanawa is usually described as a lyric soprano, and has descibed herself as this (for example, in her book Opera for Lovers). Her voice is, however, on the heavier end of that grouping, as she had success in some rather heavier roles than that which most young lyric sopranos would be expected to sing. Kiri Te Kanawa and Conrad Wilson, Opera for Lovers (Auckland: Hodder Moa Becket Headline, 1996), 45.

${ }^{7}$ Although the concept of 'bel canto' (beautiful singing) arose in Italy, then prevailed throughout most of Europe from the 18th century, and was developed and written about by various teachers through to the 19th century, with no audio recordings made in that period it is difficult to be sure of what was really meant by 'beautiful' tone at the time. The precepts of bel canto however do involve a blend of chiaro (bright) and oscuro (dark) tone colour that is exemplified by Te Kanawa's distinctive vocality. Manuel Garcia, in his Traité complet de l'art du chant called these the timbre clairs et sombres (clear and dark tones) and 'continued to place great importance on blending registers and the development of beautiful tone'. Elliott, Singing in Style, 137. While we do have some recordings of singers whose careers and training derive from this period, such as Adelina Patti, as Daniel Leech-Wilkinson shows, while there are some aspects we can judge from her recordings, such as the precision and fluidity with which she handles fast runs and ornamental passages, other aspects are harder to determine. Partly this is due to the lack of information about
} 
emerging singer, she becomes aware that she needs to develop and refine the distinctive qualities set up by her individual physiological make up, in order to claim her own quality of sound.

This was the situation for the young Te Kanawa in the late 1960s, yet the distinctive quality of her beauty of tone and personal beauty were recognised in her sensational debut as the Countess in Le nozze di Figaro in 1971. The critical response to her as a debuting artist reveals the values placed on voice for the diva opera singer in this period. She went on to have a career based on international success as an opera singer, and established her status through many highly successful recordings. While her individuality of sound, and the beauty of her vocal tone and vocality, were all rightly celebrated as part of that success, her agency in forming and producing that vocal sound was not always recognised. In this chapter I uncover the processes underlying the production of this beautiful sound and examine the degree of agency she had in determining her vocality and how it could be maintained in the recorded media through which it was distributed.

Te Kanawa's initial success in professional opera occurred at a time when recorded media began to be readily available in high quality, and this, along with the developing interest in opera on television and film, allowed her vocality to reach hundreds of millions and to be stamped into their memories as an alternative to the Callas concept of the diva. Her influence on later singers, and the influences on her in terms of sound show that there was a return to the aesthetics of beauty and 'vocal presence' that ran parallel to the interest in Callas's style of dramatic expression.

I show, through an examination of her vocality and the reception of her early career performances, how Te Kanawa represents a continuation of the Tebaldi line, set up by fans and critics as an aesthetic in opposition to that of Callas's during their careers. Te Kanawa's agency as a singer has tended to be overlooked due to the emphasis on her beauty, but in fact her vocal beauty is, at least in part, a result of her agency. My analysis of her vocality provides for an understanding of the vocal production processes underlying it, and thus gives a sense of the nature of that agency. In particular I show here the way in which her vocality and vocal production has been controlled by her since her early years as a singer, and moulded by her for different modes of performance. I argue that as a singer her power lies within her distinctive and consistent vocality, which she has maintained throughout all forms of mediatised performance, and her authorship and the 
strength of her influential power as a diva lie in this combination of distinctive vocal sound and style of singing.

In this case study I consider how others described and evaluated Te Kanawa's vocality and vocal performance and the values around the operatic voice that such evaluations reveal to be in play during this mid- to late-period of the twentieth century. I then trace elements of Te Kanawa's distinctive sound in the vocal quality of lyric sopranos who followed her, highlighting the increase in this type of sound from around the time of her success on the Covent Garden stage in 1971, which continued throughout her ensuing decades of fame. Her prolific output of vinyl and compact disc solo recordings, her film, video and television appearances, such as that of the royal wedding performance, as well as the use of her recordings within other media have all contributed to this influential effect.

This chapter explores the way in which Te Kanawa's style of vocality and her style of divahood came to have such a strong impact and influential power through both live and mediatised performances, and uncovers attitudes and expectations that affected and influenced the discourse around her as well as examining the aesthetic trend for vocal beauty that reached new heights with Te Kanawa in relation to the dichotomy set up by the Callas-Tebaldi rivalry in the 1950s.

\section{Exquisitely Constructed Beauty}

Te Kanawa's successful debut at the Royal Opera Covent Garden was preceded by a series of auditions for the company (her memory was of nine auditions being required), and a year of preparation for the role, in the form of coachings with Jeffrey Tate, who at that stage was a repetiteur at the Garden. ${ }^{8}$ Colin Davis, the incoming Musical Director, auditioned her and required the multiple auditions, as well as the lengthy and intensive preparation. He commented about the reason for the numerous auditions:

I just could not believe my ears the first time I heard her. I had to check that it was not a fluke performance but the truly remarkable voice it seemed. ${ }^{9}$

Davis went on to feature Te Kanawa as the main soloist for his upcoming recording of Mozart religious music in April 1971, prior to her main role debut for the company in

\footnotetext{
${ }^{8}$ Fingleton, Kiri Te Kanawa, 80. Fingleton states: 'Kiri believes she auditioned for the Royal Opera no fewer than nine times. Even if that is slight retrospective exaggeration it is certain that a substantial number of auditions took place'.

${ }_{9}$ Te Kanawa and Wilson, Opera for Lovers, 14.
} 
December. John Copley, the director for Figaro, set up an extra six weeks of staging rehearsals for her before the rest of the cast began. Obviously the Royal Opera wanted to be absolutely sure that this relatively inexperienced young singer would be totally ready for the exposure of the lead role.

Te Kanawa had started lessons with Hungarian singing teacher Vera Rózsa at the end of 1969 and remained with her for as long as Rózsa continued to teach. David Fingleton suggests in his biography Kiri, that Rózsa's 'wholeness of approach and emphasis on interpretation [...] enable[d] Kiri to make the fullest use of her natural and instinctive assets', an approach that lined up with what her New Zealand teacher, Sister Mary Leo had espoused: 'I'm really just a psychologist. [...] If you can get inside the person and bring out the best in their character, you also bring out the best in their voices.'10 Both of these statements have an implication of the essential quality of the singer existing as a part of their personality, or their instinct. As discussed earlier, the voice is personal because each individual personality makes it so, but this does not necessarily indicate that the voice is unique, or of the essence of a person or their body. Because the voice is organic (an organ or a collection of organs of the body), Eidsheim suggests it is '[so] infinitely malleable and shaped by daily usage, formed by the way a given society identifies a person and the way a person identifies herself, that it can sound according to the social groups identified by a given society.'11 Fingleton's use of the word 'instinctive' downplays the work done by Te Kanawa as a singer by relegating it to an unknown and unknowable realm. The implication of Te Kanawa's artistry as an instinctive asset that needed to be drawn out of her, while on one level seems to have an element of truth, in that all musicians have some musical instinct that is a basis for their artistry, plays into the trope of the 'natural' singer, and of the singer as a non-intellectual and not in control of her voice. A truly 'natural' singer would need no training at all. In learning to sing expressively with her voice, within the expectations of operatic style, Te Kanawa was learning to make changes that were under her personal control.

We can better understand this process of control and agency in Te Kanawa's singing by considering an example of a specific quality of her signature vocality. This is one that can be traced to a particular use of the voice's functionality and was part of the teaching of Florence Norberg, with whom Te Kanawa studied in London prior to commencing lessons

\footnotetext{
${ }^{10}$ Fingleton, Kiri Te Kanawa, 83; Margaret Lovell-Smith and Luisa Shanahan, The Enigma of Sister Mary Leo: The Story Behind New Zealand's Most Famous Singing Teacher (Penguin Group New Zealand, Limited, 1998), 196. See also page 155 of The Enigma where Sister Mary Leo is quoted saying: 'I can never make a singer - I can develop the voice... The singer must come from within'. ${ }^{11}$ Eidsheim, 'Voice as Action', 29.
} 
with Rózsa. Norberg's teaching philosophy included the formation of tone with the 'mouth in a smiling position'.12 The effect of this physical positioning of the organs of articulation is to create a brighter, somewhat more focused tone, in which the listener may perceive something of the sound of a smile, but also an increase in the warmth of the tone if done with a small pouting of the lips. This is an element that remains in Te Kanawa's signature sound as will be discussed later in this chapter with respect to a particular recording of Mozart's aria 'S'altro che lagrime'.13

Given opera's traditional bent, an individual 'brand' or style of vocal sound must relate in some way to prevailing tastes, and the very fact that Te Kanawa's voice excited such interest when she auditioned for the Royal Opera in London shows that this sort of sound was thought of as very desirable. The exquisite beauty of her tone raised this aesthetic to new levels, and the impact she made was also bound up to a degree with her looks and her onstage presence. Reviews of the debut performance focus on these aspects: for example, Harold Rosenthal, writing in Opera, notes her 'youth, beauty, and a voice of rich creamy quality, used exquisitely'.14 This turn of phrase contains the implication that a voice, while beautiful, may not always be utilised beautifully, and Rosenthal is therefore making a distinction between the inherent quality of a voice and the quality that arises from 'playing' the instrument, effectively acknowledging, even if only indirectly, the creative agency of the singer.

\section{The Embodiment of Ideals}

When Te Kanawa made her debut at Covent Garden, the renowned critic Andrew Porter was ecstatic:

\footnotetext{
12 Florence Wiese Norberg, 'Voice Production for Singers', The Journal of the Royal College of General Practitioners 13, no. 3 (May 1967): 378. Norberg states: 'It is important to relax the mouth into a smiling position with the lips just parted'.

13 We can see from her many videos that Te Kanawa does not sing with a broad smile, but there is evidence of the so-called 'Mona Lisa' smile: a gentle smile with just a slight pouting of the lips. This 'smiling' position relates to the forward buccal placement and zygomatic arch engagement that $\mathrm{Te}$ Kanawa makes use of consistently in her signature sound and can be heard on the recording analysed later in this chapter.

${ }^{14}$ Fingleton, Kiri Te Kanawa, 100. The Harold Rosenthal quote is from Opera, January 1972.
} 
The new star is Kiri Te Kanawa. [...] [S]uch a Countess Almaviva as I have never heard before, not at Covent Garden, nor in Salzburg, or Vienna, at once young, fullthroated, a singer of great accomplishment and a vivid character. "Porgi amor" was attacked with warm, beautiful, confident tone; the cavatina was sung out, in long, smooth, well-controlled lines. Again to "Dove sono" Miss Te Kanawa brought her rare command of legato, her beautiful control of the moves from note to note, and her lovely tone-quality. [...] As an actress Miss Te Kanawa is accomplished. She commands the stage, wears costumes well. She was a young, beautiful, dignified, warm-hearted and affecting Countess. (Andrew Porter, The Financial Times) ${ }^{15}$

Andrew Porter's review represents an outstanding accolade from this critic. He was in fact so excited that he placed a photograph from the show in the previous day's issue with a mini-review of her in the caption and the promise 'more about it all tomorrow'. ${ }^{16}$ Porter had also been ecstatic about Callas's debut at Covent Garden in 1952 - but for quite different reasons. As we saw in his review of Callas, his interest in her singing centred around her 'range of vocal colours' her 'exceptional dramatic understanding' and her 'affecting' and 'thrilling' tones. ${ }^{17}$ In the case of Te Kanawa he is enthusiastic about her 'command of legato' and the way she 'attacked' the arias with 'warm beautiful' tone, and the way she achieved an exceptional characterisation of the role overall. His choice of words for Te Kanawa such as 'vivid', 'full-throated', 'confident', 'command', reflect what he clearly senses as an active power in her performance, and the form this power takes is to one that is related to warmth, as well as control. Porter's impression of Te Kanawa is reinforced by almost all the other reviewers in similar terms. The reviewers in The Observer and The Sunday Times commented:

As soon as her voice, full, warm, radiant and admirably supported, sailed, not only with ease but with understanding, into the treacherous, opening bars of 'Porgi amor,' it was evident that we were in the presence of a singer of quite exceptional promise. Miss Te Kanawa not only has the emotional antennae of an artist but the vocal resources and technique to give them flesh. The radiant tenderness with which this Rosina finally forgave her erring spouse was evidence enough that Covent Garden here has a pearl of great price. (Peter Heyworth, The Observer) ${ }^{18}$

\footnotetext{
${ }^{15}$ Andrew Porter, 'Le Nozze Di Figaro', Financial Times, 3 December 1971.

${ }^{16}$ Andrew Porter, 'Le Nozze Di Figaro (Photo Caption)', Financial Times, 2 December 1971. 'On stage, a new star shone: the young New Zealand soprano Kiri Te Kanawa... a dignified, beautiful young Countess who sang the difficult music with a warmth of tone and an eloquent full-voiced line seldom heard in the role. A memorable evening: more about it all tomorrow.'

17 Porter, “Norma" in Italian'.

18 Peter Heyworth, 'Opening Flourish', The Observer, 5 December 1971.
}

Page 96 
[Kiri Te Kanawa] has come far indeed: I should say to the threshold of international fame. [...] In both [her arias] she poured out a stream of pure, radiant, ample tone which remained ringing and assured even on [the] bridge notes between the middle and head registers [...] Her legato phrasing and musicianship were exemplary, though I think she will come to make more of her words. Since she has also a lovely and sympathetic stage presence, the enthusiasm of the house knew no bounds. (Desmond Shawe-Taylor, The Sunday Times) ${ }^{19}$

Both Heyworth and Shawe-Taylor emphasise the warmth and radiance of her tone, and the ease and assuredness of her approach. For Heyworth her voice 'sailed' into the opening bars of 'Porgi amor' while for Shawe-Taylor her tone was 'poured out' in a stream. Both these metaphors present images of steady and confident singing, and tone that flows continuously. The descriptors chosen also reflect fullness, and shapeliness, with the sense of a feminine body underpinning and supporting the tone and these bodily terms tend to be commonly used in reviews of Te Kanawa in general.

There was almost unanimous praise from the music critics for Te Kanawa's debut and this is a distinct contrast to the very mixed reception of Callas in her London debut. Since the general response to Callas from the audience was by all accounts hugely positive, the critics' negativity about her seems odd. Perhaps this difference can be partly explained by the fact that for Te Kanawa this was her first major role in the Northern Hemisphere, whereas, thanks to her success in Italy, Callas's London debut was eagerly anticipated and expected to be remarkable, which would perhaps have made the reviewers more inclined to be critical. ${ }^{20}$ But beyond these factors, Te Kanawa's singing and vocality clearly played into the expected, and desired, characteristics of the Mozartean style current at the time, and she was praised by a number of the critics for her musical style. Te Kanawa therefore 'fitted the mould' and amply fulfilled the critics' expectations without challenging the received concept of the beautiful singing (bel canto) of the beautiful female singer; instead, she extended those expectations to a higher level.

\footnotetext{
${ }^{19}$ Desmond Shawe-Taylor, 'A Fine Figaro', The Sunday Times, 5 December 1971.

${ }^{20}$ Cecil Smith's review of Callas's debut, for example, began: 'The first appearance in Britain of Maria Callas, in the title role, proved to be as supercharged an event as everyone had hoped.' Smith, 'Opera Diary: Covent Garden "Norma"'.
} 


\section{Callas or Tebaldi: Influences}

In her book Opera for Lovers Te Kanawa reveals her admiration for Callas's expressive vocal quality, naming the 'Callas-sound' as 'one of the wonders of opera'. ${ }^{21}$ Te Kanawa presumably did attempt to emulate this sound at some stage, as she continues 'Never have I been able to put that particular Callas quality into my voice.' If one had to place her on either side of the Callas-Tebaldi dichotomy built up during the late 1950s by their fans and amplified by the press, it would seem logical to align her artistic approach with that of Tebaldi. Tebaldi's legato, richness and continuity of tonal colour relates far more to Te Kanawa's signature style, than does Callas's use of emotive vocal colouring and dramatic effects.

In Kiri's 20 Favourite Voices, a series broadcast by BBC Radio 3 in 2015 and now available online on YouTube, out of the twenty voices chosen by Te Kanawa, only four have the same lyric soprano voicetype/Fach as her own: Elisabeth Schwarzkopf, Margaret Price, Mirella Freni and Renata Tebaldi. ${ }^{22}$ When commenting on the lyric sopranos, and also the coloratura soprano Joan Sutherland, Te Kanawa often stresses the 'beauty' of the voices as a reason for choosing them, the attribute with which she has been so consistently associated herself. In the case of Schwarzkopf, she describes her as having a 'lovely voice: absolutely perfection in every way' although she notes that her singing was 'very stylised'. While she clearly admired her as a singer, she points here to Schwarzkopf's tendency to be very strict with the tempi and phrasing, for example in Richard Strauss's 'Morgen': 'it was not as I would do it: today I would do it differently, a bit more free-er than that rather constrained, boxed-in [style]'.23 Te Kanawa also says she admires Price's voice: 'I loved that voice, I loved the sound of it'.24 In her comments about Tebaldi, however, she is much more effulgent. In describing her 'glorious, glorious voice' she says:

21 Te Kanawa and Wilson, Opera for Lovers, 45, 170.

22 'Kiri's 20 Favourite Voices (KiriOnLine YouTube Channel)', 4 July 2015, https://www.youtube.com/playlist?list=PL8ld2LoKhQqymLL6gvBupdir_1CLHA912; 'Kiri's 20 Favourite Voices - Downloads - BBC Radio 3', BBC, accessed 25 September 2018, https://www.bbc.co.uk/programmes/p02t03d1/episodes/downloads; 'BBC Radio 3 to Celebrate the Art of The Classical Voice This Summer', BBC Media Centre, 6 March 2015, https://www.bbc.co.uk/mediacentre/latestnews/2015/radio-3-the-classical-voice?lang=cy.

${ }^{23}$ KiriOnLine - Dame Kiri Te Kanawa, Kiri Te Kanawa s 20 Favourite Voices \#2 Elisabeth Schwarzkopf, accessed 18 September 2018, https://www.youtube.com/watch?v=B58XA9gy_YY.

${ }^{24}$ KiriOnLine - Dame Kiri Te Kanawa, Kiri Te Kanawa's 20 Favourite Voices \#11 Margaret Price, accessed 25 September 2018, https://www.youtube.com/watch?v=Zokk0Q0s0Ds\&index=12\&t=0s\&list=PL8ld2LoKhQqymLL6g vBupdir_1CLHA912. 
Tebaldi's voice had this glorious pathos: she could make you cry in a second ... I found that that was very encouraging - that if I wanted to make people cry ... she had that particular sound [...] that I never ever copied, but I thought that was the sound that made me feel that if I could get that into my singing and make people love what I did or listen to what I did, get people's attention - and I felt she got my attention a lot. 25

Te Kanawa particularly mentions how she admired Tebaldi's singing of the Puccini repertoire. Te Kanawa sang the roles of Mimì, Manon Lescaut and Tosca, which were also roles performed often by Tebaldi. Te Kanawa states 'with Tebaldi the Puccini was particularly beautiful [...] there was something very special [...] her voice immediately springs to mind, that's the voice, that if I would listen to a voice, I would listen to that.'26

Others have noted this connection between Tebaldi and Te Kanawa. Alan Rich, writing in New York Magazine about Te Kanawa on the occasion of her debut at the Metropolitan Opera as Desdemona, referred to her as a 'glorious artist' and linked her tonal quality directly to that of Tebaldi. He wrote: 'It was, most of all, the day of Kiri Te Kanawa, the young New Zealand soprano [...] This is a singer with a voice as beautiful as any I have heard in the house since the time of the young Tebaldi - like hers also in its absolute lyric creaminess from top to bottom.'27 Desdemona was a role that Tebaldi was known for and one that she had performed at the Metropolitan Opera, so it made sense from that point of view for a comparison to be made with Te Kanawa. Outside of that connection it might seem strange to link Tebaldi with her, given the difference in repertoire of the two singers: Tebaldi focused almost exclusively on nineteenth-century and verismo Italian repertoire, while Te Kanawa was particularly renowned for her singing of Mozart and Richard Strauss. Te Kanawa explained in a 1981 television documentary interview that she wished to specialise in Mozart and Strauss, saying that even though she 'touched on' Verdi and Puccini, 'I don't ever think that I will be one of those singers' ${ }^{28}$ However, both Tebaldi and Te Kanawa considered themselves as lyric sopranos in terms of Fach. ${ }^{29}$

\footnotetext{
25 KiriOnLine - Dame Kiri Te Kanawa, Kiri Te Kanawa's 20 Favourite Voices \#18 Renata Tebaldi, 18, accessed 25 September 2018, https://www.youtube.com/watch?v=7ly4Q6Nvblk\&index=18\&list=PL8ld2LoKhQqymLL6gvBupdir _1CLHA912.

${ }^{26}$ KiriOnLine - Dame Kiri Te Kanawa, Kiri Te Kanawa's 20 Favourite Voices \#18 Renata Tebaldi.

27 Fingleton, Kiri Te Kanawa, 133.

28 'Kiri Te Kanawa at the BBC' (BBC Studios, 2017), https://www.youtube.com/watch?v=oPEXrB6NRUQ. This quotation is taken from the 1981 'Friday Night... Saturday Morning with Simon Hoggart' show excerpt on this video.

29 'Renata Tebaldi', in Wikipedia, 3 July 2018, https://en.wikipedia.org/w/index.php?title=Renata_Tebaldi\&oldid=848717558; Te Kanawa and
} 


\section{Delectable Embrace: The Tebaldi Line}

A survey of the terms reviewers have used to describe the quality of Te Kanawa's vocal tone yields an array of adjectives. The expressions 'creamy' and 'warm' are common, and other terms include: fresh, succulent, full, golden, silvery, sweet, crystalline, pure, easy, ample, rounded, radiant, tender, 'rich and intense', and 'a top like a luscious rose'. ${ }^{30}$ The description of 'purity' could relate to the consistency of her tone, and likewise the term 'crystalline'. Aside from this aspect, there seem to be two main themes to the metaphors used for her vocality: ones related to warmth and shapeliness and ones related to delicious flavours or sensations of taste.

The first theme, of warmth and shapeliness, has connotations of the desirable and welcoming body and it is expressed in bodily terms such as 'ample', 'full', and 'generously rounded'. John Steane refers to her tone's 'firm centre', which provides us with a sense of steadiness and bodily presence. Rupert Christiansen conflates her beauty and her vocality in terms of her physical health, depicting her as an 'irregular but exotic beauty with a gorgeous and healthy lyric soprano'. 31 These connotations of the body with the tone are always used in a positive sense. Again, Barthes' notion of 'grain' in the voice, may seem relevant, in terms of his desire to experience the body as connected with the voice via its tone, yet, as in the case of Callas's disruptive vocality and vocal 'flaws', this type of fullness and warmth of sound is not explicitly pointed to in his texts. He does use the term 'fullthroated' as part of his description of what he finds desirable about his favourite singer, Panzéra's style of vocalisation, but this seems to be more aligned with a sense of the unadorned singing of the traditional folk song, than with a beauty of tone such as that of Te Kanawa. ${ }^{32}$ Te Kanawa's style of diction, which involves enunciating the words very distinctly, may have aligned somewhat with Barthes' aesthetic, as she forms the words and the vocal tone with a lot of care and as if she rolls the sounds around in her mouth. As noted earlier, however, Barthes' concept of 'grain' has much more to do with an aesthetic of the French language, a specific 'quality of language' which he associates with gentleness of pronunciation, and where consonants are not ever the same intensity within different syllables and words. ${ }^{33}$ Te Kanawa, by contrast, utilises strongly produced consonants and

Wilson, Opera for Lovers, 45. The Wikipedia article on Tebaldi categorises her as a 'lirico-spinto soprano', but also notes that 'Tebaldi considered herself essentially a lyric soprano'.

${ }^{30}$ Fingleton, Kiri Te Kanawa, 132, 161.

${ }^{31}$ Steane, Singers of the Century (Volume 2), 182; Christiansen, Prima Donna, 307.

32 Barthes, 'Music, Voice, Language', 83.

${ }^{33}$ Barthes, 82. 
vowels, which is particularly appropriate for texts in German, and also gives clarity in English, but is less important for French or other Romance languages.

As we have seen, Poizat locates the listener's desire for jouissance, or disturbingly intense sensual pleasure, in the sound of the inarticulate vocalism of the female voice, and he interprets our longing for the operatic singing voice as desire for the mother's voice, the baby's own lost voice, the cry of the angel, and the voice-object that 'stands for that which is irrevocably lost'. ${ }^{34}$ This means the wordless vocalisation of the soprano in opera holds particular appeal due to its alignment with this maternal connection, but such attraction can also be connected with the womanly body. During Poizat's conversations with the opera lovers queuing on the steps of the Palais Garnier, one of the fans, Claude, relates his story of the moment when he was 'won over' to opera. This was when soprano Hildegard Behrens began singing (in the flesh) on stage and he suddenly found her beautiful: 'She started to sing and from that moment on [...] she became incredibly beautiful, physically beautiful'. 35

When Poizat discusses the emotions and responses to performances described by the opera devotees such as Claude he suggests that when a listener who has an emotional response experiences that response it is not a generalised mood, but 'an acute, irrepressible irruption linked to specific musical passages in which all that is visual and all that tends toward signification fails and falls away. In these instants pure voice alone persists.' ${ }^{36}$ This is where he asserts that the singer's aim should be to present herself as 'pure voice', which effectively negates the singing body and the singer as an individual living person. Claude's statements, however, imply the desirability of the body and the entanglement of the desired body with the desired voice. Claude explains how he had previously seen Behrens perform the same role on television and thought then that she was 'extremely ugly', but once she started to sing on the stage in the performance it affected his perception of her physically. So his experience of beauty was of the singer's body, which he found through the singer's vocality. Rather than being perceived as 'pure voice', this singer's vocality in performance provided an aesthetic pleasure of the body, one that the reviews of Te Kanawa also seem to point to.

The aesthetic pleasure associated with Te Kanawa's physical person, along with her 'pure' vocalism, sits in contrast to the way that both Behrens and Callas seem to have been

\footnotetext{
34 Poizat, “"The Blue Note” and “The Objectified Voice and the Vocal Object”', 208.

35 Poizat, The Angel's Cry, 19.

36 Poizat, 32-35.
} 
perceived. In the case of Claude's experience, there was a transformation of his perception of Behrens' body through the power of her singing voice. Callas's voice and body were likewise perceived as if they were in an inverse relationship: the more attractive her bodily form (i.e. the more she conformed to societal concepts of beauty) the more her voice was perceived as suffering or 'in ruins'. While the cases of Behrens and Callas seem to reinforce Poizat's conceptualisation, the attraction of Te Kanawa's physical body in harmony with her beauty of voice would seem to situate her in opposition to Poizat's idea that the singer's success derives from a personal transformation into 'pure' voice.

In all these examples the experience of opera is discussed from the point of view of the male gaze. At the time of Te Kanawa's early career virtually all the newspaper critics were male, so the reviews from which the descriptions above are taken are written from this gendered viewpoint. Poizat's assertion that singing, 'particularly the singing of a woman, [...] that literally destroys speech in favor of a purely musical melody that develops little by little until it verges on the cry' must likewise be understood as being expressed from the position of the (heterosexual) male listener. ${ }^{37}$

The male, or female, desire for the warm, full, female shape reminds us of the Marilyn Monroe type of sensual and womanly body, as well as the warmth of the maternal embrace experienced sensually. Te Kanawa also seems to have inspired many commentators to think about how 'delicious' she was, a response which could again be related to a carnal desire for the body, even though it is used for describing her vocal tone. The list of descriptors given above includes a number of terms of this type: rich, succulent, sweet, creamy, luscious, tender, and fresh. Shawe-Taylor's description of how she 'poured out' her tone in her debut as the Countess in Figaro provides an image of not only fluidity but also an abundance of 'milk and honey' style cornucopia. A later article even describes her tone as 'rich' and 'chocolatey'.38

Some commentators have taken this concept further in emphasising these metaphors for savouring and degustation. The critic William Mann, writing in The Times about her first performance as Arabella in 1977, stated that 'Kiri Te Kanawa poured out a rich, sensuous, steady soprano voice, new to the role, but greatly delectable'. ${ }^{39}$ Susan Leonardi and

\footnotetext{
37 Poizat, 37.

38 Alice Fowler, 'Dame Kiri Talks of Her Heartache', Mail Online, 2002, https://www.dailymail.co.uk/tvshowbiz/article-119114/Dame-Kiri-talks-heartache.html. ${ }^{39}$ Simpson and Downes, Southern Voices: International Opera Singers of New Zealand, 226. 
Rebecca Pope describe their infatuation with the diva in terms of bodily and sensory nourishment:

Excitement over Kiri's voice [...] was barely distinguishable from excitement over one another's bodies. And who had time for distinctions anyway? [...] [We] let her rich warm voice feed our passion for her and for each other 40

This connection of sensual pleasure with the sound of opera is in no way limited to the sound of Te Kanawa alone, but when the descriptors used for her singing are compared with those commonly used for Callas and for her 'rival' Renata Tebaldi, different associations are clearly being made for each. For Callas the descriptors of her tone often have to do with texture: its roughness, the hardening of her tone, her fine-drawn sound and its 'cutting' edge; as well as to do with colour: as we have seen much is made of the variety of her colouration of sound. Ernest Newman described Callas's sound as 'magnificently lustrous and flexible above the stave but somewhat colourless and ineffective within it'. ${ }^{41}$ By contrast, metaphors for Tebaldi's tone are often, like Te Kanawa's, to do with shapeliness, smoothness and warmth. Louis Biancolli, reviewing Tebaldi's debut at the Metropolitan Opera as Desdemona, describes the 'glow and warmth' of the tone of her 'full and firm and beautiful' voice. ${ }^{42}$ Others describe her tone as rounded, even, ample, fluid, smooth and steady. ${ }^{43}$ Christiansen's comparison of Tebaldi with Callas not only points to Tebaldi's 'smoothness and steadiness' and her sweet smile as opposed to Callas's self-assertiveness, but also emphasises the way the media presented her 'homely body'.44 Through this association we find again the contrast of the gendered ideals outlined by Bordo: the 'masculine' roughness and self-assertion of Callas, alongside the sweetness and conformity of Tebaldi with her nurturing, shapely femininity. ${ }^{45}$

Although Te Kanawa's 'exotic' physical beauty was emphasised while Tebaldi was thought of as homely, the singing of both sopranos was described as rounded, full, ample, pure, warm and steady, giving the sense of shapely femininity and 'feminine' behaviour. In the case of Te Kanawa, this was also surrounded by connotations of the savouring of

40 Leonardi and Pope, The Diva's Mouth, 5.

${ }^{41}$ Newman, "The World of Music: "Norma"'.

${ }^{42}$ Louis Biancolli, 'Review of Otello', New York World Telegram and Sun, 1955, Metropolitan Opera Archives, http://archives.metoperafamily.org/archives/frame.htm.

${ }^{43}$ Steane, Singers of the Century (Volume 2), 162-63; Christiansen, Prima Donna, 281-82.

${ }^{44}$ Christiansen, Prima Donna, 282.

45 Bordo, Unbearable Weight, 171. Bordo refers here to 'the rules governing the construction of contemporary femininity' which 'cast woman as chief emotional and physical nurturer'. She also outlines supposedly 'masculine' values that would line up with Callas's self-assertion, as discussed in the previous chapter. 
goodness, of delectable and nourishing tone, which also lines up with Bordo's accounts of the 'feminine' ideal of the emotionally and physically nurturing, yet subservient female. ${ }^{46}$ So Te Kanawa is being framed in terms of a sensual feminine ideal, and one that lines up, at least in part, with that of Tebaldi. It is worth noting here also that many of the terms used to describe her singing would not usually be found in descriptions of a male singer. Terms such as fresh, tender, lovely, radiant, and most of the ones to do with taste, such as luscious, sweet, or succulent, definitely have feminine connotations and consequently reinforce a feminine framing of Te Kanawa as a singer of vocal and physical beauty.

\section{The Formation of Beauty}

On the IMG Artists Management website page promoting Te Kanawa, the sole excerpt displayed from her critical reviews is:

For Dame Kiri, the beauty is the voice itself. 47

This statement was taken from a New York Times review by Bernard Holland that was published in the year 2000.48 Her management's use of it in this way raises some interesting issues. The quotation melds the concepts 'beauty', 'voice' and 'Dame Kiri' in an effective way, at least for marketing purposes. Yet in the context of the full review this statement actually had ambiguous or even negative implications, since the reviewer suggested Te Kanawa focused too much on her beauty of sound and not enough on emotional communication. While initially complaining that she was 'a singer in love with the sound of herself', later in the review Holland conceded that 'to operate on the surface is not necessarily to be shallow'. However, the overall implication of the tone of his commentary is that dramatic presence, or emotive affect, has been superseded here by beauty of voice.

The self-focus that Holland complains of could be seen as another way a singer may resist 'masculine' compositional authority, like that which Jarman-Ivens points to in the case of Callas. With Te Kanawa however, the 'resistance' takes the form of (over)-indulgence in her own vocality without sufficient regard for the expression of the emotions or meanings that could be realised through the performance of the work. If, as Poizat suggests, the mission of the singer is indeed to present 'pure' voice, it is perhaps small wonder that

\footnotetext{
${ }^{46}$ Bordo, 171.

47 'IMG Artists: Kiri Te Kanawa', IMG Artists, 16 May 2016, https://imgartists.com/roster/kiri-tekanawa/.

48 Bernard Holland, 'Music Review: Philharmonic Resumes With Te Kanawa', The New York Times, 22 September 2000.
}

Page 104 
occasionally a singer might be too bound up with the control and production of that sound to satisfy the expectations of spectators such as Holland.

As we have seen, critical responses to Te Kanawa have tended to centre around the beauty of her voice, often placing it alongside comments on her physical beauty and grace. This recurring emphasis of a combination of exquisite sound and personal beauty seems to point to the perception of a compelling 'presence', but one in which this stems from the singer's vocal and physical qualities rather than embodied 'dramatic' presence. This vocal presence or 'charisma' differs therefore from the standard concept of a dramatic behaviourally based charisma, but what does a statement such as this imply about the agency of the singer? The phrase 'beauty is the voice itself' seems to imply that this voice simply 'exists' as a beautiful instrument. We know that a human voice, as an instrument to play, cannot exist apart from the body, and that when it is not being used to make 'beautiful' or expressive sounds this 'instrument' reverts immediately to being simply a bodily organ. ${ }^{49}$

Can a voice, when it is only used as an instrument for some of the time, be inherently beautiful? Perhaps the possibility for making certain types of sounds is part of the characteristic of an individual voice, if we think of it as an instrument with specific structural qualities and a certain degree of flexibility and strength associated with the various parts of the vocal tract, larynx, and the muscular and neurological system that changes this into different formations for different tone qualities. But the production of sound involves active choices and bodily actions to achieve these sounds. Singing beautifully is not about simply having a beautiful voice; it requires aesthetic awareness, physical control and actions, and finely-tuned connections between the functions of the mind and the body to achieve any particular desired tone. The 'natural' voice of the singer can be thought of as the basic qualities available to her as she plays her instrument but the vocality of the singer is what she develops and chooses to stress. In Te Kanawa's case the main features are beauty and consistency of tone, and these qualities require specific aesthetic choices and purposeful actions in order to be achieved.

For me the most memorable characteristic of Te Kanawa's vocality is one of golden tone. She spins out a consistent stream of creamy, yet vibrant, sound, and through the richness and evenness of her tone quality maintains a strength of 'core tone' and legato. This sophisticated vocality affords inflection and variation, but its production always seems

49 Meribeth Bunch, Dynamics of the Singing Voice, Fourth Edition (Wien; New York: Springer, 1997), 56. 
effortless. In the course of a vocal coaching session with her that I was fortunate to be offered in 2007, Te Kanawa talked about using the concept of 'tasting' the sound in her own singing. Clearly this lines up with the descriptors mentioned above. At the time I considered the concept on a purely technical basis. I found it a wonderfully sensuous concept, to be engaging my own senses in that specific way while singing, and I have found that such an approach, when I attempt to put it into practice myself, aligns with some of the distinctive attributes of her sound which I discuss below.

As a basis for defining Te Kanawa's vocality, I have chosen to analyse a recording of Te Kanawa singing the aria 'S'altro che lagrime', from Mozart's La Clemenza di Tito. I chose this particular aria because of Te Kanawa's reputation for the singing of the Mozart opera repertoire, and because the recording, made in 1982 with her early mentor, Colin Davis, conducting, stems from a period when she was well-established in her career. It demonstrates her distinctive sound, and her approach to singing, and is a valuable representation of her signature vocality. ${ }^{50}$

Clearly Te Kanawa's continuity of tone quality and legato line is important for this repertoire. Her distinctive vocal timbre is also closely aligned with the orchestral timbre built up by Mozart in his arias for lyric soprano. For example, in the introduction to his aria 'L'amerò, sarò costante' the warm rounded texture he develops through his use of the strings is complemented just before the voice enters by the higher harmonic 'squillo' colour of the wind instruments. ${ }^{51}$ Perhaps this orchestral colour is intended to mirror that of the singer, and the ideal Mozart vocal sound is one that reflects this, as in the vocality of Te Kanawa.

In the aria 'S'altro che lagrime' there is only a very short orchestral introduction, and the sung line often either interweaves with or is doubled by the orchestral parts, yet Te Kanawa's tone is clearly audible and seems very 'present' in the mix of sound. Perhaps the most immediate impression of her voice in this recording is of her creamy warmth of tone. This colour of Te Kanawa's tone, a characteristic sound, can be attributed to horizontal

\footnotetext{
50 Mozart Opera Arias: Kiri Te Kanawa. Sir Colin Davis, Conductor; London Symphony Orchestra, CD Audio Recording (Audio CD: Philips 411 148-2, 1982). This was made as a digital recording. A glowing review by Robert Chauls of this album in fact included the comment that 'Mozart's lyrical effusions seem written for her voice'. Robert Chauls, 'Review: Kiri Te Kanawa Mozart Opera Arias', The Opera Quarterly 1, no. 4 (1 January 1983): 144-45.

${ }^{51}$ This aria is sung by the character Aminta in Mozart's opera Il Ré Pastore. The role is simply described by Kloiber as for 'Soprano' and is usually sung by a lyric soprano, but originally was cast with a castrato (Tommaso Consoli sang the premiere performance). Rudolf Kloiber and Wulf Konold, Handbuch der Oper (5th edition) (Kassel: dtv/Bärenreiter, 1985), 510-12.
} 
space (width) in the throat, as well as her medial to forward buccal (in the mouth) tonal placement, probably related to her concept of 'tasting' the sound as it is produced. This sort of tone often involves vocal tract lengthening through lip rounding by the singer pouting the lips and the energisation of the 'smile' or cheek (zygomatic) muscles around the lower part of the nose. ${ }^{52}$ As well as pouting the lips, a low larynx position ('sob' quality) adds to the warmth and roundness of her tone from the longer vocal tract it creates. ${ }^{53}$ Her centralisation of some vowels, in other words, forming them more centrally in the mouth, in particular in the case of the open 'e' vowel, emphasises her creamy tone quality. In her sound this warmth of colour is also associated with a 'core' tone or fullness of harmonic complexity, with relatively thick vocal folds (i.e. 'vocal cords') and a longer amount of time when the folds are closed (lengthened closure) in the vocal fold vibration cycle. 54

There is also a 'brilliance' that can perhaps be linked to her fine, fast vibrato, produced by consistent and well-stabilised crico-thyroid tilt in the larynx, and the speed of this vibrato strengthens the impression of the higher harmonic overtones already present in the sound. ${ }^{55}$ In this example she is controlling the onset of vibrato - starting it late on some long notes and tending to minimise it on shorter notes. The 'soaring' high notes constitute a release of constraint: she allows a swift bel canto slur to signal the approach of the high note, then 'spins' the tone out with airflow and crico-thyroid tilt ('cry') once she is on the upper pitch, adding in extra high harmonics to the tone. In this example her energetic approach to the diction and its clarity is also demonstrated. These elements of her vocality are noted where they occur in the recording on the musical score that follows.

52 Steinhauer, Klimek, and Estill, The Estill Voice Model, 180-84.

53 Steinhauer, Klimek, and Estill, 216.

54 Steinhauer, Klimek, and Estill, 73, 77-78.

55 Steinhauer, Klimek, and Estill, 91. 


\section{Musical Example 2: 'S'altro che lagrime' - Kiri Te Kanawa}

'S'altro che lagrime' (Servilia) from La Clemenza di Tito by W. A. Mozart. The vocality features that are marked in the score relate to the studio recording made by Te Kanawa with Colin Davis in 1982.56

\section{Tempo di Menuetto}
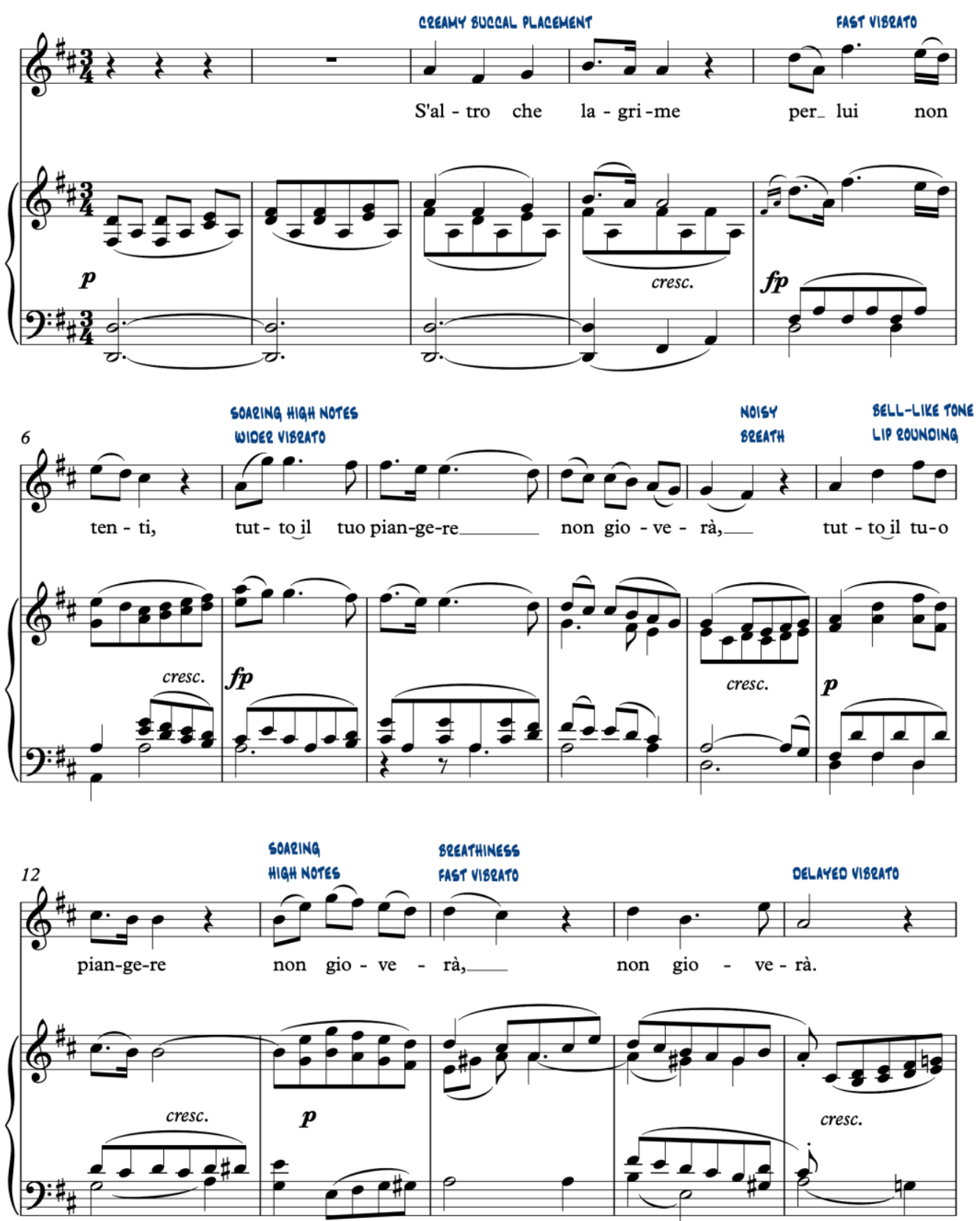

56 Mozart Opera Arias: Kiri Te Kanawa. Sir Colin Davis, Conductor; London Symphony Orchestra. This can currently be found online at: Mozart: La Clemenza Di Tito, K.621 / Act 2 - 'S'altro Che Lagrime' [Te Kanawa], n.d., https://www.youtube.com/watch?v=NmQCDVwQvSQ. 

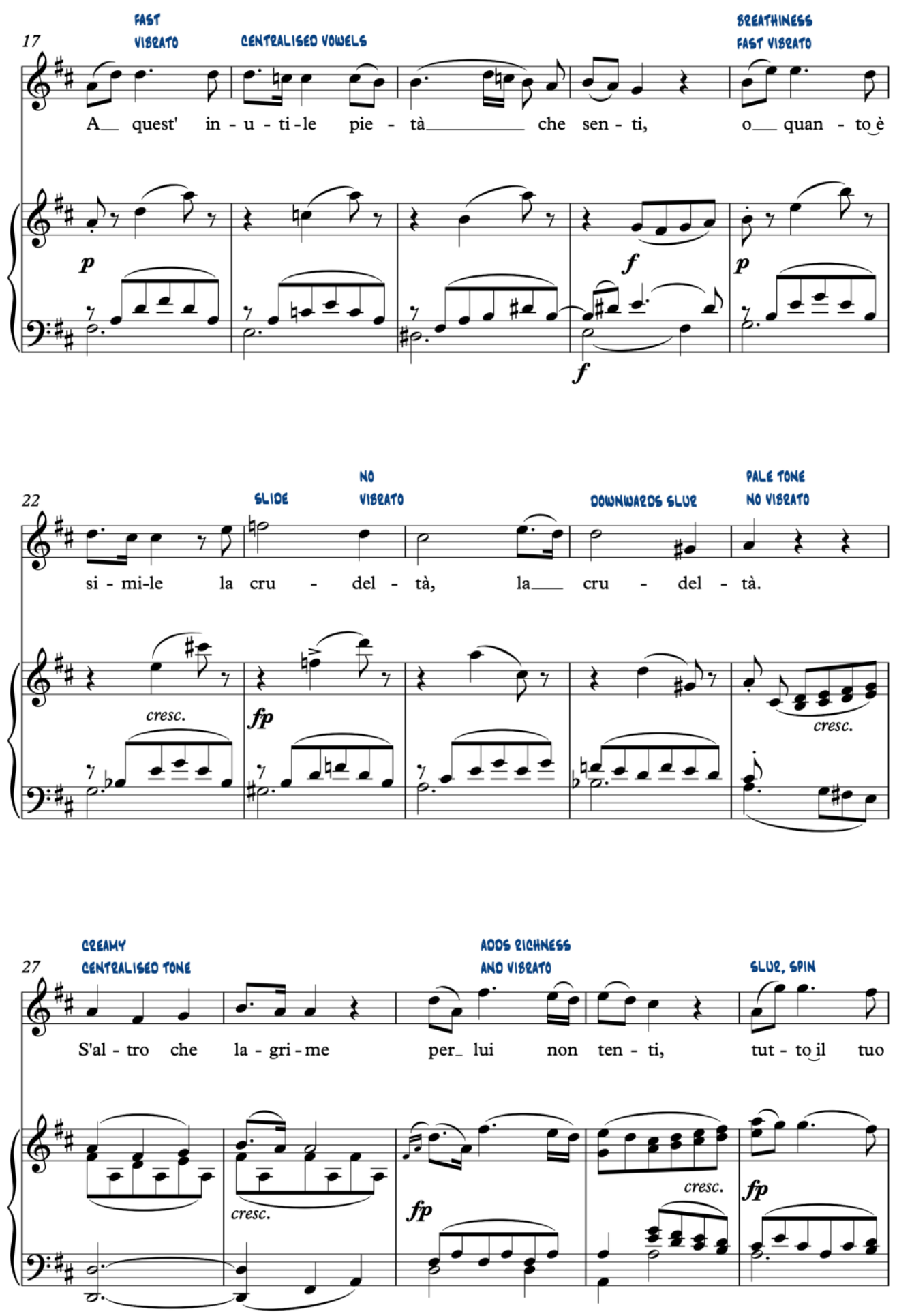

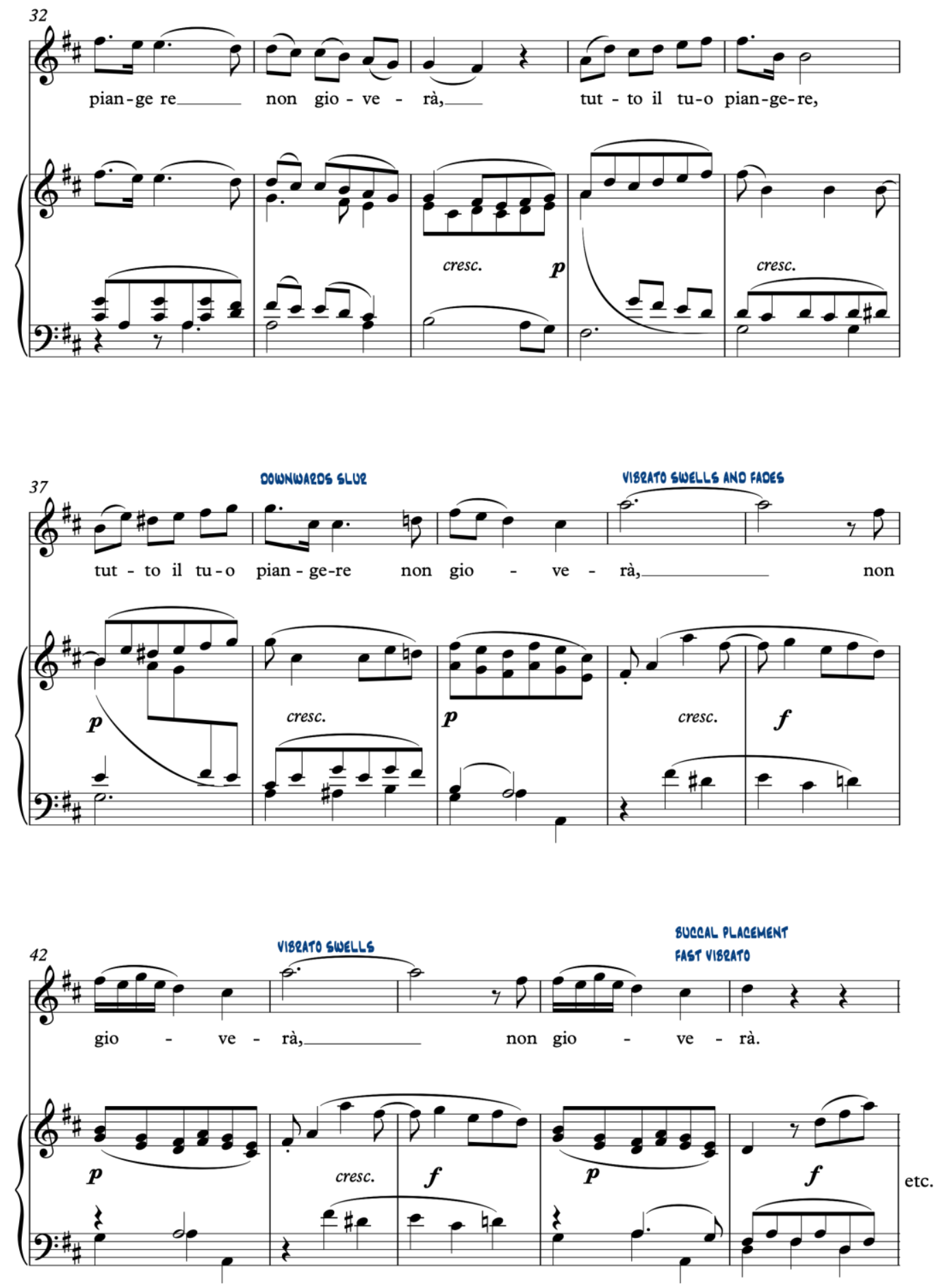

Te Kanawa's particular form of vocal beauty satisfies the requirements for operatic vocal tone in that it falls easily within the range of acceptable qualities for an operatic sound. It melds two key characteristics: that of warmth and brightness, in a particularly elegant way. These two aspects of sung tone quality can be described as chiaroscuro, which, as previously noted, refers to the use of light and dark tone in combination to provide for the 
'sculpting' and shaping of vocal tone. ${ }^{57}$ In this way, Te Kanawa's distinctive 'creaminess' effortlessly combines a darker, rounded, warm sound with a brighter clarity known as squillo in the bel canto tradition. ${ }^{58}$ This adds to her very creamy sound a 'sheen' that comes through as an integral part of her tone, and this and her elegance of phrasing and consistency of vocal production are key features of her vocality.

Te Kanawa's retention of the chiaro brilliance in the otherwise rounded tone, reinforced by the somewhat fast vibrato and allied with the continuity of all of these elements, results in a tone that is more than vibrant: it is almost as if it is 'buzzing' with continuous energy, one that creates a sense of 'presence'. By 'presence' I mean vocal presence, which in this instance might be defined as the degree to which a singer's tone stands out from other sounds in a recording or performance. Her energy and activeness of enunciation adds to this to give a tone that seems to check all the time that it is still being heard. This gives a sense almost that Te Kanawa's own self or her consciousness of herself is always present in the tone rather than the tone being simply a vehicle for her emotion. ${ }^{59}$

All of these 'effects' and approaches to vocal sound are choices made by the singer: they may become habitual and swift, as a distinctive style is developed, but for every note that is produced, decisions relating to choices of tone colour must be made in order for it to be created in this particular way. While the acclaim for Te Kanawa's singing centres around the beauty of the voice, there is a tendency to treat beauty, and vocal beauty in particular, as simply 'natural', and not managed or created.60 This has a trivialising effect on the work done by artists such as Te Kanawa whose vocality is based around beautiful and consistent tone. This is perpetuated by the fact that beautiful tone, by definition, shows no chinks in its armour, and gives no sense of any effort being involved in its production. Beautiful tone therefore covers up the agency, and indeed the work, done by the singer.

\section{Concepts of Agency in Beautiful Singing}

This trivialising of the work done by a singer in their creation of beautiful tone contrasts strongly with the degree of agency acknowledged in a 'dramatic' artist such as Maria Callas. For example, in a review by Peter Heyworth quoted by Steane, Callas's vocal control

\footnotetext{
57 'Chiaroscuro | Art'.

${ }^{58}$ As already noted, this dual quality is held to be an ideal in the bel canto singing tradition. For a discussion of this aspect and spectrographic analysis of some famous sopranos see Richard Miller, Training Soprano Voices (Oxford University Press, 2000), 68-73.

59 It is possible that this quality perturbs those who do not enjoy her singing, yet the same time it may be what attracts others to it.

${ }^{60}$ Fleming, The Inner Voice, xvii, 51, 222.
} 
is described in tandem with her 'understanding' of the role of Violetta. Heyworth, reviewing her 1958 appearance in the role at Covent Garden, shows his appreciation of this 'dramatic' singer's creation of vocal tone and describes what he calls 'perhaps the most marvellous moment of the evening'. This is the sustained note before 'Dite alla giovine', 'the moment of decision on which the whole opera turns':

By some miracle, Callas makes that note hang unsuspended in mid-air; unadorned and unsupported she fills it with all the conflicting emotions that besiege her'. As she descends to the aria, which she opened with a sweet, distant mezza voce of extraordinary poignancy, the die is cast.'61

This is one example of a tendency for performers who are dramatically focused to be taken more seriously than singers whose art centres around vocal quality. By contrast, the excerpt below from a very appreciative review of a performance by Te Kanawa also critiques the singing in fine detail, but the critic, Stanley Sadie, avoids mentioning anything to do with her creation of the sound. Instead he restricts his terminology to wording that draws attention to the 'simplicity' of her use of the musical elements and the accurate placing of the notes. He avoids acknowledging any creation of them, even though he states the vocal performance was 'beautiful and deeply felt'. There is an implication therefore of the tone simply being a part of the voice, something that exists already, without the singer doing anything other than 'feeling' the emotion, and that the sound simply needs to be released at the right time. In other words, it aligns with the trope of the 'natural' singer, who 'has a beautiful voice' and does not need to make any effort to create or produce the sound.

Kiri te Kanawa had just sung 'Ach, ich fühl's' in a way that, very properly, drew from the audience a bout of frenzied, rhythmical applause. [...] [Her performance of] 'Ach, ich fühl's' was characterized, to use inadequate descriptive critical terminology, by rich and intense tone, a precise placing of each note and phrase, and carefully timed and shaped cadences. It was a performance in thousands because it remained simple while being exceptionally beautiful and deeply felt. ${ }^{62}$

This implication of the singing voice as a natural and a pre-existing entity contrasts with responses to Callas that pointed to the willpower required to make her vocal tone, as

\footnotetext{
61 Steane, Singers of the Century (Volume 2), 256.

62 Stanley Sadie, 'Horst Zankl's Paris Production Anatomizes The Magic Flute', The Times, 20 May 1977.
} 
discussed earlier. At least one media writer actually dubbed Te Kanawa 'the new Maria Callas'. ${ }^{63}$ While this shows the continued influence of Callas in terms of the public's conceptualisation of the diva, there is little, as we can see, other than Te Kanawa's level of fame, to connect the two. Te Kanawa's association with beauty as a 'natural' attribute physically and in terms of her singing is bound up with concepts of the 'natural' singer, and the myth of voice as something that is essential and unique to each person. The consistency of her tone would seem to play into that concept, since if the sound is 'natural' to that person, it needs only to be released for the sound to be created, and this will be surely be easy to achieve as long as the singer allows it to happen. This concept of allowing the sound to flow out easily and naturally is one that is used in vocal pedagogy as a way to encourage the normal functions of the vocal apparatus (larynx, muscles, articulators etc.) to be used without undue tension or hyperfunction. The impression given to listeners when this is achieved is very likely to be one of ease and 'naturalness', so it is not surprising that a singer such as Te Kanawa is perceived in this way.

Unfortunately, the alignment of beauty with passivity rather than agency, and with intellectual weakness, can also come into play, and this has been a common feature of the image built up around the divahood of Te Kanawa. John Steane comments on this in terms of her performance of Richard Strauss's Capriccio for the San Francisco Opera in 1993, which was released on video. ${ }^{64}$ She had admitted in a media interview that she had learned the words for this complex work phonetically as she did not speak German. According to Steane, for some people this 'reinforced the comforting notion that a pretty woman cannot be expected to be clever as well'. Noting that since the performance was recorded for video it was able to be 'scrutinised in infinite detail on home-video the world over', he pointed out that those making the complaints about this were often not German speakers themselves, so were not actually qualified to judge how effectively she put the text across. He concluded: 'I cannot claim to have been over it [the video] in the minute detail required, but have paid sufficient attention to suggest that if this is not indeed the work of an intelligent woman playing an intelligent woman it is the best imitation of an intelligent woman playing an intelligent woman the world has ever seen.'65

As Steane has realised, learning and successfully performing such a work without the knowledge of the German language, given the opera's intensely complex musical form and

\footnotetext{
63 'Kiri Tipped as Another Maria Callas', New Zealand Herald, 17 October 1974. 64 'Capriccio, by Richard Strauss, June 1993', in San Francisco Opera Archive, n.d., http://archive.sfopera.com/reports/rptOpera-id455.pdf.

65 Steane, Singers of the Century (Volume 2), 183-84.
} 
the fact that the plot itself revolves around the relative importance of words and music, is a feat requiring a great deal of intellectual fortitude. In an interview for the book Diva, Te Kanawa gives a sense of how she approached the memorisation of her next Strauss role, the Marschallin in Der Rosenkavalier. She describes having to memorise 'all the mood changes, thought changes, all those wonderful little details [Strauss] devised' in her own part. She also describes how she memorises the timing of all the other parts in relation to hers so she will be able to 'react to all the different characters' moods and words, and to what they're saying in relation to what I'm saying'.66 Given the complexity of the harmonic and rhythmic structure of Strauss's writing this is truly a mammoth task, which clearly Te Kanawa was able to undertake faultlessly, given the fact that she performed these roles frequently and to acclaim as a mainstay of her career.

This trope of the 'natural' singer, whose voice exists as a perpetual feature of her person or body can also be traced in a number of Te Kanawa's reviews. As Eidsheim points out, such narratives about the singing body tend to be built upon 'ancient and contemporary sentiments about the female body', rather than any current understanding of the physiology or functions of the body or the voice. ${ }^{67}$ This has resonance with the case of Te Kanawa, whose 'beautiful voice in a beautiful body' reflects an historical and contemporary narrative relating to the construction of ideals of feminine beauty. ${ }^{68}$ The preconceptions around beauty and the female body are transferred in her case to beauty of voice, where the voice is treated as an existing entity, and one engendered with immutable characteristics of beauty. In this conceptualisation, Te Kanawa's voice exists as a beautiful object, and she merely utilises it, or in the case of two reviews of the same performance as Micaëla in Carmen, she 'brings it' to her performances as if it were something that she packed up in her suitcase along with her clothes.

Kiri Te Kanawa brought her full, sweet soprano to Micaela's music, and made of her a more natural and positive character than usual. (Desmond Shawe-Taylor, The Sunday Times) 69

Miss Te Kanawa brings an aptly warm personality, and a warm fresh voice to match, to Micaela's music. (Stanley Sadie, The Times) ${ }^{70}$

\footnotetext{
${ }^{66}$ Helena Matheopoulos, Diva: Great Sopranos and Mezzos Discuss Their Art (Victor Gollancz, 1991), 215.

${ }^{67}$ Eidsheim, 'Maria Callas's Waistline and the Organology of Voice', 250.

68 Bordo, Unbearable Weight, 171.

${ }^{69}$ Fingleton, Kiri Te Kanawa, 121.

${ }^{70}$ Fingleton, 121.
}

Page 114 
While these may be seen as simply the use of a particular 'turn of phrase', this usage feeds into concepts of the instrumentalisation of the voice as existing apart from the body of the singer, as well as the concept of it as a unique, or 'essential' characteristic of the singer, and clearly negates any sense of the singer's involvement or agency in the creation of the sound, or of the creation of the performance itself. ${ }^{71}$ It is not enough to assume that the construction and presentation of beautiful sung tone occurs without any care or voluntary action on behalf of the singer. Singing is an active process where the sound is produced and maintained by the singer continuously undertaking the necessary physical actions required for the production of that sound, as well as monitoring the resultant tone. The sound is thus both created and controlled, and this process is enacted voluntarily by the singer herself.

Moreover, as we can see from the analysis of the recording by Te Kanawa of 'S'altro che lagrime', a performance such as this, which is steeped in vocal beauty, involves continual management of expressive choices in terms of timbre, dynamics, vibrato, line, and energy. While the beautiful and expressive tone used may have its basis in a specific physiognomy (that is, the 'natural' shape and size of the particular singer's vocal tract, larynx and bone structure may lend itself more readily to this type of sound), producing such tone still involves precise coordination of specific actions to bring the instrument into particular states. The sound is thus constructed and presented in a particular form for each note as well as being shaped within a musical phrase and context. The process of formation of the sound in this way is not 'unnatural' but it is done, created, and controlled by the singer herself. The next section examines some instances in which Te Kanawa herself has discussed her approach to the control and realisation of her vocal sound in the specific context of mediatised performances.

\section{Agency in Mediatised Performances}

While there is creative agency in shaping vocal sound, and in producing it in performance, for the modern diva the development and maintenance of her career is largely done through recorded performances. Whereas in live performances the acoustics of the venue often require the singer to fine-tune their vocal production for good projection, comments

${ }^{71}$ Eidsheim, 'Maria Callas's Waistline and the Organology of Voice', 257; Eidsheim, 'Voice as Action', 9. Eidsheim makes an eloquent case in these articles against both the instrumentalisation of the voice (the 'voice-as-instrument-thesis') and the 'quotidian discourse' that thinks of the immutability of voice as a 'sonic fingerprint' or 'inborn, natural, and a true expression of the person'. She applies these to: the supposed relationship between Callas's weight and her vocal sound and the 'construction of race' in the context of racialised voice, respectively. 
made by Te Kanawa point to even more refinement being required in recorded performances. This implies an even higher level of control and agency in creation of the sound, which shows the fallacy of the conception of her as a 'natural' singer whose vocal sound is something fixed and not controlled by her.

There are several published examples relating to Te Kanawa's early career where she describes adjusting her approach in order to deal with recording and live performance situations differently. In the 1983 Fingleton biography Kiri, Te Kanawa comments about her recording technique around the time of her 1971 Covent Garden debut:

I was pleased with the Decca sound for Parsifal, but I still hadn't got it quite right. There's a special technique for singing into the microphone: for the Philips set of Mozart church music with Colin Davis I was trying too hard and the voice wasn't coming through [...] You have to manage to come through on the plastic as if they're hearing you in the concert hall. ${ }^{72}$

Another important milestone for Te Kanawa was the 1965 Mobil Song Quest competition in New Zealand, and again her comments on this event reveal her consciousness of the need to modify her approach for the creation of an appropriate sound in such situations. She won the competition that year, having only placed second, somewhat controversially, the previous time it was held..$^{73}$ The Song Quest was a radio competition, where the judges were not present in the hall with the audience and singers, but instead were located in a radio studio listening to the broadcast sound of the performances. This focus on radio as the medium for the competition reflects its place as the main form of mediatisation of classical music at that time, and the singers were judged on their readiness and suitability for taking part in radio broadcasts. ${ }^{74}$

\footnotetext{
72 Fingleton, Kiri Te Kanawa, 114-15.

73 The final round of the previous competition, in 1963, was held in the city of Hamilton, in the North Island, and was won by the soprano Malvina Major, who was also a student of Sister Mary Leo. It was run in the same way as the 1965 final, with the judge being located away from the concert venue, listening to the competitors' performances via radio. It was judged by English conductor James Robertson, who was at that time director of the London Opera Centre, the advanced training centre for opera singers attended by a number of young New Zealand singers in the period, and which Te Kanawa and Major went on to study at. The judge noted the audience was 'slightly surprised' by his choice, but he said the judging was very close between the two singers and he based his choice on the sound alone. Fingleton, 30.

74 This competition continued to focus on audio rather than visual performance through to the 1980s, when the initial two rounds of the competition were still judged solely on the basis of audio recordings, although the final was judged within a live concert situation.
} 
This example from 1965 shows how Te Kanawa learned to recognise the different styles of vocal production that worked for her in different live and mediatised situations, even while she was still in the early stages of developing her own vocality. In a biography published the following year, she commented that she changed her approach in the second competition, having realised that it had counted against her in the first one. The second time she reached the final round in the competition she concentrated on singing to the microphone, rather than 'performing' to the audience who were in the hall:

This time when she sang it was to the microphone. At Hamilton she had sung to the audience. But the judges could not see the singer, they heard only the sound which was relayed to them from the microphone. So you sang to the microphone, that was all. You concentrated on giving it the purest and loveliest sound that this particular human machine could produce. ${ }^{75}$

A critical consideration of this recording of Te Kanawa's performance in the final of the 1965 Mobil Song Quest competition held in the Dunedin Town Hall does reveal quite a different vocal approach from the signature vocality to be heard in the 1982 recording of 'S'altro che lagrime' discussed above (in the section analysing her vocality). ${ }^{76}$ It is not that the 1965 recording in which she 'performed to the microphone' was ideal: as Fingleton comments in his biography, it sounds 'curiously unrelaxed'. ${ }^{77}$ The vocal production sounds stilted - heavy and too careful. She is making a very consistent tone: but one that has little of the brilliance of her later 'signature' sound. However, we do gain a sense of the choices being made and the control being exercised by her when we compare this to other recordings she made around that time, and it is clear that she did modify her vocality significantly for this performance.

One might imagine that as a young singer with little formal training Te Kanawa just followed her instincts when 'singing for the microphone' in this competition, but although she was only 21 years old, she had had copious amounts of live and mediatised performance experience in the years leading up to her Mobil Song Quest win. Tony Vercoe, the newly appointed manager of Kiwi Records, realised some years earlier that she was a

\footnotetext{
75 Norman Harris and Kiri Te Kanawa, Kiri: Music and a Maori Girl (Wellington: A. H. \& A. W. Reed, 1966), 37. (My emphasis).

${ }^{76}$ Te Kanawa's performance in the 1965 final of the competition included the song 'Do not go, my love' by Richard Hageman and the recording of this from the competition can be heard on the album 'The Young Kiri' (published 1990: Decca 430 325-2).

${ }^{77}$ Fingleton writes that the recording sounds 'curiously unrelaxed, the voice displaying a heavy, careful, mezzo quality which seems unnatural to it. Of all Kiri's early recordings it is possibly the least like her voice as we know it now.' Fingleton, Kiri Te Kanawa, 30.
} 
rising star and decided that the company should invest in a series of recordings of her while she was still resident in New Zealand. He started on this project for the label in $1964 . .^{78}$ Vercoe produced all of the recordings of Te Kanawa, which were released within New Zealand with great success as $45 \mathrm{rpm}$ EPs. ${ }^{79} \mathrm{He}$ commented later that for these recordings he coached her through the process and that she was 'responsive, open to ideas and impressions' ${ }^{80}$ This shows not only were there choices to be made in terms of her vocal approach (i.e. she did not have a 'natural' voice that produced the right sound without any thought on her part), but also that through working with Vercoe she was learning new tools and developing her ability to control her instrument and use it in different ways for different situations, even in the decade prior to her London debut.

A useful contrast to the 1965 Mobil Song Quest recording is the live recording from the following year of Sibelius's 'The Tryst'. ${ }^{11}$ This recording was made in the Auckland Town Hall, at her farewell concert there in 1966, as she was about to leave New Zealand to go study at the London Opera Centre. She gives a performance that has a number of differences from the Song Quest final recording. It seems a very lively performance, and she is flexible with the energy in the sound and makes plenty of use of rubato. The crispness of her formation of the consonants, and her energetic tone, lend an excitement to special moments within the song and her style of projection is quite different to the careful control and rather cautious approach of her 1965 performance. There is a depth of warm tone, but also the glimmer of the fast vibrato effect she later developed in her signature sound. 82

Although there was much more work to be done to develop it further, Te Kanawa's nascent signature vocality is evident in these recordings and she is clearly making choices

\footnotetext{
78 Max Cryer, The Young Kiri - CD Booklet (Decca 430 325-2, 1990), 25.

79 Te Kanawa had in fact had a 'hit' record in New Zealand through this project with Kiwi Records: The Nun's Chorus. Max Cryer, in the CD Booklet for The Young Kiri writes: '[it] went into the local hit parade charts, and for over a year was the most asked-for item on Les Andrews' popular radio request session.' She recorded three EPs (extended play 45 rpm records) in the years before the 1965 Mobil Song Quest, two of which would have been released prior to the final. These EPs extended play, 45rpm vinyl records - would have allowed for approximately 7 mins of recording on each side. Cryer, 27.

80 Cryer, 28.

81 This recording is with Barbara Connelly, piano, and can also be found on The Young Kiri (Decca 430 325-2, 1990).

82 It may be that Sister Mary Leo did not encourage her to use much vibrato at that time. In the recording of Te Kanawa singing 'Vissi d'arte' ('Love and Music') from Tosca in the Melbourne Sun Aria competition which she won soon after the 1965 Mobil Song Quest, it her high notes seem quite constrained - there is no 'bloom' on them compared to how she would later go on to sing such notes, and they have no vibrato at all. This recording may be heard (as one of two of this aria) on The Young Kiri (Decca 430 325-2, 1990). It was originally released in 1966 by Kiwi Records on the vinyl LP album 'Kiri in Concert'.
} 
and constructing the sound she judges to be fit for a particular purpose, even as a very young artist prior to her London training. Kiri Te Kanawa's conscious management of her developing vocality in recorded and live performances, as discussed here, can be seen to work against the trope of the singer as subservient within the authorial process, or not creatively involved in the production of their sound. It points instead to the creative agency that is exerted by opera singers, in particular the modern diva working to maintain a consistent impression of her vocality in this mediatised age.

\section{Vocal Fashion: The Marketable Sound}

Even before she had left New Zealand to undertake formal training at the London Opera Centre in 1966, Kiri Te Kanawa had amassed a huge public following within the country. ${ }^{83}$ Evidence of her popularity at the time (during the 1960s) is clear from her series of six farewell concerts in the main towns and cities throughout the country. Her wedding was a major event attracting crowds of well-wishers, and took place in Auckland when she returned home for a three-week concert tour in August 1967.84 In the same year she gave two outdoor concerts at the 'Bowl of Brooklands' in New Plymouth. The concerts attracted an audience of 9,000 - an extremely large attendance, given they were held in a town with a population of only 35,000 people. ${ }^{85}$

To trace the reasons for the huge popularity of Te Kanawa within New Zealand, and later on in Europe and North America, where she also became a 'household name', we must acknowledge the impact of mediatisation on her career path. The commercial release of audio and video recordings was a crucial feature of Te Kanawa's career and one that continued throughout her career. As we have seen, her first audio recordings were made in New Zealand. In London, in the early 1970s, she started to record for major international labels, and she was soon contracted as an exclusive recording artist for Decca (known as London Records in the USA). In fact she made and released more

\footnotetext{
${ }^{83}$ Simpson and Downes, Southern Voices: International Opera Singers of New Zealand, 222.

${ }^{84}$ Fingleton, Kiri Te Kanawa, 54-58, 64.

85 'Kiri Te Kanawa - Kiri Sings Opera', Discogs, accessed 6 October 2018, https://www.discogs.com/Kiri-Te-Kanawa-Kiri-Sings-Opera/release/6495975. This gives details of the recording released by Kiwi Pacific. Information on the town's population at that time is from the New Zealand Official Year-book. The New Zealand Official Year-Book, 1967, accessed 6 October 2018,

https://www3.stats.govt.nz/New_Zealand_Official_Yearbooks/1967/NZOYB_1967.html\#idchapter_ 1_8591. Te Ao Hou, published by the Maori Affairs Department in June 1967, reporting on the concert stated that 'an estimated 9000 attended both concerts, given by the N.Z.B.C.'s Little Symphony, with Kiri as soloist.'
} 
recordings than most classical artists at the time, and had one of the highest record sales for her generation. 86

Te Kanawa's very 'clean' vocal performance style, which is highly accurate and employs little in the way of portamento, rubato or other overtly expressive devices, lines up with the post-war trend towards the literal interpretation of the score that has been identified by Leech-Wilkinson. Apart from hearing others' recordings and performances, the conductors with whom Te Kanawa made so many of her early discs, in particular Georg Solti, would have had an important part in shaping her stylistic approach. ${ }^{87}$ These conductors were of course working under the same stylistic influences as Leech-Wilkinson describes.

While Callas's style also involved careful adherence to the written score, Te Kanawa's continuity of colouration and beauty of tone contrasts with her dramatic variety of tonal colour. The consistency of the vocal tone produced by Te Kanawa is one of the features of her vocality that is particularly important in terms of her building of fame and popularity within her career. Not only was her tone within each aria or role on an album or opera recording consistent and identifiable (as noted earlier in my analysis of her vocality) but her tone also remained consistent between different recordings. While for some listeners this may be a feature they find troublesome, in that some may find it boring or inexpressive to have the sound unchanging to this degree, at the time of her rise to international stardom, and during the ensuing decades through the 1990s, this was an aspect of her appeal as a recording artist. It made her recordings particularly 'marketable', in that the recording companies could be confident that her new recordings would align with her previous ones and the individual vocality she was known for. The purchase of an album recorded by her was therefore a less risky prospect for consumers, as her quality of sound was a known and consistent feature.

Along with commercially-released video recordings many of Te Kanawa's television appearances were readily available to consumers from the 1980s on, formalising the relationship between her consistent beauty of tone and her physical beauty as a marketable and marketed combination. Te Kanawa was able to be viewed performing opera roles on films, in television appearances and in specially-recorded concerts

\footnotetext{
${ }^{86}$ Christiansen, Prima Donna, 300.

${ }^{87}$ Robert Chauls describes this appreciatively as her 'no nonsense approach' when reviewing her recording of Mozart opera arias with Colin Davis. Chauls, 'Review: Kiri Te Kanawa Mozart Opera Arias'.
} 
throughout her career. This outlines a clear difference between the nature of her career and that of Callas's, for whom few filmed performances exist, particularly during the period of the height of her fame and acclaim as an artist. The advantage to Te Kanawa of repeated appearances on television, not only in major events such as the Royal Wedding in 1981 but also shows such as the Southbank Show, Harry Secombe show, and broadcasts of opera performances such as 'In Performance: the Royal Opera' on the BBC in the UK, was inestimable in terms of imprinting her as a known star in the cognisance of the general population in the countries where these were broadcast, and her reputation as a star singer in general.

As discussed in the previous chapter, those who experienced Maria Callas performing live often maintained that her recordings did not match up to what they had heard in the live performances. This is not a common theme in comments made with respect to $\mathrm{Te}$ Kanawa's recordings, whether for those from the early period of her career or later ones. In fact, Te Kanawa herself can be seen to take responsibility for the sound and the vocal quality on her recordings and also the consistency of its impact, through her own vocal production. ${ }^{88}$ As a newly arising young star she was fortunate to have come to prominence in a period where audio and audio-visual recordings of opera and other vocal music were becoming more popular, and her signature vocality would prove to transmit equally well in recordings as in live performances. John Steane refers to both live and mediatised versions of her performances as providing the highest quality of vocal performance: speaking for those who experienced Te Kanawa's London debut as the Countess and 'have watched ever since', he comments that 'some of the loveliest singing we have heard in our entire lives, both "in the flesh" and on records, has been hers; [and] some of the most exultantly lit-up of nights in the opera house have owed their incandescence to her'. ${ }^{89}$

My experience of Te Kanawa's recorded and live performances is that her 'presence' as a singer was located more strongly within the vocal tone she created than in her stage acting. A clear example of this was brought out to me during her performances as Mimì in La Bohème in 1991, in Auckland, New Zealand, when I was the understudy for that role, and thus attended all rehearsals and the complete series of ten performances. While those on stage next to her commented on her intense involvement in the drama - she was apparently in tears every night during the Act IV death scene, for example - comments I heard made by other members of the audience showed that her engagement with the emotion of the scene did not in fact transmit to them effectively. The 'acting' was evident,

88 Fingleton, Kiri Te Kanawa, 114-15.

${ }^{89}$ Steane, Singers of the Century (Volume 2), 185. 
but it was conveyed within the sound of the voice. I enjoyed this expression of Mimi's passionate emotion that came through to me in her tone, which was filled with precise and intense vocal colouration, but I can understand how it might be possible that someone who was not versed in the operatic style or musical expression of this type might find it difficult to sense. They would not have found the emotion overtly displayed in Te Kanawa's acting and movements on the stage, which came across as restrained and underplayed in terms of the embodiment of this passion. Te Kanawa's vocal presence does generally come through strongly in both her live and mediatised performances, and this is a fundamental factor that was unusually prominent in her quality as a star singer and made such fame possible. This vocal presence and the beauty of her vocality was loved by her fans, and was both promulgated and reinforced by the multitude of mediatised performances she now leaves as her legacy. This legacy of recordings provided for her influence on the fashion in classical singing during the ensuing decades.

\section{Tracing Te Kanawa's Influence}

Power, for a modern diva, resides not only in the immediacy of demand for and interest in her performances, but also in her legacy and influence through mediatisation. Elements of Te Kanawa's distinctive timbre and her habitual vocal approach to text and phrasing can be traced in numerous sopranos who followed in her footsteps during the late twentieth and early twenty-first century, particularly in performances of Mozart operas. Perhaps the strength of this effect was due to the degree to which her vocal style epitomised the beauty of tone and line that Tebaldi practised and the way the vocality of both singers were allied to the fundamental richness of their vocal instrument. I think it was more than that however: Te Kanawa's tone provides a richness of texture and complexity of harmonic structure that in some ways surpasses that of Tebaldi in terms of its 'presence' and distinctiveness.

By no means all of the features of Te Kanawa's distinctive vocality are evident in every successful lyric soprano who follows. This is only to be expected - not all sopranos have a basic timbre that is close to that of Te Kanawa, and even those who do may prefer to focus on producing a different sort of sound. However, a surprising number of lyric sopranos, and in fact, lyric mezzo-sopranos, whose careers rose to an international level in the ensuing decade had a similar vocality to Te Kanawa. Elements of Te Kanawa's vocality can be traced, for example, in the recordings of Barbara Bonney, Kathleen Battle and Renée Fleming. All of these singers came to prominence during the years following the rise of Te Kanawa and like her were lauded for their performances of the Mozart and Richard Strauss repertoire. 
A feature of Barbara Bonney's vocality is her expressive use of a fast and regular vibrato, similar to that used by Te Kanawa. In both cases this vibrato is often withheld on some notes then brought out as an expressive effect on a stressed note that follows. Since so many of her recordings were with 'Early Music' specialists such as Nikolaus Harnoncourt, Christopher Hogwood and Trevor Pinnock, perhaps it is significant that Bonney does use so much vibrato and richness of tone for expressive effects. In her recording of Exsultate Jubilate with Pinnock in 1994, Bonney uses some Te Kanawa-like devices in the 1st movement. ${ }^{90}$ In bar 46, for example, for the phrase 'psallant aethera cum me', her vowel 'ae' has Te Kanawa's centralised vowel sound and the warmth of a lengthened vocal tract (through a low larynx and/or lip rounding) allied with a burst of fast vibrato. This tendency to add vibrato for the stressed notes, and the rounding of the 'open e' vowel sound to give a gleaming warmth of tone is characteristic of Te Kanawa, and is used by Bonney here a number of times. In general Bonney varies the amount of vibrato often and also tends to make use of quieter dynamics as a variation but in the aria 'S'altro che lagrime', recorded with Hogwood in 1995, her sound opens up so fully in terms of colour and vibrato at the phrase 'o quanto e simile' that when I first heard it I would have believed it was Te Kanawa singing this phrase had I not known otherwise. ${ }^{91}$

While Kathleen Battle often makes use of a bright, almost 'girlish' tone for her main expressive emphasis, she frequently contrasts this with a warm rounded tone and centralised vowel colour very much aligned to that of Te Kanawa. For example, in her 1990 recording of 'L'amerò, sarò costante' with André Previn, at the beginning of the $B$ section she starts the phrase 'in si caro e dolce oggetto' with a very rounded 'i' vowel, yet by the time she reaches the word 'caro' she has taken away the rounding, and uses an almost breathily-bright 'a' vowel. ${ }^{92}$ She returns to an even more warmly golden and rounded tone on the word 'oggetto' to finish off this phrase. She also makes this contrast within words, for example, in the B section of this aria at the words 'la mia pace'. At this point, within a single word, she makes the contrast of a brighter tone in the form of a very

\footnotetext{
90 Barbara Bonney, Mozart: Coronation Mass - Exsultate, Jubilate - Vesperae Solennes: Trevor Pinnock, The English Concert, Audio CD (Archiv/Deutsche Grammophon 28944535327, 1994). Currently available at: Barbara Bonney; 'Exsultate, Jubilate'; Wolfgang Amadeus Mozart, accessed 19 September 2019, https://www.youtube.com/watch?v=RMi2v8-_cfs.

91 Barbara Bonney, La Clemenza Di Tito by Mozart: Christopher Hogwood, The Academy of Ancient Music (L'Oiseau-Lyre (Decca) 00028944413120, 1995). Currently available at: Barbara Bonney; 'S'altro Che Lagrime'; La Clemenza Di Tito; Wolfgang Amadeus Mozart, accessed 19 September 2019, https://www.youtube.com/watch?v=2DqvlWm8_R0.

92 Kathleen Battle, Kathleen Battle Sings Mozart, with André Previn and the Royal Philharmonic Orchestra, CD Audio Recording (EMI Angel CDC-7 47355 2, 1990). Currently available at: Kathleen Battle; 'L'amerò, Sarò Costante'; Il Re Pastore; Wolfgang Amadeus Mozart, n.d., https://www.youtube.com/watch?v=lX6LPBwcS78.
} 
forward-placed ' $a$ ' for the first syllable, followed immediately by a warmly rounded creamy tone on the final ' $e$ ' of 'pace'. When Battle uses this warm, rounded tone consistently, as in her 1997 recording of 'S'altro che lagrime' with James Levine, she reproduces the vocality of Te Kanawa much more closely in terms of tone, phrasing, and style. Battle adds high harmonics on 'gioverà' and other high notes, as does Te Kanawa in her soaring 'release' on the high range notes, and her vibrato is swift and regular. Her consistent use here of this rounded, fuller tone gives Battle a legato line and continuity of colour that readily matches that of Te Kanawa. ${ }^{93}$

Bonney and Battle are both light lyric/lyric coloratura sopranos whose careers followed that of Te Kanawa and were centred round Mozart. Renée Fleming is a full lyric soprano whose vocality aligns even more closely to that of Te Kanawa. It was Fleming's creaminess of tone and relatively fast vibrato that first led me to connect her vocality with $\mathrm{Te}$ Kanawa's. From my analysis of multiple recordings by Fleming of music of different genres, it is clear that the similarity of vibrato is strongest in the middle range of Fleming's voice, while the creaminess is found throughout. Both singers performed extensively with conductor Georg Solti, who in fact nicknamed Fleming's voice double-crème (double cream). ${ }^{94}$

Fleming's choice of vowel colour and tone on specific vowels often aligns very closely with that of Te Kanawa. Fleming can be heard also to have a similar creaminess and moderate speed of vibrato on the middle range 'a' vowels in the recording made with Charles Mackerras of 'L'amerò sarò costante' in 1996, and in 'Porgi amor', recorded with Georg Solti in 1997.95 In her recording of 'Laudate dominum', made with Andreas Delfs in 2005, Fleming's vowel colouring, the general tone and use of vibrato are very similar to those employed by Te Kanawa. ${ }^{6}$ Here the first two words are sung with a similar creaminess,

\footnotetext{
${ }^{93}$ Kathleen Battle, Kathleen Battle, Mozart Opera Arias, with James Levine and the Metropolitan Opera Orchestra, CD Audio Recording (Deutsche Grammophon 00028943994927, 1997). Currently available at: Mozart: La Clemenza Di Tito, K.621 / Act 2 - 'S'altro Che Lagrime' [Battle], accessed 19 September 2019, https://www.youtube.com/watch?v=sIVEWJzeVtw.

94 Fleming, The Inner Voice, 95.

${ }^{95}$ Renée Fleming, Renée Fleming, Mozart Arias, with Charles Mackerras and the Orchestra of St Luke's, Audio CD (Decca 28945260228, 1996); Renée Fleming, Renée Fleming, Great Opera Scenes, with Sir Georg Solti and the London Symphony Orchestra (Decca 28947509424, 1997). Currently available at: Renée Fleming; 'L'amerò, Sarò Costante'; Il Re Pastore; Wolfgang Amadeus Mozart, accessed 20 September 2019, https://www.youtube.com/watch?v=amynaF3Vc94.; Mozart: Le Nozze Di Figaro, K.492 / Act 2 - 'Porgi Amor' [Fleming], accessed 20 September 2019, https://www.youtube.com/watch?v=xDkLKdWEZF8.

${ }^{96}$ Renée Fleming, Renée Fleming, Sacred Songs, with Andreas Delfs and the Royal Philharmonic Orchestra, Audio CD (Decca 28947564508, 2005). Currently available at: Mozart: Vesperae Solennes de Confessore in C, K.339 - Laudate Dominum Omnes Gentes [Fleming], accessed 20 September 2019, https://www.youtube.com/watch?v=nu_ZbM6qno4.
} 
suggesting lip pout and zygomatic muscle use. Her 'o' and 'e' vowels are often given a 'centralised' colour, for example on 'domini' and 'ejus', and the bright yet creamy clarity of her 'a' vowel gives a particularly 'Te Kanawa' style of colouring, for example in the word 'quoniam'.

At the higher and lower range Fleming's tone tends to diverge from Te Kanawa's, with Fleming using a darker lower range and a more 'steely' tone for sustained high notes (high A to high C) with less vibrato. ${ }^{97}$ In her middle range, however, Fleming's vocality has much that reflects Te Kanawa's. Often singing the same Mozart and Strauss repertoire that Te Kanawa was acclaimed for, Fleming also has taken on the arias by Puccini and Korngold that have been strongly associated with Te Kanawa. She included these arias in her 2015 concert with the New Zealand Symphony Orchestra, during which she openly acknowledged her connection with Te Kanawa, commenting that it was 'very moving' for her to sing in New Zealand because classical singers were measured by those who come before them and 'in my case, my predecessor was Kiri Te Kanawa'. ${ }^{98}$ Clearly there were many other singers who sang the same repertoire at the same period as Te Kanawa, and including the period prior to Fleming's career but Fleming here seems to be aligning herself specifically with Te Kanawa, acknowledging the influence and heritage that came from her as a diva, and implying that Te Kanawa's style of singing provided a base for her to follow in her footsteps.

This consideration of some representative examples of recordings by these three major artists has shown how aspects of the same vocal style and tone that are found in the signature vocality used by Te Kanawa also form prominent features of their customary stylistic approach, used by them here in repertoire by Mozart. All the singers discussed above might be expected to exhibit similar vocal characteristics, since they all possess lyric voices. According to the standard Fach voice classification system as developed by Kloiber, based on their repertoire these sopranos would all be classified as lyric coloratura, or lyric sopranos. Despite this expectation, the degree of similarity of specific traits found through the above analysis seems to go beyond such norms and I contend that it therefore implies some form of influential effect.

\footnotetext{
97 This 'steely' tone seems to relate to Anne Midgette's description in the Washington Post quoted on the Renée Fleming IMG Artists page: 'the shining freshness that grabbed everyone's attention when she was just coming onto the scene: gl eaming high notes arcing downwards like wires of gold'. Anne Midgette, 'From Fleming, a Satisfying Night of Gleaming Voice', The Washington Post, 10 January 2011, sec. C10, EBSCO Host; 'IMG Artists: Renée Fleming', IMG Artists, 17 May 2016, https://imgartists.com/roster/renee-fleming/. 98 'Renée Fleming: Gala Evening Concert with New Zealand Symphony Orchestra, Recorded 12th September 2015', Music Alive (Radio New Zealand Concert, 25 December 2016).
} 
Given that Te Kanawa's career started at such a critical period in operatic history, when the burgeoning availability of high-quality recordings provided an unprecedented avenue for the distribution of her work, the quality of her tone was more likely than ever to be heard with high fidelity, allowing for the wide dissemination of her lyrical timbre.

Whether other singers consciously replicated the characteristics of this sound or were encouraged by teachers and coaches to emphasise similar aspects of their own tone, is not easy to determine. At the very least, the influence of a singer such as Te Kanawa will be transmitted via those who are casting operas or engaging artists through what is effectively a process of 'unnatural selection'. ${ }^{99}$ Singers who have aspects of the desired quality within their own vocality will be more likely to be chosen in such situations. The outstanding success of a singer whose vocality is both distinctive and extremely consistent, as in the case of Te Kanawa, may thus passively influence the fashion for vocal sound for years to come, perhaps without the singers whose careers have been affected even being aware of it. Artists such as those discussed here, whether or not they have ever made any conscious connection to Te Kanawa's vocality, may have experienced increased career success and prominence due to the influential effect of the popularity of her vocal quality. 100

\section{The Authorial Voice of the 'Natural' Singer: Conclusions}

Te Kanawa's rise to stardom in the 1970s seems to have fostered an intense flourishing of an aesthetic trend in the direction of lyrical beauty. The extreme quality of this particular singer's beauty of tone, and the tonal consistency of which she was capable, marked her appearance in the profession as something outstanding. Her initial impact was strong, but she also had some strong critics, and this divergence of critical opinion can be seen to mirror that which flared so strongly around the 'rivalry' between Callas and Tebaldi in the 1950s.

\footnotetext{
${ }^{99}$ Kylie Korsnack, 'Natural or Unnatural Selection?: Darwin and the Evolutionary Success of Genetically Engineered Species in Bacigalupi's Windup Girl', Bioculture Seminars (blog), accessed 23 January 2017, https://biocultures.wordpress.com/2015/04/05/natural-or-unnatural-selectiondarwin-and-the-evolutionary-success-of-genetically-engineered-species-in-bacigalupis-windupgirl/.

100 In some cases a singer of this stature may also teach, usually after, or towards the end of their career, and in both demonstrating and encouraging a particular type of sound, will pass on their influence on the vocality of younger singers in this way. Notably Callas taught masterclasses at the Juilliard School for a full year, and Te Kanawa now teaches masterclasses and does some individual private lessons. Other examples of famous sopranos who have gone on to significant teaching careers include Nelly Miricioiu, Ashley Putnam (Manhattan), Yvonne Kenny (Guildhall), Lillian Watson (RAM, RCM), Virginia Zeani, Carol Vaness, Sylvia McNair (Indiana).
} 
Christiansen concludes that 'Callas was in the vanguard of a revolution, while Tebaldi stood tranquilly for what had now become the 'classical' verismo style'.101 I have argued in this chapter that the rise of Te Kanawa constituted the resurgence of Tebaldi's vocal aesthetic even though it was now embodied in a voice and personality that suited Mozart and Strauss more than the Italian verismo repertoire. Moreover, through the influence of Te Kanawa that I have outlined in this chapter, these two 'opposing' strands have continued to maintain their standing through to the present time. I do not consider either strand to be better than the other - rather, they epitomise two radically different aesthetics, both of which are valid and capable of communicating and expressing the emotional demands of opera within particular stylistic categories.

Barthes' famously pointed out how poor the descriptors available to us are, when we attempt to put an evaluation of music into words. ${ }^{102}$ It is quite clear, however, that certain types of words were more commonly used to describe Te Kanawa's singing, and that the ones which implied a rounded, warm (womanly/shapely) tone align closely with the way Tebaldi was described. Te Kanawa's divahood was placed firmly around the voice, which was the basis of her fame during the most active part of her career. Early in her career she already displayed agency in the processes of recording and, with the help of teacher Rózsa and conductor Solti, stayed a 'marketable product' throughout a long career, making more recordings than most other singers of her generation. This recorded legacy carries forward her traditions of vocal beauty, which continue to influence singers today, resisting the Callas model of modern divahood.

While I have noted the way Te Kanawa's vocality and musical approach lines up with Leech-Wilkinson's assessment of the post-Second World War trend towards performances of an unadorned, clean and accurate style that adhere strictly to the musical score, his study does not attempt to account for the influence of individual vocality, nor for trends in vocal fashion that relate to the sound of the singer. ${ }^{103}$ As we can see from this consideration of Te Kanawa's signature vocality, her realisation of Mozart's music was profoundly influential in this period. While there is no specifically defined set of acceptable vocal timbres for opera, it could be argued that operatic vocal fashion and tastes imply that some form of a 'canon' of vocal timbres does exist, and that adherence to this 'canon', or at least to the limitations of the range of vocal colouration as outlined by

\footnotetext{
101 Christiansen, Prima Donna, 281.

102 Barthes, 'The Grain of the Voice', 179-81.

103 Leech-Wilkinson, 'The Changing Sound of Music: Approaches to Studying Recorded Musical Performance'.
} 
that set of timbres, is a requirement of the profession. While Callas extended that set of timbres through her expressive use of a much wider range of tone colour, including some tone that many thought of as 'ugly', Te Kanawa effectively established her distinctive new vocal timbre as the epitome of beautiful tone, and a form of vocality that was particularly suited to the Mozart repertoire.

I have shown that although the agency in creating the beauty and complexity of sound that this involves may be hidden, it is deeply important from the point of view of achieving the quality of vocal sound that brings out the sublime quality of these works. The ideal of the beautiful singer, as is associated with Te Kanawa, is very much linked with the idea of the 'natural' singer, whose 'effortlessly' spun sound seems, at least to the unenlightened observer-listener, to be merely a quality of the singer, a feature of their body that is unchanging, static, and does not involve any active control or agency on their part. This trope is very generally believed, to the point where non-singers will often describe themselves as being hopeless singers, or having no voice. At the other end of the scale, a diva such as Te Kanawa is treated as 'having' a voice, one that requires little to no effort to produce or develop. This misconception is an issue which does not only affect female singers, but it unfortunately plays into the passive-feminine ideal which surrounded Te Kanawa, and gives an unrealistic idea of the work and agency of singers in general. It is intriguing to consider whether the way Te Kanawa was treated as a natural-beautifulsinger through the 'male gaze' that registered her career through the period from the 1970 s to the 2000s would in fact be acceptable or accepted today.

While Clément's Opera focuses on the victimisation of women in the plots of operas, and the way that this may perpetuate concepts of the female as passive or weak, we can see from Te Kanawa's treatment how a female singer in lyric roles is also typecast personally with reference to these gendered concepts. What is at stake here in terms of the wider view is in fact the progress towards gender equality of the society in which these operatic institutions function, in Te Kanawa's case, within Europe and North America. The slow rate of this progress is reflected and enacted in the social construction of the operatic form and through our seeming acceptance of the nineteenth-century era values and attitudes towards women that opera presents. ${ }^{104}$ This is evident not only through the elements inherent in the work as written, as pointed to by Clément, McClary, and others, but also

104 Clément, Opera, or, The Undoing of Women, xviii. In her Foreword to Clément's book, Susan McClary points to these nineteenth-century 'moral codes, values and normative behaviors' of the bourgeoisie which were disseminated through the medium of opera and remain encased within the works of opera from that time. 
through the attitudes and tropes that, as we have seen, surrounded and impacted on Te Kanawa as a lyric soprano diva in the later twentieth century.

Grover-Friedlander portrays opera as looking backwards to revive historical works and glorifying past voices. ${ }^{105}$ Now that we have video of excellent quality available of performances from Te Kanawa's era we actually can look back (and 'listen back') to past voices and their performances with some degree of confidence in these as adequate representations of the performers. Yet perhaps this element of opera - its reflection of obsolete and/or offensive societal attitudes to women - will be the sticking point for future generations of potential opera lovers, despite the clear potential for this mediatisation of performances to perpetuate the art form. How has the embodiment of the concept of the diva changed as time has moved on into the twenty-first century, and to what extent does this include an acknowledgment of agency, intelligence, and authorship? The career of Anna Netrebko, the subject of my next case study, shows how a modern diva from this period is able interact with these issues and wield power through new forms of media.

The importance of Te Kanawa's distinctive vocality was closely allied with her personal beauty and 'camera loves her' appeal. Her influence on lyric soprano vocality and her suitability as a star of video, film and television programming shows how mediatisation was changing the field during her career. Meanwhile, her distinctive vocality and vocal 'presence' both allowed for and reinforced her success in this period, within the historical progression from the career of Callas to that of Netrebko in the twenty-first century.

105 Grover-Friedlander, Vocal Apparitions, 136-37. 


\section{CHAPTER 4: GLOBALISATION AND THE 'UN-PRIMA DONNA': ANNA NETREBKO}

Ms. Netrebko seems blissfully unaware of the rules of the diva handbook. She doesn't suck the air out of a room with the force of a powerful personality; [...] she is unimaginably down-to-earth for a very beautiful young woman who happens to be world famous.

('A Diva Who Breaks the Divadom Rules', Anne Midgette, The New York Times) ${ }^{1}$

Netrebko rose to international stardom in the early 2000s - a period which saw huge changes in the media pertaining to audio and audio-visual performances. The impact she made is inherently bound up with the mediatised environment of this period and provides an opportunity to trace forms and degrees of authorship within a twenty-first century incarnation of divahood. Moreover, Netrebko's 2017 publicity biography asserted that she had 'redefined what it means to be an opera star' - a major claim, and one with implications of the power, agency and influence of this 'new type' of diva. ${ }^{2}$

Born in Russia, Netrebko made her debut at the Kirov Opera in St Petersburg in 1994, and was heard in lead roles as the company toured extensively over the rest of the decade. ${ }^{3}$ Her following and status as an international opera star developed out of the huge recognition she gained in 2002 and 2003 singing Donna Anna at the Salzburg Festival. In between the two seasons, Deutsche Grammophon signed her for an exclusive recording contract and made use of the publicity around the second season to successfully launch her debut CD. 4

\footnotetext{
${ }^{1}$ Anne Midgette, 'A Diva Who Breaks the Divadom Rules', The New York Times, 27 December 2006, sec. Arts / Music, http://www.nytimes.com/2006/12/27/arts/music/27netr.html.

2 'Anna Netrebko 2017 Concert Biography', in Programme Booklet: Anna Netrebko and Yusif Eyvazov Concert, Calgary Opera, April 30th, 2017, n.d.

3 The Mariinsky opera and ballet house was called the 'Kirov Theatre' in Soviet times but the name reverted to the name 'Mariinsky Theatre' in 1992. The opera company has retained the name Kirov Opera, even though it is also known as the Mariinsky Opera and is based at the State Academic Mariinsky Theatre. For information about her early performances and international tours with the company see: Carlos Agelet de Saracibar, 'Anna Netrebko Performances Database' (Scribd, 4 September 2011), https://www.scribd.com/doc/63918608/ANPD-Sep-2011.

${ }^{4}$ Gregor Dolak, Anna Netrebko: Opernstar der neuen Generation (München: Heyne Verlag, 2006), 11-13; Marianne Reissinger, Anna Netrebko. Ein Porträt (Reinbek bei Hamburg: Rowohlt Verlag, 2005); Jürgen Kesting, Die grossen Sänger (Band IV), vol. Band IV (Hamburg: Hoffmann und Campe, 2008), 1915. The two German-language biographies of Netrebko (written by Marianne Reissinger and Gregor Dolak respectively) were published soon after her acclaimed performances in Salzburg in 2003. Despite the fact that America has since become so important for her career these biographies have not been released in English translation and are now out of print.
} 
This first recording involved the innovative use of mediatisation: at the same time as its release a DVD was produced that included both documentary-style interviews and videos that copied the style of popular commercial music clips made for MTV. In the videos she was performing the aria tracks from the CD but these were staged in a way that meant they worked as stand-alone clips, and did not require any association with the original operatic works for their effect. With so many layers of creative input for such a project, the agency of the singer may be obscured or indeed diminished. This chapter will tease out those layers to identify Netrebko's agency in the context of a range of mediatised and live performances.

Netrebko has had substantial success in terms of the popularity of her CD and DVD recordings. British music critic Hugh Canning summed up her success in such mediatised performances in his 2007 article in Opera magazine:

Deutsche Grammophon's live audio recording [of La Traviata] [...] has sold an astonishing 300,000 copies in [Germany and Austria] alone. That's chicken-feed in pop terms, but for a classical industry in supposedly terminal decline, that's titanium sales for a complete opera set. It's hard to imagine that the DVD recording will not outsell the CDs: the camera obviously loves both Netrebko and [Rolando] Villazón - they are the perfect singers for the video opera age. ${ }^{5}$

Even more significant in terms of the role of mediatisation in Netrebko's career (in terms of disseminating videos, downloading or streaming of recordings, and promoting sales of CDs and DVDs) was the internet. The form of her career can be seen to have been moulded by these technological developments, which have fundamentally altered the nature of our engagement with music and performance.

Netrebko's career thus forms a lens for the examination of the effects of this diversification in the area of mediatised opera performance. My particular interest in this study is in how her voice and vocality have featured in her career path, and whether the way she uses her signature sound is different to that of previous generations of divas, including Callas and Te Kanawa. Through social media and the internet Netrebko is able to reach and, perhaps more importantly, connect with a much larger global audience than has been previously possible, broadening the stage for her power of influence and attraction

\footnotetext{
${ }^{5}$ Hugh Canning, 'People 336: Anna Netrebko', Opera, June 2007, 647-48.
} 
through these channels. She is able to showcase her vocality, build and interact with her audience base and maintain personal control over aspects of her image as a diva.

Jürgen Kesting places Netrebko as part of the globalisation mechanism, to which, he argues, 'the opera business has often unconditionally surrendered', pointing to the promotion of The Three Tenors concerts as a forerunner to those of Netrebko and her concert partner in the 2000s, tenor Rolando Villazón. ${ }^{6}$ He attributes the ability of such mass entertainment events to attract huge audience numbers despite high ticket prices to preparation laid down by earlier developments in the recording industry. He suggests that 'the stereo technology in the 60s and 70s and the digital recording technology in the 80s [led to] a flood of outputs in which artistic considerations were less important than the wishes of ambitious stars.'7

This degree of international stardom and media attention, as well as Netrebko's success as a performer working in the highest-level opera houses of the world, is exceptional - few other opera stars today have such a record of media attention and success. To what degree this is based on her artistry, vocal ability, dramatic impression, marketability, and/or public attraction to her persona and looks, is a crucial question affecting the definition of twenty-first century divahood. The critical acclaim and scrutiny Netrebko has received as a singer emphasise the degree to which she is recognised as a major mainstream opera artist of the twenty-first century.

Although some aspects of Netrebko's promoted image may seem to relate more to those of 'popera' stars such as Katherine Jenkins, she has been regarded throughout most of her career as an artist whose status as a prima donna placed her securely within the conservative classical opera fandom arena. As the only artist to have starred in six season openers for the Metropolitan Opera's Met Live in HD series, Netrebko has been focused on the classical operatic institution, even though in more recent years she has also recorded some 'crossover' material. ${ }^{8}$ There is a complex story to her career, and for her this clarity

\footnotetext{
${ }^{6}$ Kesting, Die großen Sänger, 2008, Band IV:1861. My translation. The original text refers to '...der Begriff 'Globalisierung' zur Chiffer für die Mechanismen der modernen Märkte' and states 'Der Opernbetrieb hat sich ihr vielfach bedingungslos ausgeliefert'.

${ }^{7}$ Kesting, Band IV:1862. My translation. The original text is: 'die technischen Entwicklungen: die der Stereophonie in den sechziger und siebziger Jahren und die der digitalen Aufnahmetechnik in den achtziger Jahren. Sie führten zu einer Flut von Produktionen, bei denen künstlerische Erwägung weniger wichtig waren als die Wünsche ehrgeiziger Stars.' 8 'Metropolitan Opera Live in HD', in Wikipedia, 16 November 2017, https://en.wikipedia.org/wiki/Metropolitan_Opera_Live_in_HD. The opening titles to the 2017 Metropolitan Opera Live in HD movie version of Eugene Onegin stated that it was Anna Netrebko's 13th Live in HD appearance and that she had appeared in at least one in each of last $10 \mathrm{HD}$ seasons which occur annually. She has participated in several 'crossover' recordings since 2010 , including a
} 
of categorisation is perhaps less certain than in earlier generations. She is regarded as a prima donna assoluta by her fans and by a number of music critics, and this study seeks to clarify what such a title really means in a twenty-first century context, and what it implies for the current generation of singing students hoping to go on to a build a career in opera. ${ }^{9}$

I am situating my study in relation to existing literature on Netrebko and her contemporaries, and I draw on paradigms relating to the stereotyping of the female in considering the values and attitudes that surrounded Netrebko as a singer, particularly in her early international career. In one of the few existing scholarly essays to specifically address Netrebko and her career, Clemens Risi assesses the manner of her promotion via photographic 'poses' and identifies his own perceptions of her as a performer and/or diva. ${ }^{10} \mathrm{He}$ argues that Netrebko is not really a diva because she does not satisfy the qualities that in his opinion are required for this title. His assessment of her as an artist, at least in the early part of her international career, criticises her technical vocal ability and the quality of her vocality, with the implication that she only had such success due to the strategic promotion that she received.

Risi's observations, although purportedly intended as 'playful and ironic', could be seen as reinforcing concepts of female stereotyping in which the beautiful woman is, by definition, lacking in intellect and/or ability. Yet the degree of success Netrebko has attained in opera does not align with the categorisation implied by Risi. Given the focus in opera on vocal quality and ability, and her successful negotiation of the new and diversified forms of mediatisation around which her career has developed, a more positive conceptualisation of her as an artist and the consideration of her diva status would seem to be justified.

I argue that for Netrebko, as a twenty-first century diva, the development and maintenance of a star persona is crucial, but that ultimately it is the power and agency which is displayed through her signature vocality and is allied with her image as sexy and

collaboration in 2011 with Russian pop singer Philipp Kirkorov on a remake of the song 'La Voix', and the song 'Amoi seg ma uns wieder' in 2016, with Austrian folk singer Andreas Gablaier, which was featured in his album MTV Unplugged, and was part of a concert series for MTV. In 2017 she released an album titled 'Romanza' which included a number of 'crossover' tracks composed by Russian songwriter Igor Krutoy.

${ }^{9}$ Manuel Brug, 'Neue Rollen: Anna Netrebko Schwärzt Ihre Stimme', 8 August 2013, https://www.welt.de/kultur/buehne-konzert/article118824409/Anna-Netrebko-schwaerzt-ihreStimme.html. Other reviews using this term (prima donna assoluta) include Neue Zürcher Zeitung, and Die Zeit, reviews of her 2016 CD Verismo, and an often requoted New York Post review by James Jordan of Anna Bolena at the Metropolitan Opera in 2011.

10 Clemens Risi, 'Diva Poses by Anna Netrebko: On the Perception of the Extraordinary in the Twenty-First Century', in Technology and the Diva, ed. Karen Henson, Cambridge Studies in Opera (Cambridge University Press, 2016), 150-58. 
approachable that sets her divahood apart from earlier forms. While the use of social media may empower the star singer to connect easily with her fans, other mediatisation technology hinders her authorial voice, inhibiting her agency. I show how Netrebko embodies a 'film star' persona whose power is embedded in her vocality to provide a diva figure that she has constructed through the synthesis of warmth and competence with sexiness to form a persona that is highly successful in the modern diversity of mediatised performance and social media.

In 2017 I travelled to North America to attend performances given by Netrebko in New York and Calgary, which included the Metropolitan Opera production of Tchaikovsky's Eugene Onegin in which she played the role of Tatiana. ${ }^{11}$ Drawing on a combination of online recordings, my experience of live performances by Netrebko, and delayed screenings of the same, in this chapter I will compare different forms of mediatisation in Netrebko's career.

I begin by tracing her early international career, and the so-called 'staging' used by her managers and producers to place her as a potential star by means of marketing and through her live and mediatised performances. The development of her 'image' as a star and the way she has engaged with and made use of this image personally is then discussed from the point of view of female stereotyping and her placement as a subtype within this, and her probable agency in the development of this image. The next section surveys her reception as a new star in the mid-2000s in terms of published responses to her vocality and agency as a performer, and is followed by an in-depth analysis of her vocality and the power implied within its form, with reference to a recording from her debut $\mathrm{CD}$, which was associated with her international breakthrough. Netrebko's performances are then discussed in the context of the consumption of opera in the twenty-first century, considering the degree of agency she is able to successfully wield within the various modes of mediatisation, from audio recordings through to her performances in the Metropolitan Opera's Met Live in HD broadcasts.

\section{The Staging of Stardom}

In the early 2000s, Netrebko's career took a markedly different turn towards a truly international career with her 2002 Salzburg performances as Donna Anna. It seems that

\footnotetext{
${ }^{11}$ For residents of geographically-isolated countries such as New Zealand, to experience Netrebko's performances 'live', in the Northern Hemisphere centres where her career is based involves a considerable amount of travel. Since then Netrebko has in fact made a single concert appearance in New Zealand which took place in October 2017.
} 
there were several important steps that led to this moment, in particular the increasing level of exposure she experienced as a result of the international tours she took part in for the Kirov Opera. The mentorship and opportunities provided through the Kirov's music director, Valery Gergiev, were invaluable, and by the time of these Salzburg performances, the flame of her international stardom was ready to ignite. ${ }^{12}$

Dyer's concept of the star suggests an artist's stardom is confirmed by media and public interest in their life outside the art form in which they appear. ${ }^{13}$ Social media brings whole new channels and new ways of connecting with an artist into the picture: how can the influence and level of attention gained through this type of media be assessed? While Dyer was writing in 1991, long before the appearance of social media in its current form, these new forms of media bring an additional angle to consider with respect to his argument. Perhaps social media blurs the line that delineates the status of the star singer since many artists now connect with fans through this medium from an early stage in their career.

The question of the role played by social media in the granting of diva status will perhaps be clearer for later star-singers, but in the case of Netrebko, although she has attracted a great deal of interest on various social media platforms, the star-making events identified by her biographers actually occurred before Facebook, Twitter, or Instagram were established, or at least were launched to the public. ${ }^{14}$ Having reached star status, Netrebko has continued to be promoted to and by users of these platforms, as well as through more traditional media such as radio and television broadcasts and video releases.

Netrebko's association with the Metropolitan Opera's Live in HD movie broadcasts has been a vital part of her international career. This series, which was launched in 2006, has continued to develop its style of production, and can be seen to have transposed, and arguably modified, the presentation style of stage productions of opera. Netrebko has

\footnotetext{
12 Reissinger, Marianne Reissinger, 11; Dolak, Anna Netrebko: Opernstar der neuen Generation, 11, 43; Roger Pines, 'Ruslan and Lyudmila (Review)', The Opera Quarterly 20, no. 2 (7 May 2004): 31013. The international tours with the Kirov Opera led by Gergiev provided an excellent foundation for her as a performing artist. It was unusual for a young singer to have the amount of exposure internationally that she had at that time while fully supported by the company she was contracted to, and without having to audition for oustide companies or be promoted by agents. This sort of promotion would have been effectively handled by the Kirov and international and Russian artist agencies.

13 Dyer, 'A Star Is Born and the Construction of Authenticity', 135-36.

${ }^{14}$ Facebook opened to the public in September 2006, Twitter was launched July 2006, and Instagram was launched in October 2010. 'Facebook', in Wikipedia, accessed 1 March 2019, https://en.wikipedia.org/wiki/Facebook; 'Twitter', in Wikipedia, accessed 1 March 2019, https://en.wikipedia.org/wiki/Twitter; 'Instagram', in Wikipedia, accessed 1 March 2019, https://en.wikipedia.org/wiki/Instagram.
} 
been at the forefront of this new wave of production, having appeared in at least one opera in every season of the series since it began. ${ }^{15}$ The Metropolitan's General Manager, Peter Gelb, regarded Netrebko as an integral part of this new venture. ${ }^{16}$ Journalist Andrew Moravcsik, writing in Newsweek noticed that within six months of arriving Gelb had 'shaken things up', with his stated intention to 'market opera like a live spectator sport'. As part of this agenda, continues Moravcsik, he 'plastered New York subways with glamorous photos of opera's younger, more attractive stars', and these posters were of Natalie Dessay and Anna Netrebko. ${ }^{17}$

James Steichen, in his article considering the outreach concept behind the Met Live in HD series, argues that 'the true innovation of the broadcasts lies not just in their staging opera in a new medium, but in the way they stage the Met itself for the public through new media.'18 I suggest that this new way of 'staging of the Met' is in fact replicated in the innovative way that Netrebko, herself a star of this new form, has had a career that was developed around and through such opportunities. Netrebko has continually been 'staged' as a star, through and alongside the Met Live in HD medium.

This 'staging' of Netrebko for stardom was first mounted in 2003, when Deutsche Grammophon engaged her in the ongoing exclusive recording contract she retains with them to this day, and proceeded to produce not only her debut CD but also the associated DVD, which included video clips in which she lip-synched to tracks from her audio CD. The CD was released in time for her second appearance at the 2003 Salzburg Festival, where she was to repeat her acclaimed performance as Donna Anna from 2002. The combination of all three 'products' - a predictable reprise of her success on stage at the Festival, along with a commercially-released CD and the new video concept - contributed directly to the leap of Netrebko to international fame that Deutsche Grammophon had clearly banked on. In fact, this combination was so successful that Netrebko was soon producing multiple

\footnotetext{
15 Helena Goscilo and Vlad Strukov, 'Russian Celebrities Home and Abroad: United under Putin, March 2011', Celebrity Studies 2, no. 2 (1 July 2011): 211; 'Metropolitan Opera Live in HD (Wikipedia)'.

${ }^{16}$ Charles McGrath, 'A New Kind of Diva', The New York Times, 2 December 2007, http://www.nytimes.com/2007/12/02/magazine/02netrebko-t.html.

${ }^{17}$ Andrew Moravcsik, 'Sopranos at the Cineplex', Newsweek, 19 March 2007, International edition. While Dessay was promoted by Gelb alongside Netrebko at this point, Dessay has not continued to perform in opera, and retired in 2013, citing the lack of roles for women of her age and voice type Dessay's voice remained a light soprano/coloratura. While Netrebko initially sang some of the same roles at the Metropolitan, she was able to perform a wider range of roles, and has made the transition to 'heavier' roles which align with her increase in age, and has continued to perform as the prima donna in staged productions, as well as concerts, through till the present day. ${ }^{18}$ James Steichen, 'The Metropolitan Opera Goes Public: Peter Gelb and the Institutional Dramaturgy of The Met: Live in HD', Music and the Moving Image 2, no. 2 (2009): 24-30.
} 
bestselling CDs, and, when it was released in 2004, the Anna Netrebko - The Woman The Voice DVD even outsold popular music superstars Beyoncé and Britney Spears in Europe. ${ }^{19}$

While much of Netrebko's marketing and promotion would have been handled by others, her own personal choices around her self-presentation can be identified as an essential part of the 'staging' of her as a star. By the time of the debut $C D$, she was an experienced artist, who had performed widely on an international basis, yet she chose to maintain a public image of herself as an approachable, confident, 'normal' young woman, rather than perpetuating the 'high-culture' trope of the unapproachable, intense and ultimately 'difficult' diva. She continued with her everyday life in Salzburg, despite having become instantly recognisable there due to her huge success. Her personal engagement with the public, and with fans via social media, earned her the accolade of having established a 'new type of prima donna', an atypical and new incarnation of the diva. ${ }^{20}$

Risi argues that Netrebko was not only set up and marketed from this time onward 'according to the rules of the pop market' but that her public reception was initially manipulated and set up visually through specific types of 'poses' in media photographs and stage production settings that were chosen for her at the time of her early international success. Risi interprets these poses as belonging to three groups. The first of these he characterises as the 'erotic, seductive, provocative woman', as in the staging by Willy Decker of La Traviata for the 2005 Salzburg Festival, and the second as the 'girlnext-door' image. ${ }^{21}$ In fact, the 'girl-next-door' image seems to have been set up by Netrebko herself when she was seen cycling through Salzburg after her success as Donna Anna, thereby initiating a new image of the 'un-diva' which the media eagerly promulgated. ${ }^{22}$ Her willingness to connect socially with the public, rather than retreat from the general populace, has certainly been a deviation from the standard 'style' of the opera diva, and her use of social media, including her Facebook page ('Anna Netrebko') which she seems to operate herself, or at least engage with regularly, has added to this

\footnotetext{
${ }^{19}$ Rebecca Leung and Bob Simon, 'Anna Netrebko: A Happy Diva', 60 Minutes (CBS), 9 December 2004, https://www.cbsnews.com/news/anna-netrebko-a-happy-diva-09-12-2004/. The 60 Minutes article states: 'Call it "MTV meets the Met," or "Opera Lite." But [her opera music videos] are knocking some stuffiness out of the opera world. In Europe, her DVD soared to No. 1 on the charts ahead of Britney Spears and Beyoncé.'

${ }^{20}$ Midgette, 'A Diva Who Breaks the Divadom Rules'; Jürgen Kesting, '»... spricht eine hochwertige Zielgruppe an «: Anna Netrebko', in Die grossen Sänger (Band IV), vol. Band IV, 4 vols (Hamburg: Hoffmann und Campe, 2008), 1915-17.

${ }^{21}$ Risi, 'Diva Poses by Anna Netrebko: On the Perception of the Extraordinary in the Twenty-First Century', 151-52.

22 Kesting, Die großen Sänger, 2008, Band IV:1916.
} 
aspect of her public 'face'. While she received carefully planned strategic management of her career through this period from her agent Jeffrey Vanderveen (initially at the CAMI agency in New York then later at IMG in London) this aspect of her curated image seems to have been set up and led by her. ${ }^{23}$

The images of Netrebko as an erotic or innocent young woman tie in with concepts of closeness and accessibility as well as the star's authenticity that both Gledhill and Dyer enlarge on in describing the star's 'promise' of a personal relationship with her or his audience. ${ }^{24}$ Netrebko's 'sensual, sexy' woman, and accessible, approachable 'girl-nextdoor' images, as well as her later 'party-girl' image, play into the conceptualisation of the modern female star. These have to some extent been controlled, and fashioned by the artist herself, as she, and the video director, Vincent Paterson, both acknowledge in the interviews and printed material that accompany her DVD Anna Netrebko: the Woman the Voice. $^{25}$

The third group of 'poses' that Risi refers to align her visual image with that of Callas and other stars from Callas's era such as Audrey Hepburn, Jackie Kennedy and Marilyn Monroe. ${ }^{26}$ According to Risi, the alignment of Netrebko with these stars was achieved intentionally through the use of photographic poses that imitated those of Callas, as well as through costuming and hair styling that followed the signature 'look' of the various stars. In fact, Dolak quotes Netrebko's agent, Vanderveen, as identifying a specific strategy for Netrebko, that she should follow a Callas-like career path in terms of the roles she should choose. Vanderveen even describes how he really wanted to have Netrebko star in a Hollywood film about Callas's life. ${ }^{27}$ However, Dolak states that Netrebko 'disagreed fundamentally about the legendary heroine of the opera, the whole story, that she be marketed as the "new Callas"', and that this forced Vanderveen to downplay this angle. 28 Moreover, at the same time that Vanderveen was developing his idea for the film about Callas, Zeffirelli's film Callas Forever was released, which pre-empted such a concept. While Stratas ultimately refused to star in Zeffirelli's film, Netrebko, whether unwittingly or not, allowed herself initially to be placed in a Callas-like mould by Vanderveen's strategy of associating her visually with Callas, until Netrebko eventually disrupted her

\footnotetext{
23 Dolak, Anna Netrebko: Opernstar der neuen Generation, 195-207.

${ }^{24}$ Gledhill, Stardom, xvii; Dyer, 'A Star Is Born and the Construction of Authenticity', 133.

${ }^{25}$ Vincent Paterson, Anna Netrebko - The Woman, The Voice (Deutsche Grammophon, 2004).

${ }^{26}$ Risi, 'Diva Poses by Anna Netrebko: On the Perception of the Extraordinary in the Twenty-First Century', 151.

27 Dolak, Anna Netrebko: Opernstar der neuen Generation, 198-99.

${ }^{28}$ Dolak, 198.
} 
agent's plans through both her strong objections and open denial of any links with Callas in interviews.

The marketing-focused Vanderveen had sown the seeds of the link with Callas, however, and there were frequent mentions of Callas in connection with Netrebko in journalistic articles. Dolak describes how the media were always looking for a comparison, and often called her 'die neue Callas' (the new Callas), even using some of the same titles as had been used for Callas, such as 'the Tigress' and 'die Göttin' (the goddess, 'La Divina'). ${ }^{29}$ Jürgen Kesting likewise suggests that Netrebko was one of the 'talented and always beautiful' singers who act as 'market-conforming surrogates for the Diva [Callas]'. ${ }^{30}$

Hugh Canning commented: 'ignorant media voices have hailed her as yet another "new Callas" (it would be hard to imagine two voices and temperaments less alike, but presumably such hyperbole sells newspapers)'. ${ }^{31}$ New York critic Anthony Tommasini refuted the validity of any comparison of Netrebko with Callas in 2004, but changed his mind by 2009, when he admitted her performance of Lucia reminded him of Callas. ${ }^{32}$ Anne Midgette suggested in the New York Times in 2006 that Netrebko was 'cast in the Callas mold not only for her glamour, but also for the warm roundness of her voice and because she is a true stage animal. She is not actually much like Callas, [...] [b]ut in taking on the bel canto repertory, [...] she is taking a Callas-like step.'33

Even when intended to be complimentary, this correlation with Callas carried with it a number of implications that Netrebko was not comfortable with. In numerous interviews she rejected these comparisons. In an interview with Canning she observed:

\footnotetext{
29 Dolak, 121; Christopher Porterfield, 'The 2007 TIME 100', Time, 3 May 2007; 'Porträt: Anna Netrebko: Und dann kam sie', sueddeutsche.de, 17 May 2010, sec. kultur, https://www.sueddeutsche.de/kultur/portraet-anna-netrebko-und-dann-kam-sie-1.436731-2; 'Sucesora de La Callas', 13 September 2008, https://www.semana.com/amp/sucesora-de-lacallas/95252; McGrath, 'A New Kind of Diva'.

30 Jürgen Kesting, Die grossen Sänger (Band III), vol. Band III (Hamburg: Hoffmann und Campe, 2008), 1489. My translation. Original: 'Sängerinnen wie Renée Fleming oder Anna Netrebko... die... marktkonforme Surrogate der Diva sind'.

31 Canning, 'People 336: Anna Netrebko', 644.

32 Anthony Tommasini, 'Anna Netrebko, at the Top but Still Rising', The New York Times, 19 September 2004; Anthony Tommasini, 'Bel Canto Magic in a Scottish Castle Haunted by Pesky High Notes', New York Times, 28 January 2009.

33 Midgette, 'A Diva Who Breaks the Divadom Rules'.
} 
It's a nice compliment, of course, but everyone is different, I am different. I don't want to be like somebody else, I want to be like me. Of course Callas was a legend. I think they mean very well by writing that, but it's not me. ${ }^{34}$

In another conversation with Dolak she appears more frustrated:

This incessant comparison in the newspapers with the holy Maria sucks. Who would truly want to actually be like this woman? In the end it would not be at all healthy for me. 35

Such comparisons with 'the holy Maria' will not have hurt her career, however, at least in terms of the popular discourse generated through the media, so this frustration is probably not indicative of a real issue for Netrebko. In fact, she points to Callas as one of her influences, along with Mirella Freni and Renata Scotto, and it could be said that she invited comparison to and alignment with Callas by releasing two albums (Sempre Libera, 2004 and Verdi, 2013) specifically covering the repertoire for which Callas was known.

The emphasis on a connection with Callas, whether intentionally staged or simply coined by the media in response to the popular discourse around the diva, serves to reinforce Callas's place as the icon of modern divahood. Every mention of Callas in this type of context serves to strengthen her place as the archetypal diva. As Netrebko does have some attributes that line up with Callas, such as her looks, and her focus on passionate characterisations of her roles, it is understandable that some observers might therefore feel it was appropriate to compare her to Callas. In a sense Netrebko has succeeded in emphasising her links to Callas by claiming her own individuality as a diva who breaks away from the diva model. Without that emphasis, and the claim of a redefined form that rejects that of the earlier diva, paradoxically, the true diva is unable to claim her divahood.

\section{Fashion Models and Fantasies: The Curated Image}

Risi suggests that, at least in her early international career, Netrebko appeared as iterations of her own image within whichever role she was playing.

\footnotetext{
${ }^{34}$ Canning, 'People 336: Anna Netrebko', 647-48.

35 Dolak, Anna Netrebko: Opernstar der neuen Generation, 126. My translation. (Original text: 'Dieser Ständige Vergleich in den Zeitungen mit der heiligen Maria nervt. Wer möchte in Wahrheit schon wirklich so sein wie diese Frau? Am Ende wäre das überhaupt nicht gesund für mich.')
} 
With Netrebko, at least in the first years of her international career, the tension between representation and presence seemed often to be transformed into an oscillation between the media-created image of the soprano and what we assumed to be the "real" Netrebko [...] The onstage, incarnated character, whether Adina or Violetta, Amina or Juliette, no longer seemed important; what was important was the tension between the image and the "real" Netrebko. Thus Netrebko in performance was often nothing but a version of herself. She was completely subsumed by her own image. ${ }^{36}$

My experience of Netrebko's performances, both live and in video recordings, confirms Risi's proposition that her performances 'as herself' are much more successful. Cast as Tatiana in a 'period' production of Eugene Onegin I did not find her performance of the role compelling but the videos of her opera performances staged in modern-day dress such as the La Traviata directed by Willy Decker (Salzburger Festspiele, 2005), Le nozze di Figaro staged by Claus Guth (Salzburger Festspiele, 2006) and the MTV-style video clips staged by Vincent Paterson show her energy and commitment as a singer-actor, as well as her visual appeal. ${ }^{37}$ As Risi reports, in these stagings Netrebko not only appears in a believable modern-day staging, her movements and gestures relay her own presence in modern times. Working within the sometimes highly-stylised stagings she remains committed to herself, and/or her own publicity persona. There is not a sense of an attempt to portray another character but rather to show her own through her 'natural' or rather personal movements.

This concept of the star as playing a reiteration of their own publicity image or persona is acknowledged as accepted practice in the film industry, where stars are seen to be deliberately stereotyped. Thomas Harris describes how '[the movie] star system is based on the premise that a star is accepted by the public in terms of a certain set of personality traits which permeate all of his or her film roles. [...] If an actress has achieved recognition through the 'the-girl-next-door' roles it is important that her publicity reinforce this image.' 38 Risi's contention that the use of this public image diminishes the sense of Netrebko's own artistry has some substance, in that this portrayal of Netrebko 'as'

\footnotetext{
36 Risi, 'Diva Poses by Anna Netrebko: On the Perception of the Extraordinary in the Twenty-First Century', 157.

37 La Traviata, Salzburg Festspiele 2005 - Preludio (2), accessed 9 February 2019, https://www.youtube.com/watch?v=CYm-Sd9roIQ; Deh Vieni Non Tardar - Anna Netrebko (Sub. Español), accessed 9 February 2019, https://www.youtube.com/watch?v=R-L4DMuvzvo; Paterson, Anna Netrebko - The Woman, The Voice.

38 Thomas Harris, 'The Building of Popular Images: Grace Kelly and Marilyn Monroe', in Stardom: Industry of Desire, ed. Christine Gledhill (London ; New York: Routledge, 1991), 40.
} 
Netrebko goes against the accepted premises of the singer as actor within opera - where the normal concept is that the singer should be heard as a genuine personal interpreter of the different roles she plays. Yet this brings us back to the ideology of Poizat and his contention that the singer should negate her self when on stage in order to present as 'pure voice'. ${ }^{39}$ Risi's discomfort with Netrebko's portrayal also risks the implication of a desire for the singer's negation of the self, but in fact, Risi states that he feels the lack of 'a real history, a true sense of mystery, a genuine fragility' in Netrebko's performances. ${ }^{40}$

What this comes down to is our perception of what, or rather, who is the 'real' Netrebko, and the authenticity of her public persona. If the warmth, friendliness, and sensuality she presents to the public are indeed elements of her real personality, and her public persona simply reflects this personality, then the reiteration of that persona through different staged roles is surely valid. And if her appeal is widespread, there is much to be learned from the success of such an approach within the current age of mediatisation.

Clearly Netrebko is having to work within a style and structure set up by the director for these updated productions, and she is costumed and groomed appropriately for the conceptualisation behind them. However, her performances in such stagings continually build and maintain a curated public 'image' which is also developed and rebuilt continually by whoever is involved in producing elements of her publicity, which would include Deutsche Grammophon, her agent and her management staff.

The public image to which I am referring is not only built through photographs and video performances, it is also the discourse made up of the stories and personality traits that are discussed in the press. In the case of Netrebko this includes the 'Cinderella' story (the romantic, but not quite true, fairy tale of her 'discovery' by Valery Gergiev cleaning floors at the Mariinsky Theatre), her approachability and 'normality', and her reputation as a 'party girl' who loves fashion. ${ }^{41}$ 'Throughout the world', suggest authors Goscilo and Strukov in their 2011 article on Russian celebrities, 'the exposure of young, nubile bodies advances women's lucrative careers', and they note how Russian tennis stars and ballet dancers 'capitalise on their physical endowments through advertising exclusive clothes

\footnotetext{
${ }^{39}$ Poizat, The Angel's Cry, 35.

${ }^{40}$ Risi, 'Diva Poses by Anna Netrebko: On the Perception of the Extraordinary in the Twenty-First Century', 157.

${ }^{41}$ Kesting, Die großen Sänger, 2008, Band IV:1916; 'A Moment with Anna Netrebko', Chopard Diary | Our official blog, accessed 9 February 2019, https://www.chopard.com/intl/diary/moment-annanetrebko/; 'Anna Netrebko 2017 Concert Biography'. The jewellery company, Chopard, describes her as a 'trusted friend' and in her biography she is named as 'a global ambassador' for the brand.
} 
and their naked flesh'.42 The sexualisation of women in the media is widespread as these authors point out: it is a common aspect of the promotion of female stars. Whether the recognised negative consequences of such sexualisation may be balanced or even cancelled out by the sense of empowerment which some women claim to achieve through it, is a question which is the subject of a great deal of feminist debate and recent scholarly enquiry. 43 The \#MeToo movement, and other recent moves to assert female power and female rights, also tend to emphasise the right of women to embody both sex appeal and retain full power over its use. ${ }^{44}$ The question remains, however, as to what degree the sexualised aspects of Netrebko' s image have been led by her or set up by her marketing team.

What does seem clear is that Netrebko's open approach to engaging with the public from the time of her Salzburg Festival period onwards seems to have been the initial impetus for her press accolades as having redefined the meaning of the opera star. In Anne Midgette's article for the New York Times in 2006 Netrebko was described as being 'on her way to becoming opera's biggest megastar, [and] also one of the most singularly unneurotic individuals in the business'. Midgette concluded that another way in which she was 'breaking the divadom rules' was to admit some weaknesses, for example, in her technique, and that Netrebko was therefore 'a serious artist who is genuinely focused on improving her art'. 45 This provides for a sense of the singer as an artist who creates not only her image, but her own form of divahood, and must also actively create her sound and 'play' her instrument well, in order to achieve and maintain her status as a top singer.

\footnotetext{
42 Goscilo and Strukov, 'Russian Celebrities Home and Abroad', 212-13.

${ }^{43}$ See, for example, Miriam Liss, Mindy J. Erchull, and Laura R. Ramsey, 'Empowering or Oppressing? Development and Exploration of the Enjoyment of Sexualization Scale', Personality and Social Psychology Bulletin 37, no. 1 (2011): 55-68; Wencke Mühleisen, 'Mainstream Sexualization and the Potential for Nordic New Feminism', NORA - Nordic Journal of Feminist and Gender Research 15, no. 2-3 (2007): 172-189.

${ }^{44}$ Linda Stasi, 'Singer Claims He Was Drugged and Raped in 2010 by Classical Music Power Couple', Nydailynews.Com, 22 August 2018, https://www.nydailynews.com/news/national/ny-news-stasisinger-claims-rape-classical-music-stars-20180821-story.html. In terms of sexual assault, little has yet surfaced in terms of 'casting couch' misuse of power with regard to women within the opera industry, but it is probably only a matter of time before such charges appear. High profile accusations of sexual abuse which have been made have so far tended to be in relation to malemale interactions, but sexual misconduct in classical music has been described by one informer as 'an ugly, open secret that's gone largely unchecked for decades'. Susan McClary asserted in her 1989 foreword to Clément's Opera that the droit du seigneur was 'alive and well' in the form of conductors who 'demand sex from aspiring sopranos in exchange for casting them in roles'. Susan McClary, 'Foreword: The Undoing of Opera: Toward a Feminist Criticism of Music', in Opera, or, The Undoing of Women, by Catherine Clément (London: Virago, 1989), xvi.

45 Midgette, 'A Diva Who Breaks the Divadom Rules'.
} 
Suggesting that fame is 'no angel', Kesting examines the recent phenomenon of massmarketing of operatic artists such as Netrebko and criticises the way 'new CDs of stars like Cecilia Bartoli, Anna Netrebko or Rolando Villazón are presented with booklets which are designed in the style of fashion catalogues. ${ }^{46}$ Netrebko is certainly marketed as if she were a fashion model - the photographic postcard images 'gifted' as part of the boxed set of her CD Souvenirs are an example of this - but this style of advertising and association of her as an artist with 'fashion model' status seems unlikely to be something that was forced on her. She seems happy with these connotations and stresses them through her interviews and general behaviour. In an interview with Dolak she states that she likes to show off her beauty, and to 'bring a bit more eroticism to the opera', by wearing, for example, a dress with a plunging neckline. ${ }^{47}$ However, as Charles McGrath notes, with this approach there is a risk of her not being taken seriously as a classical artist:

\begin{abstract}
Netrebko's videos and outdoor concert appearances, her contract with Chopard, the luxury jewelry company, and her commercials for Vöslauer, the Austrian mineral water, have made her a member of what the critic Alex Ross calls the YoYo Club - classical musicians who, like the cellist Yo-Yo Ma, have attained such celebrity that their artistic credentials are deemed suspect by the purists. ${ }^{48}$
\end{abstract}

In addition, Netrebko has the tendency, like diva soprano Angela Gheorghiu before her, to sexualise her interview comments, for example, by making connections between performing and the desire for orgasm, or 'spasms of pleasure'. ${ }^{49}$ As Risi notes, stagings such as the 2005 Willy Decker Traviata emphasise sexual attraction through the raunchy poses she embodies as part of the choreographed staging, and she has even gone so far as to pose for Playboy. Stuart Jeffries alludes to these aspects in an article for The Guardian.

\footnotetext{
${ }^{46}$ Kesting, Die großen Sänger, 2008, Band IV:1862. My translation. Original text: 'Heute werden neue CDs von Stars wie Cecilia Bartoli, Anna Netrebko oder Rolando Villazón mit Büchern präsentiert, die im Stil von Modekatalogen designed sind - Setcards für Opern-Models'.

47 Dolak, Anna Netrebko: Opernstar der neuen Generation, 174. My translation. Original text: 'Ich kehre gerne meine Schönheit heraus, um abends im Licht zu erstrahlen. [...] Wenn es mir durch ein Kleid mit tiefem Ausschnitt gelingt, ein bisschen mehr Erotik in die Oper zu bringen, freut mich das.'

48 McGrath, 'A New Kind of Diva'.

${ }^{49}$ Souvenirs CD: Interview Anna Netrebko (Video), 2009, https://www.youtube.com/watch?v=Tvl72FvicI4.
} 
Despite marriage, Netrebko remains the object of sexual fantasies. It is just not true, I can reveal, that her ambition is to sing Strauss's Salome while naked. [...] She did, however, recently appear in Playboy's Sex and Music issue, and in glossy magazine after glossy magazine she drapes herself obligingly in gamine and/or raunchy poses, as women classical musicians and opera singers in this glum era of commodified sexuality seem contractually obliged to do. [...] But the biggest paradox of Netrebko's life is that, despite the saucy photo sessions, she insists she is an artist of integrity. "I have no desire to become a crossover artiste, singing with microphones. I believe in opera; that it is something that young people would love if they had a chance to hear it." Some clearly do: Netrebko's CDs sell as well as Three Tenors discs did in their heyday. 50

Netrebko's image as a beautiful, sexy and powerful woman transgresses the boundary of the common subtypes applied to women, as identified by Amy Cuddy and Peter Glick. The three categorisations they point to are: 'warm but incompetent', 'sexy but incompetent', and 'competent but cold'. 51 With her competence as a singer, and her personal confidence that underlining this, Netrebko contravenes the 'sexy but incompetent' subtype or 'norm'. As the authors note, these subtypes for women usually allow for 'one - but only one positive trait (warm, sexy, or competent), mixing flattery with derogation.'52

The model of social perception that Cuddy and Glick developed in collaboration with Susan Fiske identifies perceived warmth and perceived competence as the basic parameters by which people are judged by others. The two dimensions in which these vary allow for various combinations, such as warm and competent, cold and competent and so forth. According to this model, 'people classified as high on one dimension and low on the other elicit predictable, ambivalent affective and behavioral reactions. ${ }^{53}$ Netrebko's signature vocality, which can be seen as communicating underlying confidence and power, allied with her image as a sexy and beautiful woman, thus plays to a more positive characterisation, one that would be located in the realm of high competence and high warmth levels. I suggest that this positive combination, as reinforced by her public persona, is likely to contribute to her popularity, particularly for a younger female

\footnotetext{
50 Stuart Jeffries, '“I Conquered the Critics"', The Guardian, 26 April 2008, sec. Music, https://www.theguardian.com/music/2008/apr/26/classicalmusicandopera.russia.

${ }^{51}$ Amy Cuddy and Peter Glick, 'How Stereotypes Divide and Conquer Women', The Boston Globe, 24 October 2017; Susan T. Fiske, Amy J. C. Cuddy, and Peter Glick, 'Universal Dimensions of Social Cognition: Warmth and Competence', Trends in Cognitive Sciences 11, no. 2 (February 2007): 77-83. 52 Cuddy and Glick, 'How Stereotypes Divide and Conquer Women'.

53 Fiske, Cuddy, and Glick, 'Universal Dimensions of Social Cognition', 77.
} 
audience whose conceptualisation of female empowerment embodies this sexy and competent subtype. ${ }^{54}$

The authorial role Netrebko has played in this case is as the embodiment of recent generations' concept of the role model: in other words, the beautiful, competent young woman. In contrast to Jeffries, I do not find it odd that she 'remains the object of sexual fantasies' after having married. ${ }^{55}$ But the juxtaposition of a sexualised visual image with a confident aural and personal image is an impression which Netrebko herself fosters. The continual emphasis on her as a new type of diva is a partial acknowledgement of this aspect of her authorship, yet this recognition is ironic given that the real authorship of the singer is often undermined by the mediatisation processes involved in the audio-visual distribution of her performances.

\section{Sharing Beauty: The 'Authentic' Image}

Netrebko's involvement in connecting directly with audience and fans through social media is integral to her mediated career. This type of platform can be seen as a canvas where she has a great deal of agency in personally creating and developing her public image through a discourse based on visual, audio-visual and written material she personally provides and controls.

While the internet, as a means of disseminating recordings, is clearly an important factor in Netrebko's career, it is the social media aspect of this technology that has arguably been the most crucial aspect in terms of the maintenance and further development of her star status. It is also the arena in which it has been possible for her to personally curate her image - whereas her publicists are likely to have more sway in other areas, the singer herself seems to be directly involved in this aspect of her public face. The agency and control that this implies in terms of her career is significant. In addition she is able to personally connect with her many fans through social media in a way that would never

\footnotetext{
54 This subtype (sexy and competent) may, for example, be applied to the popular Lara Croft character from the Tomb Raider video game franchise in which she first appeared in 1996, along with three blockbuster films. As an influential role model whose character traits and behaviour have been critiqued and pointed to as influential in terms of female empowerment, outside the gaming community as well as within it, this fictional character has become 'a focal point for critical debate surrounding the representation of the female protagonist and the gendered body in games'. Esther MacCallum-Stewart, “Take That, Bitches!” Refiguring Lara Croft in Feminist Game Narratives', Game Studies 14, no. 2 (December 2014), http://gamestudies.org/1402/articles/maccallumstewart; Emily Murray, 'Lara Croft Inspired Generations Of Women And Revolutionised Video Games', UNILAD (blog), 2018, https://www.unilad.co.uk/featured/lara-croft-inspired-generations-of-women-andrevolutionised-video-games/.

55 Jeffries, "'I Conquered the Critics"'.
} 
have been possible for earlier generations of singers. The curiosity of her fans to learn more about the 'real' or 'day-to-day' sides of her life is served through her frequent Facebook postings which provide them with a direct connection to the star's 'authentic' self that Dyer points to as fundamental to a star's status.

Many singers now make use of Facebook and other social media to further their careers in this same way, but Netrebko was an early adopter of the technology and used it innovatively. ${ }^{56}$ In the book Master Singers, a number of high-level singers of the current generation are surveyed on their advice to young singers about various aspects of a singing career, and are specifically asked about the use of 'social networking'. Some, such as Ana María Martínez and Jennifer Rowley, stress its importance. Rowley suggests:

Your audience wants to follow you on Twitter or Facebook and know you as a person. The more that you can let them into your life (a filtered life), the more they want to come to the opera. They want to tweet during intermission. They want to see you in your makeup chair and behind the scenes. [...] You have to have a website (especially with orchestra sound clips), Twitter, a Facebook page, and Instagram with pictures. You need to have good headshots, modern and trendy. Sometimes that's what gives you the auditions! They say, 'Oh, she's beautiful, so we need to hear her. ${ }^{57}$

Rowley's depiction of beauty as a trigger for employability in opera in the current age is telling. Netrebko has made very good use of all of the media channels and technology that she mentions here. The more a star singer uses these platforms, and provides digital material on them that can be shared, the more it will be shared by users. By regularly 'feeding' material to her fans through these channels, Netrebko generates and maintains both her image as a star and the interest of her fan base. She is able to have direct control over this curation of her image in these contexts, but more limited control over the image developed for her by a professional publicist or publicity team. ${ }^{58}$

\footnotetext{
56 For example, she used to upload to a YouTube channel she called 'Ask Anna' where fans were encouraged to send in questions about singing and the career etc, to which she responded with videoclips where she talked about these. As of March 2017, the most recent of her uploads was three years old. Anna Netrebko, 'Anna Netrebko YouTube Channel', accessed 15 December 2017, https://www.youtube.com/user/AskAnnaNetrebko/featured.

57 Donald George and Lucy Mauro, Master Singers: Advice from the Stage (New York, NY: Oxford University Press, 2015), 106.

58 This applies to her own accounts on these platforms. There are also a number of fan's accounts, such as the Instagram account 'Anna Netrebko, La Splendida', where the content is not controlled by her.
} 
Netrebko has described her Instagram posts as simply her own view of the world that she is sharing with others:

[They are an] expression of what I see. I am showing what is happening in my life, which is amazing right now. I see so many beautiful things, beautiful countriesevery day what I see changes, and I post the pictures without expecting anything. I don't want a lot of followers, but it is fun to share these. What I see gives me inspiration for living. Without these changes, without these new things, you have only a routine, only the thoughts in your head-you will get scared, you will get insecure, and everything is so gray. I know life can be very difficult, so I choose to love this life, to embrace these new things-and to share them!59

While this may indeed be her motivation for posting the content she shares, this characterisation of their purpose builds an 'image' of the star as a sharing, caring person who looks at the world in a wide-open manner. Her emphasis on her admiration of 'beautiful' things also serves to connect her personality with her own image as a beautiful star. Netrebko's image remains tied up with the powerful woman of model-looks and a self-confident personality who likes to be her own 'kooky' self, who does not retreat from the public eye and shares her private daily life with the public. This is more than cultivating her 'brand', or building followers so that she is more likely to continue to be hired by opera houses, as suggested by a recent article in the Globe and Mail - it also maintains her 'authentic' image as a star - as the new 'un-diva' diva - and cultivates a sense of 'closeness' and connection to her fans. ${ }^{60}$

A recent exchange of comments on her 'Anna Netrebko' Facebook page gives a sense of the way she interacts using this platform. Along with the many positive comments she receives there are the negative ones, and probably at times some quite offensive ones. I found the following exchange to be revealing, however. On 28th December 2018, a video of Netrebko performing an excerpt from Cilea's Adriana Lecouvreur was posted with the descriptor 'New Years Eve at Metropolitan Opera'. This was a two-minute clip of Fedra's monologue 'Giusto cielo! Che feci in tal giorno?'. The video of the monologue features a long, orated section, which is spoken in a melodramatic style by Netrebko before she

\footnotetext{
${ }^{59}$ F. Paul Driscoll, 'Viewpoint: The Diva \& Her Followers', Opera News 82, no. 9 (March 2018). ${ }^{60}$ Catherine Kustanczy, 'Insta-Divas: How Social Media Has Become the next Stage for Opera Stars', The Globe and Mail, 18 October 2018, https://www.theglobeandmail.com/arts/theatre-andperformance/article-opera-on-insta-how-the-social-media-platform-has-become-a-tool-for/.
} 
starts to sing. This excerpt brought on some invective from Facebook users, as well as a great deal of praise in their comments.

Soon after the video was posted, Netrebko had the following exchange with a user named Carla Pohl:

Carla Pohl: 'Can't this be done more natural? It's terrible. Great singer but......' [ellipsis as in original text]

Anna Netrebko: 'Carla Pohl no. This is MY interpretation and it's GONA [sic] BE LIKE THAT!'.

Carla Pohl: 'Anna Netrebko....of course. Do it the way you want to....Your voice is great.' She later added '......and TOI TOI TOI!' [ellipses as in original text] ${ }^{61}$

Netrebko's immediate riposte to Pohl's negative comment was vehement, and showed a strong confidence in her own judgement and choices about the enactment of this role. Rather than allowing the comment to pass she made the effort to challenge its validity, showing through this her own sense of self, her sense of her own agency, and, indirectly, a sense of her power as a diva. ${ }^{62}$ Since this is within her own Facebook page this exchange and assertion of agency plays out from a position of power that she would not be able to claim if she were to attempt to respond to similar criticism on some other platforms such as YouTube. Netrebko has therefore reasserted her own image and her claim to divahood on multiple levels through this process of social interactions. ${ }^{63}$

The ubiquitous nature of Facebook, particularly in the lives of younger people, means that Netrebko is able to wield an impressive set of online tools with a global reach and potential for influence that was unheard of in previous decades. It is difficult to accurately

\footnotetext{
61 The user involved in the exchange with Netrebko, Carla Pohl, identifies herself as a retired music professional: her Facebook profile states 'soloist at Vienna State Opera' although it also shows she now lives in South Africa. As additional context, the New York Times review by Anthony Tommasini of the premiere of the opera was overwhelmingly positive about Netrebko's performance.

${ }^{62}$ Interestingly, another negative comment about her diction that appeared immediately after this exchange brought on a more powerful response from Netrebko (an interjection in Italian regarded as an expletive). This comment and the response were both removed from the feed by the following day.

63 The exchange between Pohl and Netrebko on Facebook about the Adriana Lecouvreur video, ironically, traces that of the scene in the opera itself, where a diva portrays the 'prima donna' role of a famous French actress from the eighteenth century who constantly appeals to and debunks her rival. This was pointed out by another user (Vera Mancheva) whose post defended Netrebko's performance stating that with this performance she had 'risen to the level of Callas'.
} 
gauge the extent to which Netrebko is directly, and personally, involved in curating her image on social media, and there must be a limit to how much she is able to manage, as a busy professional singer performing internationally. While some of the online posts and the monitoring of comments on her social media pages may be undertaken by a publicity team, through her engagement with Twitter, Instagram and Facebook, Netrebko is actively curating and maintaining the social media interest in her as an opera star.

It is clear that marketing and promotion, and the development of Netrebko's image in the media helped in facilitating her leap to stardom in the early 2000s. However, as we have seen with both Callas and Te Kanawa, a distinctive vocality, and one that is individually recognisable, is frequently detailed as a crucial attribute of the opera singer that is essential for her to achieve and maintain a status of divahood, even though the creative agency that produces that vocality is not always recognised. ${ }^{64}$ In the following section I examine the reception of her performances during the years after she was first acknowledged as an international star, in order to consider how her singing and vocality were perceived at the time, and the implied values to do with the agency of the singer, as revealed by these reviews.

\section{Naturalness and Artistry: Reception}

As the representative quotations below reveal, Netrebko's performances in the early to mid 2000s were positively received in three internationally important locations: London, Vienna, and New York.

Anna Netrebko, a young lyric soprano with a pearly, gleaming tone [...] projected her voice effortlessly into the house. She embodied the role of Natasha so sparklingly that it was impossible to imagine anyone else singing it. The New Yorker (War and Peace, Metropolitan Opera, Feb 2002) ${ }^{65}$

The word 'miracle' doesn't seem too extravagant [...] a great singing actress [...] completely present at every moment in her intelligently conceived, deeply moving characterization [...] flawless technique, perfect coloratura, a substantial soprano

\footnotetext{
${ }^{64}$ Risi, 'Diva Poses by Anna Netrebko: On the Perception of the Extraordinary in the Twenty-First Century', 154, 157-58.

${ }^{65}$ Anna Netrebko - Opera Arias (Wiener Philharmoniker, Noseda) (Deutsche Grammophon, 2003). Quoted in the biography on page 7 of the CD booklet.
} 
voice in every register, with a timbre of dark-hued luminosity.

Die Presse (La Traviata, Vienna State Opera April 2003)66

Netrebko's strength is not just in the mobility of her voice and the razzle-dazzle of her upper register's big-money notes - no, it's the fullness and beauty of the middle voice that singles her out [...] - properly overwhelming. For once, fullness of heart is truly matched in fullness of sound.

The Independent (La Traviata, Royal Opera House, London, January 2008)67

These extracts demonstrate a sense of the affective nature of her acting and the projection of her personality, or 'stage presence'. The reviewers found her characterisation 'deeply moving', and state that she embodied the role 'sparklingly', and with 'fullness of heart'. Their descriptions of her singing and vocality are more varied, demonstrating in part the difficulty of evaluating performances, but also in describing them: predictably they resort (as Barthes grumbled) to 'the poorest of linguistic categories: the adjective'.68 The variance in the ways her singing was perceived by these three music critics is interesting though: they cite her 'dark-hued luminosity', her 'pearly, gleaming tone', the 'fullness and beauty of the middle voice' and the 'razzle-dazzle of her upper register's big-money notes'.

There is a noticeable predominance of visual metaphors for Netrebko's vocal tone used in the corpus of reviews overall, with many descriptions such as these ones that involve light or darkness (gleaming, luminosity and dazzle). This contrasts with the womanly 'roundedwarmth' descriptors commonly used for Te Kanawa's singing, and lines up more with the tone colours associated with Callas, though there is not a great variety of colouration pointed to, just degrees of lightness or darkness. This usage of visual descriptors for Netrebko could be read as related to her visual presentation style, which, especially at this stage of her career, was active and visually engaging.

For these qualities to be allied to strength and intelligence, as they are in the review from Die Presse, is noteworthy, as is the way the text is phrased in terms of her singing versus her voice. Her strength as an actress is therefore tied up in all these reviews with the affective power and beauty of her voice, and agency is accorded to her in terms of 'project[ing] her voice', embodying the role, in her 'deeply moving characterisation'.

\footnotetext{
${ }^{66}$ Anna Netrebko - Opera Arias (Wiener Philharmoniker, Noseda). Quotation printed in the biography on page 6 of the CD booklet.

${ }^{67}$ Edward Seckerson, 'A Stellar Violetta Steals the Show', The Independent, 16 January 2008.

${ }^{68}$ Barthes, 'The Grain of the Voice', 179.
} 
The above reviews are all overwhelmingly positive, but in her early performances in London, this was not always the case. After having the critical success she enjoyed with her Violetta in January 2008, she complained to journalist Stuart Jeffries, 'I thought your critics hated me. [...] My reviews in London were always terrible. It seems [...] that I conquered them.' ${ }^{69}$ Netrebko's first opera performances at the Royal Opera in London only produced minor mentions in reviews. Two of these describing her first Donna Anna at Covent Garden make an interesting contrast. One critic enjoys her 'purity of voice' while another describes her singing as 'monochrome', but they also give opposing views on her colleague Nuccia Focile's performance:

$[\mathrm{H}]$ ow exciting, for once, to have a truly young, svelte Anna in the Russian soprano Anna Netrebko, whose purity of voice overshadows Nuccia Focile's somewhat anaemic Elvira (Anthony Holden, The Observer, 2003) 70 $^{20}$

[M] usically, the evening is glorious, though some may find Netrebko's singing monochrome [...] Focile is tremendous negotiating Elvira's lightning changes of mood. (Tim Ashley, The Guardian, 2003) 71

This season of Don Giovanni occurred immediately after the Salzburg Festival season in which she had had such an outstanding success in the same role. The reasons for such a lacklustre reception for her in London are hard to determine but it seems unlikely that her performance level would have fallen drastically in the period of the three weeks that occurred between the two seasons. Perhaps the reviewers' expectations after the news of her enormous success in Salzburg tended to make them more critical, as they seemed to be for Callas when she made her London debut in 1952. German critic Manuel Brug described Netrebko's performance in the Salzburg season as follows:

It was the first time for many years that Salzburg audiences had heard such impassioned and yet lean-toned singing, the coloratura exactly in place, the voice fully rounded in its lower register and yet free and bell-like in its upper reaches, the tone quality slightly veiled yet with a shimmering sheen to it. The sensation of this memorable evening was [...] Anna Netrebko's Donna Anna, her seeming

\footnotetext{
${ }^{69}$ Jeffries, “'I Conquered the Critics"'.

70 Anthony Holden, 'Don Giovanni - Covent Garden', The Observer, 21 September 2003.

71 Tim Ashley, 'Sex and Sadism at the Royal Opera - Don Giovanni', The Guardian, 15 September 2003.
} 
naturalness concealing supreme artistry and self-discipline, her singing marked by crystalline coloratura and fluent passagework. ${ }^{72}$

Not only is this a positive evaluation, this review designates the singing as an action, underlining and confirming Netrebko's agency in the production of sound and creation of her vocality. These comments reveal and grant Netrebko agency as a singer in a way that is not always accorded to her. For example, in a New York Times review of her 2009 'Lucia' at the Metropolitan Opera, the critic Anthony Tommasini stated 'Ms. Netrebko remains a glamorous and charismatic singer with an opulent and poignantly lovely voice.'73 This statement attaches the qualities of glamour and charisma to her person and/or body, yet describes her vocality in terms of separation, without acknowledging agency: her voice is something she owns but does not necessarily control.

Tommasini continues, however, with a much more empowering assessment of her performance. Although he notes her prioritising of 'expressive nuances and impetuosity' over 'rhythmic precision and flawless execution', he describes how she shaped the musical phrases for expression and 'created vocal magic' in a way that, for him, invited comparison with Maria Callas:

During her first scene, in the haunting aria 'Regnava nel silenzio,' she shaped the arching phrases with rich sound and lyrical suppleness. [...] [D]uring the first part of the mad scene, after Lucia stabs her husband to death on their wedding night, Ms. Netrebko was spellbinding. In the hushed pianissimo passage when the delusional young woman believes she and her beloved Edgardo are at last united, she created vocal magic, imbuing lines with spectral colorings that matched the eerie sounds of the glass harmonica [...] Her earthy, subdued expressivity had me thinking of Callas. ${ }^{74}$

The response to other aspects of Netrebko's live performances is similar to the reception of Callas, in that Netrebko tends to be granted agency in terms of her characterisation and embodiment of the roles she is playing. This example also uses language that acknowledges her creation of the chosen sound by using the phrases 'she created' and 'imbuing lines with coloring'. Her agency in singing, that is, her creation of the sound

\footnotetext{
72 Manuel Brug, 'A Promise Kept', in Booklet of Anna Netrebko Opera Arias CD - Re-Release of 2003 Recording, trans. Stewart Spencer, First Choice (Deutsche Grammophon, 2012).

73 Tommasini, 'Bel Canto Magic in a Scottish Castle Haunted by Pesky High Notes'.

${ }^{74}$ Tommasini.
} 
(which allows for those characterisations, and the role itself, to be conveyed aurally) is not always acknowledged in this way; her singing is often described in terms of the qualities of her voice rather than her actions in creating the sound. However, based on the corpus of reviews I have analysed there is more variety in this respect than in Te Kanawa's reviews. Where Te Kanawa was usually described as 'having' a voice, Netrebko is often said to be 'creating' the sound, as in the above example.

Perhaps it is easier for dramatic acting to be recognised as artistry. Even Netrebko's 'naturalness' on stage, a common theme in her reviews, is usually recognised as something that involves artistry, at least in terms of achieving it while continuing to sing. Changing this attitude towards singing may be problematic. The aim of making the production of vocal sound seem easy to the viewer and/or listener is actively encouraged by those who teach and coach singers. We work towards conveying a sense that singing is done with ease so it is not shown as being full of labour or effort. This aim of a 'free', 'natural' sound, conceals the art of a technique that is poorly recognised by non-singers or others outside of classical singing practitioners. As Eidsheim has explained, it remains a challenge to 'decipher the constructedness of timbre and to debunk the myth of its authenticity'. ${ }^{75}$ In the next section I analyse Netrebko's signature vocality and consider it in these terms, to show the way in which vocal tone is in fact created by this singer.

\section{Fearless Intensity: Vocality Analysis}

The power communicated by Netrebko through her vocality can be characterised by a sense of both control and fearlessness. The way she wields her voice is not particularly creative compared to Callas's use of colouration, nor is her vocality rich in beauty and line as is Te Kanawa's. However, where Netrebko does exert her individuality is in the way she uses her voice to display confidence and daring, which can be seen as key aspects of her star 'image'.

Netrebko does not usually manipulate tonal colouration or other musical aspects such as phrasal shaping, ornamentation or cadenzas. She tends to sing exactly what is printed on the musical score, but does so with formidable accuracy of intonation and timing, and always with a marked clarity and directness of tone. She describes 'finding' this vocality while attending the St Petersburg conservatory: 'I found something in my voice. It's very

75 Eidsheim, The Race of Sound, 54. 
clean and very recognizable. It wasn't big, but it was always very pointed - it came to a whole. That's why I continued to think I might be a singer.'76

'Blade', the type of strongly projecting tone that emphasises the high harmonics in the sound, is a strong feature in a certain pitch range of Netrebko's singing, and may be what she is referring to above. This quality is a tone colour that is steady (i.e. minimal vibrato amplitude), brilliant (high harmonics are prominent), and strong (projects well). The range in which Netrebko tends to use this 'blade' quality is centred around $e$ " to $e b$ " in the second passaggio area. It is most in evidence at that pitch, but she carries this sound up to the important range of $c^{\prime \prime}$ to $g$ ", encompassing both the passaggio and the lower part of the 'head voice' range. The quality is also heard mixed in to the tone of her high $a b$ ", but for her upper range, particularly $c^{\prime \prime \prime}$ and above, where thin vocal fold action needs to predominate in order to create the sound, this quality is replaced by a less complex 'lighter' tone.

While this 'blade' in the tone gives projection and clarity, if it dominates the tone it can sound 'hard'. In Netrebko's case this range simply lacks the subtlety that the mixing of harmonic formants (strength of high and/or low harmonics) could bring: the 'blade' tonal quality tends to be virtually monochromatic throughout the range she uses it. However, this sort of tone does enhance her power of projection and the terms 'hard', 'steel', 'cut' and 'blade', which are all commonly-used descriptors for this type of sound, are clearly terms which convey strength and power.

Although it may seem like 'semantic play' to point to the literal meaning of such terms, these connotations have a wider potential effect than simply defining vocal techniques. The development of such terms is a two-way process in that the descriptors are founded on perceptions of the physical act of producing the tone. Zachary Wallmark suggests that 'timbre perception is a motor mimetic process; we covertly mirror the bodily action implied in the production of timbre when we listen'.77 This viewpoint, that the listener's bodily response is connected intrinsically with the singer's actions, is a key component of the fundamental concepts of embodied cognition. If such reactive bodily actions are occurring when we listen to sounds made by others, then it is not surprising if the terms we choose to describe these sounds are based on the actions we perceive as having

\footnotetext{
${ }^{76}$ McGrath, 'A New Kind of Diva'. It is also noted by Necula as 'something so very clean and pure'. See Maria-Cristina Necula, Life in Opera: Truth, Tempo, and Soul: Encounters with Stars, Innovators, and Leaders of Today's Opera World (New York: Amadeus, 2009), 157.

77 Wallmark, 'Appraising Timbre: Embodiment and Affect at the Threshold of Music and Noise', iii.
} 
created them. The result in Netrebko's case is an impression of power that could be taken to imply agency, as well as strength, and a sense of the singer's strength of 'will' and selfassurance.

The other most prominent feature of Netrebko's vocality is her darkness of tone, particularly in the middle voice range. This degree of darkening is extreme by most international standards. It is compensated for somewhat by the 'gleam' of the 'blade' tone around the second passaggio range that emphasises upper partials formants in the sound.

There often seems to be a tendency for Russian-trained singers to emphasise a dark tonal quality, and this high degree of dark timbre in her tone may perhaps be accepted outside Russia simply because it fits with a general perception of the Russian 'style' of vocality or the so-called 'Slavic school of singing'. ${ }^{78}$ However, Netrebko has indicated that her teacher in Russia, Tamara Novichenko, did not encourage this dark quality. She did not discourage it, however, as much as steer her away from dramatic repertoire towards the lighter coloratura works, on the basis that the lighter repertoire was better for her at that stage of development.

[Novichenko] wanted me to sing lighter. Always. It was always good that my voice has this dark quality because it's different from typical coloraturas. I had an advantage. Maybe still now ... I don't know ... ${ }^{79}$

It is interesting to note the difference in vocality of singers whose training was not completed within Russia. An example is soprano Julia Lezhneva whose vocality does not include any hint of such darkness of tone. This Russian soprano trained first at conservatories in Moscow but subsequently spent three years undertaking advanced singing training at British music colleges, which could be the source of this difference in signature vocality. ${ }^{80}$ As demonstrated by Eidsheim:

\footnotetext{
${ }^{78}$ This comment re the dark tone of Russian singers is a generalisation based on my experience over the period of my study and career, but the tone of the Russian singers in the Eugene Onegin performances I attended at the Metropolitan Opera in 2017 reinforced this impression. The concept of 'National schools of singing' is explained by Eidsheim: 'A national school of singing implies both a preferred tone quality and the technique that produces that quality. Tone quality and technique function symbiotically on a national and regional scale and result in differing pedagogical schemes and a corresponding shaping of the voice according to a national tone ideal. (Perhaps the most commonly known national schools of singing are the English, French, German, and Italian, but there are also the Nordic and Slavic.)' Eidsheim, The Race of Sound, 53.

${ }^{79}$ Quotation from interview. Necula, Life in Opera Truth, Tempo, and Soul, 158.

80 'Julia Lezhneva: Biography', Julia Lezhneva, accessed 29 January 2019, https://www.julialezhneva.com/biography/; Julia Lezhneva Speaks to Classic FM, 2013, https://www.youtube.com/watch?v=N1SyjEPX9U8.
} 
Vocal timbral constraints are not straightforward; they are categories into which we ourselves shape our voices as well as categories that are pushed upon us, both of which are part of a broader sociocultural landscape. ${ }^{81}$

Netrebko has distanced herself from the so-called 'Russian school' of singing, defining it in relation to her repertoire:

I don't claim that I merely represent the Russian vocal establishment. My technique is more of a blend. If I had solely the Russian school, I would above all sing the Russian music. I, on the other hand, sing both Russian and so-called nonRussian, plus I do sing more of the music which isn't Russian. Let's agree to the fact that my singing school is mixed. ${ }^{82}$

Netrebko suggests that one needs to approach each role differently, and that repertoire by different composers require different vocal approaches:

[For Anna Bolena and Mimi] I can't use the same amount of vocal volume or sound intensity, as they are completely different. But it does take a lot of time and exercise to achieve the point of being able to effortlessly shift from one singing style to another. ${ }^{83}$

Darkness of tone as used by Netrebko may be achieved in two basic ways in singing: lengthening of the vocal tract or alteration of the position of the tongue. The (supralaryngeal) vocal tract encompasses the area in the throat above the larynx, through to the oral and/or nasal passages. This means it can be lengthened (at least when singing vowels) by pouting the lips to extend the top end of the tract, and/or lowering the position of the larynx in the throat to add length at the lower end of the tract.

Russian singing teacher Viktoria Belova, who trained with American pedagogue Seth Riggs, notes that she has had to reinterpret his method for teaching Russian-speaking singers. She asserts that 'the position of [the] voice box of Russian-speaking singers differs

\footnotetext{
${ }^{81}$ Eidsheim, The Race of Sound, 54.

82 Peter Bleha, 'Anna Netrebko: I work until I can't stand up any more', Opera Slovakia (blog), 16 June 2015, https://operaslovakia.sk/anna-netrebko-i-work-until-i-cant-stand-up-any-more/. 83 Bleha.
} 
from the English ones'. ${ }^{84}$ Riggs's method includes training in the ability to raise and lower the larynx, and Belova's statement implies that these speakers tend to position the larynx lower in the throat, which would create a darker, warmer sound. 85

In the Estill Voice Model a habitual voice quality such as this is referred to as an 'attractor state', and the combination of this lowered larynx position with thyroid cartilage tilt is fundamental to 'Sob quality', which gives warmth of tone plus vibrato. ${ }^{86}$ The degree of laryngeal lowering can be adjusted and needs to be varied for notes in different parts of the range: the larynx must be allowed to rise somewhat for higher notes, and there is a stylistic judgement to be made on any note as to how much lowering, and therefore warmth, is included in the sound. In addition, pouting the lips away from the teeth can be used to produce a warmer, more rounded, 'padded' sound that 'slightly darkens the tone' ${ }^{87}$

When I analysed Netrebko's vocal sound for this chapter, using the specific aria recordings from her debut CD detailed below, along with videos from later performances including the Souvenirs CD/DVD package, the degree of darkening that was present was so intense that it seemed to be more than simply a lengthening of the vocal tract. 88 The most likely method for this would be 'backing' the tongue which usually also involves lowering of the dorsum of the tongue. ${ }^{89}$ The position of the tongue determines which basic vowel sound we pick out from any speech sound or sung sound that we hear. The tongue can be in a range of positions for any given vowel sound to be perceived: for example, an 'ah' could be heard as dark or bright as long as the tongue position is close enough to the primary one for that vowel sound. By shaping the tongue for a particular vowel but placing that shape

${ }^{84}$ Alexander Bratersky, 'Viktoria Belova Teaches American Singing for Slavs', The Moscow Times, 24 September 2013, http://themoscowtimes.com/articles/viktoria-belova-teaches-americansinging-for-slavs-27938; 'Legendary Vocal Coach to Open School in Russia', Russkiy Mir Foundation Information Service, 27 December 2011, https://www.russkiymir.ru/en/news/127629/. 85 Seth Riggs, Singing for the Stars: A Complete Program for Training Your Voice, ed. John Dominick Carratello (Alfred, 1992). Riggs maintains in that the goal of these larynx height exercises is to enable the maintainance of a position that is close to that of speaking. This does not align with science-based approaches such as the Estill Voice Model, which identify the need for larynx height to change for different pitches and voice qualities, but his exercises may be useful for improving flexibility of laryngeal movement.

${ }^{86}$ Steinhauer, Klimek, and Estill, The Estill Voice Model, 13, 37, 91, 213-18. The Model defines a separate 'Opera quality' but the lowered larynx and thyroid cartilage tilt of 'Sob quality' are included as part of it.

${ }^{87}$ Steinhauer, Klimek, and Estill, 182.

${ }^{88}$ Anna Netrebko, Opera Arias: Anna Netrebko (First Choice); Wiener Philharmoniker, Gianandrea Noseda, First Choice (2012) (Deutsche Grammophon, 2003); Souvenirs, Limited Edition, Box Set CD (Deutsche Grammophon 00289477 7451, 2008); Anna Netrebko - Souvenirs (Deutsche Grammophon Video), 2009, https://www.youtube.com/watch?v=soyAJE4U_BI.

${ }^{89}$ Steinhauer, Klimek, and Estill, The Estill Voice Model, 141, 148. 
further back or lower in the mouth the singer produces a sound that is heard as darker. If the change is marked then the vowel may even be interpreted by the listener as a different vowel from the one intended. In the case of the 'ah' vowel [a] the backed version will tend towards an open 'oh' vowel [o].

This tongue position cannot always be seen by an observer, firstly because it can be a subtle difference, but also because the mouth may not be open enough for the tongue to be seen clearly. However, in the video that comes with Netrebko's CD Souvenirs, it is possible to see this backing of the tongue at a number of points, while she is recording the aria 'Heia, in den Bergen' from Kálmán's Czárdásfürstin. ${ }^{90}$ This lowering/backing of the tongue can cause issues with high notes, as it can restrict the larynx from rising far enough to sing the high pitch comfortably. ${ }^{91}$ When Netrebko sings high notes in this video, for example, the high $c^{\prime \prime \prime}$ at 2:53 minutes, she can be seen to quickly release the tongue forward. This stops the tongue from inhibiting the vocal production through its position restricting her rising larynx and allows her to achieve the high pitch without it being adversely affected.

In the musical example which follows this section, I have marked up the various features of Netrebko's vocality which can be heard in her recording of the aria 'Non mi dir' from Don Giovanni from her debut CD, which was released in between her two highly successful seasons of this role at the Salzburg Festival in 2002 and 2003.92 This example includes a number places where Netrebko darkens the tone so much that the vowel itself is changed. In bar 34, for example, the 'ee' vowel sound [i] in the word 'conosci' has changed to an 'oo' [u]; and in bar 44, the 'ah' vowel sound [a] in the word 'mora' has changed to an open 'oh' sound [0]. Other places where her darkening of the tone and/or modification of the vowels can be heard include in bars 30, 40, and 47 .

Another less obvious feature of Netrebko's vocality occurs only in the low to middle range of her voice. She often produces a sound on those pitches that reflects the signature vocality of Kiri Te Kanawa. In singing these notes from $f^{\prime}$ to $a b^{\prime}$, or even occasionally $b b^{\prime}$, in her middle range, Netrebko utilises a tone which is warm, unpressured and with a relatively centralised tongue position. This sound can be heard in the 'Non mi dir' musical example in bar 27 and bars 34-35. Because this is not a range that is generally emphasised in soprano arias, these few pitches, while tonally consistent in her singing, are not an immediately obvious feature, and so should not be treated as a key aspect of her signature

\footnotetext{
90 Souvenirs CD: Interview Anna Netrebko (Video).

${ }^{91}$ Steinhauer, Klimek, and Estill, The Estill Voice Model, 148.

${ }^{92}$ Netrebko, Opera Arias: Anna Netrebko (First Choice); Wiener Philharmoniker, Gianandrea Noseda. 
vocality. It would be difficult to make any assessment as to whether this is a conscious connection with Te Kanawa's signature vocality unless she stated it herself. This may be a difficult range for her customary signature timbre and what we hear instead might be her 'natural' tone; however, the vowel colours she uses are still darkened, which provides a connection to the rest of her range in terms of timbre. ${ }^{93}$

Another feature of Netrebko's signature vocality is her vibrato, which has a consistently fine amplitude and fast frequency. This is sometimes reduced almost to straight tone for particular notes within a line, perhaps with the intention of creating expressive shaping of the phrases. Her approach to notes is also generally very clean and immediate, with a highly accurate intonation, timing and rhythm. The qualities of her vibrato and her use of straight tone and extremely clean approach to the onset are identified where they occur in the musical example that follows, see bars $20-25$, and bar 42 , respectively.

93 This tone colour occurs in a similar range to the notes I identified previously in my analysis of Callas's vocality, where she also used what might be termed her 'natural' voice. 


\section{Musical Example 3: 'Non mi dir' - Anna Netrebko}

'Non mi dir' (Donna Anna) from Don Giovanni by W. A. Mozart. The vocality features that are marked in the score relate to the studio recording made by Netrebko with Gianandrea Noseda in 2003.94
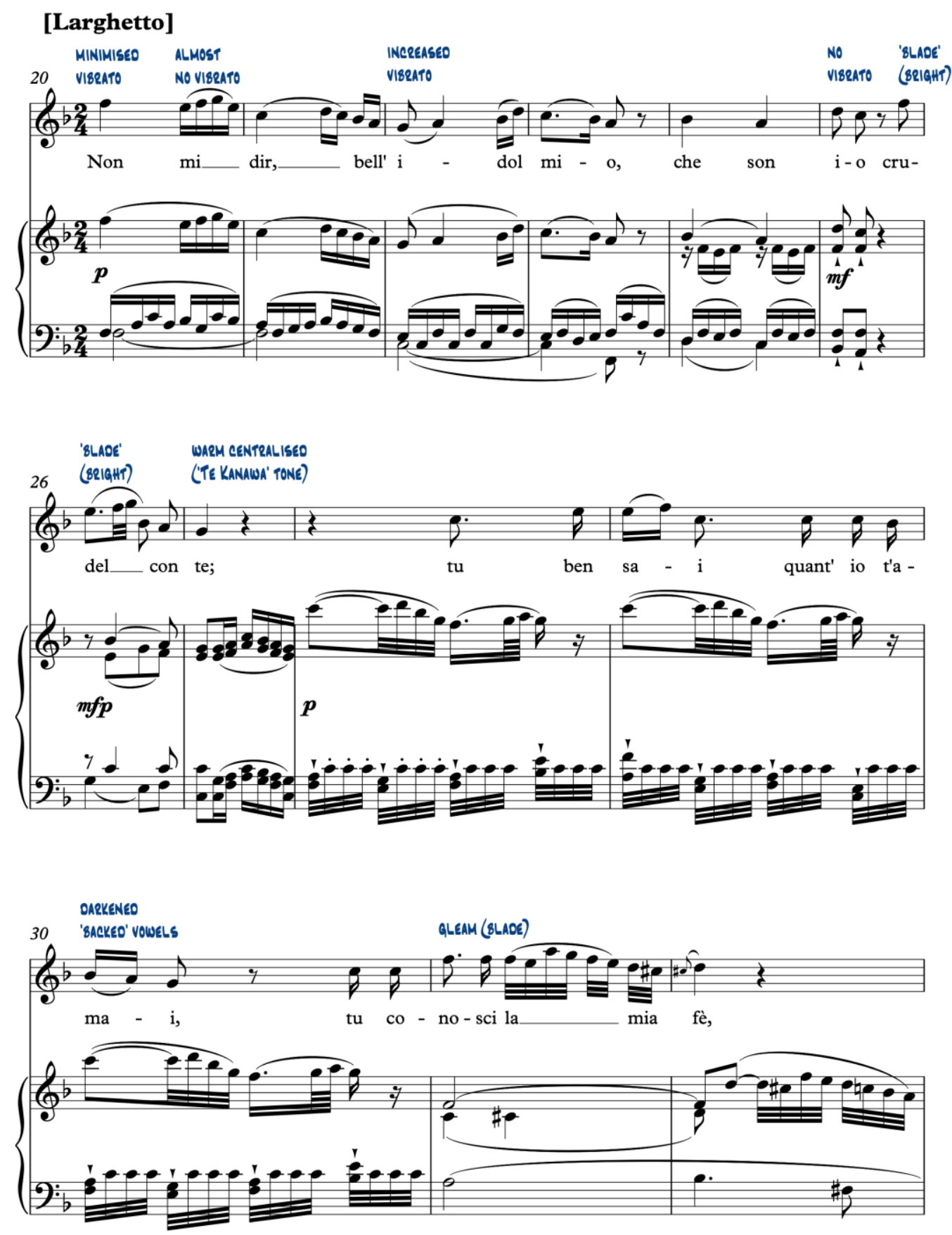

\footnotetext{
${ }^{94}$ Netrebko, Opera Arias: Anna Netrebko (First Choice); Wiener Philharmoniker, Gianandrea Noseda. Currently available at: Anna Netrebko; 'Non Mi Dir'; Don Giovanni; Wolfgang Amadeus Mozart, n.d., https://www.youtube.com/watch?v=y8ho-HnxhS0.
} 

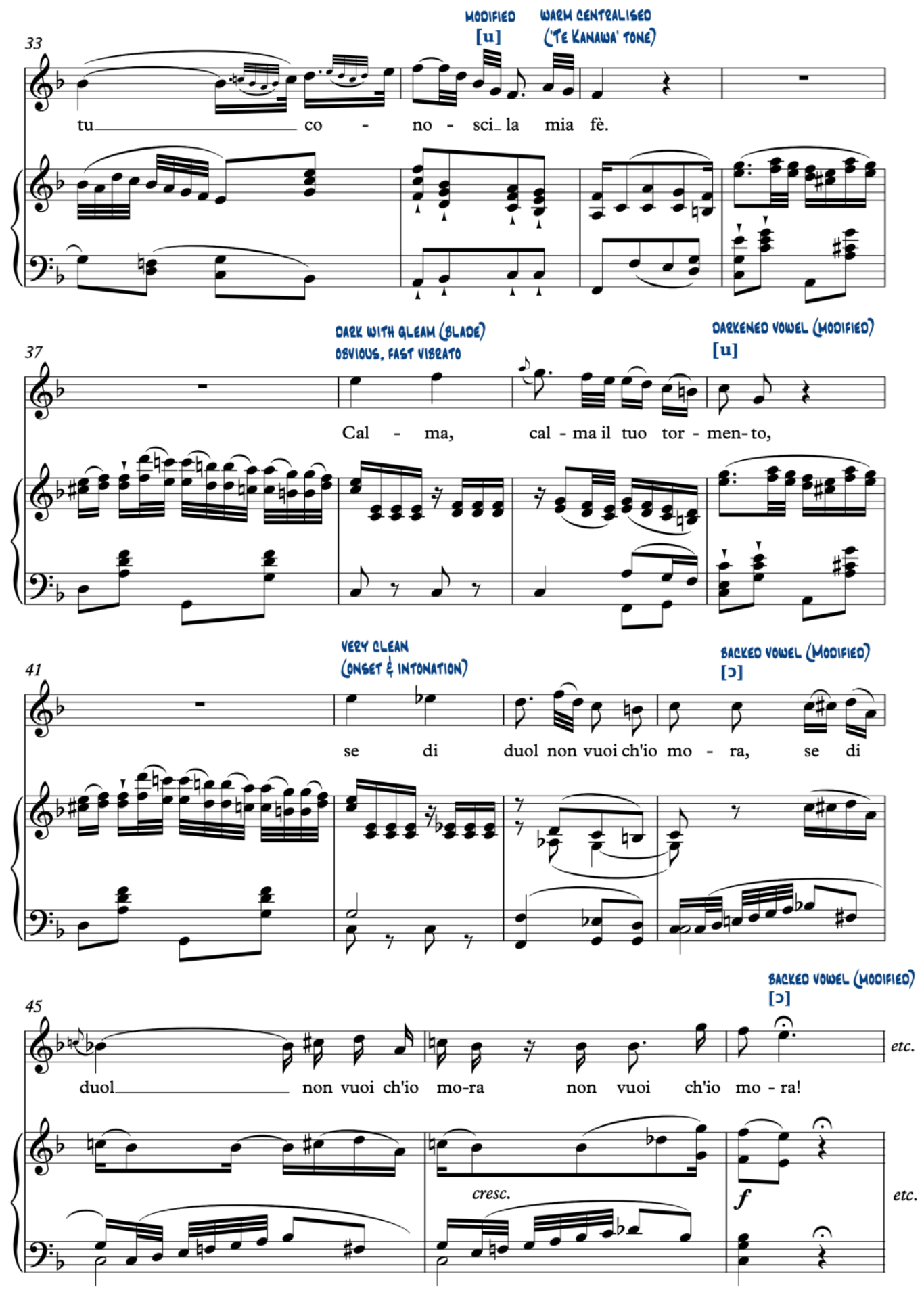

The overall tonal impression from this recording of 'Non mi dir' is of darkness, with 'backed' vowels, but this is balanced in many places with the bright 'chiaro' of the 'blade' element that she has added to the tone, as noted above in bars 25-26, bar 32, and bar 38 . This adds both projective power and a sense of strength to her signature vocality. Conveyed in this way, along with her overtly sensual and 'womanly' image, Netrebko's 
vocal power, resonating in her cutting metallic 'gleaming' tone as well as her stable fullthroated 'dark' tone, would seem to align her with the concept of the powerful diva described by Leonardi and Pope in The Diva's Mouth. They suggest that such divas 'break down binary gender and sexuality categories through their "masculine" behavior and stance toward the world.'95

The supposedly 'masculine' values of self-control, determination, mastery and emotional discipline, which are alluded to by cultural and gender studies scholar Susan Bordo in her influential text Unbearable Weight, could be seen as the attributes of the successful singer. ${ }^{96}$ In an interview on the video Anna Netrebko: The Woman The Voice Netrebko highlights the requirement for emotional coolness while performing. ${ }^{97}$

You have to be absolutely cold to sing on the stage. Absolutely. It has to be like a computer there in your head, like a mathematic [sic] and only then you will have [an] effect on the audience. If you will cry, if you will be too sensitive, nobody will understand that ... Just in some places you can put your feelings, but mostly you have to be very concentrated otherwise you cannot sing at all. ${ }^{98}$

Netrebko also describes how she feared that she was not good enough as a singer. She says this held her back in terms of her voice, and on stage, for many years:

I am that kind of person who is actually ... not so much ... believing yourself ... I am all the time doubt[ing], 'Oh my God', this is not good...

I am trying to be ... [raises fists] ... good. I am trying to give them what they are expecting from me... [sighs] ... as much as I can. ${ }^{99}$

The self-doubt that Netrebko describes in this interview contrasts with the sense of strength and 'willpower' that is transmitted through her vocal tone, and seems to imply a confident approach to its production. Gregory Berg, reviewer for the Journal of Singing, commented on this confidence, pointing to 'the consistent excellence and beauty of

\footnotetext{
${ }^{95}$ Leonardi and Pope, The Diva's Mouth, 241.

${ }^{96}$ Bordo, Unbearable Weight, 171. In the context of 'rules governing the construction of contemporary femininity', Bordo discusses 'female hunger' for public power, independence, and sexual gratification' and points to expectations that, to be successful in the professional arena, women must take on 'the "masculine" language and values of that arena - self-control, determination, cool, emotional discipline, [sic] mastery, and so on.'

97 Paterson, Anna Netrebko - The Woman, The Voice.

98 Paterson.

${ }^{99}$ Paterson.
} 
Netrebko's vocalism' in the live recordings CD of her Metropolitan Opera performances, and concluding that 'this is the kind of intense and fearless singing from which superstardom is born.' ${ }^{100}$

Netrebko's vocal materialisation, which projects this sense of strength of will, can also be seen as a sign of the vocal and personal power that works to disrupt repression and may connect with the young female listener's own sense of self. As James Q. Davies puts it:

In the liberal era, the imperative for singers (indeed for everybody) has been to work toward finding that which they supposedly already have. In the church of liberal freedom, the idea is that each of us has a secret entity within us, a living presence that might represent or stand in for us in some way. [...] The 'inner voice' has been made vital to political life and personal representation. In the biocentric conception, this voice involves coming out, articulating 'I am here.' It is about making bids for power. ${ }^{101}$

In my analysis of Netrebko's vocality above, I discussed how the qualities of her tone could be seen to relate to this modern conception of agency and power. One other crucial property of Netrebko's vocality, also true for Te Kanawa, is that her signature sound is such that it may be recognised and perceived equally well whether it is heard live, in audio recordings, or in video versions of her performances. ${ }^{102}$ This speaks to the consistency of the individual vocality, and, while in Netrebko's case it may comprise a rather simple set of qualities, the fact that its harmonic features can readily be transmitted via these different media certainly gives her an advantage in the modern era. As we shall see in the next section, the video versions of her opera performances as broadcast by the Metropolitan Opera, which form an integral part of her career and fame, involve additional layers of external authorial processing over and above those present in the original stage production. These extra layers are potentially significant to the point where vocality remains as one of the last areas of power and agency truly able to be controlled by the singer.

100 Gregory Berg, 'Anna Netrebko: Live At The Metropolitan Opera', Journal of Singing 68, no. 4 (3 April 2012): 486.

101 James Q. Davies, 'Voice Belongs: In Why Voice Now? Colloquy', ed. Martha Feldman, Journal of the American Musicological Society 68, no. 3 (1 December 2015): 680.

102 Through my experience of her live and video performances along with the audio recordings on which I based the above analysis, I can affirm that Netrebko's signature vocality is perceived as unchanged through these different performance situations and media. 


\section{Live or Mediatised? Netrebko's Performances}

The landscape for the dissemination of musical recordings has clearly changed drastically since the end of the 1990s. The amount of material now readily available to online users represents a hugely expanded reservoir of different artists and operatic performances from what was available to consumers previously. This move away from recordings as physical commodities has affected their consumption in a multitude of ways.

I first started hearing Netrebko's name frequently about 2010. This came from my singing students who often named her as their favourite soprano to listen to, yet could remember no other name but hers. At this stage the students' limited knowledge about recording artists in the field of classical music was already the norm. I had by that time realised that my students paid little attention to the identity of artists whose recordings they used as a basis for study. When I inquired how they accessed recordings, they said they were simply finding recording tracks on internet sites, downloading them to their own listening devices, then playing the tracks through headphones as they went about their day. This meant they only needed to process the name of the artist once: when they were choosing which track to download, and the identity of the recording artist was not necessarily something they encountered as they listened to them.

This lack of identification or recognition of the name of musical artists is perhaps partly a consequence of the fulfilment of Paul Goldstein's prediction of the 'Celestial Jukebox'. This intellectual property expert forecast in 1994 that recorded music would soon be available to any subscriber, supplying 'any number of selections from a vast storehouse via a home or office receiver'.103 While it may have seemed radical at the time, within a decade this mode of dissemination of musical recordings was readily available via 'file sharing' sites on the internet. However illegal the file sharing may have been, it was certainly popular among millennials, the generation to whom it was first presented. The legal purchase of audio recordings became possible online from 2003 with the launch of the iTunes Music Store, thereby setting up the commodification of individual recording tracks in digital form. ${ }^{104}$ Audio streaming platforms such as Spotify now fill this niche legally, in both 'free' and paid versions, along with numerous other internet-based music and video supply avenues.

\footnotetext{
103 Paul Goldstein, Copyright's Highway: From Gutenberg to the Celestial Jukebox (Hill and Wang, 1994), 199.

104 Jacqui Cheng, 'ITunes through the Ages', Ars Technica, 23 November 2012, https://arstechnica.com/gadgets/2012/11/itunes-through-the-ages/.
} 
Philip Auslander commented in his 2001 article 'Looking at Records' that the change to online downloading of music files entailed 'the dematerialization of the musical object, a change so fundamental as to constitute a paradigm shift'. ${ }^{105}$ In this essay he highlighted a similarly important shift a century earlier, in the 1890s, when musical performances were first provided to consumers via recordings played on a gramophone. He identified this as 'a crucial change in the sensory economy of music consumption that made hearing the dominant sensory mode', pointing out that this was a change not only from a necessarily audio-visual experience of performed music to an aural one, but also a new commodification of performances in the form of physical, collectible and tangible objects. ${ }^{106}$

As Koestenbaum has demonstrated through his personal revelations of fetishised desire based on vinyl recordings of divas such as Maria Callas, these physical objects can hold meaning in ways that an ephemeral and invisible electronic recording file is unlikely to ever provide. ${ }^{107}$ In addition the way such files are presented online changes the sites of self-presentation and promotion for the modern diva in numerous ways. This is an area where Netrebko and her promotional management have shown their ability to make an impression and build on it. The 'image' of the twenty-first century star is thus built and disseminated through different channels. The extent to which the internet platforms, social media, and other online audience and fan engagement have contributed to Netrebko's career success lends weight to Auslander's assertions about the weakening of the boundaries between live and mediatised form of presentation.

The greater part of Netrebko's career has been conducted simultaneously via both live and mediatised forms. The 'autopoietic feedback loop' Fischer-Lichte claims as an essential part of a performance is supposedly broken if performers and audience are not situated within the same physical space. ${ }^{108}$ My experiences of viewing recorded performances online, as discussed previously, point to similar affective power still being in place and flowing from the performer to the viewer or listener, and like Risi, I believe this affective power of the mediatised performances should not be discounted. ${ }^{109}$ The experience of watching a Met Live in HD video in a movie theatre with other audience members who participate in the partial feedback process (the 'incomplete autopoietic loop') is of course different from watching online performances on a computer with no one else present. The

\footnotetext{
105 Philip Auslander, 'Looking at Records', TDR/The Drama Review 45, no. 1 (1 March 2001): 77.

106 Auslander, 78.

107 Koestenbaum, The Queen's Throat, 59, also 48, 51.

108 Fischer-Lichte, The Transformative Power of Performance, 38.

109 Risi, 'The Diva's Fans', 53.
} 
Met Live in HD movies might be expected to be even more intensely affective for the cinema audience, given the large screen format and bigger sound system on which they are played and the presence of other audience members. For the purposes of comparison of her live versus mediatised performances, for this project I arranged to attend Eugene Onegin at the Metropolitan Opera in New York, in which she played the role of Tatiana, and, after returning to New Zealand, I viewed a delayed screening at my local cinema of the Met Live in $H D$ version of the same performance I had attended in New York.110

Hearing Netrebko perform live served to confirm my sense of her signature vocality as a dark-toned colouring with enough brilliance retained in the sound for good projection both in the large size of the Metropolitan Opera House and in the smaller Jack Singer Concert Hall in Calgary where I attended her concert of arias and duets with tenor Yusif Eyvazov. Unfortunately the role of Tatiana in Eugene Onegin, which she performed at the Metropolitan Opera, sits rather low in her range, and perhaps it was this, along with the reticence of the character that was emphasised by Netrebko in the first Act, which tended to make her impact on stage not as strong as I had expected. However, Netrebko's vocal performance did stand out for me from the other singers, largely due to the way she emphasised the words meaningfully: even in sections where I was not familiar with the Russian text, I had a sense of what it meant at every point. While I was familiar with the story and knew what to expect within the various scenes in terms of the plot, I found it particularly easy to follow what she was meaning, and much more so than with the other singers. She seemed to bring out the meaning of each word through the stress within the phrases, and she clearly enunciated the words for expressive meaning. I could also clearly distinguish her voice when she was singing, as her distinctive sound projected her as an individual on the stage giving her vocal 'presence'. Yet I felt that her performance was so 'naturalistic' in terms of movement and the character's shyness that this affected her overall presence in the theatre.

In the Calgary concert there was a clear difference between the audience's responses to the arias she performed from the dramatic repertoire ('Vieni t'afretta!' from Verdi's Macbeth and 'Io son l'umile ancella' from Adriana Lecouvreur by Cilèa) and the more lyric arias: Rusalka's aria from the opera by Dvořák and 'O mio babbino caro' from Puccini's Gianni Schicchi. She received standing ovations for her performances of these lyric arias,

\footnotetext{
110 '10 Seasons of The Met: Live in HD - Google Arts \& Culture', Google Cultural Institute, 2015, https://www.google.com/culturalinstitute/beta/exhibit/fwLChDzFtgqsIQ. In contrast to many Northern Hemisphere countries, the Met Live in HD screenings are not broadcast live to New Zealand, but are presented later, usually several months after the original has occurred. Forty-three theatres in New Zealand screened the HD transmissions in 2015.
} 
and there was more of a sense of a real, emotionally giving performer on stage when she sang these arias. Despite her 'dramatic' actions (she swung her fur-trimmed stole and even turned her back on the audience at times), I found I was not affected by her performance of the dramatic arias and I did not believe that she was affected by the character's thoughts or feelings. It seemed like she was focusing instead on surmounting the technical challenges of the work. She was using 'poses', perhaps related to those Risi points to, and her 'chest' voice (low range) tone gave dramatic colour, while her 'gleaming' tone was retained. ${ }^{111}$ Overall I was left cold from this performance, although I was impressed by the intensity and accuracy with which she performed.

My initial sense on viewing the cinematic Met Live in $H D$ screening of the performance of Eugene Onegin after I returned to New Zealand, was that I felt more of a sense of connection to the performers than when I was present in the opera house in New York. I found Netrebko's performance more engaging on this large screen than when I experienced it from the auditorium of the Metropolitan Opera, and my impression of the other singers was also stronger. I had thought that Netrebko's performance in New York was under-engaged as she was performing in a naturalistic way for the cameras, so I had already anticipated that her performance would come through more strongly on the screen than in the auditorium. However, there was not as much of a difference in this respect as I had expected. In fact, as the video screening progressed, I developed a sense that what I was experiencing in the cinema was in some ways related to the experience of watching television. This was not simply to do with the inclusion of interviews with the performers backstage or seeing the set from the wings as the crew reset the stage. Although I felt connected to the performers in that I could see them and hear them more easily, and the acting was more accessible in this format, I missed having the sense of this production being performed 'live' on stage. This was by no means my first time attending a Met Live in HD screening, yet this time it seemed to be less engaging than previous screenings of operas that I had attended. Whether it was to do with the more naturalistic acting, which was less energetic than I expected, or whether it was to do with the television-style camera shots 'placing' the opera as an on-screen performance rather than an on-stage performance, this was my lasting impression.

When I learned more about the processes involved in the production of the Met Live in HD transmissions, I realised that what I sensed may have been to do with developments in the 'style' of shooting these transmissions. This concerns the specific choices made by the Live

111 Risi, 'Diva Poses by Anna Netrebko: On the Perception of the Extraordinary in the Twenty-First Century', 151-52. 
in $H D$ director, in this case Gary Halvorson. ${ }^{112}$ Perhaps some of this is inevitable - as Kay Armatage explains, in order to make sense of the plot for the cinema audience, the HD director may choose to add views that display a particular action (the character who dons a disguise on stage, for example) and it may have been the way that this was related to a style employed for television dramas that I had unconsciously recognised. ${ }^{113}$

Various scholars have considered issues that arise from the transfer of live opera performance to audio-visual media. ${ }^{114}$ Cenciarelli and Senici note that the Met Live in HD transmissions tap into an 'ideology of authenticity' through the implication of 'liveness', since they are not only filmed at an actual live performance, but also, at least in the Northern Hemisphere, they are broadcast to the participating cinemas at the same time that the performance takes place. On this basis the HD transmission broadcast is thought to be more 'live' or more 'authentic' than a regular video of a staged performance such as one might find on an opera DVD. ${ }^{115}$ Yet my own experience, which was admittedly based on a delayed screening rather than a live transmission, was that the form of this filmed version reduced the sense of this liveness. If the reason for this was the way that it had been filmed, then it would be expected that this sense of liveness would accordingly be reduced also for the audience watching the live transmission. This form of 'live' broadcast may give off more of a sense of the 'wildness' or risk involved in live performance, as described by Abbate, due to the fact that, for example, something could go wrong, and the live transmission audience would experience that difference in the performance. ${ }^{116}$ In fact the filming itself has added another layer of authorial direction in its creation that seems to affect our sense of its authenticity. The act of video recording inevitably reconstructs the performance into a different stylistic form at the same time as the performance is mediated in a different format. As Senici puts it: 'video does not simply mediate, relate, or translate a live performance, but rather constructs it according to video's own technical and medial characteristics as well as to a complex set of cultural and social assumptions about its function and role'.117

\footnotetext{
112 Tchaikovsky: Eugene Onegin, accessed 21 February 2019, http://www.imdb.com/title/tt6505176/.

${ }^{113}$ Armatage, 'Cinematic Operatics', 923.

${ }^{114}$ Emanuele Senici, 'Porn Style? Space and Time in Live Opera Videos', The Opera Quarterly 26, no. 1 (1 January 2010): 63-80; Carlo Cenciarelli, 'At the Margins of the Televisual: Picture Frames, Loops and "Cinematics" in the Paratexts of Opera Videos', Cambridge Opera Journal 25, no. 2 (July 2013): 203-23; Melina Esse, 'Don't Look Now: Opera, Liveness, and the Televisual', The Opera Quarterly 26, no. 1 (1 January 2010): 81-95.

115 Senici, 'Porn Style?', 66; Cenciarelli, 'At the Margins of the Televisual', 204.

116 Abbate, 'Music-Drastic or Gnostic?', 508-9.

117 Senici, 'Porn Style?', 66.
} 
Because of these differences, Roger Parker beseeches us not to judge a DVD of a 'live' performance, or therefore, a HD transmission, as if it were the 'real' production. He suggests it would be 'perfectly possible for the same viewer to come to different, even contradictory conclusions about both the musical and visual aspects of a production, were she or he to migrate from recorded viewing to live viewing: were, for example, her ears attuned to new sonic balances; were his eyes no longer enslaved by the video director's imperious, roving gaze.'118

As I have outlined above, my own impression, in moving from the live to the recorded version of the same performance by Netrebko, was that many aspects of the production worked better in the video version, but one constant between the two was my impression of her signature vocality. My focus here is on the transmission of power via vocality and the degree of control allowed the singer in the use of these media, and I discuss this below through the lens of Netrebko's mediatised performances.

\section{Authorial Voices in Mediatised Production}

Of all the forms of mediatised outputs examined in this dissertation, these Met Live in $H D$ transmissions provide for the fewest opportunities for the singer to exert her creative agency. This is because of the high level of technological interaction that must be layered over the original sung performance in order to form the final product. For these broadcasts, the singer's performance on stage is overlaid by the work of many others. This includes the live filming of the show with multiple cameras, and a 'television-style' live transmission production during the performance, where decisions on focus, camera shots and specific views are made by a transmission director both before and during the filming. In addition, as Christopher Morris argues, 'the choreography and gestural vocabulary introduced by one of today's celebrated directors may be open to negotiation during rehearsal, but it is rarely the singer's prerogative to improvise from performance to performance'.119

Within this type of mediatised environment, constrained in terms of movement by the combination of the stage director and the transmission director, the singer's vocality, that is, their signature sound and their spontaneous expressivity through changing tone colours, perhaps remains the last bastion of their individual contribution and authorial voice within the performance. While the singer is expected to conform to or negotiate with

\footnotetext{
118 Roger Parker, 'Giuseppe Verdi's Don Carlo(s): “Live” on DVD', The Opera Quarterly 26, no. 4 (1 October 2010): 605.

119 Morris, 'Digital Diva', 101.
} 
multiple directorial agents in terms of the visual aspects of her performance, vocally she still retains the power and agency to construct her own versions of the aural aspects, including the way she presents her signature vocality.

Armatage's article gives a sense of the layers of directorial authorship within such a production. She considers the contribution of Barbara Willis Sweete, one of the directors for the Met Live in HD transmissions, offering insights into the processes and necessary additions and modifications that are built into the mediatised versions of these performances.

With Sweete's emphasis on both visual narrativity and visual architecture, we see in her HD transmissions the emergence of a new form, as the limitations of camera placement, blocking, and editing are exacting their own reworkings of film grammar and technological evocations of affect and sensation. Rather than excoriating the cinematic as intrusive or manipulative, deploring the experience as different from attending a performance in the opera house [...] I think we will come to see these broadcasts as a truly intermedial hybrid that, as Marcia Citron puts it, 'is a carefully crafted construction that is distinct from the performance it is recording. 120

The pressures on acting styles may also create difficulties for singers who are expected to make an impact in the theatre at the same time as within this filmic genre. Armatage suggests that 'more naturalistic performances are lauded [...] while stiff or histrionic performances are denigrated' and gives as an example Netrebko "listening" as her lover sings to her in Lucia di Lammermoor' in the 2008-09 season series. ${ }^{121}$ However, as New York Times critic Zachary Woolfe notes, to be effective, the singers' performances 'must now work on several levels at once, some of which might be accessible live and some on screen'.122

In addition to the visual elements above, for the sound reproduction in the Met Live in $H D$ performances, as for the regularly given live radio broadcasts of performances at the house, the audio producers must make choices about the positioning of microphones and the type of technology used. They make judgements about the desired emphasis in terms

\footnotetext{
120 Armatage, 'Cinematic Operatics', 926.

121 Armatage, 917.

122 Zachary Woolfe, 'The Met's HD Broadcasts Are Changing Opera', The New York Times, 27 April 2012, sec. Music, https://www.nytimes.com/2012/04/29/arts/music/the-mets-hd-broadcastsare-changing-opera.html.
} 
of the tonal spectrum, as in the case of any recording producer, plus there is the potential for the variable quality of the sound equipment this version will be played on when heard in the various movie theatres around the world.

The amount of control that the singer has over the actual sound heard and the visual impression gained by the viewers of these Met Live in $H D$ performances is therefore much diminished from the level of control she is able to command within the opera house. In the live performances she has, proportionally, much more agency, relative to the number of people involved in the overall output. In terms of singing in particular she makes choices throughout the performance about the particular type of vocal sound she will produce for any given note, and the way in which she will project her sung tone into the space. In the opera house itself, this control and the choices she makes have a direct effect on what is heard by the audience present. But in the audio-visual mediatised outputs this is only one part of a series of layers of decisions that will be made during the process of creating the mediatised version, so her input may be less effective in the final hearing and viewing.

In the case of commercial video recordings such as Netrebko's MTV-style video clips on her DVD 'The Woman The Voice', there could be more potential for acknowledged authorship, where a director may involve her in decision making around aspects of the staging or image that goes beyond the limits of a staged production. The film in this case includes video clips of Netrebko based around five of her audio recordings of well-known arias, as well as interviews with the singer and the director. In the DVD booklet, the director, Vincent Paterson, describes the project as a vanguard project, and the working situation as a collaboration between singer and director:

Anna and I were aware that many opera purists might find it difficult appreciating classical opera arias in a new light. The combining of tradition with a contemporary edge, the music video style presentation, the lip-synching, and interpretations that did not always follow the actual story of each opera were risks we chose to take. But we never wavered in our love for the opera and our joyful desire to 'make art.' We relished the collaboration with brilliant international artists and we hope that music lovers of all ages and tastes can enjoy the result.123

The 'music videos' on this DVD attempt to amalgamate the sound of the classical singing style with sometimes understated lip-synching and are not all equally successful in this

123 Paterson, Anna Netrebko - The Woman, The Voice. 
experiment. At times Netrebko is shown making the actions that relate to the fullyembodied vocal production of the opera singer, but in some places her lip-synching is reduced to 'mouthing' the words as if they were just being spoken or even mumbled. This may be common and therefore appropriate in 'popular music' video clips but at times Netrebko seems uncomfortable, as if she has been required to move her mouth as little as possible, which draws attention to the power of the singer that is normally communicated through this aspect of the physical embodiment of the creation of sound. This dislocation from the body-voice connection undermines her power as situated in the sound and projection of the singing voice.

This dislocation of the bodily production of the sung sound is reminiscent of the effect of the Callas hologram, in which the unconvincing visual representation of Callas by the actress separates our experience of the vocal sound from the body with which it is meant to connect. In Zeffirelli's film Callas Forever, the film-Callas objects to such reincarnation attempts on the basis that the original voice must be left 'whole' and 'in its time'.124 JeanPierre Ponnelle's 1975 television production of Le nozze di Figaro 'solves' the problem of lip-synching by doing away with it altogether at times, for example, when the Countess (played by Kiri Te Kanawa) sings the aria 'Dove sono', she 'hears' the sound of her own voice, as we do also, yet she does not 'sing along' - in fact closes her eyes, with the resulting impression that she is 'dreaming' the words rather than actually singing them at the time - an internal monologue, rather than an externally expressed one. ${ }^{125}$

Mouthing of the words without any sense of the physicality required for its production is a form of acousmatisation of the voice: we see the singer 'singing' but we sense the fact that she is not really producing the sound that we hear. As Jaume Radigales argues, 'singing in the mask', the classical singer's use of facial muscles as part of the vocal production, does create an unnatural look - unnatural to the general public, but natural to the opera audience, especially those now accustomed to watching close up views of singers in operatic videos. ${ }^{126}$ The lack of connection for the viewer between the sound and the singer undermines our sense of the singer's ownership of that vocality, and further, it weakens our ability to appreciate her agency in creating that sound.127

\footnotetext{
124 Grover-Friedlander, 'The Afterlife of Maria Callas's Voice', 40.

125 Radigales, 'Playback Problems When Filming Opera for the Screen: Two Case Studies', 118.

${ }^{126}$ Radigales, 116.

${ }^{127}$ It is perhaps worth noting that if we are listening to an audio recording there is not an issue of this type of disjunction, since we do not expect to see the performer, but if we are watching the singer not creating the sounds of her own voice, the impression may be that she cannot make that sound herself.
} 
Netrebko has made many audio recordings, and with these there is more control over the vocal output that may be wielded by a singer of her standing. However, as Kesting acknowledges, in the current 'mass-marketing' and globalised economic approach there is less time allowed for the recording of such albums than was normal in the past. ${ }^{128}$ Kesting refers to the rise of Fliessbandproduktionen (production line manufacturing), which was denounced by critics such as Andrew Porter as far back as the 1970s, pointing out that these products were often recordings of standard roles that the stars had never sung on stage and could in fact hardly sing. Today, complains Kesting, 'it is not uncommon that especially sought-after stars are only in the studio for one or two days, cannot do all the recording, only the ensemble pieces, and the missing passages are added in later'. ${ }^{129}$ This contrasts with the situation for earlier generations of divas where there was more time allowed and perhaps more engagement in the process, which determined the final product in terms of decisions around the inclusion of particular 'takes' and re-recording of numbers.

In the case of Netrebko, the notes in the booklets for her CDs emphasise her involvement in choosing the arias or songs to be recorded and in one interview she mentions her excitement about working with the conductor and other artists to create a new sound - in the case of the new orchestration created for two of the songs on Souvenirs CD. ${ }^{130}$ She clearly had input into the decisions being made about the specifics of this orchestration, but she remains confined by the usual non-authorial boundaries since the vocal sound and overall performance she has created for the recording is not acknowledged as work that is linked to her as author or creator.

'Women,' Eidsheim observes, 'find themselves the object of the gaze of assessment and criticism [and] are also continuously assessed for vocal and non-vocal bodily sounds. While singers are allegedly judged on the basis of their vocal performance,' she continues, 'for female singers this judgment is intensely applied in the visual as well as the sonorous realm.'131 Eidsheim points out that for some Callas gained a reputation for a charisma of physical presence that superseded all other aspects of her performance.132 However, in Netrebko's case I propose that her projection of her personal image captures the

\footnotetext{
128 Kesting, Die großen Sänger, 2008, Band IV:1862.

129 Kesting, Band IV:1862. My translation.

130 Souvenirs CD: Interview Anna Netrebko (Video).

131 Eidsheim, 'Maria Callas's Waistline and the Organology of Voice', 249.

132 Eidsheim, 254, 268. The author references Zachary Woolfe's 2011 article in the New York Times, the Obituary by Ericson in the same paper in 1977, and Evelyn Lear's comments in Opera News, as examples showing this aspect of Callas's reputation.
} 
imagination of her fans, but it is the sense of her agency and willpower that is carried by her vocality that produces the full impact of her divahood.

As Rutherford concludes, audio-visual media tend to emphasise the visual aspect: 'If audio recordings created the 'disembodied' voice', she states, 'visual recordings, with their emphasis on what is seen rather than what is heard, appear to encourage a critical 'devoicing' of the body.'133 While Netrebko's vocality imparts a sense of willpower, it is her active presentation of self, her image as physical body, which provides for much of her success as a mediatised performer.

\section{The New Type of Diva: Conclusions}

Netrebko has claimed and developed her role as a new type of diva, based on an image of self-assurance and approachability that is communicated through her vocality and her star persona, and this form of divahood has been hugely successful for her in a range of diverse media. Her public persona, which carries the construction of warmth in combination with sexiness, glamour, and evident talent and facility in her singing and acting, aligns with and builds on the power and agency implied by her signature vocality. Since the promotion strategies used for her have emphasised visual attributes and her personality, to some degree her vocality may seem less important for her career than for previous opera stars. However, she has been successful also in producing extremely high sales of her audio recordings, and has continued to record new solo albums over the course of her career.

Netrebko is recognised for her commitment to the character she plays and the concepts behind the staged opera productions she performs in and has had huge success with DVDs of many operas, but it is in the large-scale mediatised opera productions of the Met Live in $H D$ series for which she is perhaps best known, at least outside Europe. She has been a key featured artist in this series for the past decade, and this series has been extremely important for the Metropolitan Opera and opera globally. Its popularity reflects current trends towards the audio-visual that are championed by social media and internet platforms such as YouTube.

While the agency that Netrebko has in these video-broadcast performances can be seen as minimised, vocality is perhaps the last remaining site of individuality left to the opera singer in such performances. Vocally, in both live and mediatised opera productions the

\footnotetext{
133 Rutherford, 'Voices and Singers', 127. One example of this noted by Rutherford was a series of comments provoked by a particular video of Netrebko. Interestingly, this video has been removed from YouTube.
} 
singer has a great deal more freedom to make individual choices about the sound she produces than many other aspects of the on-stage activities. These choices of vocal sound include alternatives of tone colour, the shaping of specific expressive moments in terms of sound, and the ability to control her vocal sound and choose how to present her signature vocality. While the recording of sound is also subject to decisions made by the recording engineers involved in the live transmission broadcast, as in any audio recording or radio broadcast, within these limits the singer's individual sound and choices around vocal colouration remain under her control.

Individuality of vocality is no less important in this mediatised context than in a live one our understanding of both live opera and video screenings relies on our recognition of the performer's individual voice as we view and return to their performances. The innovative use of media and social media that Netrebko's career has involved sets up a new blueprint for operatic stardom that works with mediatisation. Her image, or as Risi differentiates, her images, appeal to the general public and work well with these new media formats. ${ }^{134}$

A final proof of Netrebko's distinctive brand of divahood can be found through comparison with other contemporary sopranos who have also been classed as divas. The careers of Angela Gheorghiu, Kathleen Battle, and Renée Fleming overlap the period of Netrebko's career. While Fleming maintains a quite different public image, Gheorghiu and Netrebko are in some ways very similar: they recognise and acknowledge that as opera stars they are playing a part and must continue to do so in their public life, where maintaining an appealing and yet 'authentic' image is necessary for the modern diva. While Gheorghiu acquired a reputation for being difficult, Netrebko does this without the fierceness or lack of approachability popularly thought to be part of the diva model. According to Kesting, Netrebko bucks the trend of the prima donna because journalists want her to be unassuming and without 'the 'grandes allures' of difficult divas such as Kathleen Battle and Gheorghiu. ${ }^{135}$ Yet such journalists, for example, Richard Morrison and Stuart Jeffries, make 'good copy' out of what the diva feeds them, and Gheorghiu is correct in saying that it is 'the game' they play. ${ }^{136}$ Netrebko thus feeds a persona to the press, which in turn enthusiastically and endlessly repeats the epithet that she is not an ordinary prima donna. 137

\footnotetext{
${ }^{134}$ Risi, 'Diva Poses by Anna Netrebko: On the Perception of the Extraordinary in the Twenty-First Century', 151-52.

135 Kesting, Die großen Sänger, 2008, Band IV:1915.

136 Richard Morrison, 'Angela Gheorghiu "If I Make Love, Do You Think I Should Call You?"', The

Times, 2 July 2010; Jeffries, '“I Conquered the Critics"'.

137 McGrath, 'A New Kind of Diva'; Midgette, 'A Diva Who Breaks the Divadom Rules'.
} 
There is a self-assurance bound up with Netrebko's image that gives out a sense of control and self-awareness, a sense of power emanating from the diva. These attributes also manifest in her live and recorded performances, and translate therefore into her influence. She has readily become a symbol for young singers: she seems to show them how to be 'glamorous' and at the same time 'natural' and also an opera star. She is always beautifully presented, popular on the internet, and ready to connect with them directly by engaging with social media. On YouTube Netrebko has had a huge impact, as can be seen from the fact that her clips arrive alongside those of Callas and Te Kanawa as top favourites for the sort of arias studied by young sopranos. ${ }^{138}$ This popularity generates continued impetus for top opera houses to employ her and for Deutsche Grammophon to retain their exclusive recording contract with her, thereby maintaining her position as a diva. However, none of this would occur if she did not sing to a sufficient level. No matter how much Netrebko's looks and acting talent may have contributed to her stardom, as Metropolitan Opera General Manager Peter Gelb confirmed soon after he took over the post, the voice is a non-negotiable foundation of the star singer: 'We're not looking to replace great singing with great bodies. We want both'.139

As a twenty-first century diva, Netrebko's career path, and her way of negotiating it, shows us much about the way that the modern female star, and divahood, may be incarnated in the digital era. While her authorship as a creator of performances may still be less likely to be acknowledged than it would be for many other non-singing artists in comparable situations, she has made claims to, and seized her opportunities for building and maintaining her power of influence and attraction through both externally curated and personally curated forms of her public image. In particular, her agency in controlling her image as a star through the use of social media and other internet platforms is clear. Her signature vocality, which conforms to classical norms, while not being strongly innovative, has a clarity that works well in both mediatised and live performance situations. Through its implications of willpower and strength, her vocality also plays into the image of her as sexually attractive while demonstrating her fearless skill and ability. Together these generate a form of diva power that fits with modern claims to feminine empowerment.

\footnotetext{
${ }^{138}$ As an example, in March 2017, the aria title 'O mio babbino caro', a popular aria for younger sopranos, rendered as the top three results the singers studied here: Callas, Te Kanawa, and Netrebko. This seemed to be true for all users and in similar searches Netrebko's videos were always in the top ten. Her popularity at that time, at least in this repertoire, was clear. By March 2019 other artists, such as the popular child 'stars' Jackie Evancho and Amira Willighagen, had moved Netrebko further down the list, but at least nine videos of Netrebko singing this aria may still be viewed on YouTube and several of these have had more than 2.5 million views to date. ${ }^{139}$ Necula, Life in Opera Truth, Tempo, and Soul, 81.
} 
Netrebko's appeal for modern audiences therefore aligns with the modern themes of individuality and personal voice, and she can be seen to wield her power through the strength and confidence of her comments in personal postings and interactions on social media. She utilises this direct connection with her fans and others to show and declare her agency in this process. Such claims can be seen as allied with the so-called 'masculine' values of self-control and emotional discipline she herself refers to in describing her performance processes.

In an increasingly mediatised environment, Netrebko has made her own bid for power and successfully negotiated the rise to and maintenance of her position of divahood. While acknowledgement of her authorship in the creation of sound in terms of vocality is not always firmly granted, and some forms of mediatised performance modes through which she has had great success work against the location of power and authorship within the voice-body of the performer, she has ridden the new wave of mediatisation of opera and has staged herself as a star. The often repeated assertion that she has 'redefined what it means to be an opera star' does have some truth, but it has not been brought about solely through her atypical behaviour as an 'un-prima donna'. ${ }^{140}$ It has been achieved also through the expert use of a curated image that has persisted through all forms of discourse around her as a star singer. In the digitalised environment of this century, where image is no longer distributed solely through the press and commercially released recordings, she and her promoters have successfully developed and utilised this new form of dispersal and maintenance of the image of the star for a global audience.

Netrebko's career was made possible through a public image that plays into a popular conceptualisation of modern femininity that mixes sexuality with competency. The sense of willpower and strength bound up with her signature vocality aligns with this concept, and although it may be rather simplistic in its form, this vocality is effective in both live and recorded performances, including, importantly, audio-visual renderings of staged operas. Her vocality is distinctive and can be easily 'read' by the listener as her sound and it draws attention to her presence on the stage within the soundscape and to her expression related through it. But ultimately, the power of Netrebko, as a twenty-first century diva, is bound up with her image, which is supported by the power conveyed by her vocality and related to the popular concept of the young, beautiful, and inherently competent woman.

140 McGrath, 'A New Kind of Diva'; 'Anna Netrebko 2017 Concert Biography’. 


\section{CHAPTER 5: CONCLUSION}

In opera it is still common to talk about a singer 'creating' a role. Yet, paradoxically, singers' creativity, and agency in creating sound, both tend to be overlooked. Although they may describe singers as 'creating' roles, the creator that scholars typically privilege is the composer. Julian Rushton identifies the reason for this terminology as the fact that composers often had a particular singer in mind for whom they were writing the role and this meant the vocality and vocal ability of that singer informed the specific elements of the role as written. ${ }^{1}$ The term 'creating a role' is usually applied, accordingly, to the very first (premiere) season of a particular operatic work, and the singer who 'created' each role is noted in texts about opera works, such as Kobbés Opera Book or Oxford Music Online. ${ }^{2}$ But it seems strange to consider the role as only having being created in performance once. Moreover, the term would seem to imply that the first singer to perform the role put some sort of indelible impression on the role itself. In the case of most of the standard operas performed today the first performance occurred in the nineteenth century or earlier. The performances in which these roles were 'created' therefore took place long before the arrival of recordings and so would only have influenced those who were there at the time to see and hear them. These 'lost' voices, for which the roles were written, and the 'lost' performances in which the roles were first heard can only resonate today through contemporary descriptions and through analysis of the compositions. ${ }^{3}$ Under this definition Callas did not 'create' any roles. In fact, more often than not, she performed in productions that had originally been staged for other singers. ${ }^{4}$

\footnotetext{
${ }^{1}$ Julian Rushton, 'The Prima Donna Creates', in The Arts of the Prima Donna in the Long Nineteenth Century, ed. Rachel Cowgill and Hilary Poriss (New York: Oxford University Press, 2012), 116.

${ }^{2}$ Earl of Harewood, The New Kobbe's Opera Book, 11 edition (London: Ebury Press, 1997); 'Opera Roles | Oxford Music', accessed 22 January 2019, http://www.oxfordmusiconline.com/page/operaroles.

${ }^{3}$ Smart, 'The Lost Voice of Rosine Stoltz', 32.

${ }^{4}$ Given Callas's stature in the opera world, it seems odd that she often was expected to perform in productions that had been designed for other singers, rather than having operas specially mounted for her. In the case of Lucia Fitzgerald notes 'Callas never had the opportunity to build a detailed visual realization of Lucia with a director such as Visconti or Zeffirelli. With the exception of one production staged especially for her at Scala [sic], her Lucias were always performed with stock sets and run-of-the-mill directors. It was not until 1958, with the Dallas Civic Opera, that she finally appeared in a major staging of the opera, a Zeffirelli production originally created for Joan Sutherland at Covent Garden.' Gerald Fitzgerald, 'The Great Years', in Callas: The Art and the Life The Great Years, 1st edition (New York: Holt, Rinehart and Winston, 1974), 67.
} 
This dissertation has argued that singers do not merely subordinate themselves to the agency of the composer; rather, they also exercise agency in forming their own interpretation of the music, and/or the role, and also in realising the music through creating the sound that constitutes that performance. Such agency has occasionally been implied in relation to the singers under examination here. For example, London Green, after noting several complimentary descriptions of Callas's singing, states: 'With such musical techniques did Callas create her Lucia.'5 Green's article is an in-depth examination of the specifics of her performance as Lucia, which was recorded live in Berlin in 1955 with Herbert von Karajan conducting. What is missing from such accounts, however, is a proper understanding of the means through which this creative agency is manifested: the singer's vocality.

Callas established her individual vocality through her performances of roles such as Lucia using a multitude of expressive colours and an assertive approach to the vocal tone she produced. While Callas did not premiere her opera roles, as she did not have any roles written for her, she is recognised as having created individual interpretations in her performances of the roles. These performances have come down to us as audio recordings. They were produced at first in tangible forms, as LP vinyl records - collectable, ownable, and 'fetishisable' - and even when dematerialised to the electronic formats of today they continue to be highly influential. This emphasises the fact that it is not the physical object that is influential, it is the intangible, ephemeral sound that emanates from it: the vocality of Callas. Is this not a product of creativity? The sound was first brought into being by Callas, in a specific and individual way, and, thanks to recording technology, the completed musical performance can be passed on through subsequent generations as an audible object.

Other acclaimed singers such as Te Kanawa have not had their art and artistry treated as creation, or often even acknowledged. The underlying implication is that singers who have a great voice simply 'bring' their voice to a role, rather than creating the sound that brings the role from the written score into an ephemeral vocal presence. Critics and other writers tend to imply that such singers are incapable of thinking about what they are doing in the context of a particular role, or that even if they could think about it, they do not tend to do so. In my case study of Te Kanawa I have demonstrated how she applied her voice to singing a role and to making the sounds of each note and phrase, and I have shown how this creation of sound is done with intention even though her vocality remains centred

\footnotetext{
5 Green, 'Callas and Lucia', 66.
} 
around consistency of tone and tonal beauty. Te Kanawa's beauty of tone is created and set to a specific purpose within the sung performance and is personally crafted by her for each performance.

This sense of the singer's agency tends to be recognised more often where a singer changes her sound quality a great deal, or where she displays agility, the ability to reach high notes, or a wide vocal range, as in the case of Netrebko. For the diva, the perception of this vocal control and technical skill is further clouded by attitudes around the agency and authority of women. One might expect that with the changing attitudes towards women that have developed over the period this study covers, particularly in the countries within which western classical opera is performed, the treatment of the female singer would likewise have changed and improved. Unfortunately, there is not a great deal of evidence of this sort of enlightenment to be found within the journalistic reviews I have covered in my analysis. However, with the rise of the 'un-prima donna' style of diva embodied by Netrebko, we do see some change, in her particular case, and a move towards acceptance of her as capable and self-assured despite her attractiveness (the latter being a quality that would usually dominate discourse around her to the detriment of those other qualities). Where Callas's self-assertion may have been seen as a threat, and Te Kanawa's perfection of beauty hid the creative agency underlying it, Netrebko, in the twenty-first century, shows a different possibility for the form of divahood, one which encompasses affective power (as sexiness and vocal or physical expression) and personal agency, both vocal and histrionic.

It is recognised that the diva needs to have an individual sound or vocality, and a distinctive one. She needs a signature sound that makes her readily identifiable, yet which fits within the accepted limits of the range of operatic sound. Intrinsic to that individual sound are also the aspects of the diva's personality that it carries. In other words, the sound communicates the singer's 'presence', which encompasses her 'drive', willpower, and the urgency of her need to communicate, display and/or create, is able to be perceived within that sound by the listener.

The singer may, as in Callas's case, be thought to be too disruptive, when this sort of intention is conveyed by the sound. Perhaps this effect is a psychological one. I am not meaning to say that the listener will be upset by the stylistic aspects or the 'vocal flaws' of the singer, although that may occur; rather, the listener may be upset by the power that is signified and conveyed through the sound itself. While we still have few tools to describe or analyse sound convincingly or to discuss the specifics of vocal sound in this way, to 
ignore vocality and how it is able to communicate the singer's power, is to miss out on a fundamental aspect of how opera functions as a communicative discourse between the singer and the listener. This is one aspect which the present study has addressed by providing a way of analysing and discussing the specifics of individual vocality in terms of sound and what it communicates to us as listeners.

Mediatisation, in the form of audio or video recordings of performances, provides a documentation of what those past performances entailed. More than simply documenting the work, as we have seen, it is possible for carefully produced audio or audio-visual recordings to present a version of the live, on-stage performance that may have a strongly affective communication and thus provide a different but still satisfying experience of the performance. This alternate version constitutes another type of legacy for the artists involved, but since it also requires further layers of authorial input, overall the singer can be seen to have less authorial power than in a performance that is experienced live by an audience present within an auditorium. For all the singers considered here, the particular qualities of their vocality, and its affective and metaphorical power in both live and mediatised performances have been integral to their career success as performers in opera and concerts and to the success of their recorded legacies.

Te Kanawa's legacy is more complex than Callas's in that the increase in diversity of media has meant that many more of her performances in the studio, as well as those made live on stage and on film, remain in both audio and audio-visual form for future reference and influence. As I have shown, her influence is able to be traced in the vocal fashion and vocality of later sopranos, and she can be seen as continuing the legacy of Tebaldi, the 'opposing' version of the aesthetic dichotomy set up in the 1950s alongside Callas. Te Kanawa's non-disruptive agency is evident in this power of influence, in that her extreme form of beauty of voice and the sense of self (vocal presence) that it transmits, gives a readily recognisable sound. Te Kanawa's 'package' of the beautiful voice within the beautiful body was marketable, so her image, as well as her vocality, were emphasised in the mediatised forms that set up her global celebrity. This allowed her to reclaim beauty as a vehicle for divahood and gave her power within the media because of it. However, the beauty of vocality itself required the hiding of effort. This concealment of work done contrasts with the overt self-assertion of agency that is evident in Callas's vocality.

The illusion of 'perfect' singing, made without effort, unfortunately played into the trope of the 'natural singer' for Te Kanawa, and undermined the sense of her agency in the production of sound and her artistic creativity in the popular discourse. Not only was Te 
Kanawa marketable as a commodity, her vocality was treated or experienced, as we have seen from the critics' comments about it, as a consumable, 'delectable' and 'delicious' aural incarnation of beauty that aligned with ideals of feminine and womanly, maternal loving. By contrast, Netrebko's vocality, like Callas's, was received by critics as intense and assertive, fearless, and displaying values supposedly aligned with 'masculine' power and agency. In the case of Callas, the sense of 'blade' or 'edge', in her sound transmitted this assertive power, and I have argued that her transgression of the bel canto principles of vocal beauty and sense of ease was used by her intentionally to create emotive expression. This meant that Callas's agency and indeed her authorship - particularly of the aural materialisation of a particular role - were clearly evident and often openly recognised.

The fact that Netrebko set up another type of diva with her public persona that was approachable, 'natural', and therefore 'authentic', could suggest that she has established a model that will be emulated. However, given the diversity of forms of divahood during past decades it would be imprudent to imagine that this will be a 'blueprint' for future divas. In fact, through her behaviour and her statements, Netrebko stresses that she is an individual, and that is really the point: Netrebko's 'form' of divahood is based on her individuality, and the fact that she has forged her own style, in accordance with the liberal era imperative of 'personal representation'. ${ }^{6}$

However, Netrebko's marketed image as a singer was intended by her agent to link through to the divahood of Callas, and this was effective despite her own denial of such a connection. Vocally there is some connection in terms at least of the dramatic foundational tone she chooses to use for her signature vocality. Like Callas, Netrebko's singing has been perceived as fearless and intense, and this power can be related to the same qualities that are fundamental to the signature vocality of Callas. While Callas made choices of vocal tone and colouration that risked showing her vulnerability (her vocal 'failures') this vulnerability was displayed alongside the sense of power and assertion that came through in her singing and vocality. Her disruptive approach and risk-taking also conveyed a sense in the sound of how the singer's body was involved in the creation of that sound, which can be seen as the reason for the various assertions of listeners that they can 'see' Callas, or react with a physical sensation themselves when they hear her singing on recordings.

What really happened after Callas? I have shown that there is no single line of influence nor of progression that one can trace through the range of different styles of divahood in

${ }^{6}$ Davies, 'Voice Belongs', 680. 
those who have attained that status since her time. In terms of values and attitudes to singers, progress is more about change (Netrebko as a new style of diva) than the diminishing of stereotypical gender concepts. It is still possible for a star singer to capture the public's awareness and imagination in the early twenty-first century despite opera supposedly receding in terms of its relevance, which has been a call seemingly made for decades - if not centuries. ${ }^{7}$ However, the audience for live opera as enacted within the 'hallowed halls' of the opera house does seem to be diminishing, and managers such as Peter Gelb at the Metropolitan Opera are trying various (perhaps desperate) tactics to maintain the institution and therefore the artform, at least in its live form. ${ }^{8}$

If the finding of the diva's intention is difficult, so is the finding of her real ideas and opinions, and even basic facts, when the media are so intimately involved in the processes of constructing her and seem so often to be filled with exaggerated or even deliberately manufactured statements supposedly made by her. This is where the notion of signature vocality becomes vitally significant. The reliable 'text' of the diva's work exists in the form of sound (vocality) and vision (acting) and these we can try to interpret for meaning and intention, within the context of opera as an industry and an artform. Supposedly Callas effected a bel canto revival through her focus on that repertoire, but perhaps a more lasting or important legacy is her effect on concepts of vocality: in particular in terms of an expansion of the range of colours that are acceptable and may be used expressively by an opera singer.

What might be the implications of these factors for the careers young singers of today may have in the future? Presumably they will have to sing like goddesses and act like Oscarnominated actors - in other words, they will still need to be compelling to watch and compelling to listen to, and they will probably have to negotiate new forms of mediatisation and work with new platforms for the distribution of their performances. They will surely need to be self-assured and negotiate their way through the minefield of working with conductors and directors who deny them authorship while holding the power to guide, promote, and foster them in their careers.

\footnotetext{
${ }^{7}$ Benzecry, The Opera Fanatic, 1-2; Mladen Dolar, 'If Music Be the Food of Love', in Opera's Second Death / Slavoj Žižek and Mladen Dolar. (New York: Routledge, 2002), 2-3.

${ }^{8}$ Norman Lebrecht, 'Empty Seats At The Met | Norman Lebrecht', Standpoint, 23 May 2016, https://standpointmag.co.uk/issues/june-2016/music-june-16-norman-lebrecht-metropolitanopera-new-york-audience/; Michael Cooper, 'Sunday Performances Still Elude the Met', The New York Times, 31 December 2015; Martin Bernheimer, 'New Broom at the Met', Opera 57, no. 5 (May 2006): 532.
} 
Perhaps this is the same as it ever was. Is an opera career still based fundamentally on the voice, as Leontyne Price informed the young Renée Fleming? ${ }^{9}$ My research shows that signature vocality is still the most important aspect of the singer's art. Having a recognisable vocal sound is important both on the stage and in audio and audio-visual recordings, and it seems likely that it will always be that way. The singer's vocality will continue to be crucial for the communication of affect and for recognition of the artist on the stage and within the complex textures of recorded sound. Yet-to-be-invented modes of mediatisation may also provide for more control by the singer over her mediatised performances and more recognition of her authorship of those performances.

The importance of signature vocality within all types of audio-visual media that the singer may encounter, whether now or in the future, is paramount. For the singer to be recognisable not only visually but also through her individual sound is key to our understanding of opera performances. Moreover, the singer's individual style of singing, and approach to the production of the sound is transmitted visually as well as aurally in a live performance or audio-visual mediatisation. This contributes to our sense of them as real 'live' performers and authentic stars since for singers the body and the sound are inescapably bound up together.

In this dissertation I have considered the power of the diva's voice from the point of view of the agency of the singer - both in terms of the creative agency required to produce an expressive operatic vocality and, in the case of Netrebko, in terms of the agency and authorship aspects of her public image and the discourse that linked her to Callas. I have examined underlying attitudes towards voice and singing, and traced some of these to the listener's sense of the female body and the expectations placed on women.

A true diva will never conform to a template, but will always redefine the terms of divahood. The power of that divahood encompasses various facets, from the power of 'sheer voice', Poizat's cry of the baby and the jouissance of the maternal connection, the divinely empowered soulful sound, the power of attraction, of inspiring desire, pain or joy. There is also the power of authorship, including the construction of a particular meaning through an individual vocal interpretation of a song, aria or role within an opera; the power gained and wielded within the hierarchy of opera; the economic power of the desirable, marketable diva 'product'; and the power of legacy and influence.

${ }^{9}$ Fleming, The Inner Voice, 72. 
In the end, however, it is the signature vocality that carries the most diva's most important legacy, which shows fundamentally her creative power and her creative influence. I have endeavoured to shed light on the inner workings of the singer's instrument through my explanations of the production of vocal sound out of nothing, out of 'thin air' - nothing, that is, but air and an ordinary human body. Perhaps the diva singer may have some specific vocally oriented advantages, but hers is still a human body that looks very much like any other in terms of what makes up the vocal apparatus. In other words, while the voice is an instrument, it must be made into an instrument by the singer. The singer does not have voice, and singing well is not about being a good singer. Fundamentally the singer makes: she makes tone, she makes voice, and she makes meaning. The great singer, the diva, or even the simply good singer, makes all of these with her body. She constructs her vocality, she makes her instrument, and she creates the sound that ultimately allows for the role, and the performance itself, to be realised. 
'10 Seasons of The Met: Live in HD - Google Arts \& Culture'. Google Cultural Institute, 2015. https://www.google.com/culturalinstitute/beta/exhibit/fwLChDzFtgqsIQ.

'1981: Charles and Diana Marry', 29 July 1981. http://news.bbc.co.uk/onthisday/hi/dates/stories/july/29/newsid_2494000/24 94949.stm.

'A Moment with Anna Netrebko'. Chopard Diary | Our official blog. Accessed 9 February 2019. https://www.chopard.com/intl/diary/moment-anna-netrebko/.

Abbate, Carolyn. In Search of Opera. Princeton University Press, 2001.

_-_. 'Music_Drastic or Gnostic?' Critical Inquiry 30, no. 3 (Spring 2004) (2004): 50536.

- - - 'Opera; or, the Envoicing of Women'. In Musicology and Difference: Gender and Sexuality in Music Scholarship, edited by Ruth A. Solie, 225-58. University of California Press, 1995.

-_- Unsung Voices: Opera and Musical Narrative in the Nineteenth Century. Princeton University Press, 1991.

Abramson, José Z., Ma Victoria Hernández-Lloreda, Lino García, Fernando Colmenares, Francisco Aboitiz, and Josep Call. 'Imitation of Novel Conspecific and Human Speech Sounds in the Killer Whale (Orcinus Orca)'. Proc. R. Soc. B 285, no. 1871 (31 January 2018): 20172171.

Adair, Marcia. 'Supertitles, Once Denounced, Loom Large in Modern-Day Opera'. Los Angeles Times, 19 May 2013.

http://articles.latimes.com/2013/may/19/entertainment/la-ca-cm-supertitlesopera-20130519/2.

Allain, Paul, and Jen Harvie. The Routledge Companion to Theatre and Performance. 2nd edition. London ; New York: Routledge, 2014.

Allison, John. 'Soprano Sensations: Contributor Comments'. BBC Music Magazine 15, no. 8 (2007): 5.

Allison, John, Earl of Harewood, Harold Rosenthal, and Elizabeth Forbes. Sopranos in Opera: Profiles of Fifteen Great Sopranos. Opera Magazine Ltd, 2001.

Anna Netrebko - Opera Arias (Wiener Philharmoniker, Noseda). Deutsche Grammophon, 2003.

Anna Netrebko - Souvenirs (Deutsche Grammophon Video), 2009. https://www.youtube.com/watch?v=soyAJE4U_BI.

'Anna Netrebko 2017 Concert Biography'. In Programme Booklet: Anna Netrebko and Yusif Eyvazov Concert, Calgary Opera, April 30th, 2017, n.d.

Anna Netrebko; 'Non Mi Dir'; Don Giovanni; Wolfgang Amadeus Mozart, n.d. https://www.youtube.com/watch?v=y8ho-HnxhS0.

Ardoin, John. Callas at Juilliard: The Master Classes. New York: Knopf, 1987.

- - - Terrence McNally: A Casebook. Edited by Toby Silverman Zinman. CRC Press, 2016. . 'The Art and the Life'. In Callas: The Art and the Life - The Great Years, 1st edition. New York: Holt, Rinehart and Winston, 1974.

- - - The Callas Legacy: The Complete Guide to Her Recordings on Compact Discs. Fourth. Gerald Duckworth \& Co, 1995.

Armatage, Kay. 'Cinematic Operatics: Barbara Willis Sweete Directs Metropolitan Opera HD Transmissions'. University of Toronto Quarterly 81, no. 4 (21 November 2012): 909-27.

Ashley, Tim. 'Sex and Sadism at the Royal Opera - Don Giovanni'. The Guardian, 15 September 2003.

Auslander, Philip. Liveness: Performance in a Mediatized Culture. Psychology Press, 1999.

_-_. 'Looking at Records'. TDR/The Drama Review 45, no. 1 (1 March 2001): 77-83. 
Barbara Bonney; 'Exsultate, Jubilate'; Wolfgang Amadeus Mozart. Accessed 19 September 2019. https://www.youtube.com/watch?v=RMi2v8-_cfs.

Barbara Bonney; 'S'altro Che Lagrime'; La Clemenza Di Tito; Wolfgang Amadeus Mozart. Accessed 19 September 2019. https://www.youtube.com/watch?v=2DqvlWm8_R0.

Barthes, Roland. 'Le grain de la voix'. Musique en jeu, no. No. 9 (November 1972): 57-63.

- - - 'Music, Voice, Language'. In Music, Words and Voice: A Reader, edited by Martin Clayton, 79-84. Manchester University Press, 2008.

-_- 'The Grain of the Voice'. In Image, Music, Text - Essays Selected and Translated by Stephen Heath, 179-89. Fontana/Collins, 1977.

Battle, Kathleen. Kathleen Battle, Mozart Opera Arias, with James Levine and the Metropolitan Opera Orchestra. CD Audio Recording. Deutsche Grammophon $00028943994927,1997$.

- - Kathleen Battle Sings Mozart, with André Previn and the Royal Philharmonic Orchestra. CD Audio Recording. EMI Angel CDC-7 47355 2, 1990.

'BBC Radio 3 to Celebrate the Art of The Classical Voice This Summer'. BBC Media Centre, 6 March 2015. https://www.bbc.co.uk/mediacentre/latestnews/2015/radio-3the-classical-voice?lang=cy.

Benzecry, Claudio E. The Opera Fanatic: Ethnography of an Obsession. Chicago: University of Chicago Press, 2011.

Berg, Gregory. 'Anna Netrebko: Live At The Metropolitan Opera'. Journal of Singing 68, no. 4 (3 April 2012): 485-86.

Bernheimer, Martin. 'New Broom at the Met'. Opera 57, no. 5 (May 2006): 530-37.

Biancolli, Louis. 'Review of Otello'. New York World Telegram and Sun, 1955. Metropolitan Opera Archives. http://archives.metoperafamily.org/archives/frame.htm.

Bleha, Peter. 'Anna Netrebko: I work until I can't stand up any more'. Opera Slovakia (blog), 16 June 2015. https://operaslovakia.sk/anna-netrebko-i-work-until-i-cantstand-up-any-more/.

Bonney, Barbara. La Clemenza Di Tito by Mozart: Christopher Hogwood, The Academy of Ancient Music. L'Oiseau-Lyre (Decca) 00028944413120, 1995.

-_- Mozart: Coronation Mass - Exsultate, Jubilate - Vesperae Solennes: Trevor Pinnock, The English Concert. Audio CD. Archiv/Deutsche Grammophon 28944535327, 1994.

Bordo, Susan. Unbearable Weight. University of California Press, 2003.

Bratersky, Alexander. 'Viktoria Belova Teaches American Singing for Slavs'. The Moscow Times, 24 September 2013. http://themoscowtimes.com/articles/viktoria-belovateaches-american-singing-for-slavs-27938.

Brug, Manuel. 'A Promise Kept'. In Booklet of Anna Netrebko Opera Arias CD - Re-Release of 2003 Recording, translated by Stewart Spencer. First Choice. Deutsche Grammophon, 2012.

———. 'Neue Rollen: Anna Netrebko Schwärzt Ihre Stimme', 8 August 2013. https://www.welt.de/kultur/buehne-konzert/article118824409/Anna-Netrebkoschwaerzt-ihre-Stimme.html.

Bunch, Meribeth. Dynamics of the Singing Voice. Fourth Edition. Wien; New York: Springer, 1997.

Burian, Jarka. The Scenography of Josef Svoboda. Connecticut: Wesleyan University Press, 1974.

Callas En Concert, the Hologram Tour - Habanera (Carmen), 2018. https://www.youtube.com/watch?v=BCclI5sUoRg.

Cameron, Deborah, and Don Kulick. Language and Sexuality. Cambridge University Press, 2003.

Canning, Hugh. 'People 336: Anna Netrebko'. Opera, June 2007, 644-51.

Capell, Richard. “'Norma” Sung With Spirit: Brilliant Soprano At Covent Garden'. The Daily Telegraph. 10 November 1952.

'Capriccio, by Richard Strauss, June 1993'. In San Francisco Opera Archive, n.d. http://archive.sfopera.com/reports/rptOpera-id455.pdf. 
Carding, Paul, Eva Carlson, Ruth Epstein, Lesley Mathieson, and Christina Shewell. 'Formal Perceptual Evaluation of Voice Quality in the United Kingdom'. Logopedics Phoniatrics Vocology 25, no. 3 (1 January 2000): 133-38.

Castle, Terry. 'Breath's End: Opera and Mortality'. In The Arts of the Prima Donna in the Long Nineteenth Century, edited by Rachel Cowgill and Hilary Poriss, 1 edition., 206-13. New York: Oxford University Press, 2012.

Cavicchi, Daniel. 'Loving Music: Listeners, Entertainments, and the Origins of Music Fandom in Nineteenth Century America'. In Fandom: Identities and Communities in a Mediated World, edited by Jonathan Gray, Cornel Sandvoss, and C. Lee Harrington, 10-15. New York: New York University Press, 2007.

Cenciarelli, Carlo. 'At the Margins of the Televisual: Picture Frames, Loops and "Cinematics" in the Paratexts of Opera Videos'. Cambridge Opera Journal 25, no. 2 (July 2013): 203-23.

Chauls, Robert. 'Review: Kiri Te Kanawa Mozart Opera Arias'. The Opera Quarterly 1, no. 4 (1 January 1983): 144-45.

Cheng, Jacqui. 'ITunes through the Ages'. Ars Technica, 23 November 2012. https://arstechnica.com/gadgets/2012/11/itunes-through-the-ages/.

'Chiaroscuro | Art'. Encyclopedia Britannica. Accessed 14 June 2017. https://www.britannica.com/art/chiaroscuro.

Christiansen, Rupert. Prima Donna: A History. Pimlico, 1995.

Clément, Catherine. Opera, or, The Undoing of Women. Translated by Betsy Wing. London: Virago, 1989.

Cook, Nicholas. 'Music as Performance'. In The Cultural Study of Music: A Critical Introduction / Edited by Martin Clayton, Trevor Herbert, Richard Middleton., 20414. New York: Routledge, 2002.

- - - 'We Are All (Ethno)Musicologists Now'. In The New (Ethno)Musicologies, edited by Henry Stobart. Rowman \& Littlefield, 2008.

Cooper, Michael. 'Sunday Performances Still Elude the Met'. The New York Times, 31 December 2015.

Couldry, Nick. 'Liveness, "Reality," and the Mediated Habitus from Television to the Mobile Phone'. The Communication Review 7, no. 4 (1 October 2004): 353-61.

Cowgill, Rachel, and Hilary Poriss, eds. The Arts of the Prima Donna in the Long Nineteenth Century. New York: Oxford University Press, 2012.

Cryer, Max. The Young Kiri - CD Booklet. Decca 430 325-2, 1990.

Cuddy, Amy, and Peter Glick. 'How Stereotypes Divide and Conquer Women'. The Boston Globe, 24 October 2017.

Cusick, Suzanne G. 'On Musical Performances of Gender and Sex'. In Audible Traces: Gender, Identity, and Music, edited by Elaine Barkin and Lydia Hamessley, 25-48. Zurich ; Los Angeles: Carciofoli, 1999.

'Dame Kiri Te Kanawa: Biography'. The Arts Foundation, 26 September 2015. https://www.thearts.co.nz/artists/dame-kiri-te-kanawa.

Davies, James Q. 'Voice Belongs: In Why Voice Now? Colloquy'. Edited by Martha Feldman. Journal of the American Musicological Society 68, no. 3 (1 December 2015): 677-80.

Davis, Peter G. 'The Diva Standard. Still.' Opera News 80, no. 4 (November 2015): 34.

Davis, Tracy C. 'From Diva to Drama Queen'. In The Arts of the Prima Donna in the Long Nineteenth Century, edited by Rachel Cowgill and Hilary Poriss, 252-71. New York: Oxford University Press, 2012.

Deh Vieni Non Tardar - Anna Netrebko (Sub. Español). Accessed 9 February 2019. https://www.youtube.com/watch?v=R-L4DMuvzvo.

Dolak, Gregor. Anna Netrebko: Opernstar der neuen Generation. München: Heyne Verlag, 2006.

Dolan, Jill. Utopia in Performance: Finding Hope at the Theater. University of Michigan Press, 2005.

Dolar, Mladen. 'If Music Be the Food of Love'. In Opera's Second Death / Slavoj Žižek and Mladen Dolar., 1-5. New York: Routledge, 2002. 
Driscoll, F. Paul. 'Viewpoint: The Diva \& Her Followers'. Opera News 82, no. 9 (March 2018).

Dunn, Leslie C., and Nancy A. Jones, eds. Embodied Voices: Representing Female Vocality in Western Culture. Cambridge University Press, 1994.

Dyer, Richard. 'A Star Is Born and the Construction of Authenticity'. In Stardom: Industry of Desire, edited by Christine Gledhill. London ; New York: Routledge, 1991.

Dyer, Richard, and Paul McDonald. Stars. BFI Publishing, 1998.

'E-Coustic Systems - Opera \& Ballet'. Accessed 25 January 2018. http://www.ecousticsystems.com/applications.

Eidsheim, Nina. 'Voice as Action: Towards a Model for Analyzing the Dynamic Construction of Racialized Voice'. Current Musicology, no. 93 (2012): 8.

Eidsheim, Nina Sun. 'Maria Callas's Waistline and the Organology of Voice'. The Opera Quarterly 33, no. 3-4 (2017): 249-68.

- - - 'Marian Anderson and "Sonic Blackness" in American Opera'. American Quarterly 63, no. 3 (2011): 641-71. https://doi.org/10.1353/aq.2011.0045.

- - - The Race of Sound: Listening, Timbre, and Vocality in African American Music. Duke University Press, 2019.

Elliott, Martha. Singing in Style: A Guide to Vocal Performance Practices. Yale University Press, 2006.

Esse, Melina. 'Don't Look Now: Opera, Liveness, and the Televisual'. The Opera Quarterly 26, no. 1 (1 January 2010): 81-95.

'Facebook'. In Wikipedia. Accessed 1 March 2019. https://en.wikipedia.org/wiki/Facebook.

Fast Company. Robert Lepage's 'La Damnation de Faust': Opera in the Age of Windows [PART 2]. Accessed 1 August 2018. https://www.youtube.com/watch?v=lAyqWwk52w8.

Feldman, Martha, Emily Wilbourne, Steven Rings, Brian Kane, and James Q. Davies. 'Why Voice Now? The Interstitial Voice: An Opening; Demo's Stutter, Subjectivity, and the Virtuosity of Vocal Failure; Analyzing the Popular Singing Voice: Sense and Surplus; The Model Voice; Voice Belongs'. Journal of the American Musicological Society 68, no. 3 (1 December 2015): 653-85.

Fingleton, David. Kiri Te Kanawa: A Biography. London: Collins, 1983.

Fischer-Lichte, Erika. The Transformative Power of Performance: A New Aesthetics. Translated by Saskya Iris Jain. Routledge, 2008.

Fishzon, Anna. Fandom, Authenticity, and Opera: Mad Acts and Letter Scenes in Fin-de-Siècle Russia. Palgrave Macmillan, 2013.

Fiske, Susan T., Amy J. C. Cuddy, and Peter Glick. 'Universal Dimensions of Social Cognition: Warmth and Competence'. Trends in Cognitive Sciences 11, no. 2 (February 2007): 77-83.

Fitzgerald, Gerald. 'The Great Years'. In Callas: The Art and the Life - The Great Years, 1st edition. New York: Holt, Rinehart and Winston, 1974.

Fleming, Renée. Renée Fleming, Great Opera Scenes, with Sir Georg Solti and the London Symphony Orchestra. Decca 28947509424, 1997.

- - Renée Fleming, Mozart Arias, with Charles Mackerras and the Orchestra of St Luke's. Audio CD. Decca 28945260228, 1996.

-_- Renée Fleming, Sacred Songs, with Andreas Delfs and the Royal Philharmonic Orchestra. Audio CD. Decca 28947564508, 2005.

- - - The Inner Voice: The Making of a Singer. Viking Penguin, 2004.

Fowler, Alice. 'Dame Kiri Talks of Her Heartache'. Mail Online, 2002. https://www.dailymail.co.uk/tvshowbiz/article-119114/Dame-Kiri-talksheartache.html.

George, Donald, and Lucy Mauro. Master Singers: Advice from the Stage. New York, NY: Oxford University Press, 2015.

Gledhill, Christine, ed. Stardom: Industry of Desire. London ; New York: Routledge, 1991.

Glyndebourne. Insight into The Turn of The Screw. Accessed 24 June 2018. https://www.youtube.com/watch?v=2LiA8G5F15k. 
Goldstein, Paul. Copyright's Highway: From Gutenberg to the Celestial Jukebox. Hill and Wang, 1994.

Goscilo, Helena, and Vlad Strukov. 'Russian Celebrities Home and Abroad: United under Putin, March 2011'. Celebrity Studies 2, no. 2 (1 July 2011): 209-13.

Green, London. 'Callas and Lucia'. The Opera Quarterly; Cary 14, no. 3 (Spring 1998): 6571.

Grover-Friedlander, Michal. 'Fellini's Ashes'. In Vocal Apparitions: The Attraction of Cinema to Opera, 131-81. Princeton University Press, 2014.

- - _. 'The Afterlife of Maria Callas's Voice'. The Musical Quarterly 88, no. 1 (1 March 2005): 35-62.

- - - Vocal Apparitions: The Attraction of Cinema to Opera. Princeton University Press, 2014.

Hadlock, Heather. 'Opera and Gender Studies'. In The Cambridge Companion to Opera Studies, edited by Nicholas Till, 257-75. Cambridge University Press, 2012.

Hamdan, Abdul-Latif, Bassem Safadi, Ghassan Chamseddine, Maher Kasty, Zaahir A. Turfe, and Georges Ziade. 'Effect of Weight Loss on Voice After Bariatric Surgery'. Journal of Voice 28, no. 5 (1 September 2014): 618-23.

Harewood, Earl of. The New Kobbe's Opera Book. 11 edition. London: Ebury Press, 1997.

Harris, Norman, and Kiri Te Kanawa. Kiri: Music and a Maori Girl. Wellington: A. H. \& A. W. Reed, 1966.

Harris, Thomas. 'The Building of Popular Images: Grace Kelly and Marilyn Monroe'. In Stardom: Industry of Desire, edited by Christine Gledhill, 40-44. London ; New York: Routledge, 1991.

Heidemann, Kate. 'Hearing Women's Voices in Popular Song: Analyzing Sound and Identity in Country and Soul - ProQuest Dissertations \& Theses Global - ProQuest'. Dissertation, Columbia, 2014.

Heyworth, Peter. 'Opening Flourish'. The Observer, 5 December 1971.

Holden, Anthony. 'Don Giovanni - Covent Garden'. The Observer, 21 September 2003.

Holland, Bernard. 'Music Review: Philharmonic Resumes With Te Kanawa'. The New York Times, 22 September 2000.

Hope-Wallace, Philip. 'A Controversial Prima Donna: Mme Callas in "Norma”'. The Manchester Guardian, 4 February 1957.

. “Norma” at Covent Garden: After 20 Years'. The Manchester Guardian. 10 November 1952.

Hutcheon, Linda, and Michael Hutcheon. Bodily Charm: Living Opera. University of Nebraska Press, 2000.

'IMG Artists: Kiri Te Kanawa'. IMG Artists, 16 May 2016. https://imgartists.com/roster/kiri-te-kanawa/.

'IMG Artists: Renée Fleming'. IMG Artists, 17 May 2016. https://imgartists.com/roster/renee-fleming/.

'Instagram'. In Wikipedia. Accessed 1 March 2019. https://en.wikipedia.org/wiki/Instagram.

Jarman-Ivens, Freya. Queer Voices - Technologies, Vocalities, and the Musical Flaw. Palgrave Macmillan, 2011.

Jeffries, Stuart. '“I Conquered the Critics"'. The Guardian, 26 April 2008, sec. Music. https://www.theguardian.com/music/2008/apr/26/classicalmusicandopera.russ ia.

Johnson, James H. Listening in Paris: A Cultural History. Vol. 21. Studies on the History of Society and Culture. University of California Press, 1995.

'Julia Lezhneva: Biography'. Julia Lezhneva. Accessed 29 January 2019. https://www.julialezhneva.com/biography/.

Julia Lezhneva Speaks to Classic FM, 2013. https://www.youtube.com/watch?v=N1SyjEPX9U8.

Kathleen Battle; 'L'amerò, Sarò Costante'; Il Re Pastore; Wolfgang Amadeus Mozart, n.d. https://www.youtube.com/watch?v=lX6LPBwcS78. 
Katz, Mark. Capturing Sound: How Technology Has Changed Music. Berkeley: University of California Press, 2004.

Kesting, Jürgen. '»... spricht eine hochwertige Zielgruppe an «: Anna Netrebko'. In Die grossen Sänger (Band IV), Band IV:1915-17. Hamburg: Hoffmann und Campe, 2008.

- - Die grossen Sänger. 4 vols. Hamburg: Hoffmann und Campe, 2008.

-——. Die grossen Sänger (Band III). Vol. Band III. 4 vols. Hamburg: Hoffmann und Campe, 2008.

- - - Die grossen Sänger (Band IV). Vol. Band IV. 4 vols. Hamburg: Hoffmann und Campe, 2008.

-_- Maria Callas. Translated by John Hunt. First Edition edition. Boston: Northeastern, 1993.

'Kiri Te Kanawa - Kiri Sings Opera'. Discogs. Accessed 6 October 2018. https://www.discogs.com/Kiri-Te-Kanawa-Kiri-Sings-Opera/release/6495975.

'Kiri Te Kanawa at the BBC'. BBC Studios, 2017. https://www.youtube.com/watch?v=oPEXrB6NRUQ.

'Kiri Tipped as Another Maria Callas'. New Zealand Herald, 17 October 1974.

KiriOnLine - Dame Kiri Te Kanawa. Kiri Te Kanawa s 20 Favourite Voices \#2 Elisabeth Schwarzkopf. Accessed 18 September 2018. https://www.youtube.com/watch?v=B58XA9gy_YY.

- - - Kiri Te Kanawa's 20 Favourite Voices \#11 Margaret Price. Accessed 25 September 2018.

https://www.youtube.com/watch?v=Zokk0Q0sODs\&index=12\&t=0s\&list=PL8ld2 LoKhQqymLL6gvBupdir_1CLHA9l2.

- - - Kiri Te Kanawa's 20 Favourite Voices \#18 Renata Tebaldi. Accessed 25 September 2018.

https://www.youtube.com/watch?v=7ly4Q6Nvblk\&index=18\&list=PL8ld2LoKhQ qymLL6gvBupdir_1CLHA9l2.

'Kiri's 20 Favourite Voices - Downloads - BBC Radio 3'. BBC. Accessed 25 September 2018. https://www.bbc.co.uk/programmes/p02t03d1/episodes/downloads.

'Kiri's 20 Favourite Voices (KiriOnLine YouTube Channel)', 4 July 2015. https://www.youtube.com/playlist?list=PL8ld2LoKhQqymLL6gvBupdir_1CLHA91 2.

Kloiber, Rudolf, and Wulf Konold. Handbuch der Oper (5th edition). 2 vols. Kassel: dtv/Bärenreiter, 1985.

Koestenbaum, Wayne. The Queen's Throat: Opera, Homosexuality and the Mystery of Desire. Da Capo Press, 2001.

Korsnack, Kylie. 'Natural or Unnatural Selection?: Darwin and the Evolutionary Success of Genetically Engineered Species in Bacigalupi's Windup Girl'. Bioculture Seminars (blog). Accessed 23 January 2017. https://biocultures.wordpress.com/2015/04/05/natural-or-unnatural-selectiondarwin-and-the-evolutionary-success-of-genetically-engineered-species-inbacigalupis-windup-girl/.

Kustanczy, Catherine. 'Insta-Divas: How Social Media Has Become the next Stage for Opera Stars'. The Globe and Mail, 18 October 2018. https://www.theglobeandmail.com/arts/theatre-and-performance/article-operaon-insta-how-the-social-media-platform-has-become-a-tool-for/.

La Traviata, Salzburg Festspiele 2005 - Preludio (2). Accessed 9 February 2019. https://www.youtube.com/watch?v=CYm-Sd9roIQ.

Laver, John. 'Phonetic Evaluation of Voice Quality'. In Voice Quality Measurement, edited by R. D. Kent and M. J. Ball, 37-48. San Diego: Singular, 2000.

Lebrecht, Norman. Covent Garden: The Untold Story-Dispatches from the English Culture War, 1945-2000. London: Pocket Books, 2001.

'Empty Seats At The Met | Norman Lebrecht'. Standpoint, 23 May 2016. https://standpointmag.co.uk/issues/june-2016/music-june-16-norman-lebrechtmetropolitan-opera-new-york-audience/. 
Leech-Wilkinson, Daniel. 'The Changing Sound of Music: Approaches to Studying Recorded Musical Performance'. London: CHARM, 2009. www.charm.kcl.ac.uk/studies/chapter/chap4.html.

'Legendary Vocal Coach to Open School in Russia'. Russkiy Mir Foundation Information Service, 27 December 2011. https://www.russkiymir.ru/en/news/127629/.

Leonardi, Susan J., and Rebecca A. Pope. The Diva's Mouth: Body, Voice, Prima Donna Politics. Rutgers University Press, 1996.

Leung, Rebecca, and Bob Simon. 'Anna Netrebko: A Happy Diva'. 60 Minutes (CBS), 9 December 2004. https://www.cbsnews.com/news/anna-netrebko-a-happy-diva09-12-2004/.

Levin, David J. Unsettling Opera: Staging Mozart, Verdi, Wagner, and Zemlinsky. University of Chicago Press, 2008.

Lincoln Center. Matthew Polenzani: Beyond 'Park and Bark', 2014. https://www.youtube.com/watch?v=ezJUCYBaQtE.

Liss, Miriam, Mindy J. Erchull, and Laura R. Ramsey. 'Empowering or Oppressing? Development and Exploration of the Enjoyment of Sexualization Scale'. Personality and Social Psychology Bulletin 37, no. 1 (2011): 55-68.

Lovell-Smith, Margaret, and Luisa Shanahan. The Enigma of Sister Mary Leo: The Story Behind New Zealand's Most Famous Singing Teacher. Penguin Group New Zealand, Limited, 1998.

Lowe, David A., ed. Callas: As They Saw Her. First Edition edition. New York: Ungar Pub Co, 1986.

Lumley, Benjamin. Reminiscences of the Opera. Hurst and Blackett, 1864.

MacCallum-Stewart, Esther. “Take That, Bitches!” Refiguring Lara Croft in Feminist Game Narratives'. Game Studies 14, no. 2 (December 2014). http://gamestudies.org/1402/articles/maccallumstewart.

Maria Callas - Suicido! - La Gioconda 1952 Studio with Sound Externalisation GREAT SOUND! Accessed 19 September 2019. https://www.youtube.com/watch?v=7Xws7wKuc4w.

Maria Callas - Un Bel Di Vedremo, n.d. https://www.youtube.com/watch?v=c-r2vu4t9-g.

Maria Callas (1962) At Covent Garden - Georges Bizet - Habanera (Carmen), 1962. https://www.youtube.com/watch?v=RbX8WDAXUmg.

Maria Callas at Juilliard: The Masterclasses (Audio CD). EMI Classics, 1987.

Matheopoulos, Helena. Diva: Great Sopranos and Mezzos Discuss Their Art. Victor Gollancz, 1991.

McClary, Susan. 'Excess and Frame: The Musical Representation of Madwomen'. In Feminine Endings: Music, Gender, and Sexuality, 80-111. University of Minnesota Press, 1991.

- - - 'Foreword: The Undoing of Opera: Toward a Feminist Criticism of Music'. In Opera, or, The Undoing of Women, by Catherine Clément, ix-xviii. London: Virago, 1989.

McDonald Klimek, Mary, Kerrie B Obert, Kimberly Steinhauer, and Think Voice International. Estill Voice Training System Workbook Level Two. Pittsburgh, PA: Estill Voice Training Systems International, 2005.

- - Estill Voice Training System Workbooks (Level One \& Two). Pittsburgh, PA: Estill Voice Training Systems International, 2005.

McGrath, Charles. 'A New Kind of Diva'. The New York Times, 2 December 2007. http://www.nytimes.com/2007/12/02/magazine/02netrebko-t.html.

'Metropolitan Opera Live in HD'. In Wikipedia, 16 November 2017. https://en.wikipedia.org/wiki/Metropolitan_Opera_Live_in_HD.

Midgette, Anne. 'A Diva Who Breaks the Divadom Rules'. The New York Times, 27 December 2006, sec. Arts / Music. http://www.nytimes.com/2006/12/27/arts/music/27netr.html.

_-_. 'From Fleming, a Satisfying Night of Gleaming Voice'. The Washington Post, 10 January 2011, sec. C10. EBSCO Host.

Miller, Richard. Training Soprano Voices. Oxford University Press, 2000. 
Monelle, Raymond. 'Review: The Angel's Cry: Beyond the Pleasure Principle in Opera by Michel Poizat and Arthur Denner'. Cambridge Opera Journal 74, no. 3 (August 1993): 453-55.

Moravcsik, Andrew. 'Sopranos at the Cineplex'. Newsweek, 19 March 2007, International edition.

Morris, Christopher. 'Digital Diva: Opera on Video'. The Opera Quarterly 26, no. 1 (1 January 2010): 96-119.

Mozart: La Clemenza Di Tito, K.621 / Act 2 - 'S'altro Che Lagrime' [Battle]. Accessed 19 September 2019. https://www.youtube.com/watch?v=sIVEWJzeVtw.

Mozart: La Clemenza Di Tito, K.621 / Act 2 - 'S'altro Che Lagrime' [Te Kanawa], n.d. https://www.youtube.com/watch?v=NmQCDVwQvSQ.

Mozart: Le Nozze Di Figaro, K.492 / Act 2 - 'Porgi Amor' [Fleming]. Accessed 20 September 2019. https://www.youtube.com/watch?v=xDkLKdWEZF8.

Mozart Opera Arias: Kiri Te Kanawa. Sir Colin Davis, Conductor; London Symphony Orchestra. CD Audio Recording. Audio CD: Philips 411 148-2, 1982.

Mozart: Vesperae Solennes de Confessore in C, K.339 - Laudate Dominum Omnes Gentes [Fleming]. Accessed 20 September 2019. https://www.youtube.com/watch?v=nu_ZbM6qno4.

Mühleisen, Wencke. 'Mainstream Sexualization and the Potential for Nordic New Feminism'. NORA - Nordic Journal of Feminist and Gender Research 15, no. 2-3 (2007): 172-189.

Murray, Emily. 'Lara Croft Inspired Generations Of Women And Revolutionised Video Games'. UNILAD (blog), 2018. https://www.unilad.co.uk/featured/lara-croftinspired-generations-of-women-and-revolutionised-video-games/.

Necula, Maria-Cristina. Life in Opera: Truth, Tempo, and Soul: Encounters with Stars, Innovators, and Leaders of Today's Opera World. New York: Amadeus, 2009.

Netrebko, Anna. 'Anna Netrebko YouTube Channel'. Accessed 15 December 2017. https://www.youtube.com/user/AskAnnaNetrebko/featured.

_-_. Opera Arias: Anna Netrebko (First Choice); Wiener Philharmoniker, Gianandrea Noseda. First Choice (2012). Deutsche Grammophon, 2003.

Newman, Ernest. 'The World of Music: “Norma”'. The Sunday Times. 16 November 1952.

Norberg, Florence Wiese. 'Voice Production for Singers'. The Journal of the Royal College of General Practitioners 13, no. 3 (May 1967): 377-80.

'Opera Roles | Oxford Music'. Accessed 22 January 2019. http://www.oxfordmusiconline.com/page/opera-roles.

Paltridge, Brian. Discourse Analysis: An Introduction. Continuum, 2012.

Parker, Roger. 'Giuseppe Verdi's Don Carlo(s): “Live” on DVD'. The Opera Quarterly 26, no. 4 (1 October 2010): 603-14.

Paterson, Vincent. Anna Netrebko - The Woman, The Voice. Deutsche Grammophon, 2004.

Phelan, Peggy. Unmarked: The Politics of Performance. Routledge, 1993.

Picard, Anna, George Hall, Michael Tanner, Hugh Canning, John Allison, Robert Thicknesse, David Nice, Richard Morrison, Anthony Pryer, and Ashutosh Khandekar. 'The 20 Greatest Sopranos of All Time'. BBC Music Magazine 15, no. 8 (2007): 27-37.

Pines, Roger. 'Ruslan and Lyudmila (Review)'. The Opera Quarterly 20, no. 2 (7 May 2004): 310-13.

Plotkin, Fred. 'In Opera, There Is No Such Thing as a Magic Mike'. WQXR, 16 July 2013. http://www.wqxr.org/story/306794-opera-there-no-such-thing-magic-mike/.

Poizat, Michel. The Angel's Cry: Beyond the Pleasure Principle in Opera. Translated by Arthur Denner. Cornell University Press, 1992.

"'The Blue Note" and "The Objectified Voice and the Vocal Object"'. Cambridge Opera Journal 3, no. 3 (November 1991): 195-211.

Porter, Andrew. 'Le Nozze Di Figaro'. Financial Times, 3 December 1971.

———. 'Le Nozze Di Figaro (Photo Caption)'. Financial Times, 2 December 1971. . 'Opera in London: “Norma” in Italian'. The Musical Times 94, no. 1319 (January 1953): 34.

Porterfield, Christopher. 'The 2007 TIME 100'. Time, 3 May 2007. 
'Porträt: Anna Netrebko: Und dann kam sie'. sueddeutsche.de, 17 May 2010, sec. kultur. https://www.sueddeutsche.de/kultur/portraet-anna-netrebko-und-dann-kamsie-1.436731-2.

Pozderac-Chenevey, Sarah. 'Diva Rivalry for Fun and Profit: An Examination of Diva [Mis]Conceptions via the Rivalry of Maria Callas and Renata Tebaldi'. University of Cincinnati, 2013.

Radigales, Jaume. 'Playback Problems When Filming Opera for the Screen: Two Case Studies'. In Opera and Video: Technology and Spectatorship, edited by Héctor Pérez, 115-28. Bern; New York: Peter Lang, 2012.

'Recording of the Year 2015'. MusicWeb International (blog), 2015. http://www.musicwebinternational.com/classrev/2015/ROTY/ROTY_2015_AL.htm.

Reissinger, Marianne. Anna Netrebko. Ein Porträt. Reinbek bei Hamburg: Rowohlt Verlag, 2005.

'Renata Tebaldi'. In Wikipedia, 3 July 2018. https://en.wikipedia.org/w/index.php?title=Renata_Tebaldi\&oldid=848717558.

'Renée Fleming: Gala Evening Concert with New Zealand Symphony Orchestra, Recorded 12th September 2015'. Music Alive. Radio New Zealand Concert, 25 December 2016.

Renée Fleming; 'L'amerò, Sarò Costante'; Il Re Pastore; Wolfgang Amadeus Mozart. Accessed 20 September 2019. https://www.youtube.com/watch?v=amynaF3Vc94.

Richard Morrison. 'Angela Gheorghiu "If I Make Love, Do You Think I Should Call You?"' The Times, 2 July 2010.

Riggs, Seth. Singing for the Stars: A Complete Program for Training Your Voice. Edited by John Dominick Carratello. Alfred, 1992.

Rings, Steven. 'Analyzing the Popular Singing Voice: Sense and Surplus' in 'Why Voice Now'. Journal of the American Musicological Society 68, no. 3 (1 December 2015): 663-71.

Risi, Clemens. 'Diva Poses by Anna Netrebko: On the Perception of the Extraordinary in the Twenty-First Century'. In Technology and the Diva, edited by Karen Henson, 15058. Cambridge Studies in Opera. Cambridge University Press, 2016.

- - . 'Opera in Performance-In Search of New Analytical Approaches'. The Opera Quarterly 27, no. 2 (2011): 283-95.

- - - 'Swinging Signs, Representation and Presence in Operatic Performances: Remarks on Hans Neuenfels, Jossi Wieler, and a New Analytical Approach'. Arcadia 36, no. 2 (2001): 363-73.

- - 'The Diva's Fans: Opera and Bodily Participation'. Performance Research 16, no. 3 (1 September 2011): 49-54.

Robinson, Paul. 'Book Review: It's Not Over Till the Soprano Dies: OPERA, OR THE UNDOING OF WOMEN By Catherine Clement'. New York Times, 1 January 1989.

Royal Opera House. Don Giovanni Trailer (The Royal Opera). Accessed 24 June 2018. https://www.youtube.com/watch?v=09CaqCLG8tc.

Rushton, Julian. 'The Prima Donna Creates'. In The Arts of the Prima Donna in the Long Nineteenth Century, edited by Rachel Cowgill and Hilary Poriss, 115-20. New York: Oxford University Press, 2012.

Rutherford, Susan. "La Cantante Delle Passioni": Giuditta Pasta and the Idea of Operatic Performance'. Cambridge Opera Journal 19, no. 2 (2007): 107-38.

-_- The Prima Donna and Opera, 1815-1930. Cambridge University Press, 2006.

- - - 'Voices and Singers'. In The Cambridge Companion to Opera Studies, edited by Nicholas Till, 117-38. Cambridge University Press, 2012.

Sadie, Stanley. 'Horst Zankl's Paris Production Anatomizes The Magic Flute'. The Times, 20 May 1977.

Saracibar, Carlos Agelet de. 'Anna Netrebko Performances Database'. Scribd, 4 September 2011. https://www.scribd.com/doc/63918608/ANPD-Sep-2011.

Scott, Michael. Maria Meneghini Callas. London: Simon \& Schuster, 1991.

Seckerson, Edward. 'A Stellar Violetta Steals the Show'. The Independent, 16 January 2008. 
Seletsky, Robert E. 'A Callas Recording Update'. The Opera Quarterly 21, no. 2 (7 July 2005): 387-91.

- - . 'Callas at EMI: Remastering and Perception'. The Opera Quarterly; Oxford 16, no. 2 (Spring 2000): 240-55.

- - - 'The Performance Practice of Maria Callas: Interpretation and Instinct'. The Opera Quarterly 20, no. 4 (1 January 2004): 587-602.

Senici, Emanuele. 'Opera on Italian Television'. In Opera and Video: Technology and Spectatorship, edited by Héctor Pérez. Bern; New York: Peter Lang AG, Internationaler Verlag der Wissenschaften, 2012.

-_- 'Porn Style? Space and Time in Live Opera Videos'. The Opera Quarterly 26, no. 1 (1 January 2010): 63-80.

Shawe-Taylor, Desmond. 'A Fine Figaro'. The Sunday Times, 5 December 1971.

Shils, Edward. 'Charisma, Order and Status'. American Sociological Review 30, no. 2 (April 1965).

Siff, Ira. 'Angela Gheorghiu: "Homage to Maria Callas — Favourite Opera Arias"'. Opera News 76, no. 6 (December 2011).

Simpson, Adrienne, and Peter Downes. Southern Voices: International Opera Singers of New Zealand. Auckland: Reed Books, 1992.

Smart, Mary Ann. 'The Lost Voice of Rosine Stoltz'. Cambridge Opera Journal 6, no. 01 (March 1994): 31-50.

Smith, Cecil. 'Opera Diary: Covent Garden “Norma”'. Opera. January 1953.

Souvenirs CD: Interview Anna Netrebko (Video), 2009. https://www.youtube.com/watch?v=Tvl72FvicI4.

Souvenirs, Limited Edition, Box Set CD. Deutsche Grammophon 00289477 7451, 2008.

Stasi, Linda. 'Singer Claims He Was Drugged and Raped in 2010 by Classical Music Power Couple'. Nydailynews.Com, 22 August 2018. https://www.nydailynews.com/news/national/ny-news-stasi-singer-claims-rapeclassical-music-stars-20180821-story.html.

Steane, J. B. Singers of the Century (Volume 2). Amadeus Press, 1998.

Steichen, James. 'HD Opera: A Love/Hate Story'. The Opera Quarterly 27, no. 4 (1 December 2011): 443-59.

- - - 'The Metropolitan Opera Goes Public: Peter Gelb and the Institutional Dramaturgy of The Met: Live in HD'. Music and the Moving Image 2, no. 2 (2009): 24-30.

Steinhauer, Kimberly, Mary McDonald Klimek, and Jo Estill. The Estill Voice Model: Theory and Translation. Estill Voice International, 2017.

Story, Brad H. 'Modification of Emotional Speech and Voice Quality Based on Changes to the Vocal Tract Structure'. In Emotions in the Human Voice (Vol 1), edited by Krzysztof Izdebski. San Diego: Plural Publishing, 2008.

'Sucesora de La Callas', 13 September 2008. https://www.semana.com/amp/sucesora-dela-callas/95252.

Tchaikovsky: Eugene Onegin. Accessed 21 February 2019. http://www.imdb.com/title/tt6505176/.

Te Kanawa, Kiri, and Conrad Wilson. Opera for Lovers. Auckland: Hodder Moa Becket Headline, 1996.

The New Zealand Official Year-Book, 1967. Accessed 6 October 2018. https://www3.stats.govt.nz/New_Zealand_Official_Yearbooks/1967/NZOYB_1967 .html\#idchapter_1_8591.

The Ultimate Maria Callas Collection (Audio CD). EMI Classics, 2003.

Tommasini, Anthony. 'Anna Netrebko, at the Top but Still Rising'. The New York Times, 19 September 2004.

- - - 'Bel Canto Magic in a Scottish Castle Haunted by Pesky High Notes'. New York Times, 28 January 2009.

.'Wearing a Wire at the Opera, Secretly, of Course'. The New York Times, 28 June 2013, sec. Music. https://www.nytimes.com/2013/06/30/arts/music/wearing-awire-at-the-opera-secretly-of-course.html. 
- - - 'What a Hologram of Maria Callas Can Teach Us About Opera'. The New York Times, 16 January 2018, sec. Arts.

https://www.nytimes.com/2018/01/15/arts/music/maria-callas-hologramopera.html.

'Twitter'. In Wikipedia. Accessed 1 March 2019. https://en.wikipedia.org/wiki/Twitter.

Wallmark, Zachary. 'Appraising Timbre: Embodiment and Affect at the Threshold of Music and Noise'. Dissertation, University of California, 2014.

Warner Classics. 'Maria Callas Live: Bizet's Carmen Habanera, Hamburg 1962'. Accessed 13 December 2018. https://www.youtube.com/watch?v=EseMHr6VEM0.

Watt, Douglas. 'Callas a Success in Met Debut'. Daily News. 30 October 1956.

Webster, Paul. 'Callas the Divine Is Dead: From the Archive, 17 September 1977'. The Guardian, 17 September 2014, sec. Music. https://www.theguardian.com/music/2014/sep/17/maria-callas-dead-opera1977.

Whitson, James C. 'The Callas Legacy'. Opera News 70, no. 4 (2005): 18-22, 24.

Wilson, Alexandra. 'Galli-Curci Comes to Town: The Prima Donna's Presence in the Age of Mechanical Reproduction'. In The Arts of the Prima Donna in the Long Nineteenth Century, edited by Rachel Cowgill and Hilary Poriss, 328. New York: Oxford University Press, 2012.

Wisneski, Henry. Maria Callas: The Art Behind the Legend. London: Robert Hale, 1976.

Wollerman, Jenny. New Zealand Singers Taking Flight. Kiri Te Kanawa Foundation, 2008. http://www.kiritekanawa.org/assets/Article-attachments/NZ-SINGERS-TAKEFLIGHT-MARCH-2008.pdf.

Woolfe, Zachary. 'The Met's HD Broadcasts Are Changing Opera'. The New York Times, 27 April 2012, sec. Music. https://www.nytimes.com/2012/04/29/arts/music/themets-hd-broadcasts-are-changing-opera.html. 